\title{
Management decision-making in the transition of a multinational company's internationalisation strategy
}

Gehrlein, Mario

A thesis submitted to the University of Gloucestershire in accordance with the requirements of the degree of Doctor of Philosophy in the Faculty of Business School.

Submission date: August 2020 Word Count: 83.917 


\section{Abstract}

In a globalized world economy, it is more beneficial for companies to have international activities because a larger group of customers can be served (Hollensen, 2017). As the business environment is continuously evolving (e.g. through enhanced transport systems), international active companies need to constantly investigate whether their strategy for an international activity (e.g. working with a local distributor) is the most appropriate or not and if not, to efficiently switch to a new market strategy (mode switching). This decisionmaking process of mode switching is considered as critical for companies since finding the most appropriate strategy for an international activity results in maximizing the profit of companies (Sachse, 2010).

A literature review process combined with a qualitative thematic analysis of the selected studies have shown that within multinational companies (MNC) there can be multiple simultaneous switching processes because MNC have a global network of several international activities (Rezende, 2006; Hollensen, 2017). These simultaneous decision-making processes can be connected within the network of the MNC and can impact each other (interdependencies). One example of interdependence is that the used human resources for one process are only available for a limited extent of a simultaneous decisionmaking process (Rezende, 2006; Asmussen et al., 2009). Ignoring the interdependencies of this network within MNC can result in increasing complexity, costs and not using synergistic effects to raise the efficiency within MNC (Rezende, 2006; Asmussen, 2009).

Using a single case study approach from a phenomenological philosophical position, the mode switching process of one MNC has been investigated by conducting 15 semi-structured interviews with managers of the decisionmaking process and by documentation reviewing. This detailed and in-depth analysis has led to the outcome of a new process model which illustrates three set-ups for the decision-making process of mode switching within MNC 
PhD Thesis Mario Gehrlein

including the interdependencies existing between multiple simultaneous mode switches. 


\section{Author's Declaration}

I declare that the work in this thesis was carried out in accordance with the regulations of the University of Gloucestershire and is original except where indicated by specific reference in the text. No part of the thesis has been submitted as part of any other academic award. The thesis has not been presented to any other education institution in the United Kingdom or overseas.

Any views expressed in the thesis are those of the author and in no way represent those of the University.

Signed

Date: 06.08 .2020

doi: $10.46289 /$ BUSM5286 


\section{Confidentiality and Restricted Access}

This thesis contains some sensitive data of the selected single case company and therefore its general access should be restricted for at least two years from the submission date. 


\section{Acknowledgements}

I wish to express my gratitude to Dr. Louise Reid and Professor Claudio Vignali for their continuous and excellent guidance, support, supervision and input. Without their help a submission would not have been possible. Dr. Reid has been supporting me from the initial stages of developing the PHD thesis and especially the great support during the RD1 process in which she gave me valuable advices and recommendations which were very helpful and highly appreciated. Professor Vignali's guided my research process with his experienced and broad knowledge base and his inspiring and positive way of supervising were extremely valuable.

I also wish to express my gratitude to Professor Anthony Gear, who was my first supervisor of at the beginning of the research journey and unfortunately passed away during the first research modules. Without the assistance of Professor Gear the submission of the MR 401 would not have been possible.

Without the financial and general support of the company I worked for during this research process the completion of the research journey would not have been possible. I highly appreciate this support and also intend to express my gratitude to my colleagues who have contributed valuable insights to the research projects as participants of the research project.

Last but not least, I would like to express my sincere appreciation to my wife Magdalena and my family for their understanding throughout the whole research journey and their patience and constant positive support. 


\section{Table of Contents}

Abstract__ 2

Author's Declaration ___ 4

Confidentiality and Restricted Access ___ 5

Acknowledgements __ 6

Table of Contents ___ 7

List of Figures ___ 13

List of Tables _ 17

1. Introduction 19

$1.1 \quad$ Introductory Comments ___ 19

1.2 Background ___ 19

1.3 Research Questions and Objectives ___ 25

1.4 Thesis Structure ___ 26

1.5 Chapter Summary ___ 27

2. Literature Review__ 29

$2.1 \quad$ Introductory Comments ___ 29

2.2 Purpose of Literature Review _ 29

2.3 Systematic Literature Review Process ___ 31

2.3.1 Review Questions and Objectives ___ 33

2.3.2 Define Parameters __ 35

2.3.3 Generating and Refining Key Words___ 37

2.3.4 Conducting the Search__ 38

2.3.5 Analysis and Synthesis of Selected Literature___ 46

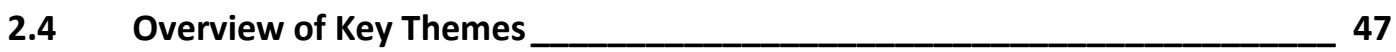

$2.5 \quad$ Management Decision-Making ___ 52 
2.6 Mode Switching 60

2.6.1 Market Entry Decision ___ 65

2.6.1.1 Entry Options ___ 66

2.6.1.2 Market Entry Process and Factors of Influence __ 70

2.6.2 Research about Mode-Switches __ 73

2.6.3 The Mode Switching Process___ 80

2.7 The School of Internationalisation ____ 87

2.7.1 Traditional Approaches of Internationalisation ___ 88

2.7.1.1 Transaction Cost Approach __ 88

2.7.1.2 Agency Theory ___ 90

2.7.1.3 Eclectic Theory by Dunning ___ 91

2.7.1.4 Competition-Oriented and Strategic Approach ___ 93

2.7.1.5 Real Option Theory __ 95

2.7.2 Process-Based Approaches __ 97

2.7.2.1 Process Perspective __ 98

2.7.2.2 Born-Global Approach __ 100

2.7.2.3 International Entrepreneurship Research___ 101

2.7.2.4 The Relationship School of Network Perspective __ 102

2.7.2.5 The Configuration and "Gestalt" Approach __ 103

2.7.2.6 The Three-Level Model by Swoboda___ 105

2.7.2.7 Path Dependency in Internationalisation _ 107

2.8 Critical Evaluation of Literature Review ____ 111

$2.9 \quad$ Conceptual Framework ___ 120

$\mathbf{2 . 1 0}$ Chapter Summary ___________ 130

3. Methodology _ـ 132

3.1 Introductory Comments ____________ 132

3.2 Research Design and Core Considerations ____ 132

3.3 Research Philosophy ________________ 133

$3.4 \quad$ Research Approach _____________ 139

3.5 Research Strategy ______________ 140 
3.7 Case Study Design

3.7.1 The Lubricant Industry and the Global Market___ 145

3.7.2 Case Selection _ 147

3.7.3 Boundaries of the Case Study _ 150

3.7.4 The Structure and Culture of the Multinational Company ___ 151

3.7.5 My Role in the Research and the Reflexivity___ 157

3.8 Methods __________________ 163

3.8.1 Semi-Structured Interviews _ 165

3.8.1.1 Conducting the semi-Structured Interviews __ 168

3.8.1.1.1 Data collection Phase___ 168

3.8.1.1.2 Transcribing the Audio-Recorded Data _ 172

3.8.1.2 Analysing the Interview Transcripts ___ 173

3.8.2 Collection of Secondary Data ___ 182

3.8.2.1 Conducting the Documentation Review _ 185

3.8.2.2 Analysing the Documentation Review __ 187

$3.9 \quad$ Sampling _____________ 188

3.9.1 Sampling Methods___ 188

3.9.2 Sample Size and Process __ 189

3.10 Quality in qualitative research ___ 198

3.11 Research Ethics _______ 201

3.12 Chapter Summary __________________ 202

4. Analysis and Findings___ 204

4.1 Introductory Comments ___ 204

4.2 Findings from the Interviews_____ 204

4.2.1 Decision-Making Process of a Single Mode Switch___ 206

4.2.1.1 Rational Decision-Making Process___ 206

4.2.1.1.1 Starting Impulse _ 208

4.2.1.1.2 Situational Analysis __ 214

4.2.1.1.3 Final Decision Step 219

4.2.1.1.4 Mode Options _ 221 
4.2.1.1.5 Incremental Process __ 223

4.2.1.1.6 Strategic Process __ 224

4.2.1.2 Influencing Factors___ 225

4.2.1.2.1 External influencing factors __ 227

4.2.1.2.2 Circumstances / Opportunities __ 241

4.2.1.2.3 Internal Influencing Factors __ 242

4.2.1.3 Model Integration: Decision-Making Process of a Single Mode Switch__ 250

4.2.2 Short-Cut Decisions _ 256

4.2.3 Decision-Making Process of Multiple Mode Switches ___ 259

4.2.3.1 Interdependencies of Simultaneous Decision-Making Processes _ 259

4.2.3.1.1 Internal Interdependencies__ 260

4.2.3.1.2 External Interdependencies __ 268

4.2.3.1.3 Impact of Interdependencies on the global mode network of the multinational company___ 271

4.2.3.1.4 Handling of Interdependencies__ 275

4.2.3.1.5 Learning Process __ 280

4.2.3.2 Global Strategy___ 281

4.2.3.3 Model Integration: Decision-Making Process of Multiple Mode Switches __ 288

4.3 Documentation Review ______________ 296

4.3.1 Rational Decision Process __ 296

4.3.2 Influencing factors ___ 301

4.3.3 Interdependencies of simultaneous Decision-Making Processes __ 301

4.4 Chapter Summary __________________ 303

5. Discussion _ 305

5.1 Introductory Comments _________ 305

5.2 Comparison with Literature___________________ 305

5.2.1 Decision-Making Process of a Single Mode Switch___ 305

5.2.1.1 Rational Decision-Making process ___ 305

5.2.1.1.1 Starting Impulse _ 307

5.2.1.1.2 Situational Analysis___ 308

5.2.1.1.3 Final Decision Step and Mode Options __ 309

5.2.1.1.4 Revisiting Research Objective $2 \ldots 311$

5.2.1.2 Influencing Factors __ 313 
5.2.1.2.1 External Environment 314

5.2.1.2.2 Internal Environment 316

5.2.1.2.3 Revisiting Research Objective $2 \ldots 318$

5.2.2 Short-Cut Decisions _ 319

5.2.3 Decision-Making Process of Multiple Mode Switches __ 320

5.2.3.1 Interdependencies __ 320

5.2.3.2 The final model ___ 325

5.2.3.3 Revisiting Research Objective 3 and $4 \ldots 329$

5.3 Research Propositions ___ 330

5.4 Closing the gaps of the literature ___ 333

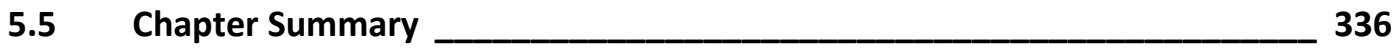

6. Conclusions __ 338

$6.1 \quad$ Introductory Comments _____________ 338

6.2 Revisiting the Research Questions and Aim ___ 338

6.3 Revisiting the Research Objectives ____ 344

6.3.1 Literature Review (Objective 1)___ 344

6.3.2 Preliminary Research (Objective 2 and 3)___ 345

6.3.3 Model Building (Objective 4)__ 345

6.4 Contribution to Knowledge _____________ 345

6.4.1 Theoretical _ 346

6.4.2 Practical 348

6.5 Research Limitations 349

6.6 Recommendation for Further Research 350

6.7 Concluding Comment___ 351

List of References ___ 353

Appendix 1: Philosophical positions, Approaches and Alternative Positions _ 374

Appendix 2: Overview of the main mode switch research from 1997 to 2016 _ 376 
Appendix 3: Preparation Check-List for Semi-Structured Interviews (Saunders et

al., 2012) 382

Appendix 4: Design of the semi-structured Interviews 384

Appendix 5: PARTICIPANT INFORMATION SHEET 389

Appendix 6: Initial Code Overview 396

Appendix 7: First Concept Map 397

Appendix 8: Final Concept Map 398

Appendix 9: Extract of a Colour Coded Interview Transcript 399

Appendix 10: Invitation E-Mail 401

Appendix 11: List of codes Extracts 402

Appendix 12: Approval process within the selected case company 407 


\section{List of Figures}

Figure 1: Share of Export of the Gross Domestic Product of the World Economy (Bank, 2019) …........................................................... 20

Figure 2: Prism diagram of the literature review process (Saunders et al., 2015)

Figure 3: The iterative literature review process (Saunders et al., 2015) .... 33

Figure 5: Overview of the Key Themes of Internationalisation and Mode

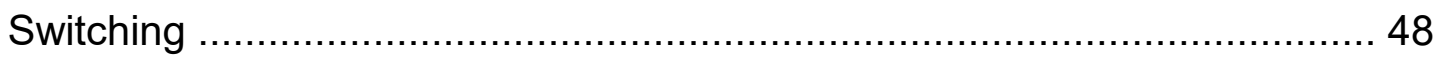

Figure 6: The literature house_decision-making ……………………..... 52

Figure 7: Rational Decision-Making Process (Albaum \& Duerr, 2008)........ 55

Figure 8: Decision-Making with Analytical Hierachy Process Modelling (Matzler, Bailom, \& Mooradian, 2007)..................................................... 56

Figure 9:Integrated Multi-Level Decision-Making Model (Albaum \& Duerr,

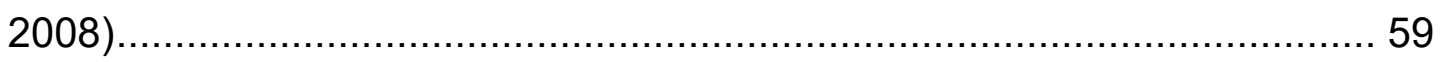

Figure 10: The literature house_Research about market entry decisions and

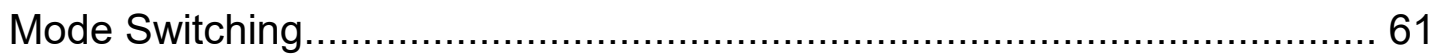

Figure 11: Model of mode switching (Sachse, 2010) ................................ 64

Figure 12: Modes of foreign market entry (Georgiou, 2014) ...................... 67

Figure 13: Descriptive model for decision-making process for market entry

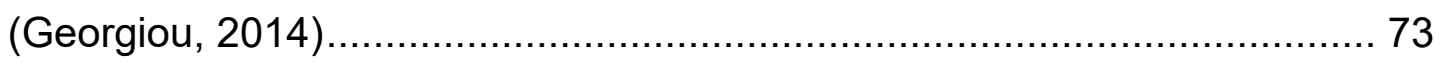

Figure 14: The Mode switching Process of the current Literature Body - the

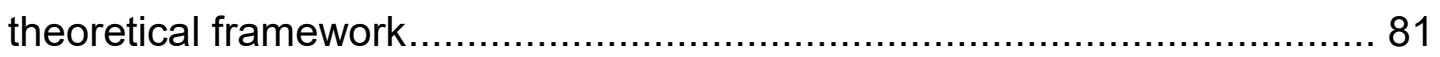

Figure 15: Evaluation Stage of the Mode Switching Process (Sachse, 2010)

Figure 16: The literature house_School of Internationalisation Research .... 87

Figure 17: Extract of the theoretical framework_Transaction costs.............. 90

Figure 18: Extract of the theoretical framework_agency theory ................... 91

Figure 19: Extract of the theoretical framework_Eclectic Theory of Dunning 92 Figure 20: Organization forms of multinational firms (Harzing \& Van

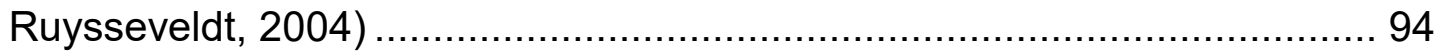


Figure 21: Extract of the theoretical framework_Competition-Oriented

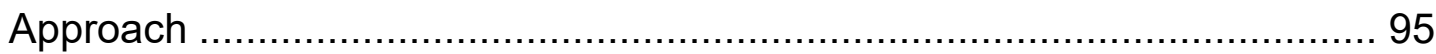

Figure 22: Extract of the theoretical framework_Real Option Theory.......... 97

Figure 23: The level model of internationalisation (Swoboda, 2002)......... 106

Figure 24: Extract of the theoretical framework_The Three-Level Model by Swoboda 107

Figure 25: Papers with Focus on multinational companies 114

Figure 26: Conceptual Framework Level 1 120

Figure 27: Finalized Conceptual Framework (The colours and shapes in the figure are only provided to make them more readable and do not have a specific meaning) 125

Figure 29: The Research Process 138

Figure 30: Inductive Research Approach (Dudovskiy, 2018) 140

Figure 31: Regional Breakdown of the global lubricant market (Grand View Research, 2020) ........................................................................ 146

Figure 32: Boundaries of the Case Study ........................................ 151

Figure 33: Operational Structure of the Internationalisation Process ......... 153

Figure 34: Regional Breakdown of the Global Sales (Holding, 2020) ........ 155 Figure 35: The Flow of Power Relation in Qualitative Research (Karnieli-Miller et al., 2009) 162

Figure 36: 6-step framework of thematic analysis (Braun \& Clarke, 2006) 175

Figure 37: General Overview of the Concept Map 181

Figure 38: Sample Universe (Robinson, 2014) ................................... 190

Figure 39: Research Design .................................................... 202

Figure 40: Summarized concept map ............................................ 205

Figure 41: Extract of the Concept Map_Rational Decision Process........... 207

Figure 42: Extract of the Concept Map_Influencing Factors ................... 227

Figure 43: Extract of the Concept Map_Qualitative external influencing factors 228

Figure 44: Extract of the Concept Map_Quantitative external Influencing Factors. 238 
Figure 45: Extract of the Concept Map_Qualitative Internal Influencing Factors

Figure 46: Extract of the Concept Map_Quantitative Internal Influencing Factors. 248

Figure 47: Model of the Rational Decision-Making Process of a single mode switch 250

Figure 48: Final Model of the decision-making process of a single mode switch 253

Figure 49: Extract of the Concept Map_Short-Cut Decisions 256

Figure 50: Extract of the Concept Map_Interdependencies of Simultaneous Decision-Making Processes. 260

Figure 51:Extract of the Concept Map_Internal Interdependencies of Simultaneous Decision-Making Processes ..... 261

Figure 52: Extract of Concept Map_External Interdependencies of Simultaneous Decision-Making Processes 268

Figure 53: Extract of Concept Map_Impact of Interdependencies on the global mode network of the multinational company.

Figure 54: Extract of Concept Map_Handling of Interdependencies 275

Figure 55: Extract of the Concept Map_Global Strategy 282

Figure 56: First Level Model of the Decision-Making Process of Multiple Mode Switches 291

Figure 57: Final Model of Simultaneous Decision-Making Processes of Multiple Mode Switches within a Multinational Company (The colours and shapes in the figure are only provided to make them more readable and do not have a specific meaning) 295

Figure 58:Highlighted remaining elements of the final model 325 Figure 59: Final Model of Simultaneous Decision-Making Processes of Multiple Mode Switches within a Multinational Company (The colours and shapes in the figure are only provided to make them more readable and do not have a specific meaning) 339 
PhD Thesis Mario Gehrlein

Figure 60: Highlighted Contribution to Knowledge in the New Process Modell (The colours and shapes in the figure are only provided to make them more readable and do not have a specific meaning) 346 


\section{List of Tables}

Table 1: Features of a systematic literature review (Pope et al., 2007) ....... 30 Table 2: Elements for the review questions and objectives (Denyer \& Tranfield, 2009)

Table 4: Selected Parameters for the first filter of the systematic literature review

Table 5: Selected key words for the systematic literature review. 38

Table 6: Internet data bases for the systematic literature review (Georgiou, 2014) 39

Table 7: Number of hits per key phrase and per data base 40

Table 8: Number of hits per key phrase and per search engine. 41

Table 9: Inclusion and Exclusion criteria....

Table 10: Summary of the studies which passed the inclusion and exclusion criteria 45

Table 11: Number of Studies per Key Theme 48

Table 12: Overview of the main theories existing in the literature 51

Table 13: Mode Options 66

Table 14: Overview of the main mode switch research from 1997 to 2016.. 77 Table 15: Comparison of Evaluation step from Sachse (2010) and the integrated multi-level approach (Albaum \& Duerr, 2009) 85

Table 16: Number of Papers per Key Topic 112

Table 17: Overview of the Research Methods per Key Topic 115

Table 18: Overview of the Gaps within the Literature 119

Table 19: Components of the literature discussion in the conceptual framework

Table 20: Strengths and Weaknesses of Case Study Research (Simons, 2009; Merriam, 2009). 143

Table 21: Largest Multinational Lubricant Manufacturers (Mang \& Dresel, 2007) 
Table 22: Key Actors and their Responsibilities within the decision-making process

Table 23: Ethical and Methodological Recommendations ensuring the Power Relation between Researcher and Participant (Karnieli-Miller et al., 2009) 163 Table 24: Use of different interview strategies depending on the purpose of the research (Saunders et al., 2015) .................................................. 166

Table 25: Example Extract of the List of codes .................................... 178

Table 26: Provided Documents for the Documentation Review ................. 185

Table 27: Provided Documents per Participant.................................... 186

Table 28: Four-point approach to qualitative sampling (Robinson, 2014) .. 189

Table 29: Inclusion and Exclusion Criteria of the Sample Universe ........... 191

Table 30: Number of interviews per key actor group............................. 193

Table 31: Recommended Sample Sizes.............................................. 195

Table 32: Sampling strategies adopted for each objective (Saunders et al.,

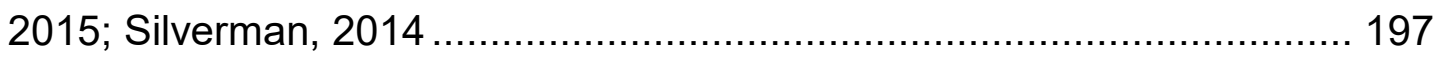

Table 33: Competitor Evaluation Criteria_Business Plan Example............ 299

Table 34: Comparison of the rational process steps of the literature and this

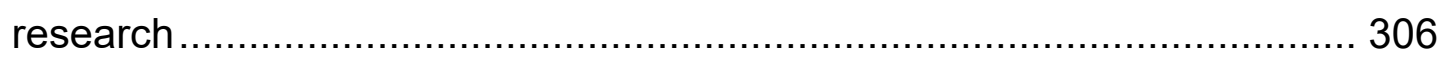

Table 35: Summary of Result Discussion_Rational Decision-Making Process

Table 36: Summary of Result Discussion_Influencing factors 319

Table 37: Summary of Result Discussion_Decision-Making process of multiple mode switches 330

Table 38: Closing the Literature Gaps ........................................... 336

Table 39: Summary of Objective Achievement .................................. 352 


\section{Introduction}

\subsection{Introductory Comments}

This chapter introduces the research topic and presents the structure of the thesis. The thesis starts with introducing the research idea and with explaining how the research problem came up that this study intends to solve. Afterwards, the research aim and research questions are discussed, followed by the objectives. Finally, the thesis structure is presented, and a short summary of this chapter is given.

\subsection{Background}

The business environment and industries are continuously changing during the last decades because of the globalisation of the world economy (Levitt, 1983; Hollensen, 2017). According to Levitt (1983) and Hollensen (2017) it is more beneficial for firms to have international activities because customer requirements and preferences become more homogeneous worldwide which help firms to work more efficiently and to use economies of scale effects. Therefore, companies are increasingly expanding in foreign markets through internationalisation besides their domestic market because they intend to benefit from the higher efficiency by using their existing resources more profitability. The term international activity is defined as the trading of goods, services, technologies or investments of a firm across the national borders of its domestic market where the headquarter is established (Harzing \& Van Ruysseveldt, 2004). The importance of internationalisation for the world economy and for the success of a company is shown by the estimated market share of exports of the Gross Domestic Product (GDP) which was 29\% for the world economy in 2017 because approximately one third of the GDP is related to the international activities of firms (Bank, 2019). Exports refers to the supply of goods from a company across the national borders of its domestic market (Harzing \& Van Ruysseveldt, 2004). The remaining part of $71 \%$ of the GDP refers to the supply of goods from the firms into their domestic markets. Figure 
1 shows the trend of the export market share of the GDP for the world economy over the last decades (increased from 19\% in 1990 up to $30 \%$ in 2018). This figure shows the positive and increasing trend of the export market share of the GDP, which is mainly caused by the reduction of trade restrictions, trading barriers, investment barriers and the intention of single countries to open their economy and to stop the isolation of their domestic market (Harzing \& Van Ruysseveldt, 2004). Additionally, the development of the mobility and global transport systems have supported globalisation and internationalisation (Lynch, 2009). Due to this positive trend, some countries have developed an export orientation and their export market shares of the GDP are approx. 50\%, e.g. in Germany 2018 (47\%), or even above 50\%, e.g. in Netherlands (84,3\%) (Bank, 2019).

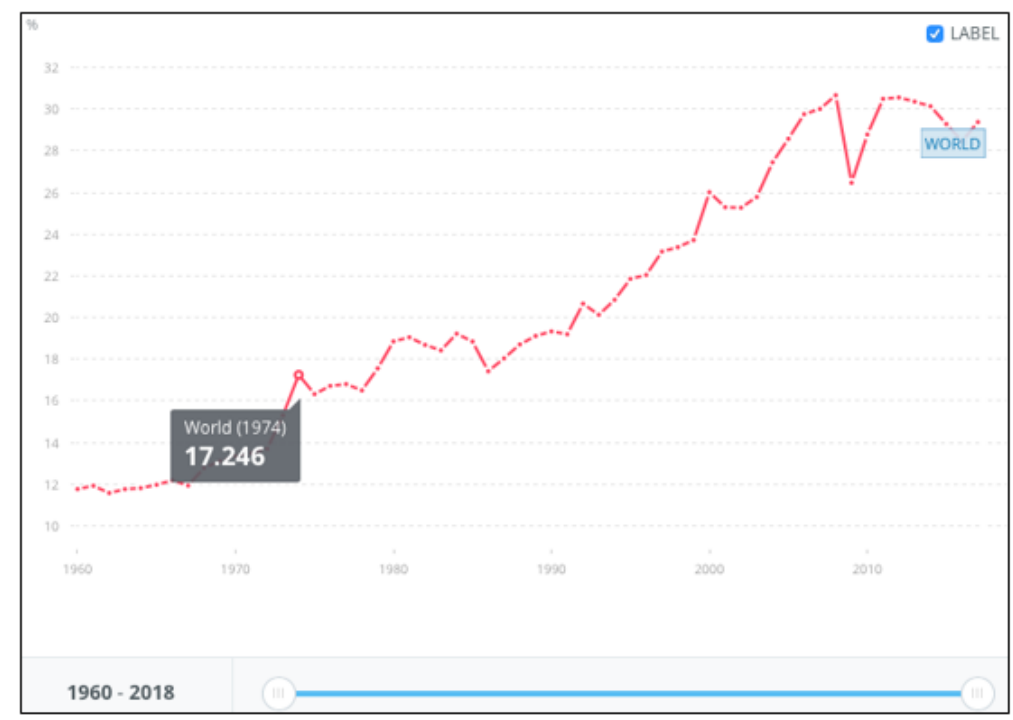

Figure 1: Share of Export of the Gross Domestic Product of the World Economy (Bank, 2019)

As a consequence, there are companies which have developed an internationalisation orientation as well and have used several mode options of working in a foreign country (Hollensen, 2017). The mode option is the market development strategy that a firm is using to supply and service their customers in a market (Sachse, 2010; Georgiou, 2014). There are different mode options, 
e.g. partnerships with distributors, international license agreements, management contracts, local sales companies or subsidiaries in the foreign market (Sachse, 2010). Entering into a foreign market with a mode option is the first step of internationalisation of a firm (Hollensen, 2017) and therefore important for this study that focuses on the management decision-making in the transition of a multinational company's internationalisation strategy.

Internationalisation is traditionally viewed as a process of business activity defined by the Uppsala model as an incremental and gradual process of organisational transition in their expansion to overseas markets (Hollensen, 2017). The core statement of the Uppsala model is that firms in practice begin to internationalise in geographically closer countries to avoid uncertainty and minimize risks (Rezende, 2006; Hollensen, 2017). Calof and Beamish (1995) and Sachse (2010) extend this process driven view by illustrating the importance of management decision-making within this progression. These extensions of the Uppsala model demonstrate that the internationalisation process evolved originally from the theory of decision-making (Calof \& Beamish, 1995; Sachse, 2010).

It is evident that internationalisation and the decision-making process behind is influenced by many factors from the world economy, like increasing wealth and significance of the emerging markets, the different growth prognoses of the historically strong markets like Germany, USA and Japan in comparison to the growth prognoses of China, India, Brazil, etc., the increasing penetration of the world economy through the internet, the increasing networking through the modern communication options, demographic changes, the increasing complexity of the raw material supply chain and the upcoming budget deficit of some countries like Greece (Reinhart \& Rogoff, 2009; Roubin \& Mihm, 2010). Each of these changes and adjustments in a respective market or country can be a starting impulse for a company to change its market development strategy (mode option) in a respective market or country and to switch its mode option to align its strategy according to the new environmental requirements. The 
term "mode switching" is defined as a change of a previous mode (market development strategy) which was established in a respective market to another mode option (Welch, Benito, \& Petersen, 2007). For example, if an existing external distributor is exchanged and a company is launching an own subsidiary in the country. A survey from Sachse (2010) shows that $51 \%$ of 192 internationally active firms investigated have switched their entry strategy once at least. Swoboda et al. (2010) and Picot-Coupey (2014) support this perspective and acknowledge that the first choice of the market entry mode is only the start of a firm's international development and mode switching can improve the performance abroad.

Academic literature surrounding mode switching is typically focused on the analysis of one international activity across several companies (Asmussen, Benito \& Petersen, 2009). This typically involved a quantitative survey where managers of different companies are interviewed or contacted via questionnaires only regarding one international activity and the decisions which were made for this international activity, e.g. which mode switches happened and why these mode switches happened (Fletcher, 2011; Nan, 2013). This means that the international activity itself is explored. However, according to Rezende (2006) there are multinational companies that typically have several international activities which can be conceptualized as a loosely coupled system with several internationalisation processes linked in a global network. A multinational company is defined as a company that has facilities and other assets in several foreign countries and a centralized headquarter in its domestic market that typically coordinates the global management (Harzing \& Van Ruysseveldt, 2004). The previous studies and the literature around mode switching with their focus on exploring one international activity of firms do not consider the network of the global internationalisation strategy of a multinational firm (Rezende, 2006). Due to this methodological approach the influencing factors and links in a mode network of a multinational company between countries and international activities and their effect on the mode 
switching process are missing from the existing literature (Rezende, 2006; Asmussen et al., 2009). These mode switching processes which are running in parallel at the same time (simultaneous) within the global network of a multinational company can exert interdependencies regarding the supply chain process (e.g. supply the countries from a regional hub), the brand awareness (competition between subsidiaries in the same markets), costs (e.g. product registration costs for specific regions), political factors (e.g. global sanctions if a subsidiary offend an embargo), internal competition regarding resources (e.g. which project receives the human resources), geographical factors (e.g. exchange risks) and cultural factors (e.g. historical conflicts of several cultures) (Albaum \& Duerr, 2005; Rezende, 2006; Guenzi, 2011). Ignoring the interdependencies within this network can result in increasing complexity, costs, not using synergistic effects to increase the efficiency and finally that a mode switch needs to be reversed due to a lack of success which causes the inefficient use of resources (Rezende, 2006; Asmussen et al., 2009; Hollensen, 2017). It is therefore essential to explore the interdependencies in a global mode network of a multinational company and how mode switching is influenced by them (Rezende, 2006; Guenzi, 2011) which contributes practical and theoretical knowledge.

According to Drake and Heath (2011) practitioner researcher (research conducted within the business life of a researcher) often starts from issues in the workplace and may provide contribution to theoretical and practical knowledge by bridging the gaps between theory and practice. My research problem in the area of the decision-making process of mode switching within multinational companies emerged by my role as an Area Sales Manager in the Export Division of a multinational manufacturer of lubricants and was stimulated by my daily business. In my role, I am usually at the receiving end of the decision process regarding mode switches and responsible for implementing the decision, which is made by a strategy team. In some cases, the final decisions appear not to be justified, inconsistent or even irrational for 
the implementation team, because these decisions seem to follow the personal interests and behaviours of the managers in charge as indicated by Calof and Beamish (1995) who argue that the attitudes of executives often drive internationalisation decisions and not economic factors. Next to this, in some cases the interdependencies between simultaneous international activities and the effect that one decision in an international activity can have on another, are often not considered by the decision makers. E.g. that if the multinational company decides to switch the mode in an international activity by launching an own sales subsidiary, that this decision preserves human resources within the multinational company which might be necessary for another mode switch decision that coexists and consequently influences this simultaneous decision process. This results in challenges and problems for the firm because some decisions need to be reversed in the long-term which causes high costs due to the lack of successes which is suggested by the survey results from Sachse (2010) and by Hollensen (2017). The survey of Sachse (2010) demonstrates that $95 \%$ of the investigated firms post mode-switching reported higher growth in turnover and performance satisfaction in the short-term. But in the long-term, the satisfaction of the performance improvement decreased after the mode switch (Sachse, 2010). According to the firms, this is caused by an irrational and lack of strategical mode switching process (Sachse 2010; Swoboda et al., 2010). Consequently, mode switching is not in itself a prerequisite for success and therefore, the understanding of the holistic mode switching process is essential to contribute to business success and subsequently extend existing knowledge because a wider knowledge about the process can avoid wrong decision-making (Subramanian \& Metin, 2009). This initiated the research problem and the idea to investigate the decision-making process of modeswitching within multinational companies with the main focus on the interdependencies between simultaneous international activities and the influencing factors of the decision-making process. 
The aim of this research is to understand the multinational firm's management decision-making process of mode switching, the influencing factors of the decision-making process and the reason how these mode switching activities occur. The study will develop a new process model to illustrate and explain this business activity and expand the international management literature base.

By achieving the research aim, this study will contribute theoretical knowledge with a new process model by bridging the existing gaps in the current literature body. This model contributes practical knowledge by supporting managers to establish their decision-making process of mode switching within their multinational company set-up in a transparent and consistent way or to support companies which are on their journey to become a multinational company. Following the guidelines of the developed model can help managers within multinational companies to avoid increasing complexity, costs, not using synergistic effects to increase the efficiency and finally that a mode switch needs to be reversed due to a lack of success which causes an inefficient use of resources. Next to this the model will help managers to find the most appropriate mode option for a respective foreign market during the mode switching process that helps to maximize the profit of a multinational company.

\subsection{Research Questions and Objectives}

To develop the process model of the decision-making process the following research questions and objectives shall be achieved:

\section{Research Questions:}

What is the process of management decision-making for mode switching in a multinational company's international activity?

What are the interdependencies at play when decision-making processes for mode switching occur simultaneously? 
How are the interdependencies of simultaneous internationalisation processes managed within the decision-making process of mode switching?

\section{Objectives:}

Objective 1: To conduct a review of literature to position the research within the current internationalisation and management literature and identify key gaps where a meaningful contribution could be made.

Objective 2: To explore the process of management decision-making of mode switching within a multinational company's internationalisation strategy.

Objective 3: To determine the interdependencies and their role between simultaneous decision-making processes of mode switching.

Objective 4: To build a process model of management decision-making for mode switching which considers interdependencies of simultaneous internationalisation processes within a multinational company.

\subsection{Thesis Structure}

This thesis has the following structure to achieve the research questions, aim and objectives:

Chapter 1 is the introduction of the thesis, providing the reader the overview of my idea and background of the research topic. Additionally, the I present my research questions, the aim of the study and the objectives that I intend to achieve.

Chapter 2 presents the literature review process of this thesis. It identifies and discusses the key themes of internationalisation, mode switching and decisionmaking in the existing literature body. As a result, the main gaps in the literature are outlined and a conceptual framework for this study is developed. 
Chapter 3 presents the methodological approach and methods of this research project by using the key elements and determinants of Saunders, Lewis and Thornhill (2012) research onion.

Chapter 4 presents myfindings that I found in the data set of my semistructured interviews and the provided documents from the participants. Additionally, the model of the simultaneous decision-making processes of multiple mode switches in a multinational company is developed.

Chapter 5 discusses the research findings and the developed model. Additionally, this chapter illustrates the research propositions and the comparison of the model with the existing concepts, theories and approaches of the literature body.

Chapter 6 closes the thesis and the research project by presenting the final conclusions, revisiting the research questions, aim and objectives of the research and explaining the contribution to knowledge of the key findings. Finally, the research limitations and recommendations for future research are presented.

\subsection{Chapter Summary}

This chapter has outlined an introduction of the research subject and has introduced the dimensions of the $\mathrm{PhD}$ thesis by describing the research problem on which basis the research questions, aim and objectives are defined.

A lack of understanding regarding the complexity of the internationalisation process and more specifically of the decision-making process of mode switching within multinational firms was identified because the traditional rational perspective of previous studies predominated by quantitative surveys have not focused on the simultaneous nature and interdependencies that occur between mode switching processes which are running in parallel and at the same time within a multinational company. The overall research aim of the 
thesis is to close this gap and to develop a new process model to illustrate and explain the business activity of decision-making for mode switching in an international activity within multinational companies and expand the international management literature base. Next to this the study intends to contribute practical knowledge by providing managers a tool in the context of their internationalisation process to avoid increasing complexity, costs, not using synergistic effects to increase the efficiency and finally that a mode switch needs to be reversed due to a lack of success which causes wasting resources. 


\section{Literature Review}

\subsection{Introductory Comments}

The purpose of this chapter is to present the literature review process of this thesis and to provide a theoretical underpinning as well as a conceptual framework based on the findings of the literature. By using a qualitative thematic analysis, the following key themes are identified and discussed, internationalisation, mode switching and decision-making in the existing literature body. The literature body and the respective studies were selected through a systematic literature review process. Last but not least the identified main gaps in the current literature body are outlined and discussed and a conceptual framework is developed.

\subsection{Purpose of Literature Review}

A literature review is a reproducible method to develop a holistic and comprehensive understanding of the existing body of recorded work written by researchers, scholars and practitioners (Fink, 2014). The main purpose is to build an underpinning based on findings of previous studies that enables a researcher to synthesise his own research and ideas (Fink, 2014). The purpose of the literature review of this research is to give the reader an understanding of the existing literature body behind the decision-making process of mode switching within mutlinational companies and to identify the key gaps of the current studies in this research area.

In management research, Tranfield, Denyer, and Smart (2003) argue that a literature review process is a key method to structure the amount of previous works and to map the progress / development of the research area.

Generally, literature reviews are categorized in first generation reviews or second generations (Bettany-Salitkov, 2012). The first generation reviews use traditional approaches, also called critical or narrative reviews (Pope, Mays \& Popay, 2007). These reviews are a summary of single studies and their 
purpose is to tell a story which the reviewer wants them to, to provide justification of the researcher's own arguments and opinions (BettanySalitkov, 2012). Due to the selectively nature, the narrative reviews may not always content the most important literature on the topic and sometimes the selected literature are biased, because the researcher selects and search the respective studies according to his personal subjective opinion (Pope et al., 2007).

In contrast the second generation reviews are more sytematic and follow transparent and holistic approaches in identifying and selecting evidence and previous works in the respective research area (Pope et al., 2007).

According to Pope et al. (2007) the main purpose of a systematic literature review is to synthesize high quality evidence which includes the features in Table 1.

\begin{tabular}{|l|}
\hline Features of a systematic literature review \\
\hline A review protocol to guide the review process \\
\hline Holistic literature search with a pre defined search strategy \\
\hline Critical evaluation of the evidence \\
\hline Overt data extraction \\
\hline Explicit analysis
\end{tabular}

Table 1: Features of a systematic literature review (Pope et al., 2007)

Fink (2014) argues that the systematic literature reviews follow a transparent process and are more credible because they are based on more comprehensive and holistic understanding of the research area without bias. Similarly, Tranfield, Denyer and Smart (2003) support that a systematic 
literature review is the most efficient and high quality way for identifying, analysing and evaluating the existing literature and previous works of a respective research areas (Tranfield et al., 2003; Bryman \& Bell, 2011; Fink, 2014).

The main purpose of this chapter is to carry out a systematic literature review process for selecting the most valuable studies for this thesis. The analysis and synthesis of the selected studies which is the last step of the review process is done with a qualitative and inductive thematic analysis to find the main themes about the decision-making process of mode switching which are the theoretical and conceptual background of this research project. I will follow the systematic literature review process suggested by Saunders et al. (2015) to find and select the relevant literature for his research to ensure the credinility and quality of the selected study. The analysis and synthesis of the content and the data of the selected literature will follow a qualitative and inductive thematic analysis approach which fits to my phenomenological position which is outlined in chapter 3 of this thesis. Using this approach of conducting a systematic literature review process for selecting the studies and analysing the studies using a thematic analysis is suggested by the PHD thesis of Schröter (2014). As recommended by Tranfield et al. (2003) the final outcome of this chapter will be an initial conceptual framework of the existing intellectual area of the decision-making process for mode switching in the context of internationalisation.

\subsection{Systematic Literature Review Process}

I conduct a systematic literature review process for selecting the most valuable existing studies in the literature body which help to answer his research questions by opening his research to studies which might be beyond his research area and networks (Saunders et al., 2015). According to Mallett et al. (2012), systematic reviews have a high trustworthiness and credibility as a greater breath of studies is included and because the researcher typically 
conducts the literature review more critically and considers the quality of the selected research outcome. As objective one of this study is to conduct a review of literature and to identify the key gaps of the current literature body in a broad and wide research area of internationalisation and management decision-making, there are many studies which could be of interest for this project. The systematic literature review helps to manage the high amount of possible studies in the research area and to select the most credible studies for answering the research questions through purposeful selected inclusion and exclusion criteria (Saunders et al., 2015).

Many authors (Tranfield et al., 2003; Pope et al., 2007; Saunders et al., 2015) have defined a process to conduct a systematic literature review. The systematic literature review process and its iterative manner can be illustrated in a prism diagram as shown in Figure 2. Chapter 2.3 is structured according to this described literature review process.

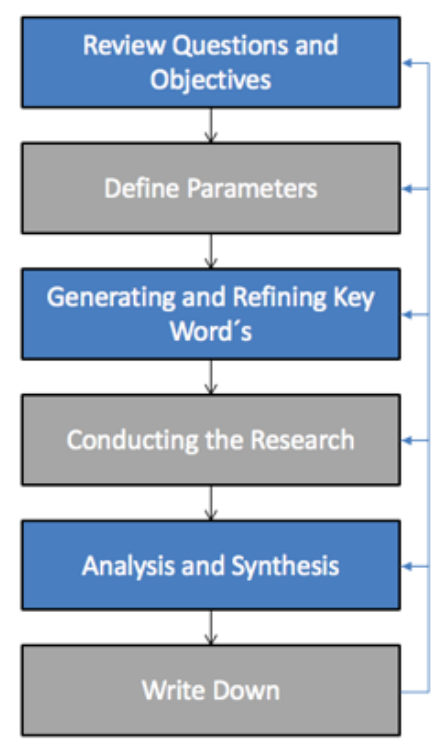

Figure 2: Prism diagram of the literature review process (Saunders et al., 2015)

The research questions and objectives are formulated based on the research interests and research area, before the systematic literature review process starts (Tranfield et al., 2003). 
During the process, the researcher identifies new ideas and topics which are interesting for his / her research and therefore the previous defined review questions, objectives must be redefined once the initial literature review is finalized (Pope et al., 2007). Therefore, the systematic literature review process is described as an upward spiral process with several iterative steps, as visualized in Figure 3 (Saunders et al., 2015).

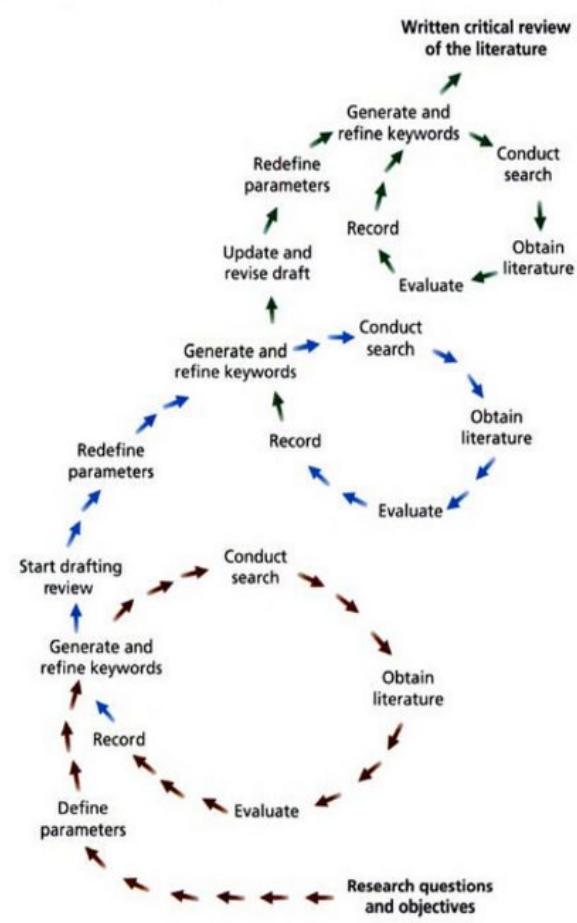

Figure 3: The iterative literature review process (Saunders et al., 2015)

The review process as described by Saunders et al. (2015) should be repeated throughout the whole research journey to ensure an up to date record of all relevant studies (Bryman \& Bell, 2011).

\subsubsection{Review Questions and Objectives}

Certainly, review questions and objectives should be clear and answerable. According to Denyer and Tranfield (2009) the review questions and objectives should additionally cover four elements as mentioned in Table 2. 


\begin{tabular}{|c|c|}
\hline Elements & Description \\
\hline Context & $\begin{array}{l}\text { what is being studied (individuals, } \\
\text { relationships, institutional settings, } \\
\text { and systems) }\end{array}$ \\
\hline Intervention & $\begin{array}{l}\text { what effects, actions, or activities are } \\
\text { being studied }\end{array}$ \\
\hline Mechanisms & $\begin{array}{l}\text { the mechanisms that explain the } \\
\text { relationship between the } \\
\text { interventions and the outcomes }\end{array}$ \\
\hline Outcome & the effects of the intervention \\
\hline
\end{tabular}

Table 2: Elements for the review questions and objectives (Denyer \& Tranfield, 2009)

The research questions set at the beginning of the thesis are repeated below and are the foundation for the literature review process:

What is the process of management decision-making for mode switching in a multinational company's international activity?

What are the interdependencies at play when decision-making processes for mode switching occur simultaneously?

How are the interdependencies of simultaneous internationalisation processes managed within the decision-making process of mode switching?

As discussed in previous chapter the research objectives are:

Objective 1: To conduct a review of literature to position the research within the current internationalisation and management literature and identify key gaps where a meaningful contribution could be made. 
Objective 2: To explore the process of management decision-making of mode switching within a multinational company's internationalisation strategy.

Objective 3: To determine the interdependencies and their role between simultaneous decision-making processes of mode switching.

Objective 4: To build a process model of management decision-making for mode switching which considers interdependencies of simultaneous internationalisation processes within a multinational company.

Evidently, objective 1 is the research objective which I intend to achieve with his literature review process outlined in this chapter.

\subsubsection{Define Parameters}

Due to the large number of studies, especially within the business and management research areas, a literature search without any restriction could be very time consuming (Saunders et al., 2015). According to Fink (2014) there are filters to screen studies.

Fink (2014) stresses several parameters in Table 4 which should be considered as filters of a literature review (Table 4).

I selected the following parameters in Table 4 to conduct the systematic literature review around the transition of multinational company's internationalisation strategy and the mode switching process:

\section{Parameters Choice}

Language of Publication English, German

Subject area and business sector Decision-making within the process of mode switching and the search 
was carried out in the business, marketing and management sectors

\begin{tabular}{|l|l|}
\hline Geographical area & Unrestricted \\
\hline Time Frame & Twenty years, 2000-2020
\end{tabular}

\section{Date and duration of data Unrestricted} collection

\section{Literature type}

$$
\begin{aligned}
& \text { Primary and secondary sources of } \\
& \text { literature, specifically academic } \\
& \text { journals, books and company reports }
\end{aligned}
$$

Table 3: Selected Parameters for the first filter of the systematic literature review

Selecting the English language is primarily based on practical issues and because English is mainly used in academic journals in Europe and United States of America. As German is my first language, I also include academic journals written in German.

Choosing the "Decision-making within the process of mode switching" as a subject area and business, marketing and management as business sector is a logical selection based on the research questions and objective 1 of this study.

As this research is about decision-making within the process of mode switching, internationalisation and interdependencies between simultaneous international activities of multinational companies, the research does not restrict the literature review to limited geographical areas.

The first loop of the literature review process was conducted in 2018 but the iterative loops were conducted during the whole research journey. It was monitored if relevant further developments happened by establishing 
automatic email alerts if a new study of the research focus was published (Fink, 2014, Georgiou, 2014).

\subsubsection{Generating and Refining Key Words}

For generating data, the available electronic databases were mostly undertaken because it is easier to search and filter the required studies for selecting according to the inclusion and exclusion criteria (Saunders et al., 2015). Due to the large amount of studies in the investigated research areas, a careful selection of key words is required to identify the most relevant studies for this research (Fink, 2014). According to Saunders et al. (2015) the key word selection is an iterative process in which new key words are added and existing key words are refined if relevant articles are identified during the review process (Georgiou, 2014; Schröter, 2014).

Due to the purpose of this research, the first loop of the iteratirve process was initialised by using the key phrase "mode switching process". Based on the first loop and the identified relevant studies, the key words in Table 5 were selected to cover the research area after several iterations, because these key words are mainly mentioned and get most attraction in the key words and abstracts of the identified studies in the respective loops of the iterative process of selecting the studies (Saunders et al., 2015). 


\section{Mode switching}

\section{Internationalisation process}

Second step of internationalisation

International Growth

\section{Foreign market expansion}

\section{Global export strategy}

\section{Decision-making in Internationalisation}

\section{Interdependence in internationalisation process}

\section{Global mode network}

Table 4: Selected key words for the systematic literature review

\subsubsection{Conducting the Search}

I followed the research strategy suggested by Tranfield et al. (2003) and Saunders et al. (2015) because their strategies and approaches were used by other research studies as well (Georgiou, 2014; Schröter, 2014). According to Tranfield et al. (2003) and Saunders et al. (2015) the large amount of studies in the field of management and business makes it useful and sometimes necessary to conduct a "scoping study" before doing the full systematic literature review, to build a first and preliminary understanding of the research area. Therefore I conducted a "scoping study" using "mode switching process" as key phrase and the business source complete (EBSCO) as electronic database without any other restrictions. This first search produced 274 studies. By going through the titles, abstracts and key words of the studies, it became apparent that the selected research area of mode switching has several themes that were focused by several researches. Finally, the first search 
revealed and this was suggested by the iterative loops of the systematic literautre review (Tranfield et al., 2003) that the key words selected in the previous section are adequate and cover the research area sufficiently.

For an electronic search via databases to find published studies, unpublished studies, conference proceedings and internet, the following three internet data bases, illustrated in Table 6 were used, conducting the systematic literature review process and using the off-campus facilities of the University of Gloucestershire because these databases were also suggested in other $\mathrm{PhD}$ studies, e.g. in the study of Georgiou (2014) and Schröter (2014).

\section{Data base Desiption}

Business Source $\quad$ This database contains more than

Complete (EBSCO) $\quad 4000$ full text titles, of which more than 1600 are peer reviewed. Some of the subjects included in the database are management, business, marketing, health and education.

Emerald Full Text More than 800 full text journals. The subscription of this database was suspended at the end of 2012 by the university and this disabled the automated updates from this database since

IngentaConnect More than 300 full text journals and other titles contain abstracts. It is the world's largest resource for scholarly publications

Table 5: Internet data bases for the systematic literature review (Georgiou, 2014)

I used the key words selected in the previous section as Boolean operators in the title and abstract of the internet data bases. This means that the journal, study or article meets the criteria and is selected if the key word is mentioned 
in the title or the abstract of an article. As previously stated and as argued by Fink (2014), a systematic literature review is following an iterative process of defining, clarification and refinement. Table 7 shows a summary of the final iterative loop of the electronic search that was finalized in November 2020 and updated with additions received via email alerts from the selected data bases. The table provides the numbers of studies that were selected according to the matchs of the key words in their titles and abstracts.

\begin{tabular}{|l|c|c|c|c|}
\hline \multicolumn{1}{|c}{ Key Phrases } & Ebesco & Emerald & Ingenta & Total \\
\hline International growth & 121 & 44 & 145 & 310 \\
\hline Internationalisation process & 14 & 489 & 152 & 655 \\
\hline $\begin{array}{l}\text { Second step of } \\
\text { internationalisation }\end{array}$ & 95 & 195 & 12 & 302 \\
\hline Entry mode switching & 274 & 26 & 13 & 313 \\
\hline Foreign market expansion & 24 & 321 & 336 & 657 \\
\hline Global export strategy & 242 & 93 & 335 & 670 \\
\hline $\begin{array}{l}\text { Decision-making in } \\
\text { Internationalisation }\end{array}$ & 89 & 128 & 80 & 297 \\
\hline $\begin{array}{l}\text { Interdependence in } \\
\text { internationalisation process }\end{array}$ & 85 & 53 & 29 & 167 \\
\hline Global mode network & 0 & 30 & 370 & 400 \\
\hline Total number of Papers & 920 & 1.397 & 1.472 & 3.771 \\
\hline
\end{tabular}

Table 6: Number of hits per key phrase and per data base

Most of the results were provided by the Ingenta database because in this database the key phrases are searched in the title, abstract and keywords. In this database it is only possible to search in all three categories or in one of these categories. In comparison in the Ebesco and Emerald database, I was searching the key phrases only in the abstracts and titles of the studies because searching the key phrases within the whole documents would have 
provided a not manageable amount of studies. Finally, the results show that the generic and general key phrases like "international growth", "internationalisation process", "foreign market expansion", "global export strategy" and "global mode network" produced the highest number of matched studies.

At the same time, I extended my electronic search to unpublished studies, conference proceedings and internet (Tranfiel et al., 2003; Fink, 2014; Saunders et al., 2015) to cover the holistic spectrum of evidence. Therefore a search was conducted using Zetoc which is a database with journals, conference proceedings and reports and Google Scholar. Using these search engines was also suggested in other PhD studies, e.g. in the study of Georgiou (2014) and Schröter (2014). Applying the same key phrases as above resulted in the summary of Table 8.

\begin{tabular}{|l|c|c|c|}
\hline \multicolumn{1}{|c}{ Key Phrases } & ZETOC & $\begin{array}{c}\text { Google } \\
\text { Scholar }\end{array}$ & Total \\
\hline International growth & 155 & 336 & 491 \\
\hline Internationalisation process & 345 & 353 & 698 \\
\hline Second step of internationalisation & 2 & 3 & 5 \\
\hline Entry mode switching & 7 & 7 & 14 \\
\hline Foreign market expansion & 271 & 891 & 1.162 \\
\hline Global export strategy & 108 & 27 & 135 \\
\hline $\begin{array}{l}\text { Decision-Making in } \\
\text { Internationalisation }\end{array}$ & 80 & 8 & 88 \\
\hline $\begin{array}{l}\text { Interdependence in } \\
\text { internationalisation process }\end{array}$ & 1 & 2 & 3 \\
\hline Global mode network & 22 & 44 & 66 \\
\hline \begin{tabular}{l} 
Total number of Papers \\
\hline
\end{tabular} & 991 & 1.671 & 2.662 \\
\hline \begin{tabular}{l} 
Table 7: Number of hits per key phrase and per search engine \\
\hline
\end{tabular} & & & \\
\hline
\end{tabular}

Table 7: Number of hits per key phrase and per search engine 
Similar to the observations from the summary of the databases also the search engines identified most of the matches with the generic and general key phrases.

According to Tranfield et al. (2003) and Fink (2014) and their definition of the systematic literature review process, I have to define inclusion and exclusion criteria to reduce the selected numbers of studies to a manageable amount. Tranfield et al. (2003) argue that the inclusion and exclusion criteria have to be connected with the purpose and desire of the researcher to find the most relevant and best quality evidence for his / her research field. Therefore, the selection of the inclusion and exclusion criteria always have a subjective character (Tranfield et al., 2003; Fink, 2014).

In consideration of the arguments and suggestions in the literature (Pope et al., 2007; Fink, 2014) the inclusion and exclusion criteria shown in Table 9 were selected.

Typically, product or service specific studies do not provide evidence and results that can be generalized (Bettany-Salitkov, 2012). Therefore, only studies which are not focused on a specific industry or products and studies which are focused on the lubricant industry are included into the literature review as this is relevant for the focus of this research. For example, the study of the market entry and exit process with focus on the lubricant manufacturer BP (Georgiou, 2014). This study is included in the systematic literature review although it is focused on specific products because the focus is on the lubricant industry which fits to the study aim and the selected industry for the in-depth analysis (see chapter 3.7).

\begin{tabular}{l|l|lll} 
Parameter & \multicolumn{2}{l}{ Inclusion } & \multicolumn{2}{l}{ Exclusion } \\
& "Non product/service & "Product & or & service \\
Study Focus & specific studies, or & specific & with & limited
\end{tabular}


PhD Thesis Mario Gehrlein

\begin{tabular}{|c|c|c|}
\hline & $\begin{array}{l}\text { studies specific on } \\
\text { lubricants/oil related" }\end{array}$ & $\begin{array}{l}\text { applicability for other } \\
\text { products/services" }\end{array}$ \\
\hline Study Focus & "Non country specific" & $\begin{array}{l}\text { "Country specific with } \\
\text { limited applicability } \\
\text { elsewhere or with focus } \\
\text { on Europe" }\end{array}$ \\
\hline Study Focus & "Multionational firms" & $\begin{array}{l}\text { "Firms without } \\
\text { international activities or } \\
\text { with the main focus on } \\
\text { their domestic market" }\end{array}$ \\
\hline Study Focus & $\begin{array}{l}\text { "Studies describing the } \\
\text { whole process or single } \\
\text { steps of } \\
\text { internationalisation in } \\
\text { detail" }\end{array}$ & $\begin{array}{l}\text { "Studies describing single } \\
\text { steps of the mode } \\
\text { switching process in no } \\
\text { proper way and not } \\
\text { detailled enough" }\end{array}$ \\
\hline Study output & $\begin{array}{l}\text { "Prescriptive models for } \\
\text { decision-making or any } \\
\text { other output that } \\
\text { facilitates the decision- } \\
\text { making process" }\end{array}$ & $\begin{array}{l}\text { "Studies, which do not } \\
\text { report any mechanisms, } \\
\text { models or process for } \\
\text { decision-making." }\end{array}$ \\
\hline Study type & $\begin{array}{l}\text { "Studies with clear and } \\
\text { sound methodologies and } \\
\text { evidenced claims." }\end{array}$ & $\begin{array}{l}\text { "Studies with unclear } \\
\text { methodologies and non } \\
\text { evidenced claims. } \\
\text { Working papers." }\end{array}$ \\
\hline
\end{tabular}

Table 8: Inclusion and Exclusion criteria

In the same way, studies with focus on one single country are often not applicable for the general use and therefore have been excluded. For example, the study "patterns of Brazilian firms and the decision to establish subsidiaries abroad (Baretto \& Da Rocha, 2001) was excluded because of the limited 
applicability to other countries. Consequently, studies without a focus on a specific country are included, while studies specifically focused on one country outside of the scope of this study have been excluded because this study is focused on multinational companies which are active in several countries and I do not intend to limit the scope of the study on one respective country. This is indicated by Welte, Feenstra, Jager and Leidl (2004) who argue that the transferability of study results between countries needs to be checked first, which would be time consuming and not manageable in the time scope of this PhD thesis.

Studies with focus on firms without international activities or with the main focus on their domestic market were also excluded because these firms are faced with different challenges and not with the internationalisation process of mode switches (Bettany-Salitkov, 2012).

Last but not least, studies that do not contain important aspects of the decisionmaking process of mode switching, were excluded from the review, because the objective of this study is to build a model of the process of management decision-making during entry mode transitions. For example, the study from Delios (2011) was excluded from the review although it contains interesting aspects regarding the impact of the internationalisation experiences of a firm on its performance, because it is not focused on the development of decisionmaking process models and the aim of this research is developing a new process model to illustrate and explain this business activity and expand the international management literature base.

Finally, all studies were excluded which are not scientific justified and with unclear research designs, e.g. if the research designs do not include all elements of the research onion of Saunders et al. (2015). One derminant for justification of this criteria is the reputation and quality of the journal in which a study is published. This exclusion criteria is suggested by Fink (2014). 


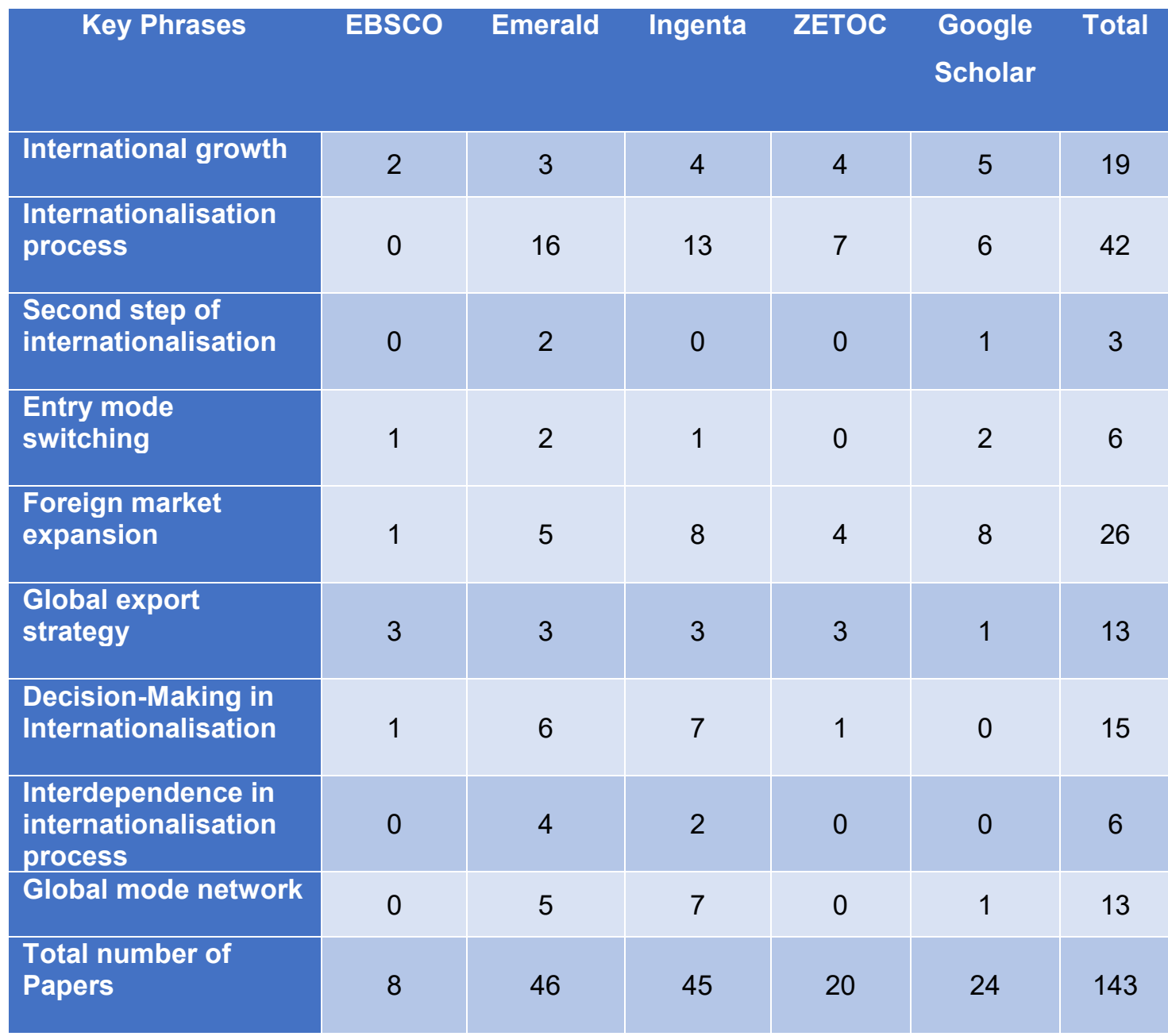

Table 9: Summary of the studies which passed the inclusion and exclusion criteria

The screening with the inclusion and exclusion criteria of the identified papers after the first practical filter was conducted in a two step process (Fink, 2014). In the initial screening the titles and abstracts of the identified papers were reviewed according to the inclusion and exclusion criteria, the resources were either passed on the next stage or rejected. In the second stage of the screening process, I reviewed the full texts of the studies that passed the first practical filter process and were selected according to the inclusion and exclusion criteria. The result and summary of this three stage screening process is shown in Table 10. It has to be noted that all studies which appeared in more than one database were included only once and typically in the database which was first used as suggested in the study of Georgiou (2014). 


\subsubsection{Analysis and Synthesis of Selected Literature}

Analysing and synthesising the selected and reviewed literature is often the most difficult but in parallel the most important step of the literature review process (Saunders et al., 2015). In this stage, I have to critically analyse and synthesise the work that has been done previously in the area of interest (Fink, 2014)

Dixon-Woods, Agarwal, Jones, Young, and Sutton (2005) group the methodologies of the synthesis of selected literature in integrative and interpretive synthesis. While integrative synthesis are focusing on collecting evidence, the key value of interpretive synthesis are the development of concepts.. The outlined research questions and the underpinned philosophical beliefs will guide the researcher by choosing the type of synthesis. Typically, quantitative research methodologies are linked with a integrative synthesis, while the qualitative research is based on a interpretive synthesis of the existing literature (Dixon-Woods et al., 2005).

There are many methods for synthesising evidence in the literature (Tranfield et al., 2003; Dixon-Woods et al., 2005; Pope et al., 2007). The authors Tranfield et al. (2003), Dixon-Woods et al. (2005) and Pope et al. (2007) analyse these methods and provide detailled descriptions as well as critique. Additionally, they emphasize the appropriateness of each type for quantitative and qualitative studies.

I intend to employ an inductive and qualitative thematic analysis as technique to analyse and interpret the findings and data of the selected studies within the literature review process. Using this method for a qualitative synthesis of the existing literature fits to the philosophical beliefs and position which is outlined in chapter 3 of this thesis. The thematic analysis bridges the gap between narrative and content analysis and is a frequently used techniques for synthesising research evidence (Pope et al., 2007). In the first step, I identify the main and most important themes in the selected literature. Afterwards the 
findings are summarized under the categorized themes (Pope et al., 2007). According to Dixon-Woods et al. (2005), the techniques tries to summarise the ideas, conclusions and outcomes of previous studies. One advantage of the thematic synthesis is that it can integrate results of previous studies which were achieved through qualitative and quantitative methods, the so called "qualitising" (Pope et al., 2007). Therefore the main strength of this techniques is that it can organize, summarize and analyse findings and evidence from a large and wide group of previous studies and present them in a qualitative way (Dixon-Woods et al., 2005; Pope, et al., 2007).

The main reason for chosing this method is that it fits to my philosophical beliefs and that it gives the systematic approach of selecting the respective literature (outlined in the previous chapter) the qualitative design and underpinning. Next to this I chose this method due to the flexible framework and the possible integration of qualitative and quantitative evidence, as argued by Dixon-Woods et al. (2005). During the literature review process and from the scoping analysis, I recognized that the studies around the research area of the internationalisation process and mode switching process are based on both quantitative as well as qualitative methods. Therefore the thematic analysis is considered as most appropriate to collect and analyse the important data and previous works. The systematice literature review process in combination with the thematic analysis are employed to identify, analyse and synthesise in a qualitative way the most relevant and important themes, ideas and theories around the internationalisation process and especially around the decision-making process of mode switiching (Schröter, 2014).

\subsection{Overview of Key Themes}

The emphasizes of this section is to give a first overview of the main themes which were identified through the inductive and qualitative thematic analysis of the selected studies. As shown in Figure 5, "the literature house", there are four main themes which build the theoretcial underpinning for this study and 
the final cenceptual framework (roof of the literature house), the general theories of internationalisation, market entry decisions research, mode switching research and literature about decision-making. These main themes arise from analysing the selected studies through the inductive and qualitative thematic analysis.

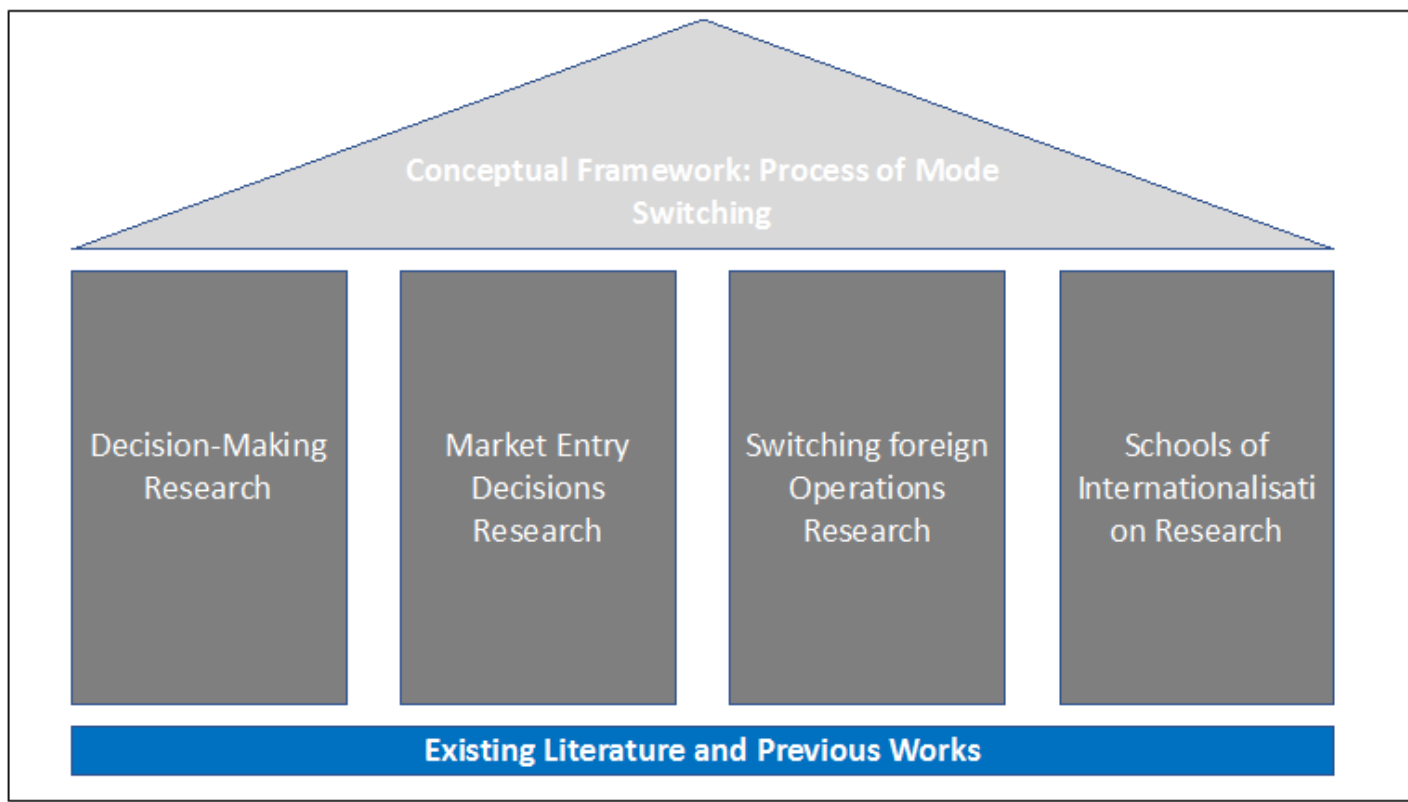

Figure 4: Overview of the Key Themes of Internationalisation and Mode Switching

Analysing the selected studies according to the key themes that are part of the literature house above provides the overview in Table 11.

\begin{tabular}{|l|r|}
\hline Key Theme & Number of Studies \\
\hline Entry Strategy & 22 \\
\hline Management Decision-making & 18 \\
\hline Mode Switching & 16 \\
\hline School of Internationalisation & 69 \\
\hline not defined & 18 \\
\hline Sum & 143 \\
\hline
\end{tabular}

Table 10: Number of Studies per Key Theme

This investigation shows that the current literature body is mainly focused on the general internationalisation theories and the entry strategies while the 
management decision-making process and mode switching research have received less attention over the last years.

In chapter 2.6, I will discuss the first pillar of the literature house, the studies which are focused on decision-making. I will discuss the classic rational decision-making processes, the intuitive as well as integrated multi-Level decision-making models. Last but not least Iwill explain how decision-making is related to the internationalisation and mode switching theory.

In chapter 2.7, I will discuss the second and third pillar of my literature house which is focused on the first step of internationalisation, the market entry and the mode switching process. Starting with explaining the different modes of market entry (exporting, foreign direct investment, etc.), the reasons of firms for choosing a respective mode will be emphasized. As entering into a market is built on a decision-making process, the influencing factors of this process will be discussed as well. As shown in Figure 5 the third pillar of the house of literature is based on mode switching research. In chapter 2.6 I will show the defined mode switching process from previous works and reasons and barriers of the mode switching decision of a firm's management team. The outcome of this chapter is the theoretical underpinning of the mode switching process for this thesis.

In chapter 2.7, I am presenting the theories regarding internationalisation which are the underpinning of the described models of the market entry process and mode switching process outlined in chapter 2.7. The selected theories will be grouped into traditional approaches which will be extended by the process-based perspectives.

In chapter 2.8, I am critically evaluating the current literature body which is the foundation of chapter 2.9 , the conceptual framework of this study and the "roof" of the literature house which is built on the afore mentioned pillars. 
In Table 12, I show an overview of the selected and investigated theories which will be explained in the respective pillars. The purpose of Table 12 is to present a step-by-step understanding of the most significant theories and their contributions to the research theme of decision-making in the mode switching process of which the research questions and objectives are built on.

It should be mentioned that due to the complexity of the internationalisation process with the two parts of market entry and mode switching and as this process is part of the decision-making theories, the explanatory theories are partial theories. These theories contribute significant findings regarding the internationalisation of firms and their decision-making, but they cannot be claimed as holistic theoretical approaches (Rezende, 2006; Asmussen et al., 2009; Sachse, 2010, Hollensen, 2017). Therefore, the aim of the literature review is to develop an underpinning of theoretical understanding of the internationalisation of firms and especially of decision-making in the mode switching process to create a conceptual framework for the research, the research questions and objectives. 


\begin{tabular}{|c|c|c|c|c|c|}
\hline Category & $\begin{array}{l}\text { Theory } \\
\text { Pillar } 1\end{array}$ & $\begin{array}{l}\text { Theory } \\
\text { Pillar } 2\end{array}$ & $\begin{array}{l}\text { Theory } \\
\text { Pillar } 3\end{array}$ & \multicolumn{2}{|c|}{$\begin{array}{l}\text { Theory } \\
\text { Pillar } 4\end{array}$} \\
\hline $\begin{array}{l}\text { Term of } \\
\text { reference }\end{array}$ & $\begin{array}{l}\text { Management Decision-making of } \\
\text { switching a foreign mode }\end{array}$ & $\begin{array}{l}\text { Researches about market } \\
\text { entry modes }\end{array}$ & $\begin{array}{l}\text { Research theories thus far on mode } \\
\text { switching }\end{array}$ & Traditional Approaches & Process-based Approaches \\
\hline $\begin{array}{l}\text { Theoretical } \\
\text { aspects of } \\
\text { emphasis }\end{array}$ & $\begin{array}{ll}\text { - } & \text { Rational decision-making } \\
\text { processes }\end{array}$ & $\begin{array}{ll}- & \text { Exporting } \\
\text { - } & \text { Foreign Direct } \\
& \text { Investment } \\
- & \text { Joint Ventures } \\
- & \text { Own Sales } \\
& \text { Force } \\
\text { - Entry Mode } & \begin{array}{l}\text { Decision } \\
\text { Process }\end{array} \\
\text { - Process } \\
\text { Influencing } \\
\text { Factors }\end{array}$ & $\begin{array}{ll}\text { - } & \text { Mode Switching Process } \\
\text { - } & \text { Reasons for } \\
\text { - } & \text { Barriers } \\
\text { - } \quad \text { Interdependencies in Mode } & \text { Switching }\end{array}$ & $\begin{array}{ll}\text { - } & \text { Transaction Cost } \\
\text { Approaches } \\
\text { - } \quad \text { Eclectic Theory } \\
\text { - } \quad \begin{array}{l}\text { Competition \& } \\
\text { Strategically } \\
\text { Oriented } \\
\text { Approach }\end{array} \\
\text { - } \quad \text { Real Option } \\
\text { Theory }\end{array}$ & $\begin{array}{ll}\text { - } & \begin{array}{l}\text { Behaviouristic } \\
\text { models }\end{array} \\
\text { - } & \text { Born Global } \\
\text { - } \quad \begin{array}{l}\text { International } \\
\text { Entrepreneurship }\end{array} \\
\text { - } \quad \begin{array}{l}\text { Relationship } \\
\text { Network }\end{array} \\
\text { - } \quad \text { GAINS Approach } \\
\text { - } \quad \text { Three-level Model } \\
\text { - } \quad \text { Path Dependency }\end{array}$ \\
\hline $\begin{array}{l}\text { Aim / } \\
\text { Objectives }\end{array}$ & $\begin{array}{l}\text { To present the current research } \\
\text { findings of previous works and to find } \\
\text { a gap in the literature regarding } \\
\text { management decision-making in the } \\
\text { mode switching process }\end{array}$ & $\begin{array}{l}\text { To present the current } \\
\text { research findings of } \\
\text { previous works }\end{array}$ & $\begin{array}{l}\text { To present the current research } \\
\text { findings of previous works and to find a } \\
\text { gap in the literature regarding mode } \\
\text { switching }\end{array}$ & $\begin{array}{l}\text { To show an overview and to } \\
\text { internationalisation which was } \\
\text { literature review }\end{array}$ & $\begin{array}{l}\text { olain each theory of } \\
\text { elected through the systematic }\end{array}$ \\
\hline
\end{tabular}

\section{Table 11: Overview of the main theories existing in the literature}




\subsection{Management Decision-Making}

According to the literature house, this chapter is describing the first pillar, as illustrated in Figure 6, the research about decision-making, which is one of the identified key themes of the thematic analysis.

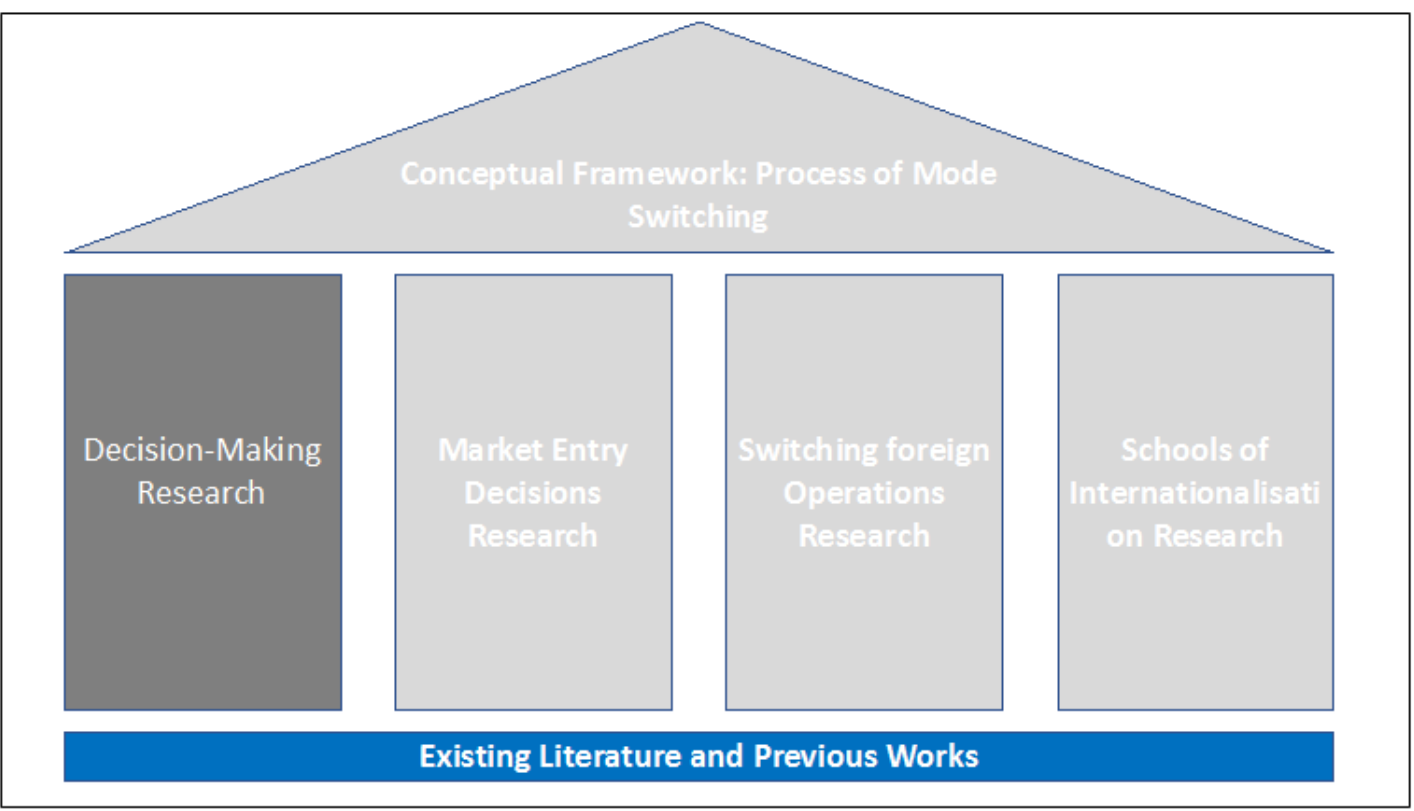

Figure 5: The literature house_decision-making

Internationalisation is traditionally viewed as a process of business activity defined as an incremental and gradual process of organisational transition in their expansion to overseas markets (Hollensen, 2017). Calof and Beamish (1995) and Sachse (2010) extend this process driven view by illustrating the importance of management decision-making within this progression. These extensions of the traditional view demonstrate that the internationalisation process evolved originally from the theory of decision-making. Therefore, the theoretical underpinning of decision-making in the internationalisation literature is discussed in this section.

Every day, managers are challenged to make decisions which affect the performance and the strategic path of their business enterprise and moreover affect their own careers (Vasconcelos, 2009). Nowadays, with the fast- 
changing world due to new technologies and the wide range of things that a manager has to handle from hiring, product portfolio, pricing policy, branding and internal relationships to legislation, stakeholders' claims, acquisitions, mergers, environmental issues, competitors, alliances, technology breakthroughs and the community which are only a few, being a manager and doing decisions is getting harder. Due to that, decision-making has been one of the most investigated topics in management science (Vasconcelos, 2009; Musso, \& Cioppi, 2015; Parnall \& Crandall, 2017). According to (Sachse, 2010), decisions regarding international activities and especially mode switching decisions have a big impact on the performance of a firm, because doing a mode switch decision which does not perfectly fit to the respective market could be a reason that a mode switch needs to be reversed which results in an inefficient use of resources. This study intends to contribute theoretical knowledge as well as practical guidance for managers in this research area. By achieving the research aim, I will contribute theoretical knowledge with his new process model and will contribute practical knowledge by providing managers a model which can be used to establish their decisionmaking process of mode switching within their global company set-up or to support companies which are on their journey to become a multinational company.

The development of the decision-making theories combined the theoretical foundations of psychology, sociology, social anthropology and economics (Miller, Galanter \& Pribram, 1960; Arntd, 1986; Francioni, Musso, \& Cioppi, 2015; Parnall \& Crandall, 2017). Therefore, human decision-making is investigated from multiple perspectives and the inter-disciplinary nature of this research field is explained. The relevant decision-making concepts for this project are the management decision-making concepts because the objectives of this research are focused on management decision-making. These concepts evolved from psychological and economic theory (Arntd, 1986; Francioni et al., 2015; Parnall \& Crandall, 2017). The purpose of this research 
is to understand the management decision-making process of mode switching in a multinational company and therefore explores the management decisionmaking theories that is interpreted through rational (orthodox perspective) and intuitive (heterodox view) dimensions within the relevant context (psychology and economic theories) (Vasconcelos, 2009; Perks \& Hughes, 2008; Francioni et al., 2015; Parnall \& Crandall, 2017).

Most studies in the field of management decision-making are highlighting either a rational decision-making approach or an intuitive one (Isenberg, 1989; Perks \& Hughes, 2008; Vasconcelos, 2009; Francioni et al., 2015; Luoma \& Martela, 2020). There are arguments trying to convince the reader for both extreme perspectives.

The rational or orthodox approach has been categorized differently by studies as logical (Bernard, 1938, Sachse, 2010), analytical thinking (Shoemaker \& Russo, 1993, Sachse, 2010; Orlandi \& Pierce, 2020) or bounded rationality (Simon, 1979; Shakun, 2001). The mental process of such an approach is underpinned by conscious reasoning, analytical tools and other symbols (Vasconcelos, 2009). This means that there are rational decision-making process models which can be used by managers and the value analysis are key elements of these processes to evaluate the respective decision alternatives and to do the final decision (Vasconcelos, 2009; Luoma \& Martela, 2020). Consequently, this thesis needs to consider the rational decisionmaking theories and models when investigating the decision-making process of mode switches in multinational companies as the rational aspects have an impact on the final decision of managers (Albaum \& Duerr, 2008; Sachse, 2010). There are many models and approaches in the literature about the evaluation process, the types of rational analysis and types of technical repertoire for the rational decision-making process. In general, the rational decision-making process is following the steps in Figure 7. 
Decision Making Process

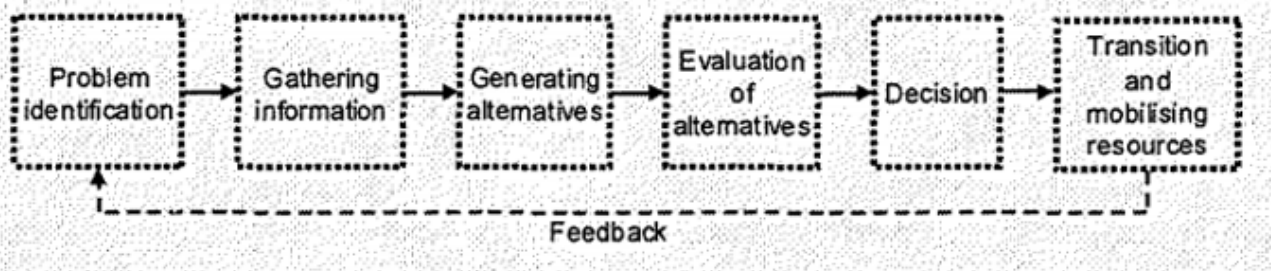

Figure 6: Rational Decision-Making Process (Albaum \& Duerr, 2008)

The rational decision-making process starts with a managerial problem. After the phase of gathering information of the situation and based on them generating alternative decision options the managers start an evaluation phase of the selected alternatives. Finally, the management do the decision and implement the selected alternative (Albaum \& Duerr, 2008; Francioni et al., 2015; Luoma \& Martela, 2020).

One example for a model based on the rational decision-making theory is the analytical hierarchy process from Saaty (2008). The analytical hierarchy process is structured in the following steps (Saaty, 2008, p. 85):

2. Structure the decision hierarchy from the top with the goal of the decision, then the objectives from a broad perspective, through the intermediate levels (criteria on which subsequent elements depend) to the lowest level (which usually is a set of the alternatives).

3. Construct a set of pairwise comparison matrices. Each element in an upper level is used to compare the elements in the level immediately below with respect to it.

4. Use the priorities obtained from the comparisons to weigh the priorities in the level immediately below. Do this for every element. Then for each element in the level below add its weighed values and obtain its overall 
or global priority. Continue this process of weighing and adding until the final priorities of the alternatives in the bottom most level is obtained.

To do the comparisons of available alternatives, the importance and dominance of an element over another element is indicated with a scale of numbers (Saaty, 2008). Additionally, the analytical hierarchy process is illustrated in a flow chart in Figure 8.

It is evident, that the rational decision-making process is not the panacea for all managerial challenges, because there are many variables and influencing factors of the management decision-making process which cannot be quantified or rationally evaluated, e.g. the impact of the managers' personal interests on the decision outcome (Albaum \& Duerr, 2008; Vasconcelos, 2009; Orlandi \& Pierce, 2020). As the objective of this research is to investigate the whole management decision-making process of mode switching inclusive of all influencing factors (which can be qualitative and quantitative) the rational decision-making concepts are important for this research but do not consider the qualitative elements of the management decision-making process (Sachse, 2010; Luoma \& Martela, 2020) and therefore additional concepts and theories need to be discussed.

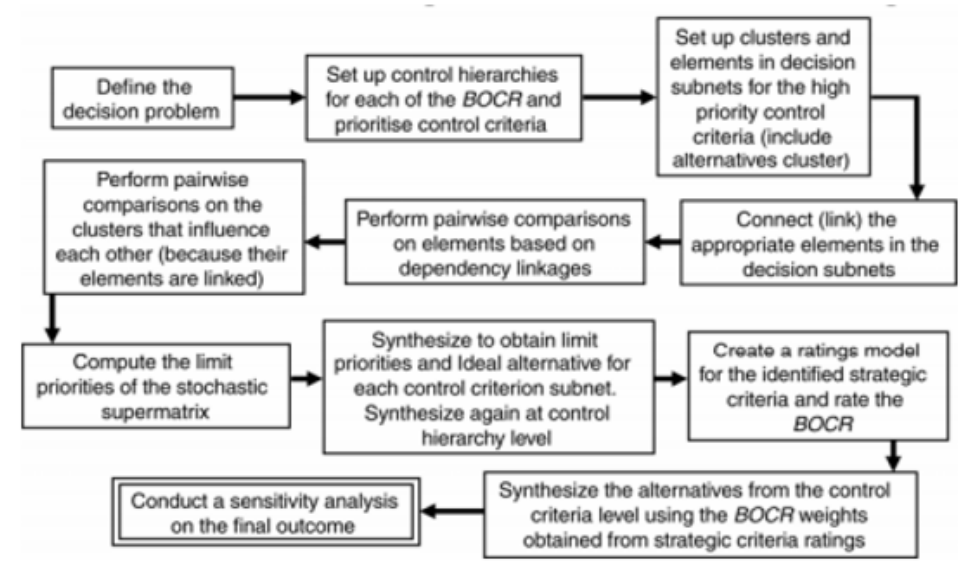

Figure 7: Decision-Making with Analytical Hierachy Process Modelling (Matzler, Bailom, \& Mooradian, 2007) 
The other extreme of this continuum is the heterodox view or the so-called intuitive decisions which is based on the intuitive skills of decision makers as a legitimate decision-making determinant (Vasconcelos, 2009; Orlandi \& Pierce, 2020). Consequently, this thesis needs to consider the intuitive decision-making theories and models when investigating the decision-making process of mode switching in multinational companies as the intuitive decisions and the managerial behaviour aspects have an impact on the final decision of managers. Intuitive decision processes have also referred as byproduct of non-logical (Bernard, 1938), non-rational (Simon, 1987), nonconscious processes (Epstein, 1994) or non -linear intelligence (Carlson \& Kaiser, 1999) in other studies. The rational decision-making process is often preferred and in focus of studies. But on the contrary, the importance of intuitive decision in corporate life is increasing because in the fast-changing environment of today's globalized and complex world, managers often have not enough time to follow a rational and incremental decision-making process but rather decide intuitively (Francioni et al., 2015; Luoma \& Martela, 2020). This means that for firms and their management the contribution to knowledge regarding intuitive decision-making and managerial behaviour is very important and this thesis needs to include these aspects in the conceptual framework and the further research. Therefore, I intend to use a multilevel approach which considers the intuitive aspects and managerial behaviour of the process as well as the rational aspects.

According to Matzler et al. (2007, p. 15):

"Analytical can never trump the intuition of a thoughtful executive, wrought by years of experience and accumulated knowledge, tempered by emotional intelligence"

As suggested by the authors, intuitive decisions are based on the experiences, accumulated knowledge and emotional intelligence of executives and therefore do not follow a strict gradual process because sometimes the 
managers do not have a coherent picture or all necessary information of the influencing variables to use a strict rational and gradual process (Matzler et al., 2007; Perks \& Hughes, 2008; Francioni et al., 2015; Luoma \& Martela, 2020; Orlandi \& Pierce, 2020). According to Sadler-Smith and Shefy (2004), intuitive decisions are especially relevant for example, if the outcomes are difficult to forecast through rational parameters, the managers need to handle uncertainties, the managers need to respond to complexities in pragmatic, intelligent and fast ways in face of unknown and if managers recognize the potential that their intuitive decision can offer. Also, Dane and Pratt (2007) remark that intuitive decisions have been part of the management decisionmaking processes in practice and is helping managers for critical management decisions. Consequently, this thesis needs to consider the impact of managerial behaviour and intuitive decisions on the decision-making process of mode switching in multinational companies as suggested by Albaum and Duerr (2008).

As discussed in the previous paragraphs, both extreme continuums are not the panacea for all managerial decisions and both approaches have advantages and disadvantages. Therefore, researchers have developed integrated decision-making approaches that combine the strengths of both approaches (Bernard, 1938; Simon, 1987; Vasconcelos, 2009; Luoma \& Martela, 2020; Orlandi \& Pierce, 2020). According to Simon (1987), intuition is a good addition under the rational process and both extreme approaches can act in a synergistic way as an effective decision-making system. Additionally, he claimed that (Simon, 1987, p. 61):

"It is doubtful that we will find two types of managers (at least, good managers), one of whom relies almost exclusively on intuition, the other on analytic techniques. More likely, we will find a continuum of decisionmaking styles involving an intimate combination of the two kinds of skill. We will likely also find that the nature of the problem to be solved will be a principal determinant of the mix" 
One multi-level integrated decision-making model that combines rational decision-making with intuitive skills was developed by Albaum and Duerr (2008) and adopted by Ahlstrom and Bruton (2010). This model is shown in Figure 9. This model represents an ideal-typical construct and as a theoretical discussion basis for each individual step of the decision-making process. In practice, decision-making processes are difficult to simplify and to illustrate them as a theoretical model because they overlap each other or may happen in opposite sequences.

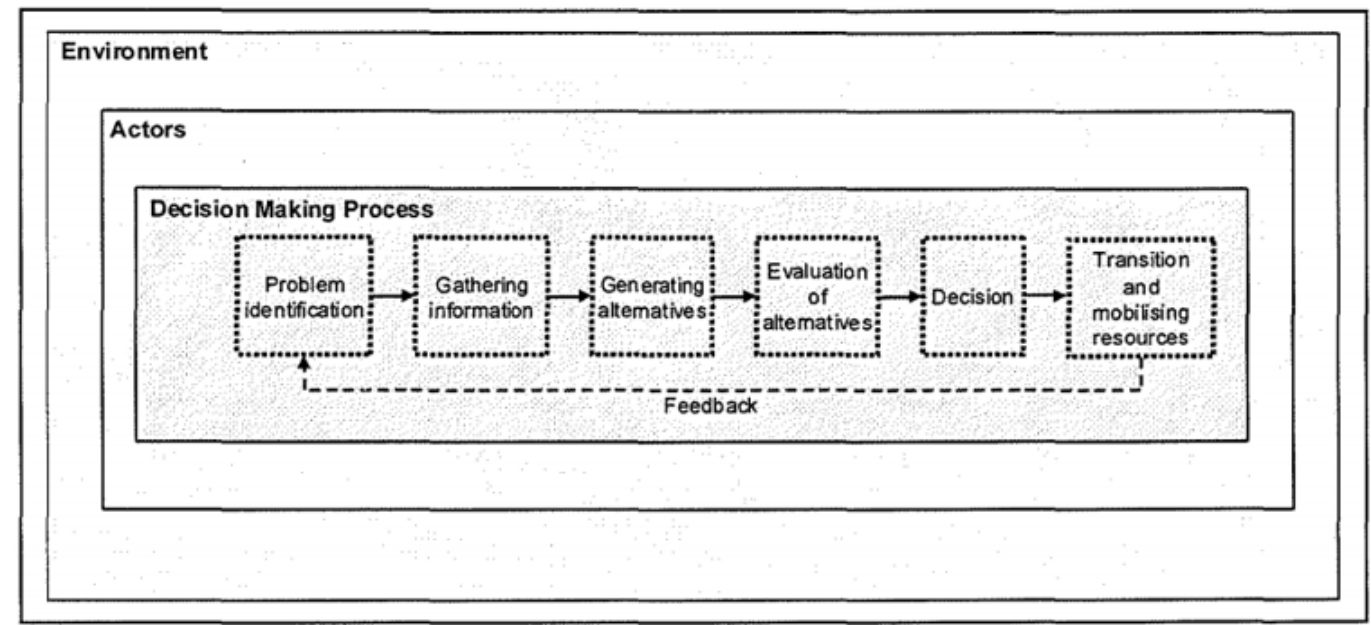

Figure 8:Integrated Multi-Level Decision-Making Model (Albaum \& Duerr, 2008)

The inner loop of the multi-level model conceptualize the rational decisionmaking process as shown in Figure 7. The integration of actors present the intuitive perspective that considers the attitudes of managers (Vasconcelos, 2009). The purely process related framework of Figure 7 is hereby expended by the behaviour of the key decision makers to achieve a more comprehensive understanding of the decision-making process because the behaviour of these key actors influence the decision-making process within the firm (inner loop) (Albaum \& Duerr, 2008). In the outer loop of the model, the environment of a company (e.g. market-relevant factors of sales organisation, cultural distance, customer behaviour, etc.) forms and influences the personal behaviour of the key actors who can be external as well as internal and represent the next level 
of the model (Ahlstrom \& Bruton, 2010; Luoma \& Martela, 2020; Orlandi \& Pierce, 2020). As the environment could also include simultaneous decisionmaking processes within a firm, the integrated mulit-level approach considers interdependencies between simultaneous and parallel decision-making processes and consequently the model fits for achieving the outlined research objectives of analysing these interdependencies (Sachse, 2010; Swoboda et al., 2010; Picot-Coupey \& Cliquet, 2014; Orlandi \& Pierce, 2020). All three levels together form a complex system which reflects the management decision-making process and its muliple levels. Within mutinational companies there are several management decision-making processes which are running in parallel at the same time (simultaneous management decision-making processes). These simultaneous decision-making processes within a multinational company are connected and interact (interdependencies) with each other. As the objective of this research is to investigate the interdependencies between simultaneous decision-making processes of mode switching within multinational companies (Ahlstrom \& Bruton, 2010), the model in Figure 9 contributes to this thesis the theoretical underpinning of the theoretical and conceptual framework of the decision-making process of mode switching within multinational companies. Using the multi-level model of decision-making from Albaum and Duerr (2008) for investigating the decisionmaking process of mode switching is supported by the study of Sachse (2010) which is related to this research topic because Sachse (2010) used the same model as theoretcial underpinning in his study. In the next sections, I develop my theoretcial and coneptual framework based on the model outlined in Figure 10.

\subsection{Mode Switching}

According to the literature house, this section is describing the second and third pillar, as illustrated in Figure 10, the research about market entry decisions and the research about mode switching. 


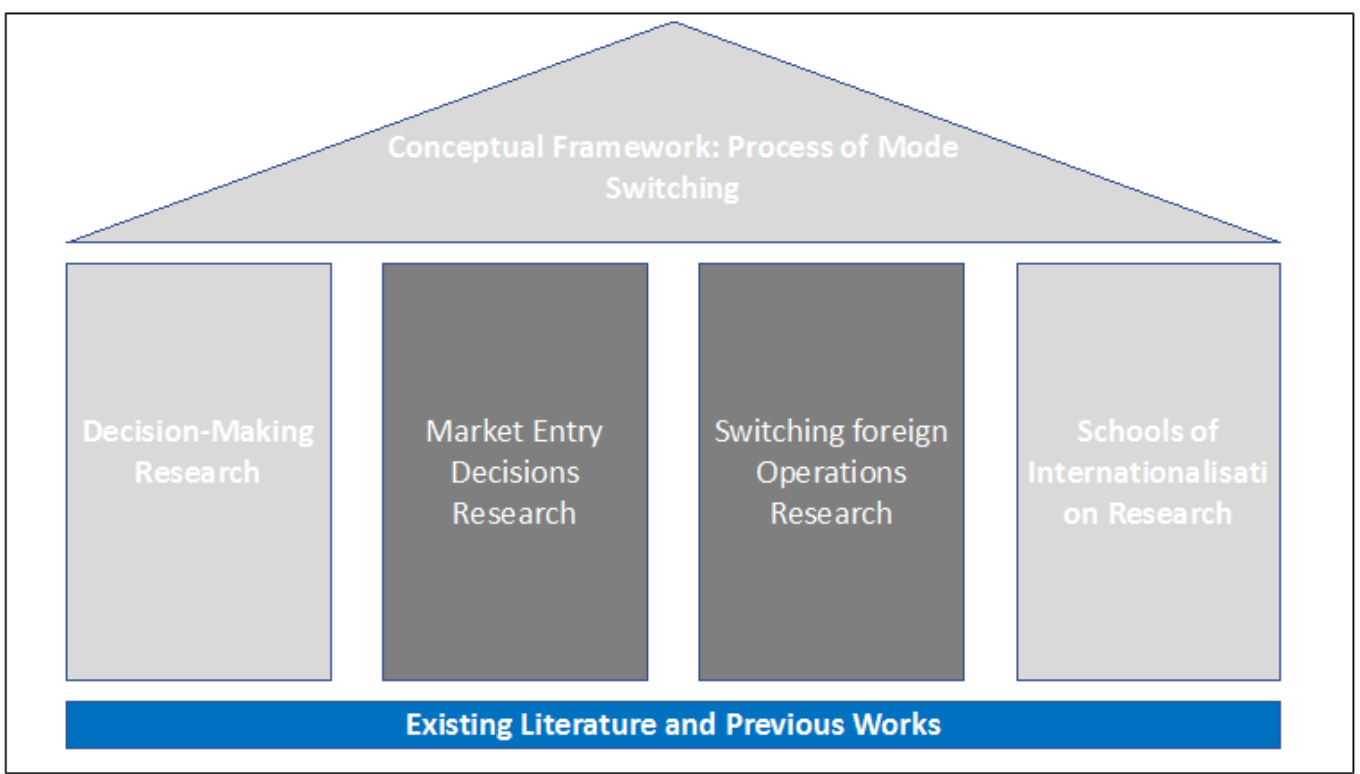

Figure 9: The literature house_Research about market entry decisions and Mode

\section{Switching}

In the literature, mode switching has different definitions which are presented in this section. Swoboda (2002), Benito et al. (2005), Fryges (2005) and Welch et al. (2007) define mode switching as replacing a previous mode (e.g. sales company replaces importers). Petersen and Welch (2002) and Welch et al. (2007) explains it as supplementing a previous mode (e.g. sales representative and sales company). Another definition of mode switching is expanding or reducing an existing mode (e.g. a representative is supplemented by one or two further representatives or the number of agents employed is reduced from ten to eight), (Swoboda, 2002; Petersen \& Welch, 2002; Fryges, 2005; Welch et al., 2007; Mujtaba \& Van Wyk, 2018; Yan, 2020). Last but not least, significant changes of an existing mode are also considered to be mode switches (e.g. a change of manager or the exchange or replacement of a sales representative) (Benito et al., 2005; Welch et al., 2007; Mujtaba \& Van Wyk, 2018; Yan, 2020). In summary the literature and previous studies refer to a mode switch if after a change, a new type and manner of market operation is implemented. 
Sachse (2010) developed a model of the mode switching process which illustrates the respective steps of a decision-making process of mode switching within a firm. As shown in Figure 11 the process contains 5 steps and the initial step of mode switching is that a company enters into a foreign market (Sachse, 2010, Georgiou, 2014; Mujtaba \& Van Wyk, 2018; Yan, 2020). Because the market entry is the basis for a later mode switch, it is evident that I need to consider and investigate the theoretical background in the literature regarding market entry to understand the contribution that the market entry theories have on the decision-making process of mode switching. The second step of the model developed by Sachse (2010) is the impetus to switch which summarizes the reasons and switching motivators for a firm to start thinking of switching a mode in a respective foreign market. One reason could be that the firm is not satisfied with the performance of the mode which was established with the market entry (Sachse, 2010; Hollensen, 2017; Yan, 2020). Step 3 is the final decision to which mode option the firm will switch which is followed by the implementation phase of the final decision, step 4 of the process. As soon as the mode decision is implemented, the last step of the process is finished as the new mode option is established. This model of Sachse (2010) contributes theoretical knowledge to this thesis because the theoretical framework (Figure 14, page 81 ) is based on this model and structured according to the 5-step approach of Sachse (2010). The limitation of this model is that it is based on a quantitative survey which investigated many companies. Due to this set-up, only one decision-making process of mode switching per participated company is investigated, because investigating simultaneous decision-making processes of mode switching within many companies in one survey would develop a not manageable amount of data (Rezende, 2006; Asmussen, 2009). Consequently, this model of Sachse (2010) does not consider that there are simultaneous decision-making processes of mode switching within a multinational company and does not investigate the interdependencies between these simultaneous processes that are running at the same time (Rezende, 2006; Asmussen, 2009; Hollensen, 2017). In the 
PhD Thesis Mario Gehrlein

next section (chapter 2.6.1), I explainthe first step of the model with the market entry, followed by the sections in which I develop my theoretical framework of this thesis (chapter 2.6.3). 


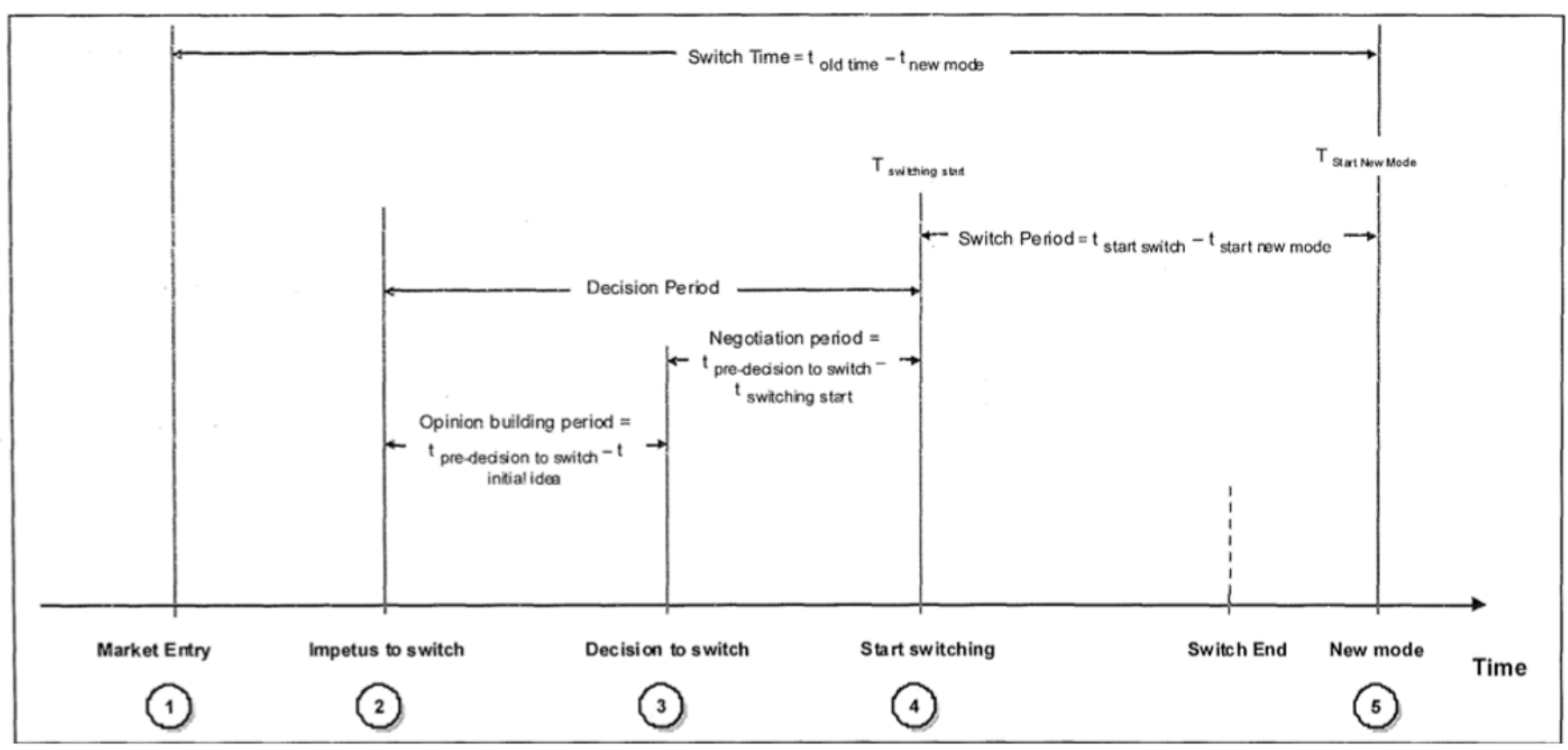

Figure 10: Model of mode switching (Sachse, 2010) 


\subsubsection{Market Entry Decision}

As explained in the previous section, entering into a foreign market is the foundation and necessary process step that the decision-making process of mode switching can occur.

By looking at the area of internationalisation and foreign market investment, international market entry is the third most researched theme (Werner, 2002). As foreign market entry decisions typically involve long term resource commitment and the decisions are dificult to reverse, the entry strategies are considered as critical and have a critical impact on the performance of the international activities of a firm (Brouthers, 2002; Brouthers \& Hennart, 2007; Larsen \& Piscitello, 2019; Yan, 2020). The foreign market decision is seen as a process by which firms are entering into a foreign market with the purpose of launching value-creating activities (Jones \& Young, 2009; Mujtaba \& Van Wyk, 2018; Yan, 2020). According to Sharma and Erramilli (2004, p. 2), an entry mode is defined as:

"a structural agreement that allows a firm to implement its product market strategy in a host country, either by carrying out only the marketing operations (i.e. via export modes), or both the production and marketing operations there by itself or in a partnership with others (contractual modes, joint ventures, wholly owned operations)."

A further definition is given by Root (1987, p. 5):

"an institutional arrangement that makes possible the entry of a company's products, technology, human skills, management or other resources into a foreign country."

As described in the literature house (Figure 10) and in Table 12 the entry decision contributes a lot of knowledge to this study as entry decisions build the foundation of each mode switching decision. Without an entry action of a 
firm in a foreign country, a mode switch is not possible and consequently the entry mode decision is the basis of this study and needs to be discussed in this thesis.

\subsubsection{Entry Options}

According to Datta, Herrmann and Rasheed (2002), there are several options for an organization to enter into a foreign market which are shown in Table 13.

\begin{tabular}{|c|}
\hline Mode Options \\
\hline Foreign direct investments (greenfield or acquisition) \\
\hline Collaborative strategies (joint ventures) \\
\hline Contractual entities (licensing, franchising, agencies, distributorship) \\
\hline Exporting \\
\hline
\end{tabular}

\section{Table 12: Mode Options}

Typically, the entry options are divided into equity (foreign direct investments and joint ventures) and non-equity (exporting, licensing, distributorship and agencies) (Pan and Tse, 2000; Mujtaba \& Van Wyk, 2018; Larsen \& Piscitello, 2019; Glowik, 2020; Yan, 2020). These two main categories are very different regarding the resource commitment and the level of investment. While the equity options like foreign direct investments and joint ventures need a high resource commitment and investments to establish them in a foreign market, typically the management require a high control over these modes. In comparison the control requirements of non-equity modes are by far less, as illustrated in Figure 12. 


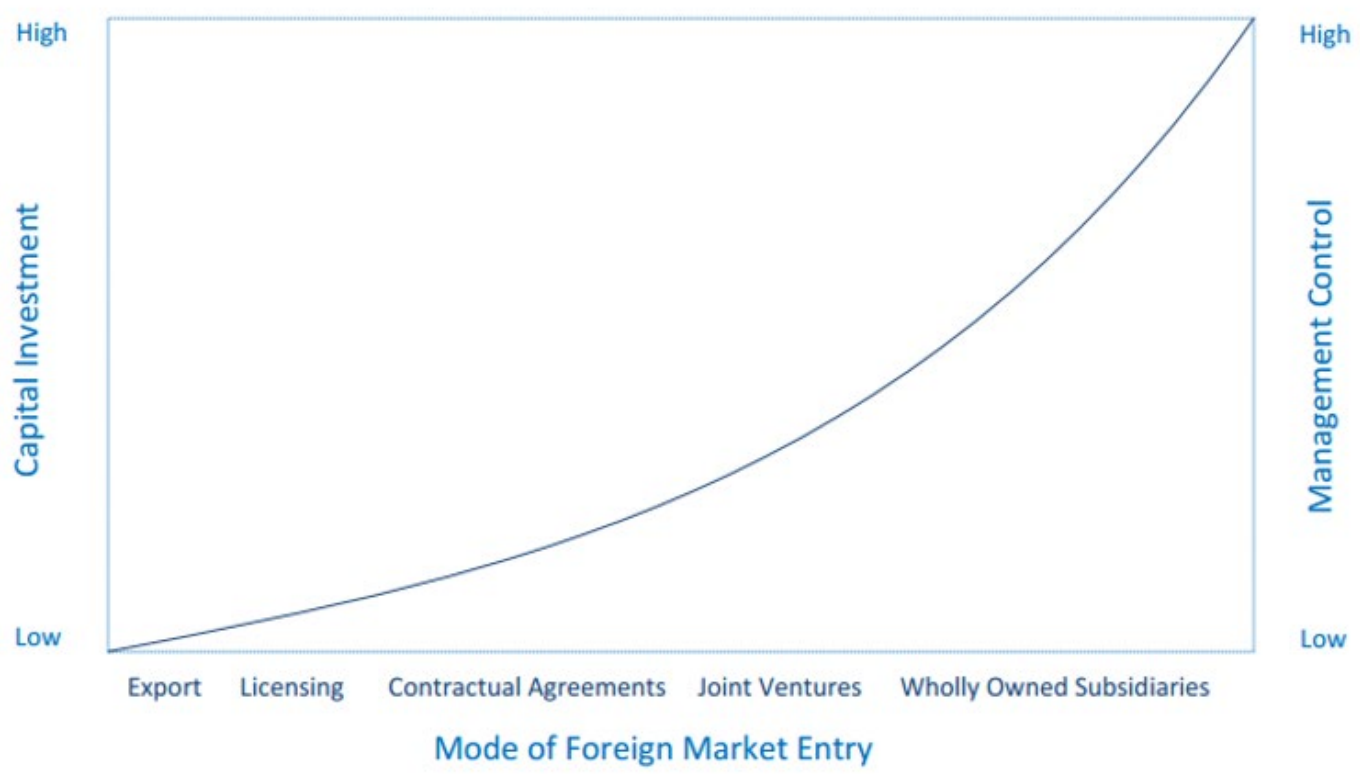

Figure 11: Modes of foreign market entry (Georgiou, 2014)

Understanding the different kind of entry options is important to discuss and investigate the decision-making process of mode switching, because the entry option which is used in a foreign market builds the foundation of a possible mode switching process as no mode switch is possible if there was no market entry through an entry option before. Next to this, also the result of the mode switching process is either to stay with the previous chosen mode option or to switch to a new mode option. Therefore, I present in detail the respective mode options in the following sections which are part of the current literature body.

Exporting is generally considered as the entry option which needs the lowest capital investment and therefore typically the required level of management control is relatively the lowest (Georgiou, 2014; Mujtaba \& Van Wyk, 2018; Larsen \& Piscitello, 2019; Glowik, 2020; Yan, 2020). Young, Hamill, Wheeler, and Davies (1989) divided exporting into direct and indirect export options. In an indirect export mode, companies export their products to an exporting agency or trading company that can be based in the home country of the exporting firm or the firm is working together with a foreign importing company 
that is buying the products in the home country of the manufacturing firm (Tihanyi, Griffith \& Russell, 2005). The main determinant for the indirect exporting mode is that all operations associated with the export process are in the responsibility of the external firm without involving the home country firm. Next to this, the domestic country firm do not have any influence and often little knowledge about the marketing and sales actions in the foreign market (Georgiou, 2014). On the other side, in the direct exporting mode, the home country firm undertakes all activities associated with the export process and therefore the level of involvement and the level of control is relatively higher than with the indirect export modes (Georgiou, 2014). The level of control is higher because the transfer of ownership of the products is in the foreign country. The level of control is increasing in the direct export modes but the home firm still does not have or limited influence on the marketing and sales actions of the foreign firm (Young et al., 1989; Larsen \& Piscitello, 2019; Yan, 2020).

Another option for foreign market entry is licensing in which the home firm authorises the firm abroad with a local license or the access to a specific technology, knowledge, product and gives a firm abroad the right to use a specific name to sell the products. These licenses are typically timely limited and require specific conditions and obligations for both parties (Young et al., 1989). In comparison to exporting the involvement of the home firm is higher and the home country has influences and knowledge about the sales and marketing action because the host firm (licensee) has contractual obligations to provide such information (Young et al., 1989; Glowik, 2020).

The next entry option with a higher level of control is the contractual agreement. Contractual agreements are similar to licensing but they often cover a bigger scope of activities in the host countries. Typically franchising, distributorship agreements and sales \& marketing alliances are considered as contractual agreement (Hollensen, 2017; Glowik, 2020). Similar to licensing, the contractual parties write the obligations of each party in the contract but in 
comparison to licensing the home firm often increases involvement in the sales and marketing actions of the host firm. In this case the home firm provides trainings and support actions as guidance and sometime the home firm even paying some of marketing expenses of the host firm (Georgiou, 2014). Based on the contractual agreements, both parties share skills, knowledge and resources and therefore the duration of such agreements are typically medium or long (5-10 years) and are renewed if both parties agree (Hollensen, 2017).

The last two mode options, according to Figure 12, are the equity modes, joint venture and wholly owned subsidiary. In a joint venture, the host and home country firm share risk, profits and the capital investment and therefore typically both parties are active in the management of the joint venture (Georgiou, 2014). Depending on the contribution of resources, like technology, capital investment, knowledge, market access and management to the joint venture, the share holding is divided (Agarwal, 1994). As both parties are involved in all operations and exert joint control of the joint venture, the agreement has often a long duration (10 years or more) and can be renewed if both parties accept. The entry option with the highest level of control is the wholly owned subsidiary (Figure 12) in which the home firm acquires a firm located in the host country or launching a new firm in the host market (greenfield) (Georgiou, 2014). In this case, the home firm has the entire control of the management but also the full risk and capital investment (Young et al., 1989). According to Pehrsson (2015) the selection of the respective entry mode option is an important decision and significantly affects the success of a firm in the international market and in general. Furthermore, Pehrsson (2015) suggests that there is not the correct or wrong mode option in general but rather that depending on the structure of the domestic company and the circumstances of a decision-making process there are mode options which are more successful for a company. And on the other side there are mode options which can cause a failure of the domestic company in an international market which would launch a mode switching process (Pehrsson, 2015). 
The above discussed entry modes can be seen as the basic modes of foreign market entry which are found in the current literature body. Next to this, these entry mode options can also be considered as the mode options which a firm can choose during the mode switching process (Sachse, 2010). There are also papers in which nine variations of entry options (Erramilli \& Rao, 1990) or even more are defined (Brouthers \& Hennart, 2007). If the variations get larger and wider, the boundaries of the entry modes are not always clear and are overlapping. Therefore I decided to define the basic modes with clear boundaries as suggested and used by other studies (Sachse, 2010, Georgiou, 2014)

Understanding and critically reviewing the research about the market entry mode options is important for this research because the previous chosen entry mode options are the starting point of each decision-making process of mode switching, as illustrated in Figure 11 (Sachse, 2010; Glowik, 2020). Next to this the available and known mode options are also the decision alternatives at the end of a management decision-making process mode switching if a company decides to switch its mode (Sachse, 2010; Glowik, 2020).

\subsubsection{Market Entry Process and Factors of Influence}

The market entry strategy and process are the first steps of each internationalisation process and mandatory before mode switching is discussed or takes place because for a mode switch another mode needs to be established before (Sachse, 2010; Georgiou, 2014; Baker, Grinstein \& Perin, 2020). Due to that the entry process into an international activity has been investigated deeply in the today's literature body. The focus of these studies is often the factors that influence the market entry decision and on developing a process model that can be used in the practical work of a firm (Georgiou, 2014; Baker et al., 2020). In the literature, the factors of influence are often divided into the four groups, efficiency, organizational, host country and marketing factors (Georgiou, 2014). The efficiency factors include the 
transaction costs elements (see chapter 2.7.1.1), institutional costs as well as value creation factors. Organisation resources contain experiences, strategic considerations, organizational politics and cultures of the home and host country. The host country factors relate to all aspects of the host country such as location, economic, political, risk, uncertainty, cultural, legal and all other environmental aspects of the host country. The marketing elements include all marketing aspects like market size, growth potential competitive arena pricing barriers to entry or exit (Georgiou, 2014; Baker et al. 2020; ).

Analysing and describing the entry process is necessary for this study to understand the process step before mode switching and to transfer knowledge to the mode switching process for better understanding.

Based on above mentioned construct of influencing factors, Georgiou (2014) conducted a case study within BP one of the biggest lubricant manufacturers and investigated the market entry process of the firm. In this regards, he conducted two case studies within the BP company to develop a descriptive model of the BP's entry process, as illustrated in Figure 13. With this model, Georgiou (2014) developed a consistent concept which can be used by managers to conduct the entry decision process and which can be used as foundation of the decision-making process of mode switching which is investigated in this study.

According to the model of Georgiou (2014) in Figure 13, the decision-making process is split in three lenses. The strategical lens in which the management of the firm narrows down the options of foreign market entry based on the organizational experiences, culture, capabilities and industry practices. The operational lens one in which the operational team of the decision-making process is analysing the financial aspects of the mode alternatives (costs, taxes, volumes, margin, turn-over, etc.). The operational lens two in which the host country aspects (political, economic, legal, market size and competition) are investigated before the final decision is implemented. While the three 
lenses contain the objective and economic factors that influencing the decision of market entry, Georgiou (2014) also included an additional factor of influence in which he indicates the importance of growth objectives and the behavioural and irrational decisions of managers. With these aspects, Georgiou (2014) indicated that the decision-making process for market entry is influenced by the personal experiences and behaviours of the managers which is also suggested from Oh, Arnett and An (2016). Therefore, the developed model of Georgiou (2014) is interesting and contributes knowledge to this thesis because Georgiou (2014) already explained the importance and influencing aspects of the managers' behaviour and other influencing factors within his decision-making process model and gives a theoretical underpinning of this research study.

Next to the research of Georgiou (2014), several other researchers investigated the decision-making process for market entry process (Yakhlef \& Maubourguet, 2004; Sleuwaegen, 2013; Ji, Dimitratos \& Huang, 2016; Oh, Arnett \& An, 2016; Liu, 2017; Baker et al. 2020). These studies mainly focused on single steps of the market entry process which is not the core focus of this research project, e.g. Oh, Arnett \& An (2016) focused on the know-how transfer between the domestic company and the external third party partner in a foreign market and is limited to this aspect. However, the model of Georgiou (2014) is one of the newest models and fits to this research as the same industry is investigated. With this model Georgiou (2014) built a model and contributed practical knowledge as managers and firms can use his model for assisting in entry mode decision. Furthermore, this model can be used as underpinning of this research and the conceptual framework because it illustrates the first process step of internationalisation before mode switching and indicates influencing factors that are connected with decision-making processes within multinational companies. 


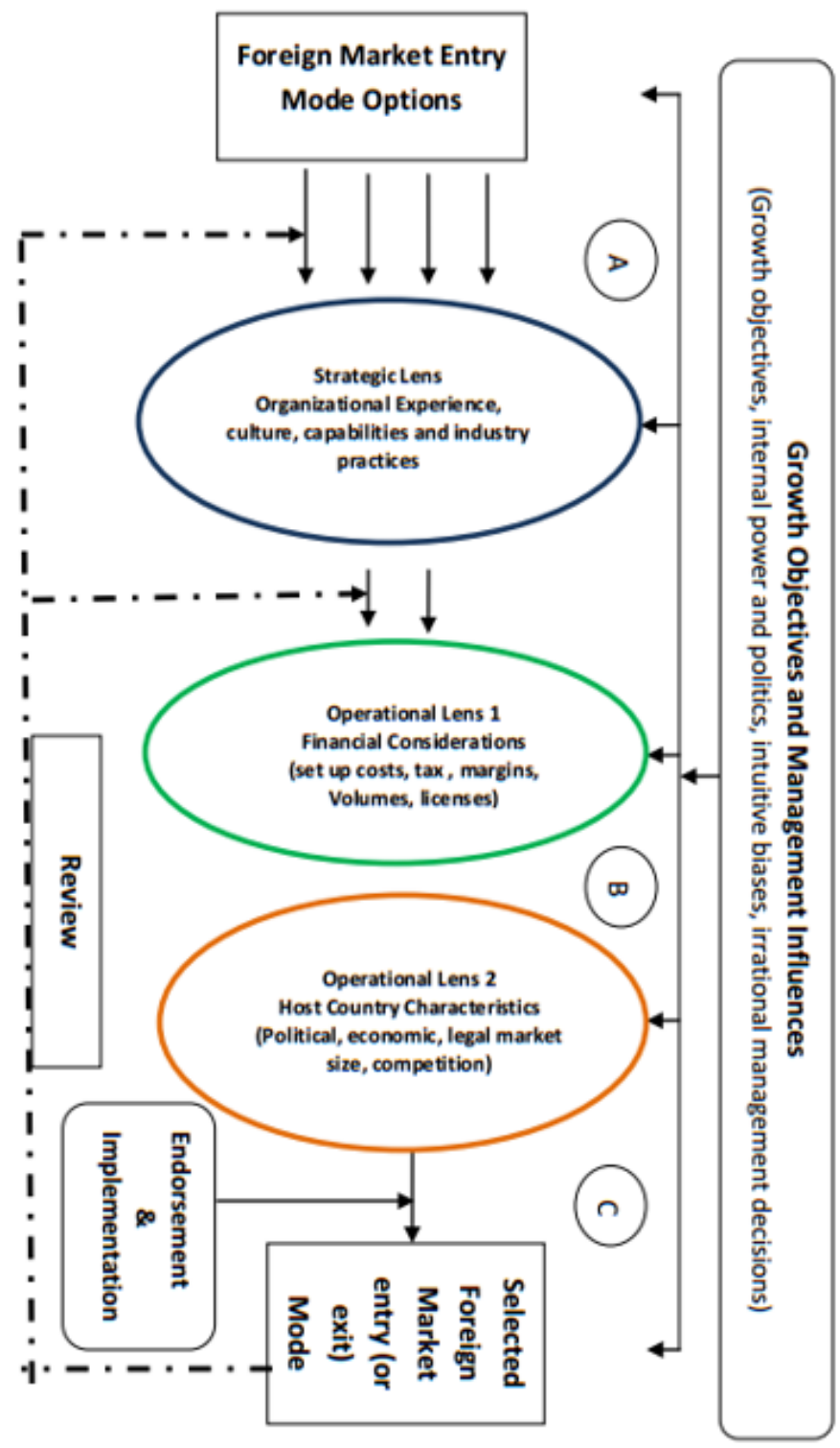

Figure 12: Descriptive model for decision-making process for market entry (Georgiou, 2014)

\subsubsection{Research about Mode-Switches}

In the following section, I present the timeline of the studies regarding mode switching which are summarised in Table 14 and how the current model of mode switching which exists in the literature body, has developed over the last decades. This is important for this research project because the current model 
of the literature body builds the theoretical underpinning of this thesis and is illustrated as the theoretical framework in the next section.

As shown in Table 14 the first studies about mode switches came in the period of the globalisation and when the reduction of international trading barriers started in the 1990s. Since the last decades there are several studies focusing on mode switches as more and more companies started to expand internationally and started to switch existing market entry modes (Table 14) which shows that decision-making of mode switching has been getting increasing attention over the last years and is a necessary success factor for firms regarding their internationalisation (Benito et al., 2005; Sachse, 2010). Calof $(1991,1993)$ was the first researcher who investigated the mode switching process in his dissertation and set the underpinning for many later studies, like those by Swoboda (2002), Pedersen et al. (2002), Petersen et al. $(2000,2006)$ and Benito et al. $(2005,2011)$. His main contribution was the learning process which is done before the pre-mode decision-making process and that mode switching has a positive influence on the firm performance. In the next period of studies, the determining factors were getting more in focus and especially the so-called switching costs were analysed in recent studies. The findings regarding the determining factors build the underpinning of the evaluation step of the mode switching process in which different decision options are compared according to the defined determining factors (Chetty \& Blankenburg Holm, 2000; Rundh, 2003). Benito and Welch (1993) as well as Clark, Pugh and Malloroy (1997) developed the model of mode combinations and based their findings on an exclusively incremental internationalisation process as suggested by Calof $(1991,1993)$. As main determinants for mode switches, they identified market-specific and generalised knowledge from previous internationalisation experiences and additionally the network and management capabilities of the management that is responsible for the respective decision-making process (Benito \& Welch, 1993; Clark et al., 1997). 


\begin{tabular}{|c|c|c|c|c|}
\hline & Authors & Main Research Question & Methodology / Data Content & Assumptions \\
\hline & $\begin{array}{l}\text { Calof } \\
(1991 \& 1993)\end{array}$ & $\begin{array}{ll}- & \text { Switching motivators? } \\
\text { - } & \text { Decision-Making Process? } \\
\text { - } & \text { Attitudes of Managers? } \\
\text { - } & \text { Impact of mode switching on firm } \\
& \text { performance? }\end{array}$ & Quantitative survey & $\begin{array}{l}\text { - } \quad \text { Mode changes and decisions are complex } \\
\text { - } \quad \text { Belief in better performance is main motivator } \\
\text { 70\% of mode decisions were based on the attitudes and beliefs of managers, } \\
\text { not on systematic review process } \\
\text { - Mode switch has a big impact on a firm's performance }\end{array}$ \\
\hline 1 & $\begin{array}{l}\text { Clark, Pugh \& Mallory } \\
\text { (1997) }\end{array}$ & - Knowledge sources? & Quantitative survey & $\begin{array}{l}\text { - } \quad \text { market-specific knowledge is not the only source of information } \\
\text { - } \quad \text { additional knowledge of the process of internationalisation }\end{array}$ \\
\hline 2 & $\begin{array}{l}\text { Pedersen et al. } \\
(2000)\end{array}$ & $\begin{array}{ll}- & \text { Switching motivators } \\
\text { - } & \text { Switching costs? }\end{array}$ & Quantitative survey & Switching costs are key decision factors \\
\hline 3 & $\begin{array}{l}\text { Petersen et al. } \\
\text { (2002) }\end{array}$ & - $\quad$ Reasons for mode switches? & Quantitative survey & $\begin{array}{ll}\text { - } & \text { Monitoring is the major driver of performance } \\
\text { - } & \text { Severance payments and contractual restrictions have no significant impact on } \\
\text { - } & \text { performance } \\
\text { Safeguards helps to solve the dilemma of the intermediary }\end{array}$ \\
\hline 4 & $\begin{array}{l}\text { Benito et al. } \\
\text { (2005) }\end{array}$ & $\begin{array}{ll}- & \text { Switching motivators } \\
- & \text { Switching deterrents? }\end{array}$ & $\begin{array}{l}\text { - } \quad \text { Quantitative } \\
\text { survey }\end{array}$ & $\begin{array}{l}\text { - } \quad \text { Mode switch decision seems to be a cost-benefit analysis } \\
\text { - } \quad \text { Accumulation of market knowledge is associated positively to the switch to another } \\
\text { sales intermediary } \\
\text { - } \quad \text { Export market growth does not have a significant effect on the switches } \\
\text { - }\end{array}$ \\
\hline 5 & $\begin{array}{l}\text { Chetty \& Campbell- } \\
\text { Hunt } \\
(2001)\end{array}$ & Internationalisation path? & $\begin{array}{ll}\text { - } & \text { In-depth case } \\
& \text { studies }\end{array}$ & A conceptual model is developed \\
\hline 6 & $\begin{array}{l}\text { Rundh } \\
\text { (2003) }\end{array}$ & $\begin{array}{l}\text { - } \quad \text { Locally adjusted variables? } \\
\text { - } \quad \text { how different functional variables } \\
\text { have influence on the marketing } \\
\text { strategy? }\end{array}$ & $\begin{array}{l}\text { - Quantitative } \\
\text { survey }\end{array}$ & $\begin{array}{ll}- & \text { Influencing factors of decision-making } \\
\text { - } & \text { Local requirements regarding local services } \\
\text { - } & \text { Factors that influence the competitive advantages }\end{array}$ \\
\hline 7 & $\begin{array}{l}\text { Rezende } \\
\text { (2006) }\end{array}$ & $\begin{array}{l}\text { - Interdependencies in mode } \\
\text { switching }\end{array}$ & Literature review & $\begin{array}{l}\text { - Multinational companies = intricate combination of independent, yet } \\
\text { interdependent, internationalisation processes }\end{array}$ \\
\hline 8 & $\begin{array}{l}\text { Kaufmann \& Jentsch } \\
(2006)\end{array}$ & $\begin{array}{ll}- & \text { Mode options? } \\
\text { - } & \text { Evolution paths } \\
\text { - } & \text { Influencing parameters of mode } \\
& \text { switches? }\end{array}$ & - $\quad$ Case studies & $\begin{array}{ll}\text { - } & \text { Approach to analyse decision-making behaviours } \\
\text { - } & \text { Identification of four main evolution pathways over a certain period of time } \\
\text { - } & \text { Characterising and describing reasons of each pathway behaviour }\end{array}$ \\
\hline 9 & $\begin{array}{l}\text { Swoboda, Jager, } \\
\text { Morschett \& Schramm- } \\
\text { Klein } \\
\text { (2008) }\end{array}$ & $\begin{array}{l}\text { - Structural and cultural changes } \\
\text { related to mode switches? }\end{array}$ & - Quantitative survey & - $\quad$ Mode switches also causes organizational, structural and systematic changes \\
\hline
\end{tabular}




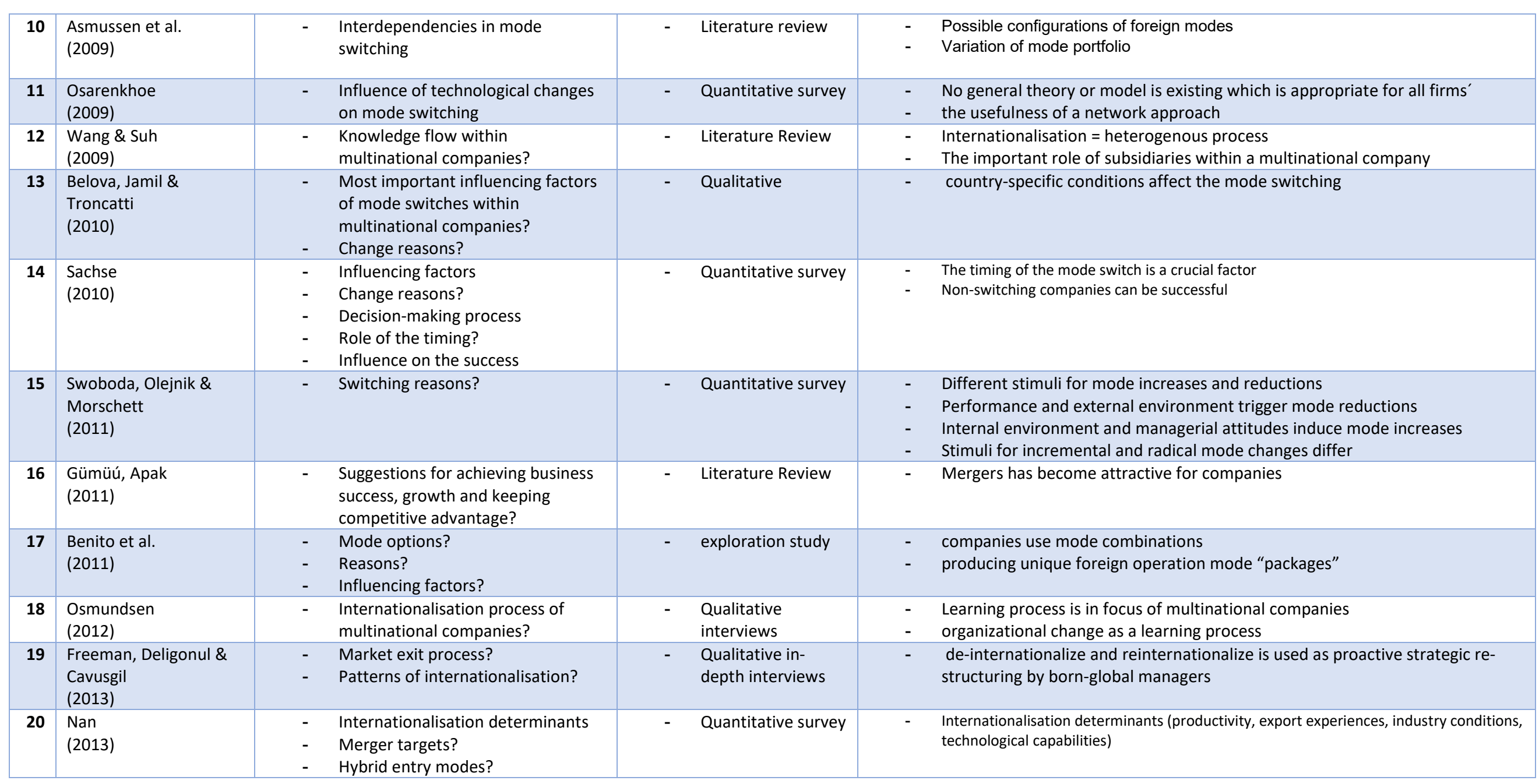




\begin{tabular}{|c|c|c|c|c|}
\hline 21 & $\begin{array}{l}\text { Egger, Fahn \& Wamser } \\
\text { (2014) }\end{array}$ & $\begin{array}{l}\text { Key drivers for multinational } \\
\text { companies and their networks? }\end{array}$ & - Literature Review & $\begin{array}{ll}\text { - } & \text { Systematic analysis of multinational affiliate networks } \\
\text { - } & \text { Knowledge transfer between affiliates } \\
\text { - } & \text { Simultaneous versus sequential market entry. }\end{array}$ \\
\hline 22 & $\begin{array}{l}\text { Fonfara, Ratajczak- } \\
\text { Mrozek \& Leszczyński } \\
\text { (2016) }\end{array}$ & $\begin{array}{l}\text { - Changes and transformations of } \\
\text { networks? }\end{array}$ & $\begin{array}{l}\text { - Conference } \\
\text { summary }\end{array}$ & $\begin{array}{l}\text { - } \quad \text { Multinational companies = network of interdependent entities } \\
\text { - } \quad \text { Change is a fundamental assumption embedded in the network approach } \\
\text { - } \quad \text { Changes occurring are caused by interdependency, interactions and mutual } \\
\text { adaptation }\end{array}$ \\
\hline 23 & $\begin{array}{l}\text { Yayla, Yeniyurt, Uslay \& } \\
\text { Cavusgil, } 2018\end{array}$ & $\begin{array}{l}\text { What is the impact of market } \\
\text { orientation, relational capital, and } \\
\text { internationalization speed on } \\
\text { market exit and re-entry decisions } \\
\text { under turbulence in a host market. }\end{array}$ & - $\quad$ Survey & $\begin{array}{l}\text { - } \quad \text { Found out that the market-oriented firms are more flexible } \\
\text { - } \quad \text { relational capital specific to the host country has a negative impact on market } \\
\text { exit decisions under conditions of political conflict. }\end{array}$ \\
\hline 24 & Yan 2020 & $\begin{array}{l}\text { - What are the internationalisation } \\
\text { theories in the current literature } \\
\text { body? } \\
\text { - How does uncertainty influence the } \\
\text { decision-making process of mode } \\
\text { switching? }\end{array}$ & - $\quad$ PhD: 2 essays & $\begin{array}{l}\text { - examine the role of uncertainty in entrepreneurial internationalization } \\
\text { process and decision-making }\end{array}$ \\
\hline
\end{tabular}

Table 13: Overview of the main mode switch research from 1997 to 2016 
In 2000, a research group around Bent Petersen analysed exporters in recent studies and dealt especially with the reason for but also against mode switches (Pedersen et al. 2000). Next to this, these researchers focused on reasons and motivations for mode switches between respective mode structures. In summary, these researchers have made contribution to practical as well as theoretical knowledge regarding mode switches. As the switching motivators which were found by Pedersen et al. (2000) are the starting impulse and the reasons for mode switches within firms, they build an important underpinning for the theoretical framework (outlined in the next section) of this thesis.

By analysing mode switches in a period of ten years, Swoboda (2002, 2008 and 2011) established several concepts for analysing management behaviours within the decision-making process and reasons for mode switches. One of his most known theory is the Three-Level Model that is explained in chapter 2.7.2.6 of this research and in Figure 23. The unique characteristics of Swoboda's concepts and findings is that he included the variable of time in his research and therefore also analysed the right time to change, the intensity and the duration of the transition process, and the sequence in which events occur (Swoboda, 2002).

In 2006, Kaufmann and Jentzsch contributed knowledge with their study of automotive suppliers to China. This was one of the first studies that was focused on one specific country and market. From that point, the researchers identified four paths of development as well as reasons for mode switches. With their research, Kaufmann and Jentsch (2006) contributed knowledge regarding switching motivators and consequently extended the knowlegde about the starting impulses for the mode switching process, which is included in the theoretical framework (outlined in the next chapter) of this thesis. However, the research of Kaufmann and Jentzsch (2006) was limited to the starting impulses and starting reasons of a company to do a mode switch, but 
not on the entire decision-making process and the influencing parameters which affects the final decision of a mode switch.

Rezende (2006) Asmussen et al. (2009) were the first researchers who considered the internationalisation process of a multinational firm as loosely coupled system of several international activities. Asmussen et al. (2009) claimed that these international activities are influencing each other and consequently interdependencies between different international activities are exisitng. Asmussen et al. (2009), were the first researchers who considered that many firms are acting as multinational companys today. Therefore, the incremental learning process model of Calof $(1991,1993)$ which is mainly focused on one international activity of a firm does not perfectly describe the loosely coupled system of a multinational company with several international activities acting at the same time (Rezende, 2006; Asmussen, 2009). This is why, this thesis is focusing on contributing knowledge regarding the mode switching process of mulitnational firms and to determine the role of interdependencies between simultaneous (happening at the same time) mode switching processes as suggested by Asmussen et al. (2009). Consequently, the findings of Asmussen et al. (2009) show the current gaps of the theoretcial framework (outlined in chapter 2.8) regarding interdependencies between simultaneous mode switching processes and are important for this thesis because the interdependencies are the core factor in the conceptual framework (explained in chapter 2.9) to be explored in this thesis.

In the newer studies (after 2009), the main focus of the researchers was on mode combinations such as Benito et al. (2011), on country specific reasons and switching motivators such as Belova et al. (2010),on affiliate network perspectives such as Egger et al. (2014) and Fonfara et al. (2016) and on influencing factors such as market orientation, internationalisation speed and management of uncertainty (Yayla, Yeniyurt, Uslay \& Cavusgil, 2018; Yan, 2020). The results of these studies contributed theoretical knowledge to the theoretical framework (outlined in the next chapter) and extended the 
knowledge about single steps of the mode switching process and are therefore essential and contribute knowledge for building the theoretical underpinning and conceptual framework of this thesis.

\subsubsection{The Mode Switching Process}

As shown in Table 14 there are many studies which investigate the holistic mode switching process as Petersen et al. (2002), Petersen et al. (2005) and Sachse (2010) or with a focus on special parts of the mode switching process as Rundh (2003), Swoboda et al. (2011) and Nan (2013). Based on the conducted literature review process about mode switching of this thesis and the selected studies of Table 14 a mode switching process model, which is predominantly used in the current literature body, can be illustrated as the theoretical framework of this thesis in Figure 14. The single steps of the theoretical framework and the influencing factors are following the 5-step approach of Sachse (2010) which is illustrated in Figure 11 and the integrated multi-level decision-making model illustrated in Figure 9 by Albaum and Duerr (2008).

The underpinning and first stage of each mode switching process is the current operation mode in place of the respective country or market. The different mode options are described in the chapter 2.6.1 in which I explained the different entry mode options, e.g. direct exporting, working together with an intermediary, having an own sales force in the foreign market, etc. (Nan, 2013; Yan, 2020). The established mode option is the first step of the decisionmaking process of mode switching which is suggested by the 5-step approach of Sachse (2010) in which the established mode after the market entry is the first step of the model. 


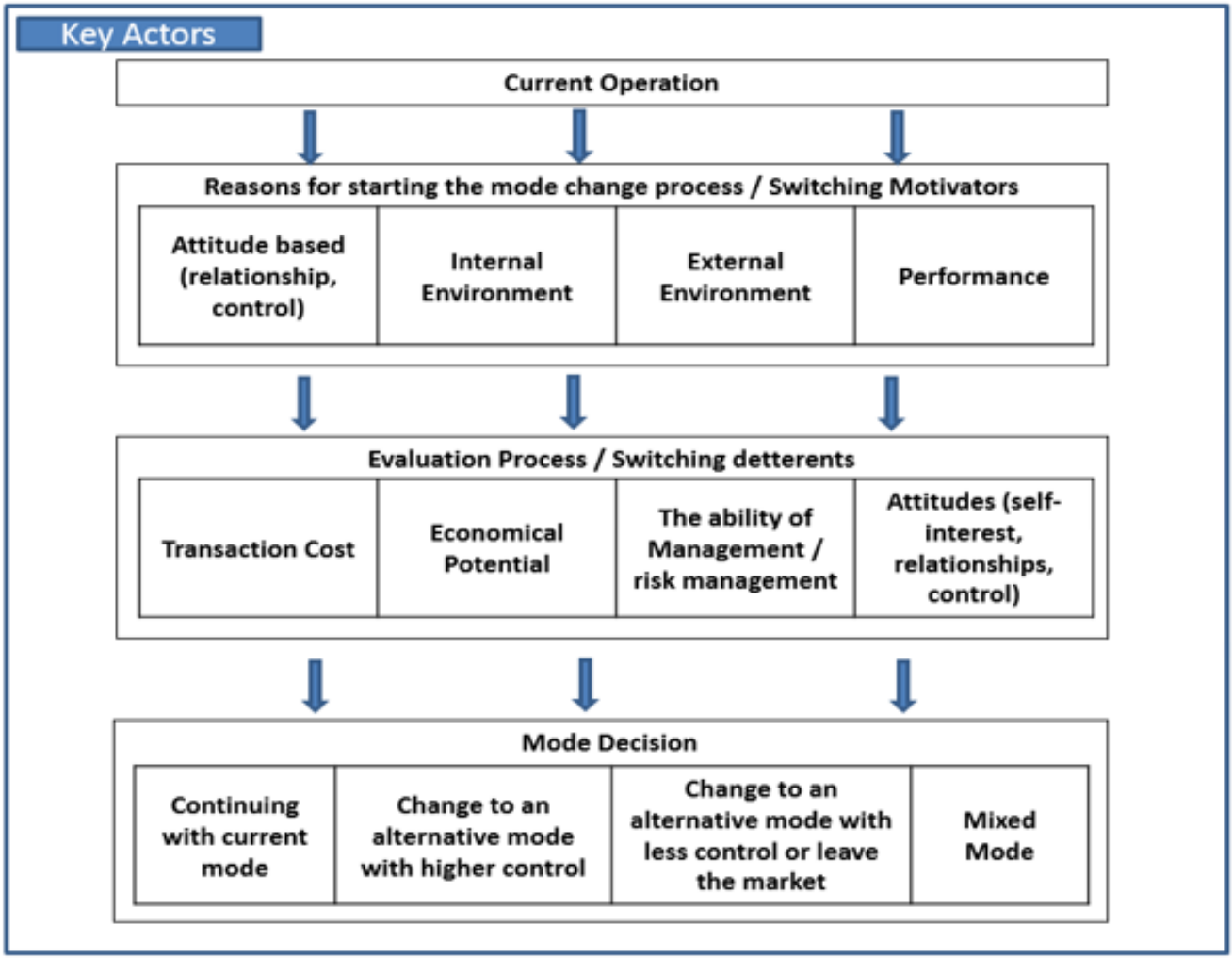

Figure 13: The Mode switching Process of the current Literature Body - the theoretical framework

Without any reason or motivator, the management of a company would not start the mode switching process and therefore the reasons and motivators compose the second stage of the general mode switching process (Swoboda et al., 2011). This step is included into the theoretical framework according to the 5-step approach of Sachse (2010), outlined in Figure 11, in which the second step of the decision-making process of mode switching is the impetus to switch, so the reasons and motivators for a firm to switch a mode option. As illustrated in Figure 14 the switching motivators are clustered in four groups, "Attitude Based", "Internal Environment", "External Environment" and "Performance" (Swoboda et al., 2011; Ciravegna, Kundu, Kuivalainen \& Lopez, 2019). Attitude based motivators are mainly caused by the behaviours of the management (Freeman et al., 2013). For instance, if the relationship between the responsible sales manager and the respective intermediary in a 
country is particularly good, the sales manager suppose to protect his intermediary internally and try to avoid a mode switch. Another example for an attitude-based reason of a mode switch could be the changed requirement of management control within a firm regarding a respective country (Freeman et al., 2013). If the management decides that the management control should be increased, the management supposed to switch from exporting via intermediary to own sales forces if possible. The internationalisation process in general is very much dependent on the knowledge and experience which firms gained in other internationalisation activities before (Georgiou, 2014; Ciravegna et al., 2019). As this knowledge and experience is mainly gained by the managers or employees who are responsible for the internationalisation process, a change in the internal environment, e.g. if some managers are leaving a firm or if the firm hire well experienced managers for the internationalisation process, have a huge impact on the mode switching process and can be a motivator to start the mode switching process (Georgiou, 2014). Next to the managers and employees, also the company structure, the values of a company and the mission of a company belong to the internal environment. As the national and international external environment of a company is a social, complex and dynamic system, the influencing factors on the internationalisation process are changing constantly (Osmundsen, 2012). External environment is defined as all actors, institutions, markets, politics etc. which are existing outside of the respective company. For example, some political or geographical changes can cause a mode switch and can be switching motivators (Swoboda et al., 2011; Ciravegna et al. 2019). For instance, the reactivation of the Iran sanctions from President Trump (of the United States of America), forces European firms to stop their business with Iran, because otherwise a European firm risk to be evaluated as "Black Firm" by US institutions and consequently would not be allowed to do business with American companies as well (Schieritz \& Thumann, 2019). Last motivator which could cause a mode switch is the performance of the mode option in use (Swoboda et al., 2011). For instance, if the respective dealer in a foreign 
country does not perform according to the business plan, budget and forecast of the exporting firm in the host country (Sachse, 2010). This less performance can can be a reason for the management of the exporting firm to start the mode switching process (Swoboda et al., 2011). Understanding the existing switching motivators in the current literature body is important for this thesis because I intend to explore the influencing factors of the decision-making process by achieving objective 2 of this research project (Sachse, 2010).

The second stage of the mode switching process is an evaluation process which starts as soon as the management has started the mode switching process due to the before described switching motivators (Osmundsen, 2012). According to Sachse (2010), this process step is described as the opinion building phase (see Figure 11) and the evaluation stage is an own process within the mode switching process as shown in Figure 15. In the first step of the process the status quo is evaluated, and the main question is if the objectives have been met that an exporting firm has set in the past (Sachse, 2010; Mostafiz, Sambasivan \& Goh, 2020). Afterwards the firm is benchmarking the potential performance of a respective market according to the country potential. In the next stage the firm is checking alternative mode option and if a new mode option would achieve more or ideally the full potential of a market (Sachse, 2010). After identifying a mode option with a higher potential for the respective market the economic advantage of a mode switch is investigated (Sachse, 2010). In this stage a firm is calculating the higher potential of an alternative mode against the mode switching costs, for instance the investment costs for launching an own sales force versus the higher potential turnover and margin that can be achieved with own sales representatives (Sachse, 2010; Mostafiz, Kuivalinen \& Sundqvist, 2020; Mostafiz et al., 2020). According to Sachse (2010) a mode switch delivers positive value if a firm is following the before mentioned stage model and consequently the performance improves in the last step (Figure 15). 


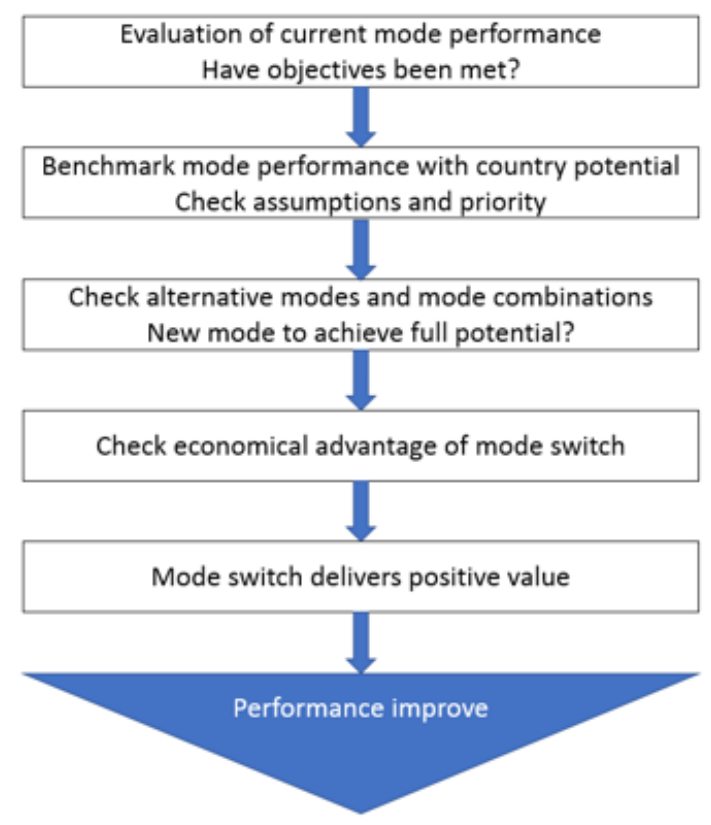

Figure 14: Evaluation Stage of the Mode Switching Process (Sachse, 2010)

The evaluation stage of the mode switching process of Sachse (2010) is built on the integrated multi-level approach by Albaum and Duerr (2009) which is illustrated in Figure 9 (page 59) of this thesis. The comparison of both models is shown in Table 15. This comparison supports firstly that the mode switching process evolved originally from the theory of decision-making and secondly that the integrated mulit-level model approach of decision-making contributes a significant theoretical underpinning to this thesis and the theoretical framework of the mode switching process outlined in Figure 14.

\section{Process Step of the evaluation Integrated multi-level approach by stage of mode switching process Albaum and Duerr (2009 (Sachse (2019)}

1. Evaluation of the current mode 1. Problem identification option performance

\begin{tabular}{ll|l} 
2. Benchmark the country potential & 2. Gathering information
\end{tabular}

3. Check alternative mode options 3 3. Generating alternatives 
4. Check economic advantages

5. Mode switch
4. Evaluation of alternatives

5. Decision

Table 14: Comparison of Evaluation step from Sachse (2010) and the integrated multilevel approach (Albaum \& Duerr, 2009)

Within the evaluation stage process a firm is also confronted with switching deterrents which can be the reason for a firm to decide to stay with the mode option in place (Swoboda et al., 2011). There are two rational switching deterrents with the transaction costs that includes the switching costs and the economic potential of an alternative mode. Additionally, there are two subjective and intuitive switching deterrents that are very much dependent onthe individual manager in charge (Osmundsen, 2012; Mostafiz et al., 2020). First, the ability of the management to handle the mode switch, the risk management that allows to switch to an alternative mode and the ability of the management to manage the potential new mode option (Swoboda et al., 2011; Mostafiz et al., 2020). For instance, if a firm intends to switch from exporting via an intermediary to an own sales force the management of the exporting firm needs the abilities to handle and manage the own sales force abroad. Second, the attitudes of the management can be a switching deterrent as each change in a firm causes less power and control for some managers (Osmundsen, 2012). For example, if a export sales manager worked together with an intermediate for a respective country, he will lose his customer if a firm decides to launch an own sales force in the foreign country because the supply chain step of the intermediary is integrated into the firm in form of the own sales force.

The last step and outcome of the mode switching process is the mode decision which was contributed by the 5-step approach of Sachse (2010) in chapter 2.6.1. Finally, the firm can decide to stay with the current mode, change to an alternative mode with higher control, higher investment and higher risk, change to an alternative mode with less control and less investment or leave the 
market completely and combine mode options for a respective market (Swoboda et al., 2011).

The key actors who are influencing and driving the mode switching process include the advisory board, top management, export manager or internationalisation team and the current team of the foreign operation mode (e.g. export managers, local sales or cooperation partners and direct customers) (Sachse, 2010; Georgiou, 2014; Wójcik \& Ciszewska-Milnaric, 2020). These actors make individual or collective decisions within the mode switching process and are the driving force, impulse-provider and context designer (Kutschker \& Schmid, 2006). During their decision-making, these actors are influenced by several stakeholders. There are internal stakeholders, like middle management and employees in different functional areas, e.g. R\&D, purchasing, logistic, etc.) and external stakeholders from the business environment, such as customers, government, suppliers and investors (Chetty \& Blankenburg Holm, 2000; Sharma \& Blomstermo, 2003; Wójcik \& Ciszewska-Milnaric, 2020). Considering this influencing aspect in the theoretical framework of this thesis is contributed by the integrated mulit-level model of Albaum and Duerr (2008) who explain that the the behaviour and personal interests of key actors often drive decision-making porocesses. Therefore, it is important for me to consider and understand the existing knowledge of previous studies regarding the key actors of the mode switching process and their influence on the process because I explore the influences of the key actor's behaviour and the environment on the decision-making process in research Objective 2.

The main gap in the literature body regarding the decision-making process of mode switching is that the existing theories do not consider that multinational companies are a complex and coupled network of several decision-making processes of mode switching which are running at the same time and can influence each other (Rezende, 2006; Asmussen, 2009). Next to this, due to the research design of previous studies the main focus was on quantifiable 
influencing factors and not on qualitative influencing factors as for example the personal behaviour of the key actors and their influence on the decisionmaking process (Albaum and Duerr, 2008; Sachse, 2010).

\subsection{The School of Internationalisation}

According to the literature house, this chapter is describing the fourth pillar and fourth main theme of the thematic analysis, as illustrated in Figure 16, the school of internationalisation research.

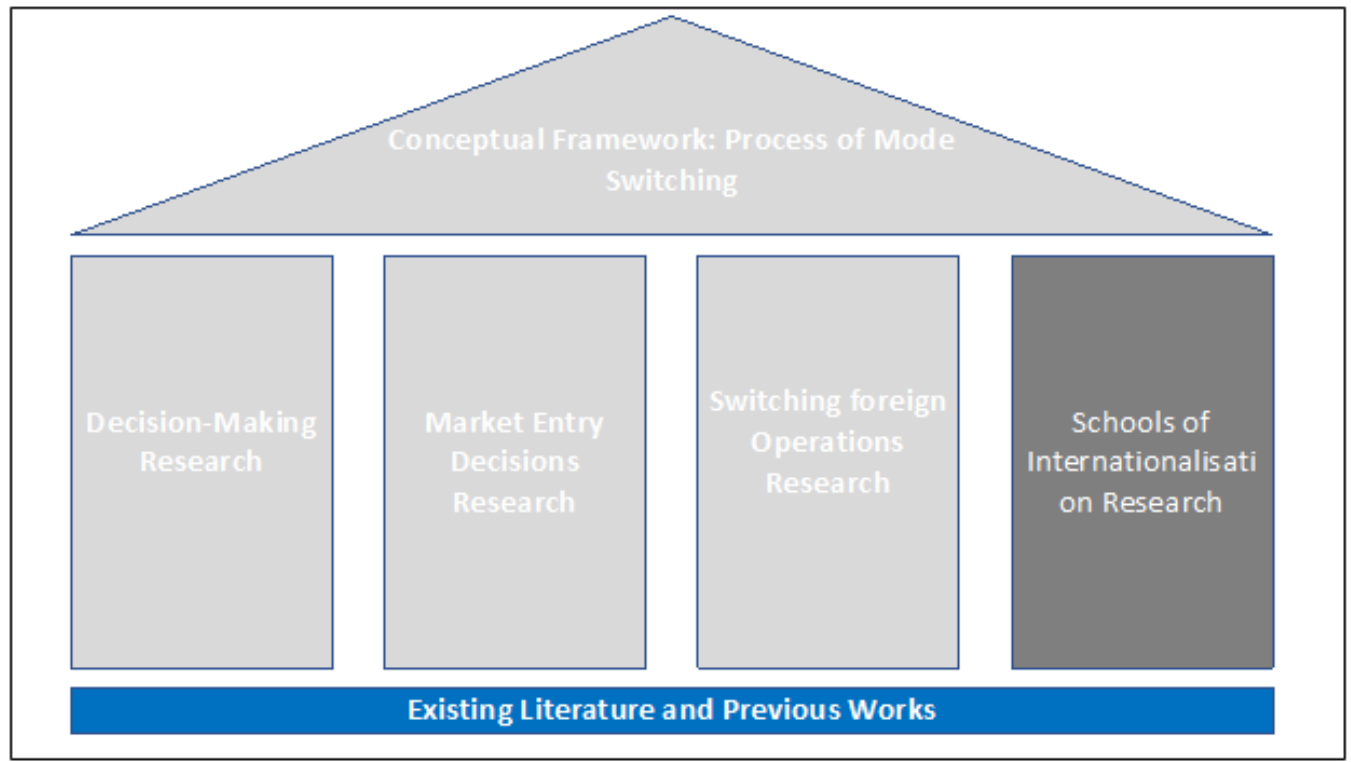

Figure 15: The literature house_School of Internationalisation Research

Regarding internationalisation of firms, the variety of theoretical models have emerged over the last 40 years in the literature (Zentes, Swoboda \& Morschett, 2004; Marcharzina \& Wolf, 2005; Becker, 2005; Kutschker \& Schmid, 2006). Sachse (2010) has shwon in his study that these theoretical models have influenced and contributed knowledge to the decision-making process of mode switching which was outlined as theoretical framework in the previous chapter, because perspectives and elements of these theories wer included in single steps of the theoretcial framework (Figure 14, page 81). Therefore, I intend to critically review the existing theories regarding internationalisation of firms 
within the next sections to discuss the theoretical contributions and underpinnings of each theory to this research topic.

As shown in Table 12 (page 51), the theories could be grouped into traditional perspective based on economical factors of influence and into behavioural/process-based perspectives that emphasises internationalisation as a dynamic process (Benito \& Welch, 1993). While the traditional approaches are typically used to answer the "why?" (the reasons for a firm to internationalise) and "how?" (process and configuration of internationalisation) concerning internationalisation, the process-based approaches see internationalisation as a dynamic process and therefore also intend to answer the "when?" (timeline and dynamic of internationalisation) questions (Johanson \& Vahlne, 1990; Sachse, 2010).

\subsubsection{Traditional Approaches of Internationalisation}

The following sections present the traditional approaches of the internationalisation literature, the transaction cost approach, the agency theory, the Eclectic Theory by Dunning, the competition-oriented and strategic approach and the real option theory.

\subsubsection{Transaction Cost Approach}

The theory of transaction cost was developed by Coase in 1937 and further investigated and adjusted by Williamson $(1975,1985)$ and by Axinm and Matthyssens (2002). The underpinning of this theory is that the decision of a firm is based on comparing the costs of the decision options. The only decision determinant is the amount of costs of each option / strategy and consequently which strategy is more cost-effective (Williamson, 1975). The discussion about the total amount of costs before and after a change of a current set-up, the so called transaction costs, are getting increasingly important in reagrds to mode switching (Axinm \& Matthyssens, 2002; Sachse, 2010; Rindfleisch 2019). According to this theory the costs for switching a previous selected mode is increasing, the higher the uncertainty, the more specific the activity is and the 
rarer the transaction is (Axinm \& Matthyssens, 2002; Calveras \& Orfila-Sintes, 2019). Considering these factors Buckley and Casson (1981) have developed a model for choosing between the entry mode options, exporting, contracting/licensing, direct investment and performing a transaction within a company. The main focus of their research was on the perfect timing for a direct investment and at what stage of the internationalisation process the cost conditions allow a switch from licensing to direct investment (e.g. launching an own subsidiary abroad). According to Swoboda (2002) and Welch et al. (2007), companies will choose the organisation form and location of a foreign activity where the transaction costs can be minimized (Welch et al., 2007; Sachse, 2010; Calveras \& Orfila-Sintes, 2019).

In the literature the transaction cost theory is often criticised for focusing only on one aspect and for ignoring aspects like resources of a company (Coase, 1937; Axinm \& Matthyssens, 2002; Rindfelisch, 2019). According to Swoboda (2002), large firms with a hierarchically structured organisation are more likely to choose a transaction with higher risk and that requires significant management time because of the availability of resources in comparison to small firms. Similiarly, the approaches which focus on achieving competitive advantages due to a transaction are also critisizing the transaction cost approach for focusing only on the costs as decision determinant (Hymer, 1976). In addition, the approach is critizised because some costs like coordination costs (cost for planning, organisation, management, communication) are only considered in a limited degree (Rugman, 1997). Last but not least it is an approach that investigate decisions with exclusion of the efficency perspective has weaknesses and is limited to one aspect (Kutschker \& Schmid, 2006; Calveras \& Orfila-Sintes, 2019).

According to Sachse (2010), the transaction cost theory is often criticized as it is one of the most investigated theories of the literature and many firms are using this approach to evaluate their internationalisation theories (Kutschker \& Schmid, 2006; Sachse, 2010). Consequently, this theory is defined as part of 
the evaluation process of the decision-making process of mode switching as illustrated in Figure 17 and is explored within this research project (Rezende, 2006; Sachse, 2010).

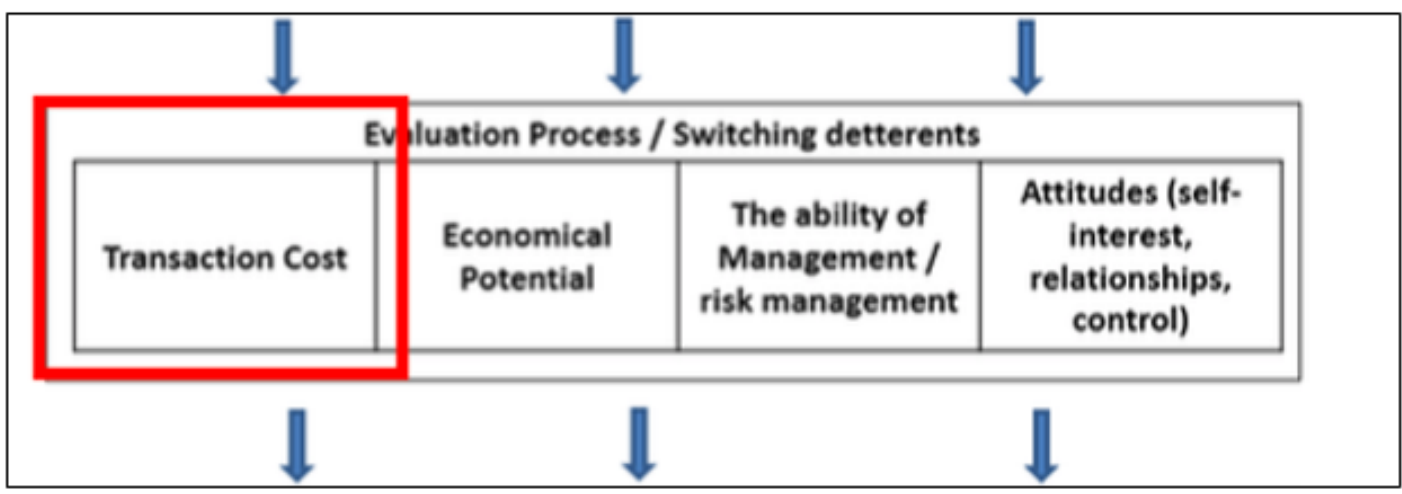

Figure 16: Extract of the theoretical framework_Transaction costs

\subsubsection{Agency Theory}

The agency theory claims that external third party partners (agents) in a foreign market (e.g. the intermediate dealer) have competitive advantage due to their higher knowledge and information about their market in comparison to the exporting company and they are using their advantages to achieve their own objectives (Welch et al., 2007; Metsola, Lappäaho, Paavilainen-Mäntymäki, Plakoyiannaki, 2020). As the decisions of a firm are influenced by the external partners, internationalising firms are increasingly focused on controlling, gradual development of knowledge and promoting trust between the partners in an international network (Welch et al., 2007). As working with external partners in a foreign country is one option for working in an international market for a multinational company, the agency theory can contribute knowledge to the theoretical underpinning of this thesis as part of the theoretical framework as illustrated in Figure 18, because the external partners are categorized as external environment within the switching motivators (Welch et al., 2007; Metsola et al. 2020). 


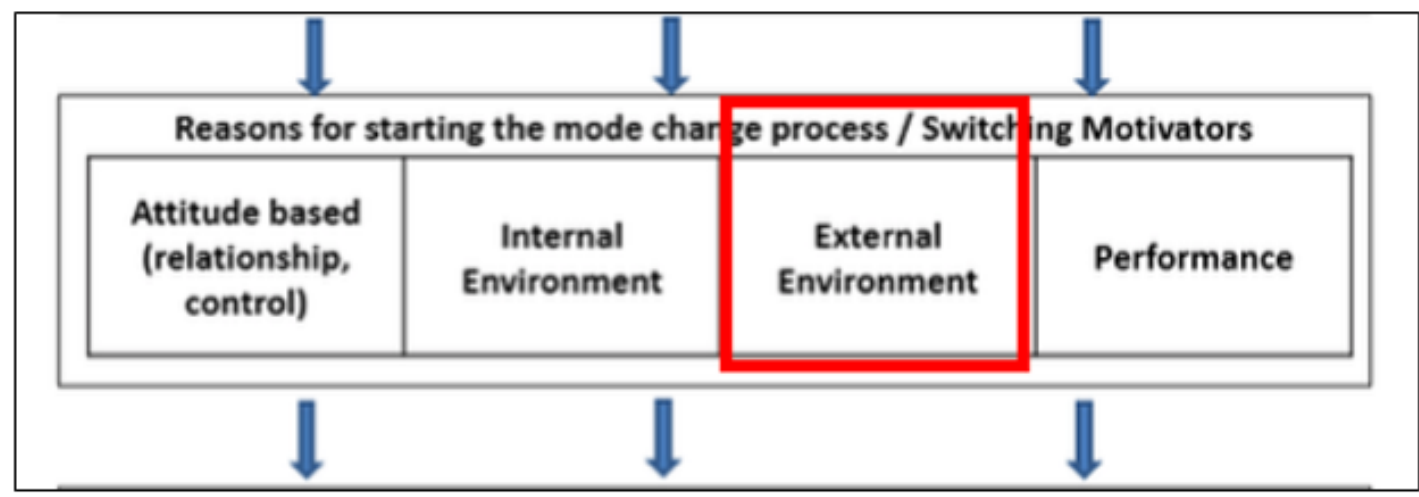

Figure 17: Extract of the theoretical framework_agency theory

\subsubsection{Eclectic Theory by Dunning}

Dunning (2000) developed the eclectic paradigm as a theoretical framework in order to integrate and join different aspects of the traditional internationalisation approaches which are described in chapter 2.7.1 (Dunning, 2000). According to Dunning (2000) the performance of the international business of a firm depends on the factors, ownership advantages (e.g. firm specific assets) ( $O$ ), location specific advantages (e.g. attractiveness of a foreign country) (L) and internationalisation advantages (e.g. the ability of a firm to internationalise within his organizational structure) (I). Therefore the paradigm is often named the OLI framework in the literature. Following the OLI Framework a firm would choose the internationalisation strategy which combines the most advantages regarding the ownership, country specific and internationalisation advantages (Dunning, 2000; Sachse, 2010; Yaw \& Keon, 2020). The core statement of the framework is that a firm which is not owning a valuable asset which develops a competitive advantage in the domsestic market would not internationalise. But if a company has exclusiv ownership advantages and no location or internationalisation advantage, it will concentrate on contractually based modes options of internationalisation (e.g. through licensing). If a company has additionally internationalisation advantages, it would start with exporting and if the company has finally also location advantages, direct foreign investments seems most attractive 
(Kutschker \& Schmid, 2006; Yaw \& Keon, 2020). The eclectic theory of Dunning (2000) bascially builds the underpinning of the switching motivators which are illustrated in the theoretical framework as shown in Figure 19. The ownership advantages (O) which mainly depends on the attitudes of the managers are categorized in the atitude based switching motivators, the location specific advantages (L) are considered as external environment and the interantionalisation advantages $(I)$ are categorized as internal environment because the organizational internal structure of a firm very much influences the internationalisation advantages (Dunning, 2000; Sachse, 2010).

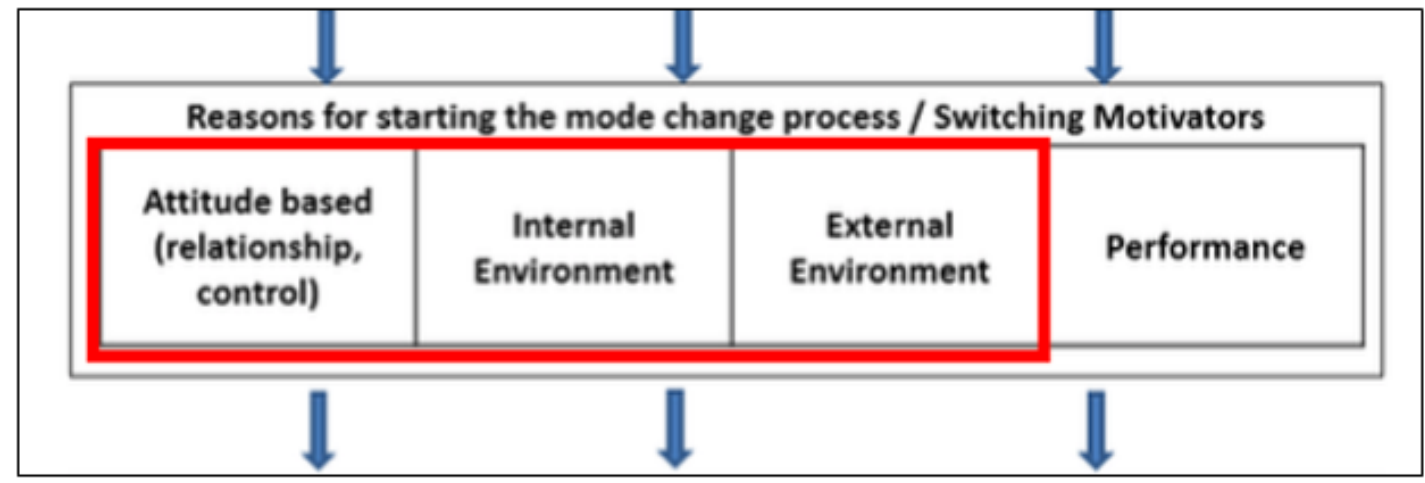

Figure 18: Extract of the theoretical framework_Eclectic Theory of Dunning

The eclectic theory is often recommended in the literature because it includes many and different explanatory variables and most important it also indicates how these variables are interacting with each other (Swoboda, 2002; Yaw \& Keon, 2020). For instance, if a company is mainly focused on research and development and is developing many new products and novel technologies (ownership advantage), this company would only start to export their products if it would be able to organize the distribution, sales and logistics abroad (internationalisation advantage) (Dunning, 2000).

The eclectic theory is frequently studied in the literature and often used by managers for evaluating internationalisation decisions (Sachse, 2010). The eclectic theory by Dunning can contribute knowledge to the theoretical underpinning of this thesis and I am using parts of the theory for building the 
conceptual framework for this research as shown in Figure 19, because this theory defines influencing factors and starting impulses of the decision-making process of mode switching framework outlined in Figure 11 (page 64).

\subsubsection{Competition-Oriented and Strategic Approach}

If a company decides to enter into a foreign market, it has initially disadvantages in comparison with the domestic competition as typically, knowledge, information and experiences with competitors, customers, partners products, markets etc. are missing (Sachse, 2010; Hollensen, 2017). The only exception could be a joint venture approach in which an internationalising firm merges with a local firm to benefit from the knowledge of the local firm (Hollensen, 2017; Han, 2019). According to the competitionoriented approach, a company can only internationalise successfully, if it overcomes the foreigness in a foreign market and becomes a well established player in the market by developing a competitve advantage (Welch et al., 2007). As this theory defines the external environment of an internationalising company as an important influencing factor of the decision-making process it can contribute knowledge to the theoretical underpinning of this thesis as part of the theoretical framework.

The researchers Prahalad and Doz (1987) claim that an internationally active firm has build an organizational set-up to balance the local responsiveness which means the need to adopt to the local host-country conditions and the global integration which means to find a globally standard approach which they can follow within its international activities. This organizational set-up determines the behaviour of a firm, determines the competition-advantage and consequently influences the international success of a firm (Prahalad \& Doz, 1987; Hollensen, 2017; Han, 2019). According to Harzing and Van Ruysseveldt (2004) firms have several options to set-up their organizsational structure as illustrated in Figure 20. 


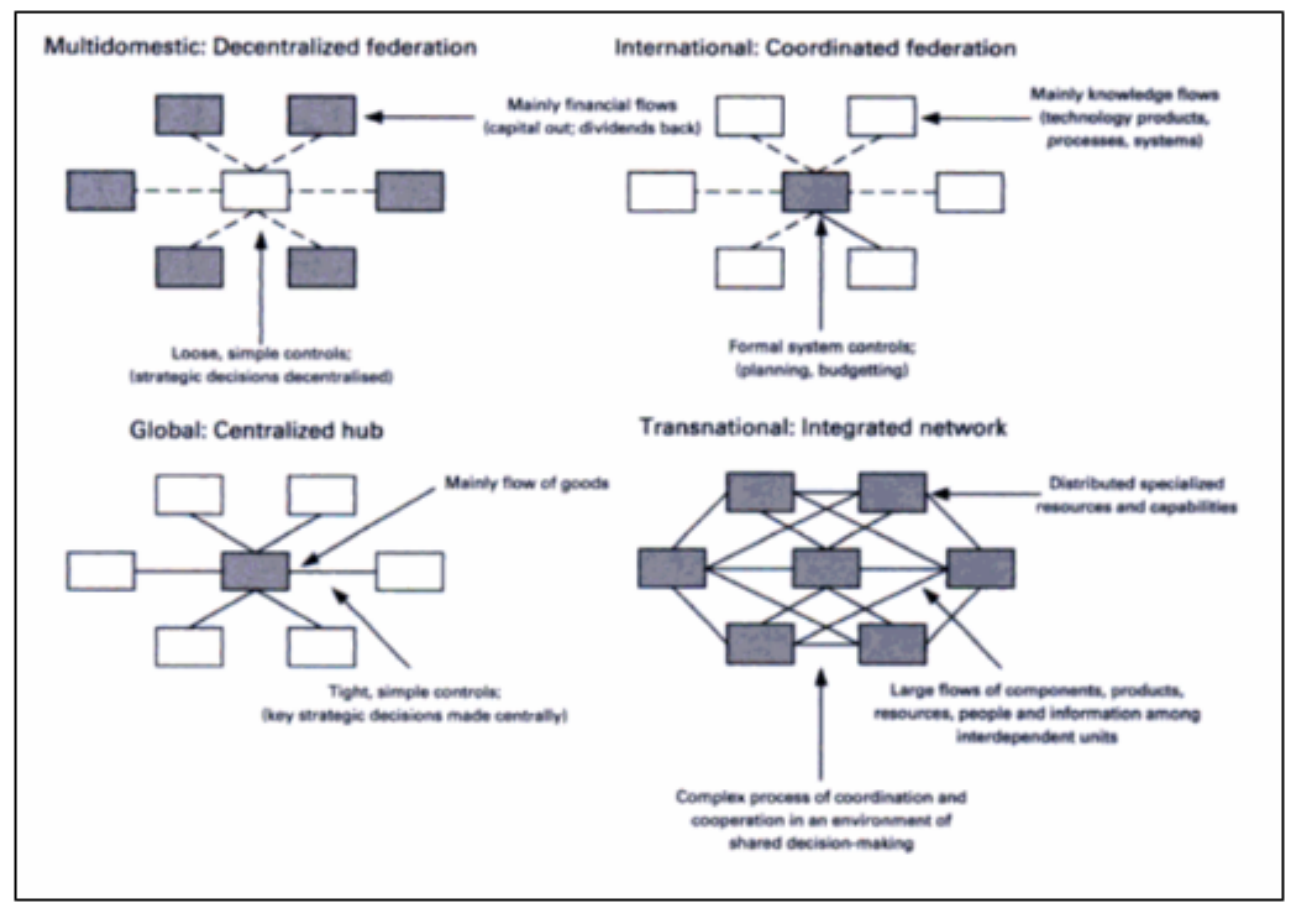

Figure 19: Organization forms of multinational firms (Harzing \& Van Ruysseveldt, 2004)

Depending on the strategic decision, the characteristics are adjusted in a company regarding organisation, management and coordination. In order to achieve competitve advantages, Barlett, Birkinshaw and Ghoshal (2004) count on economies of scale. For instance, a company with a globalization strategy whose focus is on achievieng economies of scale will build a centralized hub organisational structure to achieve scale benefits from central activities like purchasing. This theory is important to consider as it is focused on the strategical set-up of a multinational company which is categorized as internal environment within the process model of mode switching in the theoretical framework as shown in Figure 21. Conseqeuntly, according to the competitionoriented model the organizational structure of a multinational company can influence the decision-making process of mode switching (Harzing \& Van Ruysseveldt, 2004; Sachse, 2010). Therefore, I intend to explore this aspect in his research project and the aspects and perspectives of the theories are included in the theoretical framework of this thesis (Figure 14, page 81) . 


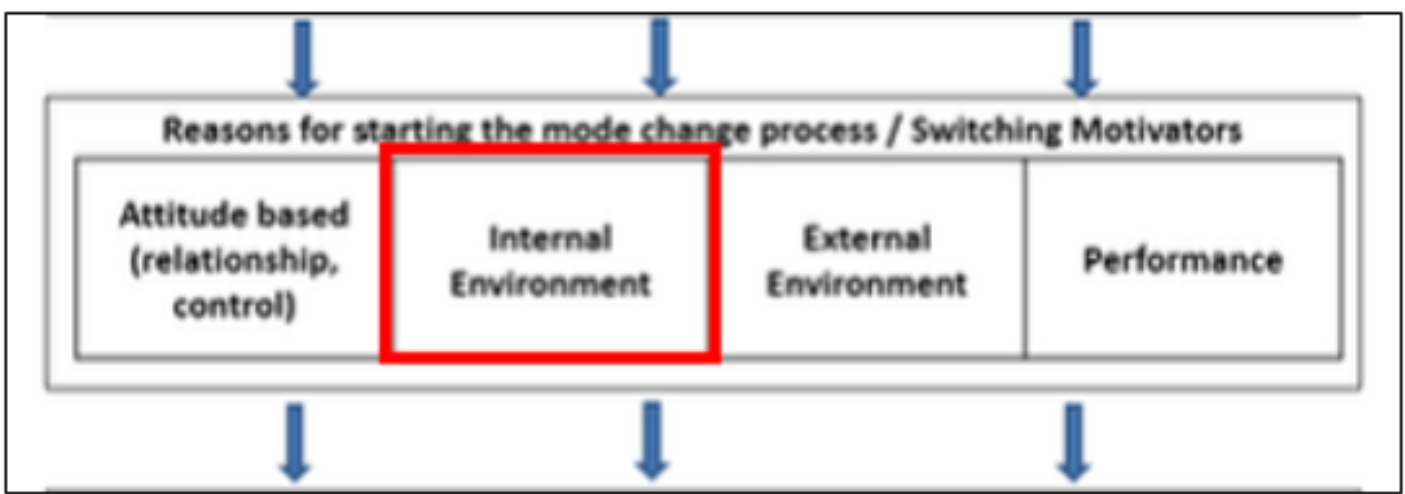

Figure 20: Extract of the theoretical framework_Competition-Oriented Approach

\subsubsection{Real Option Theory}

The real option approach is an additional economics-based theory which is analysed and used by authors in the literature (Copeland \& Tufano, 2004; Wadeson, 2020). The theoretical underpinning of the approach is that irreversible investments have a risk of loss if they are related to uncertainty. This risk can be reduced through a flexible timeframe which would put the company in the position to gather further information and to reduce the uncertainty. Generally the managers have 4 options in case of uncertainty regarding the result and outcome of their decision, to put off the action (option to wait), discontinue the action (action of withdraw), to expand (expansion option) or to use a completely different option than planned previously (option to exchange) (Copeland \& Tufano, 2004; Wadeson, 2020).

Regarding the internationalisation, the real option approach is interesting in case of the decision about a foreign direct investment (Fisch, 2004) and therefore needs to be considered in this study because this theory defines the decision alternatives that a company has at the end of the decision-making process of mode switching (option to wait, withdrawing from a market, expand the financial investment in a market or to switch the mode in a market). For instance, a firm will not make a foreign direct investment if the performance and results of the foreign direct investment are not clear or unsure. Maybe the company will invest at a later stage when the conditions are better and 
especially when the performance and outcome of an investment is clear and with less uncertainty because the risk of failling is lower. According to Macharzina and Wolf (2005), the real options approach can also be used to define and analyse the stages of an internationalisation process, because the stages can be seen as investments with different optional character. For example, is exporting seen as a delayed investment because after gaining some market knowledge and establishing the export sales channel, the company could switch the mode option to a direct investment. In comparison, the foreign sales subsidiary is an immediate option, because the company needs to invest directly to implement this mode in the foreign market. Concerning the real options theory this means that there is an investment timeline for further internationalisation from exporting up to foreign direct investments (Macharzina \& Wolf, 2005; Wadeson, 2020). As illustrated in Figure 22 the management of uncertainty and risks is considered as switching detterents within the evaluation process of the mode switching process of the theoretcial framework.

Summarized, the aspects of the real option theory can contribute knowledge to the theoretical underpinning of this thesis as this theory defines switching deterrents for the evaluation process step and because it defines the decision options of the decision-making process of mode switching (option to wait, withdrawing from a market, expand the financial investment in a market or to switch the mode in a market) (Copeland \& Tufano, 2004; Fisch, 2004; Marcharzina \& Wolf, 2005; Wadeson, 2020). The contributions to the theoretical underpinning of this thesis are shown in Figure 22. 

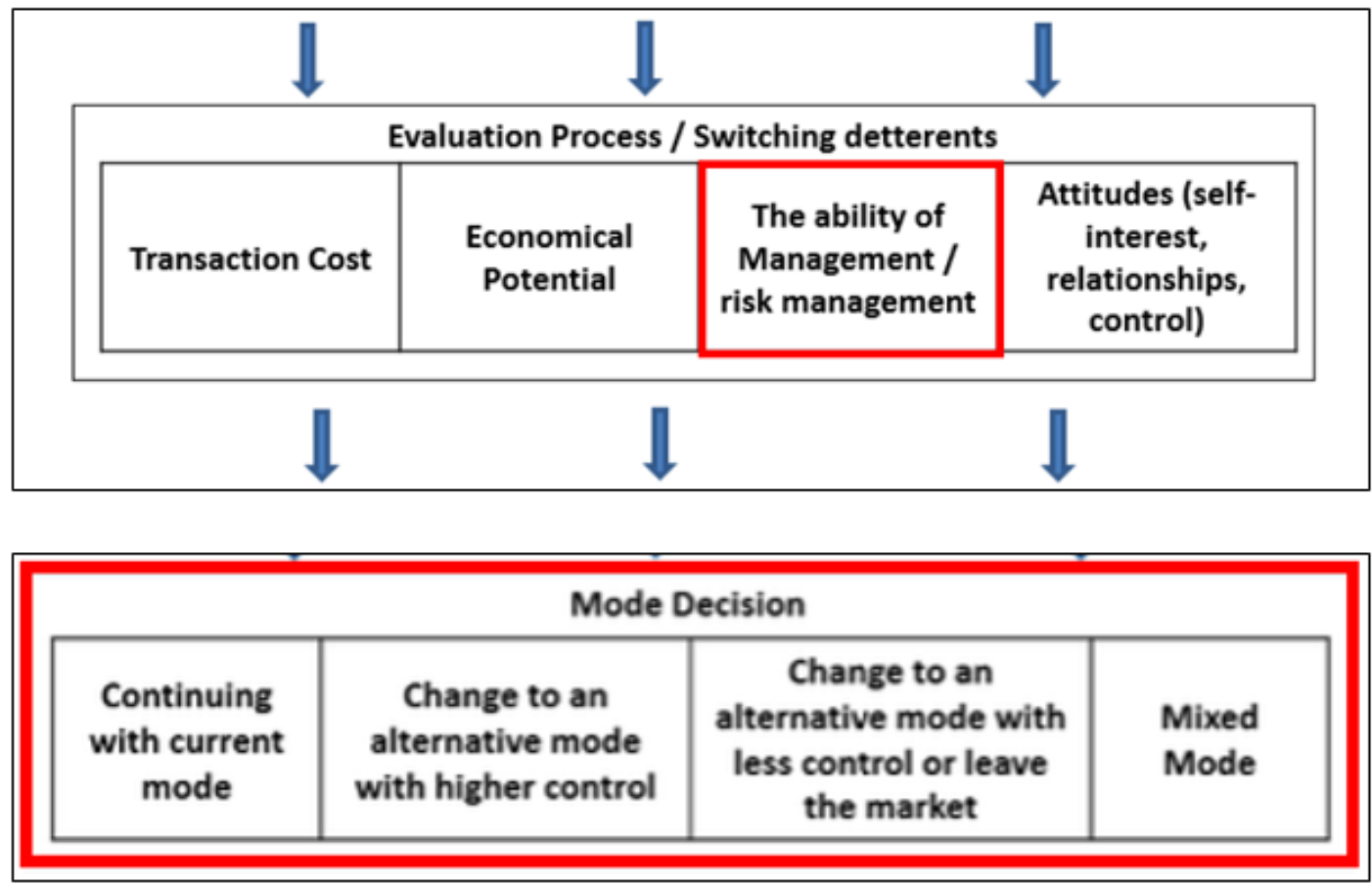

Figure 21: Extract of the theoretical framework_Real Option Theory

\subsubsection{Process-Based Approaches}

Next to the economic-based and traditional theoretical approaches in the literature which are mainly focused on rational decisions, the process-based approaches will be discussed in this chapter (Table 12, page 51). The aim of this research is to understand a global firm's management decision-making process of mode switching and the reason why these mode switching activities occur. The study will develop a new process model to illustrate and explain this business activity and expand the international management literature base. Due to the focus on the process perspective of this research (as illustrated in the theoretical framework in Figure 14, page 81) and the outlined aim of this research project in the first chapter of this thesis, the process-based approaches of the internationalisation literature body need to be considered as theoretical underpinning of the conceptual framework. 


\subsubsection{Process Perspective}

The process theories assume that the internationalisation process is a decision-making process which is realised in a step-by-step approach (Johanson \& Wiedersheim-Paul, 1975; Vahlne, 1990; Belderbos, Tong \& Wu, 2020). Often defined as the UPPSALA model, Johanson and WiedersheimPaul (1975) developed the first and most influential model of the process theories. This model assumes that the internationalisation activities occur incrementally and that a firm extend their internationalisation activities and commitment with increasing market knowledge (Johanson \& WiedersheimPaul, 1975; Belderbos et al., 2020). The main focus of the model is managerial learning and the model is describing internationalisation in terms of the mechanism of market entry decisions. For instance, a firm starts its internationalisation with exporting their goods to a similar "geographically close" market. After gaining experiences through the exporting approach, the firm is launching its own sales subsidiary due to the higher knowledge and market commitment and over time, the firm decides to invest abroad and to build their own production facility in the foreign market. This increasing market and internationalisation knowledge is leading to further internationalisation activities in more distant countries and markets. According to Johanson and Vahlne $(1977,1990)$, the time frame of the internationalisation process is relatively long and the internationalisation commitment is a gradual process with incremental steps. Steinkamp (2020) suggests in her book that the UPPSALA model is still up to date although it was firstly developed in 1975 because many firms still follow the gradually defind internationalisation process of the UPPSALA model. Following the learning process of internationalisation, a firm develops incrementally and increases its international activities over time (Steinkamp, 2020). Therefore, models like the UPPSALA theory are characterised as a systematic approach (Yip, Biscarri \& Monti, 2000). The primary goal of many business organisations is constant growth and to extend their sales and profits. If a company has stable figures it may be considered as a negative trend, even if the business is profitable 
(Penrose, 1959). Therefore, the intention of a firm regarding internationalisation is to move over time from purely exporting to foreign country production based on the managerial learning process (Johanson \& Vahlne,1990; Sachse, 2010; Steinkamp, 2020).

These assumptions are also supported by Cavusgil (1984) and Zentes, Swoboda and Morschett (2004), who argue that the internationalisation of a firm has a lifecycle and a firm passes several stages of increasing international commitment and activity. According to Zentes, Swoboda and Morschett (2004) the process-based approaches analyse the internationalisation process as a form of developing a market. Additional steps such as managing production plants or sales subsidiaries abroad are not reconsidered (Rezende, 2006; Asmussen et al., 2009). Furthermore, the processes are typically focused on one international activity or market (Rezende, 2006; Asmussen et al., 2009). Therefore, theses approaches do not consider interdependencies that occur in the global mode network of multinational companies and between simultaneous international activities that are happening at the same time which is the main focus of this research.

The process-based models are well discussed and used in the literature of internationalisation (Benito, Pedersen \& Petersen, 2005, Belderbos et al., 2019), but the models are often criticized because they are not using modern option of entering a market like web-based sales and that the models are only future-oriented and mainly focus on growth (Benito et al., 2005). Due to this set-up the models cannot consider, for instance, the relevant aspect if a firm decides to remain at one stage in the process or decides to exit from a foreign market (Benito et al., 2005). Hollensen (2017) argue that the pace of internationalisation has accelerated over the last decade and especially the internet have made it easier and faster for a firm to gain market knowledge. Therefore many firms start to expand internationally right from the beginning of their foundation and are defined as born-globals. (Moen \& Servais, 2002; 
Gabrielsson, Kirpalani, Dimitratosd \& Solberg, 2008). The born-global approach is described in the next chapter.

As mentioned at the beginning of this section, the UPPSALA model is the first and one of the most influential process theories of the internationalisation literature. As I build his theoretcial framework on a process approach and intends to investigate the decision-making process of mode switching it is evident that the most influential process theory of internationalisation contributes knowlegde and needs to be considered in this thesis (Sachse, 2010).

\subsubsection{Born-Global Approach}

Companies which are starting to expand internationally right after their foundation are called "born-global" firms (Moen \& Servais, 2002; Gabrielsson \& Kirpalani, 2004; Gabrielsson et al., 2008; Wadeson, 2020). There are many researchers who are focusing on these companies and who argue that bornglobal firms can speed up their internationalisation process by using networking and the internet (Gabrielsson \& Kirpalani, 2004). These companies do not need an incremental step-by-step process to internationalise because they start to expand into foreign markets right after foundation of the company (Sharma \& Blomstermo, 2003). The decisive step for a born-global company is the positioning in the available global networks because the born-global companies are gaining the knowledge which is necessary to be competitive in their market from their network partners (Sharma \& Blomstermo, 2003). Sharma and Blomstermo (2003) explain the international learning through networking. There are several definitions of born-global companies. Generally in the US a company is called "born-global" if $25 \%$ of the turn-over is gained abroad within the first three years. In Europe this would be a small challenge for most of the companies because of the European trading unit (Gabrielsson et al., 2008; Wadeson, 2020). Therefore, the defintion "born-global" has a more qualitative character in Europe. According to Gabrielsson, Kirpalani, 
Dimitratosd and Solberg (2008), the potential of domestic market, the product, the export market and especially the initial commitment of the management to expand international (global vision) should be considered if a company is categorized as a born-global company.

This research is focused on multinational companies which have developed their international set-up over years and decades. Consequently, the bornglobal approach does not contribute a relevant contribution to this study and is only mentioned and described to show the reader the complete scope of the internationalisation theories and that additional theories are existing (Gabrielsson et al., 2008).

\subsubsection{International Entrepreneurship Research}

The important role of entrepreneurs and their attitudes as managers is often emphasized in the literature (Jones \& Coviello, 2005; Kümmerle, 2005; Oviatt \& McDougall, 2005; Engelen, Heinmann \& Brettel, 2009; Ripollés \& Blesa, 2020). According to Young, Dimitratos and Dana (2003), resources, competences and capabiliites of the actors within a company are the most decisive factors in the internationalisation process of a firm. As already indicated in the studies of international entrpreneurship (Link, 1997; Gabrielsson, Kirpalani, Dimitratosd \& Solberg, 2008; Ripollés \& Blesa, 2020), in the early stage of the internationalisation, the position in the global networks is very important and the network of the decision makers with the actors of the partners is substantial for the international success (Link, 1997; Gabrielsson et al., 2008).

Oviatt and McDougall (2005, p. 540) stated that international entrpreneurship is:

"a combination of innovative, proactive and risk-seeking behaviour that crosses national borders and is intended to create value in organisations". 
This is supported by the model developed from Jones and Coviello (2005) where the factors level of innovativeness, level of risk tolerance and managerial competence are the most decisive regarding the behaviour in an internationalisation process. All actions in the internationalisation process are triggered by the managers and their behaviours. In sum, all actions result in an internationalisation profile and strategy of a firm and finally the performance of the internationalisation is the outcome of all actions (Jones \& Coviello, 2005). Jones and Coviello (2005) argue that the managers are going through several feedback loops and their decisions are influenced by previous successes, know-how and experiences. Due to decisive characters of the entrepreneurs in the internationalisation process, there are studies which focus on the influence of personal attitudes and values of managers (Engelen, Heinmann \& Brettel, 2009). Although the characteristics of entrepreneurs and their influence in the internationalisation process are increasingly in the research focus, it is still unclear which consequences the characteristics of entrepreneurs have for the success in foreign markets (Engelen et al., 2009; Ripollés \& Blesa, 2020).

According to the heading and aim of this study, decision-making of the management is the main focus of this research. As intuitive decisions are part of the decision-making theory as outlined in the integrated multi-level approach of Albaum and Duerr (2008), the international entrepreneurship theory can underpin the theoretcial framework of this thesis by explaining which influences the managers' behaviour have on the decision-making process model of mode switching, outlined in Figure 14 (page 81).

\subsubsection{The Relationship School of Network Perspective}

The network perspective approach is based on social exchange and resource dependency theories (Sharma \& Blomstermo, 2003). The main focus in this approach is on non-hierachical systems in which firms invest to improve and strengthen their position in global networks (Sharma \& Blomstermo, 2003; 
Ripollés \& Blesa, 2020). Especially the inter-organisational and inter-personal relationships in the global network play a decisive role (Chetty \& Blankenburg Holm, 2000; Li, Li, \& Dalgic, 2004). In this case the relationships can involve customers, suppliers, competitors, private and public agencies, family, friends, etc. According to this approach, the success of internationalisation depends more on the ability of a firm to position itself in the global networks rather than on firm-specific advantages. Therefore researchers often talk about externalisation instead of internationalisation (Li et al., 2004).

While previous discussed "stage" models suggest unilateral processes with focus on one company, the network perspective is providing a more multilateral element for internationalisation (Johanson \& Vahlne,1990). As multinational companies can be defined as multinational networks consisting of several inernational subsidiaries and external partners (like distributors in a respective country), the relationship school of the network perspective underpins the conceptual framework of this thesis (chapter 2.9) by defining the existing network of the multinational company and evaluating the connections within the network. This theory considers the existence of interdependencies and relationships between several international activities within multinational companies. Therefore it is an important theory for this study because it underpins the conceptual framework and defines the existance of interdependencies between simultaneous (happening at the same time) decision-making processes of mode switching. However, also the model of the network perspective does not explain how the interdependencies influence the decision-making process of mode switching and how they are handled within multinational companies (Rezende, 2006; Asmussen et al., 2009).

\subsubsection{The Configuration and "Gestalt" Approach}

In 1991, Macharzina and Engelhard developed a model with an holistic dynamic view on the internationalisation process which is called the GAINS approach (Gestallt-Oriented Approach of International Business). In 
comparison to the previous explained stage models, this approach tries to analyse internationalisation as dynamic processes and of the constellation environment-structure-strategy-process in the context of the categories NonExporter, Reactive Exporter and Active Exporter. The respective categories are called the "Gestalt" and there are two possible configurations, the phase of transition where the "Gestalt" gets changed and the phase of stability where the "Gestalt" does not change. Acccording to this approach, internationalisation has a process-oriented character and is a part of corporate development. The advantage of this model is that incremental change processes as well as process with revolutionary changes can be described. Macharzina and Engelhard (1991) argue that incremental changes may have the advantage of more cost favourability and less risk but the revolutionary changes can also happen during the transition phase if a firm keeps between two optimal "Gestalt" constellations which can lead to disharmony and higher costs (Swoboda \& Morschett, 2004; Sachse, 2010; Keller-Bacher \& Zerfass, 2019).

Based on the GAINS model, Kutschker (1996) and Kutschker and Bäuerle (1997) developed the "Three E's model" which was further analysed by other authors (Swoboda, 2002; Zentes, Swoboda \& Morschett, 2004). These researchers characterised internationalisation as a trial and error process. According to Swoboda (2002), within the internationalisation process a firm is going through organisational changes which have evolutionary, episodic and epochal differences. A firm is developing a foreign market in an ongoing process (international evolution) and over time the firm is doing international epochal changes. Between these two phases, there are bigger changes regarding the internationalisation process (international episode). The term "evolution" stands for the small incremental steps of a firm in its daily international business (Swoboda, 2002; Zentes et al., 2004; Keller-Bacher \& Zerfass, 2019). In comparison episodes are going faster and are more revolutionary according to Kutschker (1996). Another characteristic of this 
phase are the longer periods of increased international activities and that large parts of an organisation are faced with new and complex challenges. For instance, if a firm launches a new subsidiary by taking over a competitor, Kutscker talks about an episode in the internationalisation process (Kutschker \& Schmid, 2006). The longest period in an internationalisation process is an epoch in which several episodes can occur, for instance the establishment of a subisdiary, followed by the consolidation (evolution). The beginning of a new epoch typically triggers a fundamental change over a long time period (Swoboda, 2002; Keller-Bacher \& Zerfass, 2019). According to this model, internationalisation is always a process with incremental steps but there can be revolutionary changes during the process, while far reaching changes which would cause a new epoche are typically seldom found. Consequently, the underpinning of this theory is the UPPSALA model with categorized epoch.

\subsubsection{The Three-Level Model by Swoboda}

According to Swoboda (2002) there are three levels which are influencing the internationalisation process of a firm, as illustrated in Figure 23. The first level is grouped into internal and external environmental factors which are seen as the stimuli of international development. The main determinants of the primary level are the country portfolio, the operation mode and the transfer of value creation. The primary level is defined as the foundation and guiding principles of the internationalisation process and to develop internationalisation pathways. The secondary / basic level are the changes of structure, processes and culture within a company that occur due to the internationalisation pathways. Depending on the developed pathways, the company is creating its new configuration regarding processes, culture and structure (Swoboda, 2002; Schmid \& Morschett, 2020).

In comparison to the dynamic perspective of the GAINS and Three E's model, Swoboda (2002) argue that firms do not change permanenty the process, structure and change dimensions. According to his research, there were 
companies that have not switched their operation modes, while other firms have switched or either withdrawn from a market due to the low success. Therefore, Swoboda (2002) claims that for each international path, a successful firm creates its different "perfect" configuration. Next to Swoboda, also other researchers like Calof and Beamish (1995), Swoboda and Jäger (2008) and Schwarz (2009) have used this model in their studies. This means that the international path and the established mode option of a company is always adjusted according to the external and internal circumstances over time and therefore, mode switching can be necessary to maintain the "perfect" configuration if the circumstaces and environment of an international activity is changing (Schwarz, 2009; Schmid \& Morschett, 2020).

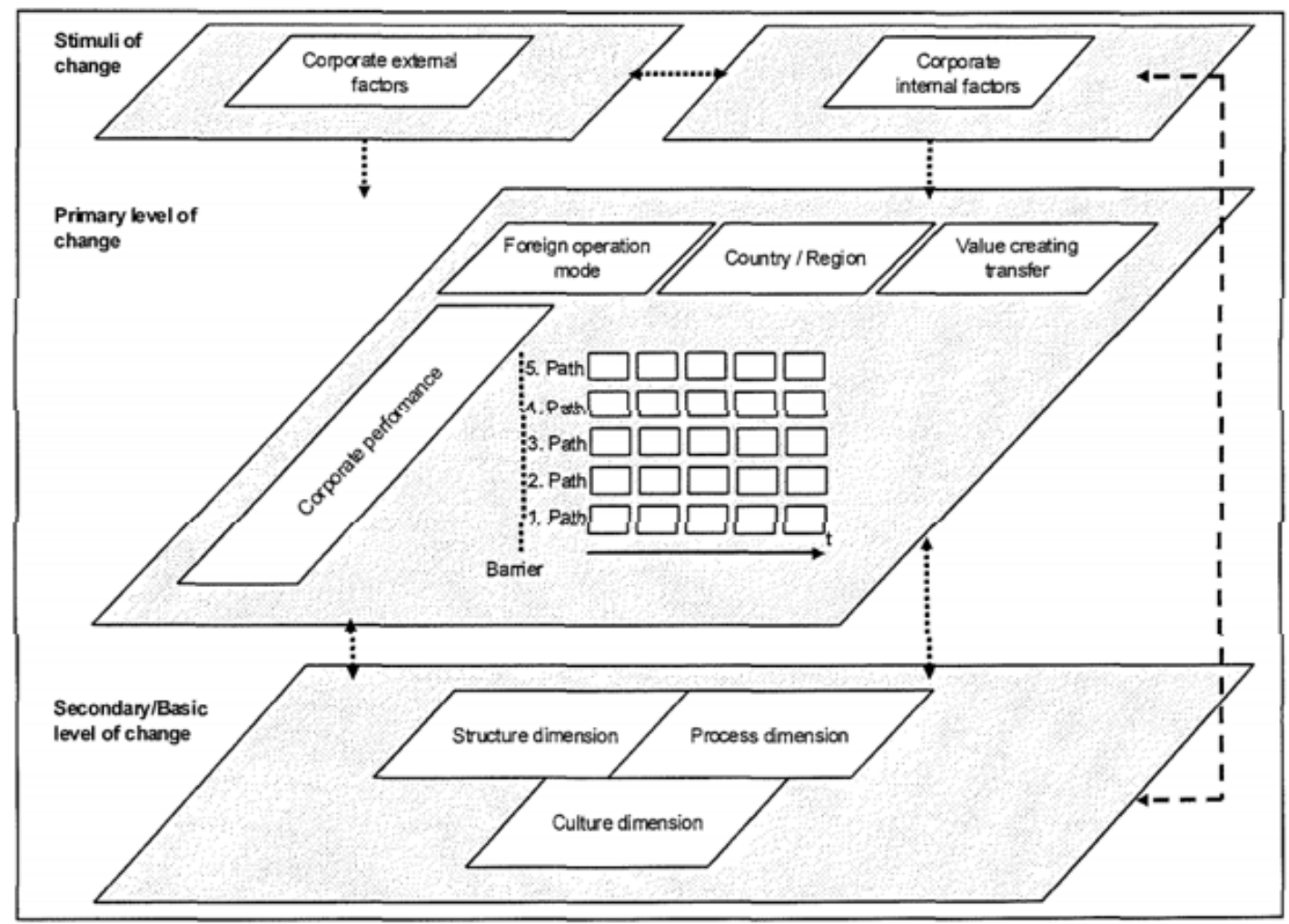

Figure 22: The level model of internationalisation (Swoboda, 2002)

According to Simon (2007), the main advantage of the three level model is the connection between the traditional market oriented dimensions and the internal company dimensions and therefore the models provides additional 
insights in comparison to previous models. On the other side, Simon (2007) critises the model for its complex structure of the different levels which can cause contradictions within the model and levels.

The level model of internationalisation has many advantages, is often investigated in many studies and used by managers and companies in practice (Calof \& Beamish, 1995; Swoboda \& Jäger, 2008; Schwarz, 2009; Schmid \& Morschett, 2020). Therefore, it underpins the conceptual framework of this study by defining the internal environment, external environment and performance of the mode option in place as important switching motivators within the mode switching process of the theoretical framework in Figure 24 (Copeland \& Tufano, 2004; Fisch, 2004; Marcharzina \& Wolf, 2005).

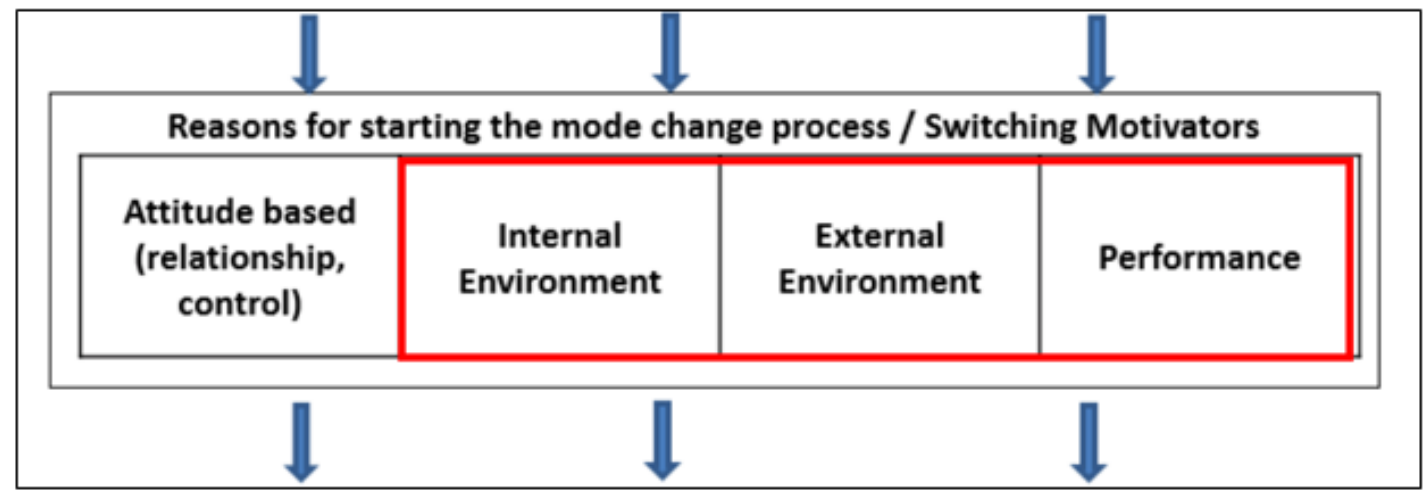

Figure 23: Extract of the theoretical framework_The Three-Level Model by Swoboda

\subsubsection{Path Dependency in Internationalisation}

Most of the internationalisation models define the learning process as a cumulative, path-dependent process where each stage adds knowledge to a firm (Eriksson, Majkgard \& Sharma, 2000; Araujo \& Rezende, 2003; Hutzschenreuter, Pedersen \& Volberda, 2007; Sune, 2018). Consequently, the underpinning for the further development of the internationalisation is given by the accumulated knowledge in the past (Hutzschner et al., 2007). Therefore, the path theory challenges the neoclassical assumptions that a so called lockin phenomenon - an inefficient and irreversible result has developed itself - 
has established itself. The most relevant study about path research was done by David (1985) who investigated the path dependency of the keyboard layout (often called QWERTY in the literature). David analysed the development of the keyboard technology by showing how an inefficient technology standard was developed and why it is still used. According to David (1985, p. 333), path dependency can be defined as follows:

"A path-dependent sequence of economic changes is one in which important influences on the eventual outcome can be exerted by temporally remote events, including happenings dominated by chance elements rather than systematic forces. Such stochastic processes do not converge automatically to a fixed-point distribution of outcomes and are referred to as nonergodic"

There are several researches in the literature, like Schreyogg and Sydow (2003), Holtmann (2008), Koch and Roedenbeck (2008) and Sydow (2009) which analyse paths as process with small events which in sum develop stable behavioural and thinking patterns. As the final pattern is not predictable at the beginning of the process, the final outcome could be an inefficient situation. In case a lock-in situation is established or the previous events lead to such a situation a firm can break the path or destabilising individual paths to return to a starting point and to the freedom of decisions.

In 1989, Luostarinen developed a concept which explains why firms are often limited in their decisions about the structure of their internationalisation pathways (Holtmann, 2008; Sune, 2018). According to Luostarinen (1989), a firm reacts "elastically" regarding further development of familiar alternatives and "non-elastically" concerning new options. Therefore, a firm stays with the exisiting pathway if the firm is more sceptical with new and unknown alternatives. The existing knowledge is determining if a firm is flexible or elastic regarding switching to a new mode in which a firm does not have prior knowledge which is described as changing the pathway in the path 
dependency theory (Holtmann, 2008). This supports that the existing knowledge of a firm can influence the decision of switching a mode or not and therefore this influencing factor is included into the conceptual framework of this research (Holtmann, 2008).

There are several studies in the literature regarding dynamic capabilities which are investigating the question of how firms react on changed environmental conditions (Teece, Pisano \& Shuen, 1997; Zollo \& Winter, 2002; Winter, 2003; Barreto, 2010). According to Teece et al. (1997, p. 516) dynamic capabilities are defined as:

"the firm's ability to integrate, build, and reconfigurate internal and external competences to address a rapidly changing environment."

The basis of this research theory is the resourced-based view and extended by the dimensions of changed capabilities of resources, abilities, operating actions, the decision-making process, opportunities and risks (Zollo \& Winter, 2002; Barreto, 2010). The resource based view is focused on the internal resources which are available for a firm. In this theory the management aims to achieve the best possible success by using the minimum possible resource commitment. In the model of dynamic capabilities, the historical development of a firms plays a decisive factor which is also stated from Teece et al. (1997, p. 522):

"Where a firm can go is a function of its current position and the paths ahead. Its current position is often shaped by the path it has travelled."

This is supported by Zollo and Winter (2002) who argue that best practices or successes that are achieved in the past are very difficult to change within a firm. Additionally, Welch, Benito and Petersen (2007) also claim that decisions about mode switches are influenced by previous experiences. Last but not least, Jones and Coviello (2005) argue that the historical environment and 
development path of a firm has to be investigated to understand the mode decisions of a firm.

According to Hutzschenreuter, Pedersen and Volberda (2007), the paths of internationalisation can be grouped in path-dependent and path-creating. The path-dependent perspective is focused on firm-specific characteristics and has therefore a limited capacity to change. Hutzschenreuter et al. (2007) argue that the internationalisation process is often a simple evolutionary journey and managerial strategic decisions are not considered by firms which means that firms often do not follow a consistent strategic decision-making process of the management but rather the managers follow an intuitive decision-making process. Therefore he claims that the path-creating perspective considers the firm's dynamic capabilities that are necessary to renew the firm's core competences over time (Hutzschenreuter et al., 2007; Menzies, Orr \& Paul, 2020).

Over the last years, this theoretical approach of path dependency has achieved increasing significance in the literature (Schreyogg \& Sydow, 2003; Holtmann, 2008; Koch, 2008; Roedenbeck, 2008; Sydow, 2009). Regarding international business, this model highlights the relevance of understanding the temporal and spatial time frame of the internationalisation process and the multiple and complex factors which can be the reason for events and activities to happen. One advantage of the approach is that not only the systematic factors are considered but rather the contingencies that are necessary to understand, investigate and analyse the open system of internationalisation that have a variety of conflicting influences (Araujo \& Rezende, 2003). This approach provides a model to understand the complex structural and cognitively strategic patterns that guide the internationalisation of a firm (Araujo \& Rezende, 2003; Menzies et al., 2020).

Werle (2007) criticises the path-dependency approach because of its focus on explaining stability and rigid behaviour of firms and therefore he claims that the 
approach only contributes small pieces to the actual change in internationalisation. Additionally, the model does not answer the question of how a firm can correct an once-taken path that have proved to be inefficient (Werle, 2007). As mode switching can correct an inefficient proven international activity of a firm, understanding the decision-making process of mode switching can contribute knowlegde to the path-dependency model and can extend the literature by closing this gap (Werle, 2007). However, the path dependency underpins the conceptual framework especially regarding objective three of this research, because it considers and mainly focuses on the knowledge that firms achieved through previous international activities as important aspect in the decision-making process of a firm (Holtmann, 2008). I will explore if this gained knowledge through previous international activities can be defined as interdependencies between decision-making process of parallel mode switches that are happening at the same time (Hollensen, 2017).

\subsection{Critical Evaluation of Literature Review}

The certain theoretical theories attempt to explain internationalisation (Zentes et al., 2004; Becker, 2005; Kutschker \& Schmid, 2006; Leonidou et al., 2010) may not provide a coherent picture as in some aspects they are contradictory, but they provide exporting companies a theoretical underpinning to build up a strategic management system for their internationalisation process (Rezende, 2006; Asmussen, 2009; Sachse, 2010; Belderbos et al., 2020).

In Table 16 I illustrate the numbers of selected papers per key theme (defined through the thamatic analysis) of this research, school of internationalisation, entry strategy, mode switching, management decision-making. Eighteen of the one hundred twenty seven investigated papers cannot be grouped in one of the key topics as these papers give input to more than one key topic or as none of the key topics are mentioned in the papers. 


\begin{tabular}{|c|c|}
\hline Entry Strategy & 22 \\
\hline Management Decision-making & 18 \\
\hline Mode Switching & 16 \\
\hline School of Internationalisation & 69 \\
\hline not defined & 18 \\
\hline Sum & 143 \\
\hline
\end{tabular}

Table 15: Number of Papers per Key Topic

According to Table 16 the theoretical internationalisation theories (School of Internationalisation) have received most attention in the literature in comparison to the other key themes with more than $50 \%$ of the papers. This is a further indication, that the underpinning of internationalisation is well discussed and investigated in the literature and the existing theories provide a holistic picture of the phenomenon internationalisation.

Evidently, the market entry strategy and the market entry process are very complex and the decision of an entry mode is influenced by many different factors that are acting simultaneously and interacting with each other (Georgiou, 2014; Baker et al., 2020). Furthermore, Table 16 shows that in comparison to the internationalisation theories the market entry process has received less attention in the literature body of internationalisation. Although, Georgiuo (2014) has investigated the decision-making process of market entry deeply and holistic in a single case study, there are still some open questions and there is still a lack of consensus in the reported evidence. For instance, Georgiou (2014) is recommending that his multi-level model (Figure 13) should be the basis for future research directions to bring improved consistency to empirical evidence, or the question of how the choice of entry mode affect the performance of an exporting company is also not finally answered (Oh, Arnett \& An, 2016; Liu, 2017; Baker et al., 2020). As the entry mode option is the starting point if a mode switching process is launched (see chapter 2.6) the market entry decision process explains how the starting point of a possible 
mode switching process developed from the beginning of the international activity. It is therefore essential for this research to review the literature regarding the market entry process because it is the underpinning of the decision-making process of mode switching of a firm (Sachse, 2010). Furthermore, the studies regarding the market entry process defind external and internal influencing factors which affect the market entry decision process (Georgiou, 2014; Oh, Arnett \& An, 2016; Liu, 2017). As the market entry decision process is the underpinning for a possible later decision-making process of mode switching, it is evident that the same influencing factors as in the market entry process can be included in the conceptual framework for the decision-making process of mode switching and need to be investigated (Sachse, 2010; Hollensen, 2017).

As an outcome of the literature review process, there were thirty four papers with the key topics mode switching or management decision-making process. Only three of them are specifically focused on multinational companies, respectively collecting data from multinational companies while the remaining papers are either focused on small- and medium-sized companies or the company characteristic was not defined for the study. As illustrated in Figure 25 , there is a gap in the literature regarding mode switching and management decision-making research with focus on multinational companies. This is also supported by Rezende (2006),Asmussen et al. (2009) and Belderbos et al. (2020). 


\section{PAPERS WITH FOCUS ON MULTINATIONAL COMPANY}

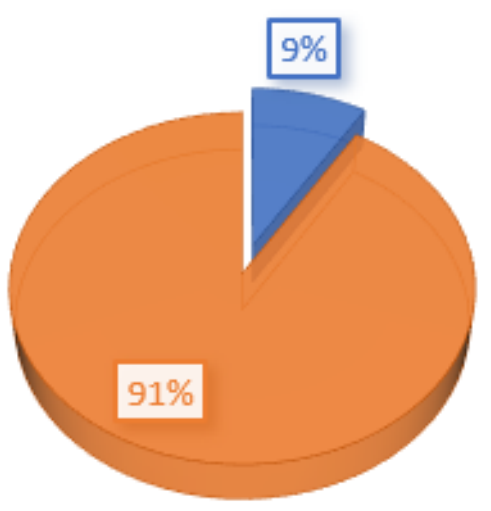

Figure 24: Papers with Focus on multinational companies

According to Rezende (2006), multinational companies can be conceputalised as loosely coupled system and within this system there are several internationalisation processes that co-evolve simultaneously (at the same time) in different and overlapping networks. From this network perpective, the processes are simultaneously independent and interdependent and they can intersect and exert influences (interdependencies) on each other across spatial and temporal contexts (Rezende, 2006; Belderbos et al., 2020). It is evident, that this special characteristic of a multinational company requires the following two meta-contingencies that have been overlooked in most of the other studies (Asmussen et al., 2009):

- Interdependencies between internationalisation processes and especially between decision-making process of multiple mode switches that are running in parallel and at the same time (simultaneous)

- The managerial capacity of the multinational company and its management to take these interdependencies into account 
This may prevail due to the limited exploration of this phenomena in the past years (Rezende, 2006; Asmussen et al., 2009; Hollensen, 2017). A gap is therefore evident in academic literature that this thesis contributes to explore. This is essential for firms as interdependencies between simultaneous international activities are a component of the decision-making process of mode switching (Rezende, 2006; Asmussen et al., 2009; Hollensen, 2017) and therefore this thesis is selecting one multinational case company to focus on the interdependencies between simultaneous mode switching process within a multinational company (see methodology chapter 3 ).

The thirty four papers regarding mode switching and management decisionmaking, which were the result of the literature review, are either based on a literature review or are collecting data from several companies and from one international activity of each company through a quantitative survey. Analysing the research methods that have been used in the selected papers about mode switching and management decision-making processes provides the overview in Table 17.

\begin{tabular}{|l|c|c|c|c|c|}
\hline Key Topic & \multicolumn{1}{|c}{$\begin{array}{c}\text { Amount of } \\
\text { Papers }\end{array}$} & $\begin{array}{l}\text { Literature } \\
\text { Review }\end{array}$ & \multicolumn{1}{c}{$\begin{array}{l}\text { Mixed } \\
\text { Methods }\end{array}$} & $\begin{array}{c}\text { Qualitative } \\
\text { Quantitativ }\end{array}$ \\
\hline $\begin{array}{l}\text { Management } \\
\text { Decision- } \\
\text { Making }\end{array}$ & 18 & 10 & 2 & 2 & 4 \\
\hline Mode Switching & 16 & 4 & 2 & 2 & 8 \\
\hline Sum & 34 & 14 & 4 & 4 & 12 \\
\hline
\end{tabular}

Table 16: Overview of the Research Methods per Key Topic

This overview shows that only four of the analysed papers are based on a qualitative research method while twenty six of the papers are either based on a literature review or on quantitative research methods. Due to this dominance of the quantitative research methods, especially regarding the mode switching papers (50\% of the papers are based on quantitative research methods) the findings and interpretations of these studies and the literature body are limited 
to statistical validation, analytical rationality, context-independent knowledge and rules (Rezende, 2006; Asmussen et al., 2009). Additionally, the studies about management decision-making processes are dominated from rational decision-making processes, rules and parameters (Rezende, 2006; Asmussen et al., 2009) and the intuitive and integrated decision-making models are typically not considered although intuitive components exists in the management decision-making concepts according to Albaum and Duerr (2008). This is the last and major critic of this literature review as attitudes of executives often drive internationalisation decisions and not only economic factors (Calof \& Beamish, 1995; Albaum and Duerr, 2008; Luoma \& Martela, 2020). Therefore, this thesis intends to do an in-depth single case study of one multinational company by using qualitative data collection methods to build a model of management decision-making during a process of mode switching which considers interdependencies of simultaneous internationalisation processes within a multinational company and the intuitive components of the management decision-making process of mode switching (Calof \& Beamish,1995; Rezenden, 2006; Albaum \& Duerr, 2008; Asmussen et al., 2009; Hollensen, 2017; Luoma \& Martela, 2020).

Last but not least I want to point out as a summary of this section the overview of the gaps in the literature as shown in Table 18 and that there are models in the literature which describes the decision-making process of mode switching, e.g. the developed model of Sachse (2010) and the underpinning theoretcial framework in Figure 14 (page 81). But these models are typically built on data from non-multinational companies and mainly the data is collected via quantitative surveys (Rezende, 2006; Asmussen et al., 2009; Belderbos et al., 2020). Therefore the existing models of the mode switching process are describing and explaining the decision-making process of mode switching process predominantly within non-multinational companies and for one international activity of the respective firms because the data in the surveys are collected in regards to one international activity of the firms (Rezende, 
2006; Asmussen et al., 2009; Sachse, 2010). According to Rezende (2006) a multinational firm can be conceptualized as a loosely coupled system with several internationalisation processes linked in a global network. These processes can exert influences (interdependencies) regarding the supply chain process (e.g. supply the countries from a regional hub), the brand awareness (competition between subsidiaries in the same markets), costs (e.g. product registration costs for specific regions), political factors (e.g. global sanctions if a subsidiary offend an embargo), internal competition regarding resources (e.g. which project receives the human resources), geographical factors (e.g. exchange risks) and cultural factors (e.g. historical conflicts of several cultures) (Albaum, 2005; Rezende, 2006; Guenzi, 2011; Belderbos et al., 2020). This loosely coupled system of a multinational company with its interdependencies within simultaneous (happening at the same time) decisionmaking processes of mode switching, cannot be described with the existing models of the literature (Rezende, 2006; Asmussen et al., 2009). Ignoring the interdependencies of this network can implicate increasing complexity, costs, not using synergistic effects to increase the efficiency and finally that a mode switch needs to be reversed due to a lack of success which causes the inefficient use of resources (Rezende, 2006; Asmussen et al., 2009). It is therefore essential to explore the phenomenon of mode switching in the context of an in-depth analysis of a multinational company to develop a model of management decision-making during a process of mode switching which considers interdependencies of simultaneous internationalisation processes within a multinational company (Rezende, 2006; Guenzi, 2011; Belderbos et al., 2020). 


\begin{tabular}{|c|c|c|c|c|}
\hline Literature Gap & $\begin{array}{l}\text { Achieve } \\
\text { Through }\end{array}$ & Objectives & Summary of the Gap & Support References \\
\hline $\begin{array}{l}\text { Identify research gaps to position } \\
\text { the research problem }\end{array}$ & Chapter 2 & 1 & Table 18 & See lines below \\
\hline $\begin{array}{l}\text { A Decision-Making process of mode } \\
\text { switching for multinational } \\
\text { companies }\end{array}$ & Case Selection & 2 & $\begin{array}{l}\text { Most of the papers pay little attention to multinational companies } \\
\text { but rather on medium-sized, small companies, born-global } \\
\text { companies or the company characteristic is not defined }\end{array}$ & $\begin{array}{cc}\text { - } & \text { Albaum, } 2005 \\
\text { - } & \text { Rezende, } 2006 \\
\text { - } & \text { Asmussen et al. } \\
2009 \\
\text { - } & \text { Guenzi, } 2011 \\
\text { - } & \text { Belderbos et al., } \\
20\end{array}$ \\
\hline $\begin{array}{l}\text { The influence of interdependencies } \\
\text { between simultaneous international } \\
\text { activities on the decision-making } \\
\text { process of mode switching }\end{array}$ & $\begin{array}{l}\text { Case Selection } \\
\text { and Data } \\
\text { Collection } \\
\text { Methods }\end{array}$ & 3 & $\begin{array}{l}\text { The previous studies are mainly focused on several companies } \\
\text { and only on one international activity per country. Consequently, } \\
\text { these studies do not consider that there are simultaneous } \\
\text { internationalisation processes within a multinational company }\end{array}$ & $\begin{array}{cc}\text { - } & \text { Albaum, } 2005 \\
\text { - } & \text { Rezende, } 2006 \\
\text { - } & \text { Asmussen et al., } \\
2009 \\
\text { - } & \text { Sachse, } 2010 \\
\text { - } & \text { Guenzi, } 2011\end{array}$ \\
\hline
\end{tabular}




\begin{tabular}{|c|c|c|c|c|}
\hline & & & & $\begin{array}{c}-\quad \text { Belderbos et al., } \\
20\end{array}$ \\
\hline $\begin{array}{l}\text { The influence of manager's } \\
\text { behaviour and external environment } \\
\text { on the decision-making process of } \\
\text { mode switching in a multinational } \\
\text { company }\end{array}$ & $\begin{array}{l}\text { Philosophical } \\
\text { Position and } \\
\text { Data } \\
\text { Collection } \\
\text { Methods }\end{array}$ & 2,4 & $\begin{array}{l}\text { Most of the studies are based on quantitative philiosophical } \\
\text { positions or literature reviews which restrict the findings and } \\
\text { interpretations to statistical validation, analytical rationality, } \\
\text { context-independent knowledge and rules }\end{array}$ & $\begin{array}{cc}\text { - } & \text { Calof and } \\
& \text { Beamish, } 1995 \\
\text { - } & \text { Rezende, } 2006 \\
\text { - } \quad \text { Albaum and Duerr } \\
\text { (2008) } \\
\text { - } \quad \text { Asmussen et al. } \\
2009 \\
\text { - } \quad \text { Luoma \& Martela, } \\
2020\end{array}$ \\
\hline $\begin{array}{l}\text { Building a model of management } \\
\text { decision-making during a process of } \\
\text { mode switching which considers } \\
\text { interdependencies of simultaneous } \\
\text { internationalisation processes within } \\
\text { a multinational company }\end{array}$ & $\begin{array}{l}\text { Research } \\
\text { Strategy, } \\
\text { Methodological } \\
\text { Approach and } \\
\text { Methods }\end{array}$ & 4 & $\begin{array}{l}\text { The literature about decision-making processes has payed more } \\
\text { attention to intuitive decisions and integrated models but most of } \\
\text { the decision-making studies related to mode switching or } \\
\text { internationalisation are domiated by rational decision-making } \\
\text { processes, rules and parameters }\end{array}$ & $\begin{array}{cc}\text { - } & \text { Calof and } \\
& \text { Beamish, } 1995 \\
\text { - } & \text { Rezende, } 2006 \\
\text { - } & \text { Albaum and Duerr } \\
(2008) \\
\text { - } \quad \text { Asmussen et al. } \\
2009 \\
\text { - } \quad \text { Belderbos et al., } \\
20\end{array}$ \\
\hline
\end{tabular}

Table 17: Overview of the Gaps within the Literature 


\subsection{Conceptual Framework}

The main constructs, parameters, variables, factors and assumptions are graphically provided in a conceptual framework. According to Miles and Huberman (1994) the conceptual framework can be elaborative or elementary and helps to study the constructs, parameters, etc. and their relationship. Maxwell (2012) defined the conceptual framework as the key model of a study that illustrates the parameters and processes that influence the study. Typically, the literature review underpins the conceptual framework which is used as a guidance from the researcher to design the study. Developing a conceptual framework is a process as the conceptual framework is changing several times during a study as more information and insights become known (Maxwell, 2012). Based on the literature review and the theoretical framwork in Figure 14 (page 81) the first level of the conceptual framework was developed and is shown in Figure 26.

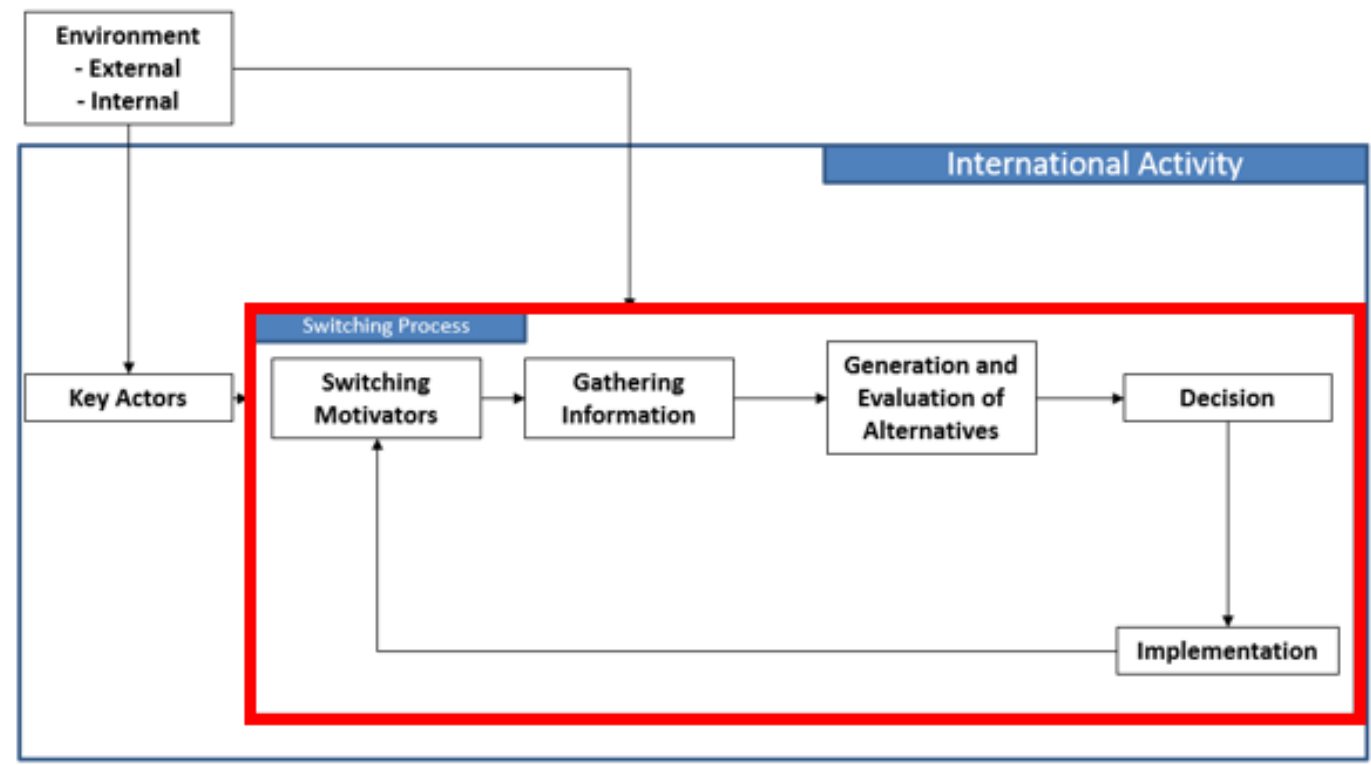

Figure 25: Conceptual Framework Level 1

(The colours and shapes in the figure are only provided to make them more readable and do not have a specific meaning) 
Table 19 (page 129) gives an overview which components of the literature discussion have been integrated in the conceptual framework and which theoretical background underpins the single components of the conceptual framework. The process structure, flow and the single process steps are underpinned by the multi-level decision-making model from Albaum and Duerr (2008) (chapter 2.5), the decision-making process model of mode switching from Sachse (2010) and the theoretical framework of the decision-making process of mode switching process in Figure 14 (chapter 2.6). The boundary of each decision-making process of mode switching is the international activity in which the possible mode switch is done. These boundaries are supported by Sachse (2010) and the theories about decision-making processes of mode switching. As argued by Albaum and Duer (2008), Sachse (2010), Hollensen (2017) and Luoma and Martela (2020), the key actors (managers) are the driving force of each decision-making process and they are the starting point of the decision-making process of mode switching (see chapter 2.5 and 2.6). Furthermore, the international entrepreneurship theory (chapter 2.7.2.3) supports that the key actors of the decision-making process of mode switching are an important element of the process. Therefore, the conceptual framework (Figure 26) includes the key actors as important component of the decisionmaking process of mode switching. The key actors are internal employees of a multinational company who are involved in the decision-making process of mode switching such as Area Sales Managers, Export Director, Sales Administrator, Chairman of the Management board, Management board, Regional Sales Manager (Georgiou, 2014; Hollensen, 2017). According to the Eclectic Theory (chapter 2.7.1.3), the competition-oriented approach (chapter 2.7.1.4), the process based approach (chapter 2.7.2.1), the configuration model (chapter 2.7.2.5), the three-level model of Swoboda (chapter 2.7.2.6) and the path dependency approach (chapter 2.7.2.7) there are influencing factors from the external and internal environment of the decision-making process of mode switching which impact the process and the decision outcome. Therefore, the internal and external environment is included into the 
conceptual framework to investigate the influencing factors in this context. The external environment can include external actors, like competitors, suppliers or customers, external factors, such as political changes (Dunning, 2000; Steinkamp, 2020). The internal environment can include internal actors and factors, like company structure around the project or employees from other departments or other projects (Dunning, 2000; Steinkamp, 2020).

As supported by Sachse (2010) and Albaum and Duerr (2008) decisionmaking process of mode switching that is influenced by the key actors as well as the environment of the international activity, is the centre of the conceptual framework (highlighted with the red box in Figure 26). As argued in the agency theory (in chapter 2.7.1.2) and in the model of Sachse (2010), the first step of the decision-making process of mode switching are the switching motivators of a firm. According to the theoretical framework (see Figure 14 in chapter 2.6), the switching motivators can be caused by the environment of an international activity, the attitudes of managers or by the performance of a current mode (Swoboda et al., 2011). Therefore, the conceptual framework in Figure 26 defines the first process step of the decision-making process as switching motivators.

As supported by Sachse (2010) and Albaum and Duerr (2008) the second process step of the decision-making process of mode switching is gathering information according to their model (see chapter 2.5 and 2.6). Within this process step, the key actors are gathering information about the current mode from the external and internal environment and from their own experiences and knowledge (Albaum and Duerr, 2008; Sachse, 2010).

Based on the investigated data, the key actors generate and evaluate mode alternatives and therefore the next process step in the conceptual framework is defined as evaluation process (Ahlstrom \& Bruton, 2010; Luoma \& Martela, 2020). This evaluation process step is supported by the transaction cost theory (2.7.1.1), by Sachse (2010) (chapter 2.6) and by Albaum and Duerr (2008) 
(chapter 2.5). Within the evaluation process, the key actors consider switching deterrents, such as transaction costs, economic potential, the ability of the management to handle a respective mode, the risk management and the behaviour of the management (Albaum \& Duerr, 2008; Sachse, 2010; Hollensen, 2017).

As defined in the model of Sachse (2010) (see chapter 2.6) and the model of Albaum and Duerr (2008) (see chapter 2.5) the last process step in the conceptual framework is the decision about the mode switch and the implementation of the decision. The key actors have the options to continue with the current mode, to change to an alternative mode with higher control (e.g. from direct exporting to own sales force), to change to an alternative mode with less control or to leave the market (e.g. from an own sales fore to exporting via an intermediate) and to launch a mixed method approach (e.g. exporting through an intermediary and in parallel launching an own sales force to approah new customers) (Nan, 2013). After the implementation phase of the selected mode, the mode switching process is closed with going back to the switching motivators as each mode decision is not unchangeable and after a certain time the key actors can restart the mode switching process in a respective international activity (Sachse, 2010; Georgiou, 2014).

As described in chapter 2.8, one of the major gaps in the literature body is that previous studies have not focused on multinational companies and consequently have not considered that there are multiple decision-making process of mode switching which are happening simultaneously within a multinational company (Rezende, 2006; Asmussen et al., 2009; Holensen, 2017; Belderbos et al., 2020). Therefore, the existing literature does not explain the complexity of interdependencies between simultaneously independent and interdependent decision-making processes of mode switching within a multinational company (Rezende, 2006). The conceptual framework level 1, outlined in Figure 26, cannot describe these multiple mode switching processes within a multinational company since it focuses on the 
decision-making process of mode switching for one specific international activity within a company. To close this gap and contribute knowledge to the literature body, the conceptual framework of level one is extended to the network of a multinational company and the interdependencies between multiple mode switching processes that are happening simultaneously. The result and finalized conceptual framework is illustrated in Figure 27 . The novelties of this finalized conceptual framework in comparison to the literature are highlighted with red boxes to demonstrate the contribution to knowledge that this research thesis intends to achieve. The first novelty is the structure of a multinational company and its influence on the mode switching process and the second novelty is the interdependencies that are existing between multiple mode switching process within multinational companies. The fact that these interdependencies are existing and are an important component of the decision-making process of mode switching within multinational companies is supported by Rezende (2006), Asmussen et al. (2009), Hollensen (2017) and Belderbos et al. (2020). As shown in Table 19 the finalized conceptual framework is underpinned by the discussed theories and concepts (see chapter 2.5, 2.6 and 2.7) that are existing in the literature. 


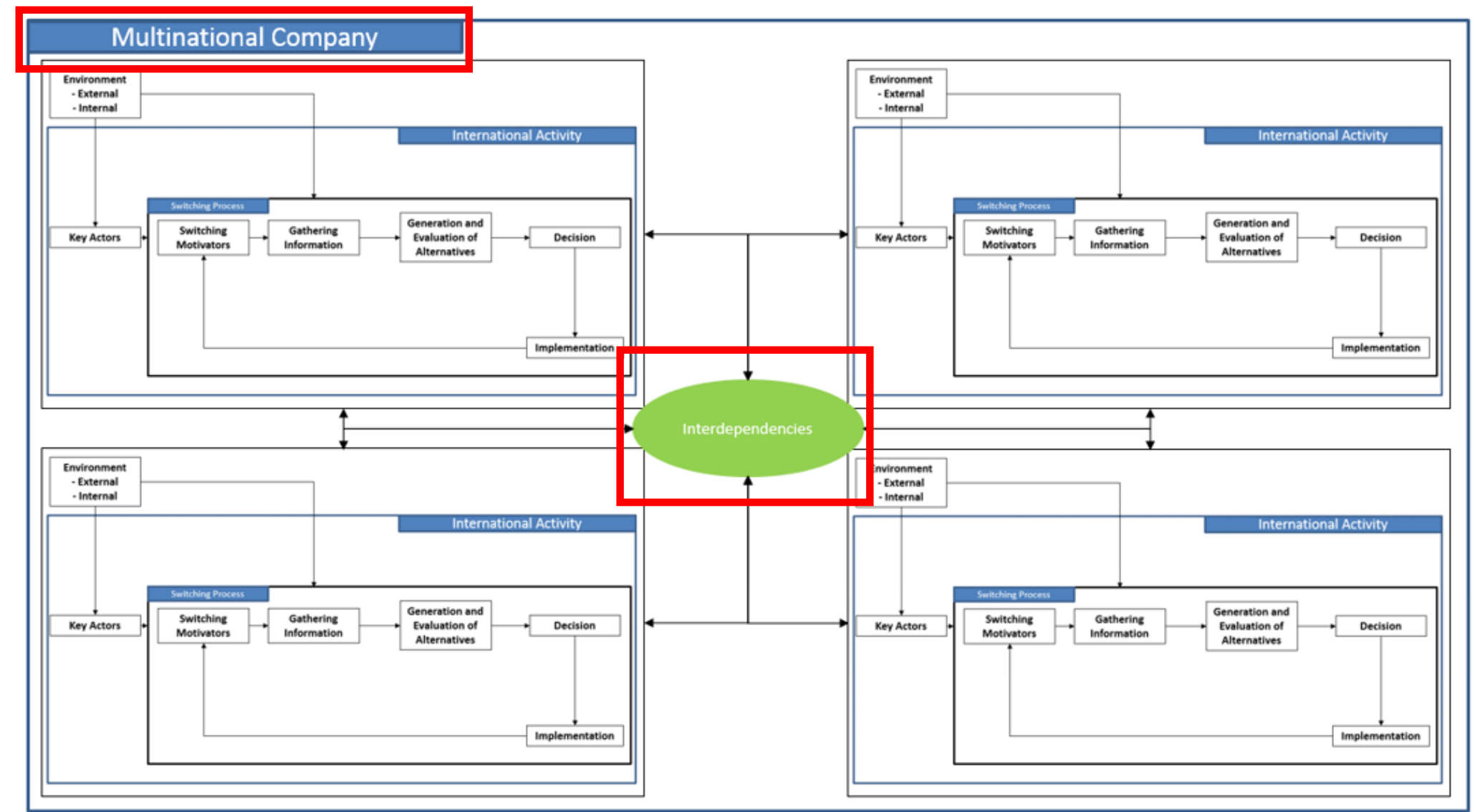

Figure 26: Finalized Conceptual Framework (The colours and shapes in the figure are only provided to make them more readable and do not have a specific meaning) 


\begin{tabular}{|c|c|c|c|}
\hline Theory/Concept of the literature & Discussed in chapter & $\begin{array}{l}\text { Included in the components of } \\
\text { the conceptual framework }\end{array}$ & Support References \\
\hline Management Decision Making & 2.5 & $\begin{array}{l}\text { The whole process structure } \\
\text { of the conceptual framework } \\
\text { is underpinned of the multi- } \\
\text { level model of decision- } \\
\text { making } \\
\text { - } \\
\text { special focus on the key } \\
\text { actors and the environment }\end{array}$ & $\begin{array}{ll}\text { - } & \text { Albaum and Duerr, } 2008 \\
\text { - } & \text { Luoma \& Martela, } 2020 \\
\text { - } & \text { Parnall \& Crandall, } 2017\end{array}$ \\
\hline Mode Switching & 2.6 & $\begin{array}{l}\text { - The mode switching process } \\
\text { and inner loop of the } \\
\text { conceptual framework is } \\
\text { underpinned of the theoretical } \\
\text { framework, illustrated in } \\
\text { Figure } 11\end{array}$ & $\begin{array}{ll}\text { - } & \text { Sachse, } 2010 \\
\text { - } & \text { Nan, } 2013 \\
\text { - } & \text { Georgiou, } 2014 \\
\text { - } & \text { Fonfara, Ratajczak-Mrozek \& Leszczyński, } 2016 \\
\text { - } & \text { Yan, } 2020\end{array}$ \\
\hline
\end{tabular}




\begin{tabular}{|c|c|c|c|}
\hline Transaction Cost Approach & 2.7.1.1 & $\begin{array}{l}\text { - Generation and evaluation of } \\
\text { alternatives }\end{array}$ & $\begin{array}{ll}\text { - } & \text { Swoboda, } 2002 \\
\text { - } & \text { Kutschker \& Schmid, } 2006 \\
\text { - } & \text { Sachse, } 2010 \\
\text { - } & \text { Calveras \& Orfila-Sintes, } 2019\end{array}$ \\
\hline Agency Theory & 2.7.1.2 & - $\quad$ Switching Motivators & $\begin{array}{ll}\text { - } & \text { Welch et al., } 2007 \\
\text { - } & \text { Metsola et al. } 2020\end{array}$ \\
\hline Eclectic Theory & 2.7.1.3 & $\begin{array}{ll}\text { - } & \text { Key actors } \\
\text { - } & \text { Switching Motivators } \\
\text { - } & \text { External and Internal } \\
& \text { Environment }\end{array}$ & $\begin{array}{ll}\text { - } & \text { Dunning, } 2000 \\
\text { - } & \text { Sachse, } 2010 \\
\text { - } & \text { Yaw \& Keon, } 2020\end{array}$ \\
\hline Competition-oriented Approach & 2.7.1.4 & - Internal Environment & $\begin{array}{ll}\text { - } & \text { Harzing and Van Ruysseveldt, } 2004 \\
\text { - } & \text { Hollensen, } 2007 \\
\text { - } & \text { Han, } 2019\end{array}$ \\
\hline Real Option Theory & 2.7.1.5 & $\begin{array}{ll}\text { - } & \text { Decision } \\
\text { - } & \text { Implementation }\end{array}$ & $\begin{array}{ll}\text { - } & \text { Copeland and Tufano, } 2004 \\
\text { - } & \text { Fisch, } 2004 \\
\text { - } & \text { Marcharzina and Wolf, } 2005 \\
\text { - } & \text { Wadeson, } 2020\end{array}$ \\
\hline
\end{tabular}




\begin{tabular}{|c|c|c|c|}
\hline Process based Approach & 2.7.2.1 & $\begin{array}{ll}\text { - } & \text { Internal Environment } \\
\text { - } & \text { Inderdependencies }\end{array}$ & $\begin{array}{ll}\text { - } & \text { Johanson and Wiedersheim-Paul, } 1975 \\
\text { - } & \text { Vahlne, } 1990 \\
\text { - } & \text { Sachse, } 2010 \\
\text { - } & \text { Steinkamp, } 2020\end{array}$ \\
\hline $\begin{array}{l}\text { International Entrepreneurship } \\
\text { Research }\end{array}$ & 2.7.2.3 & - Key Actors & $\begin{array}{ll}\text { - } & \text { Albaum and Duerr, } 2008 \\
\text { - } & \text { Engelen et al., } 2009 \\
\text { - } & \text { Ripollés \& Blesa, } 2020\end{array}$ \\
\hline The Configuration Approach & 2.7.2.4 & $\begin{array}{ll}\text { - } & \text { Internal Environment } \\
\text { - } & \text { Inderdependencies }\end{array}$ & $\begin{array}{ll}\text { - } & \text { Swoboda, } 2002 \\
\text { - } & \text { Zentes, Swoboda and Morschett, } 2004 \\
\text { - } & \text { Sachse, } 2010 \\
\text { - } & \text { Keller-Bacher \& Zerfass, } 2019\end{array}$ \\
\hline The Three-Level Model & 2.7.2.5 & $\begin{array}{ll}\text { - } & \text { Switching Motivators } \\
\text { - } & \text { Internal and External } \\
& \text { Environment }\end{array}$ & $\begin{array}{ll}\text { - } & \text { Copeland and Tufano, } 2004 \\
\text { - } & \text { Fisch, } 2004 \\
\text { - } & \text { Marcharzina \& Wolf, } 2005 \\
\text { - } & \text { Schmid \& Morschett, } 2020\end{array}$ \\
\hline Path Dependency & 2.7.2.7 & $\begin{array}{ll}\text { - } & \text { Internal Environment } \\
\text { - } & \text { Interdependencies }\end{array}$ & $\begin{array}{ll}\text { - } & \text { Araujo and Rezende, } 2003 \\
\text { - } & \text { Eriksson, Majkgard and Sharma, } 2000 \\
\text { - } & \text { Sune, } 2018\end{array}$ \\
\hline
\end{tabular}




\begin{tabular}{|c|c|c|c|}
\hline & & & - Hutzschenreuter, Pedersen and Volberda, 2007 \\
\hline Critical Evaluation & 2.8 & $\begin{array}{ll}\text { - } & \text { Interdependencies } \\
\text { - } & \text { Key Actors } \\
\text { - } & \text { External and Internal } \\
& \text { Environment }\end{array}$ & $\begin{array}{ll}\text { - } & \text { Albaum, } 2005 \\
\text { - } & \text { Rezende, } 2006 \\
\text { - } & \text { Asmussen et al., } 2009 \\
\text { - } & \text { Sachse, } 2010 \\
\text { - } & \text { Guenzi, } 2011 \\
\text { - } & \text { Belderbos et al., } 2020\end{array}$ \\
\hline
\end{tabular}

Table 18: Components of the literature discussion in the conceptual framework 


\subsection{Chapter Summary}

The aim of this chapter is to identify the main theoretical developments and the literature body of internationalisation, market entry, mode switching and management decision-making, the themes which were identified through an inductive thematic analysis. To select the most credible studies of the literature and to use the inductive thematic analysis to analyse the selected studies a systematic literature review was conducted. The literature review revealed high and considerable interest in this research area, providing 6.433 studies which were found in the electronic search of selected databases and search engines. By using inclusion and exclusion criteria, the numerous numbers of studies were reduced to a more manageable number of 143 studies. These studies were published in 72 different journals and conference proceedings from different disciplines such as marketing, management, process management and economics which shows the fragmented nature of this research area.

Applying an inductive qualitative thematic analysis, the study synthesised the main findings, theories and constructs around internationalisation theories, mode switching, market entry and management decision-making. Valuable insights into the field of internationalisation were identified and it was illustrated that most of the previous studies were focused on the internationalisation theories and market entry while mode switching, and management decisionmaking have received less attention. Despite the significance, importance and considerable advancements of mode switching and management decisionmaking, the literature review and its inductive thematic analysis has highlighted some weaknesses and gaps in the current literature body. There are models in the literature which describes a model of the decision-making process of mode switching, e.g. the developed model of Sachse (2010) and the theoretical framework in Figure 14 (page 81). However these models are mainly underpinned with data that are collected via quantitative surveys and in non-multinational companies with a focus on one international activity per 
investigated company (Rezende, 2006; Asmussen et al., 2009; Sachse, 2010). According to Rezende (2006) a multinational firm can be conceptualized as a loosely coupled system with several internationalisation processes linked in a global network as these internationalisation processes are happening simultaneously (at the same time). These simultaneous processes can exert influences (interdependencies) e.g. regarding the supply chain process (Albaum, 2005; Rezende, 2006; Guenzi, 2011). The global network of a multinational company with its interdependencies between simultaneous decision-making processes of mode switching cannot be described with the existing models of the literature because these models were not focused on multinational companies with their global network (Rezende, 2006; Asmussen et al., 2009; Hollensen, 2017). Ignoring the interdependencies of this network can implicate increasing complexity and finally that a mode switch needs to be reversed due to a lack of success which causes wasting resources (Rezende, 2006; Asmussen et al., 2009). It is therefore essential to explore the phenomenon of the decision-making process of mode switching in the context of a multinational company and to develop a model of the decision-making process of mode switching in the context of a multinational company that bridges the outlined gaps of the current literature body in Table 18 (chapter 2.8). Accordingly, a conceptual framework was developed and presented in chapter 2.9. 


\section{Methodology}

\subsection{Introductory Comments}

This chapter presents the research strategy, methodological approach and methods of this research project by using the key elements and determinants of Saunders et al. (2015) research onion. By exploring and discussing the key dimensions of the research onion, I identified the most appropriate research strategy, methodological approach and methods to answer the research questions and to achieve the objectives and overall research aim.

\subsection{Research Design and Core Considerations}

The respective methods used for the primary research and final interview phase are described in the following sections that achieve the research, aim, objectives and questions of this thesis:

\section{Research Questions:}

What is the process of management decision-making for mode switching in a multinational company's international activity?

What are the interdependencies at play when mode switching occurs simultaneously?

How are the interdependencies of simultaneous internationalisation processes managed within the decision-making process of mode switching?

\section{Objectives:}

Objective 1: To conduct a review of literature to position the research within the current internationalisation and management literature and identify key gaps where a meaningful contribution could be made.

Objective 2: To explore the process of management decision-making of mode switching within a multinational company's internationalisation strategy. 
Objective 3: To determine the interdependencies and their role between simultaneous mode switching processes.

Objective 4: To build a model of management decision-making during a process of mode switching which considers interdependencies of simultaneous internationalisation processes within a multinational company.

\subsection{Research Philosophy}

Research projects are based on assumptions about how the world is perceived and understood. For thousands of years, researchers and philosophers have been arguing about the world and the reality and yet, there is no final answer about how to understand the world (Sousa, 2010). Therefore, as a researcher I must decide how to perceive and acknowledge the world and reality around me and which philosophical approach supports me in contributing knowledge (Saunders et al., 2015). Each research programme tries to change the world or at least to contribute knowledge to an existing phenomenon through improved understanding (Sousa, 2010). According to Sousa (2010) producing scientific knowledge is related to the nature (natural world) and society (social world) with the purpose to get a closer understanding of any phenomenon through knowledge-claims. The purpose of this thesis is to contribute knowledge within the social sciences field and more specifically within the management decision-making, internationalisation- and mode switchingtheory literature to enhance the understanding of a multinational firm's management decision-making process during their transition between international entry strategies and the reason why these mode switching activities occur. By developing a model of the decision-making process of mode switching, this research is contributing theoretical knowledge and bridging the current gaps of the literature which have been outlined in chapter 2.8. Additionally, the developed model is contributing practical knowledge by providing managers a tool for handling the decision-making process of mode switching because the model defines how this process is established within 
multinational companies and which influencing factors need to be considered to finally make the right decision in regard to a possible mode switch. As one of the main gaps in the literature (see chapter 2.8) is the definition and explanation of interdependencies that are existing between simultaneous decision-making process of mode switching (happening at the same time) within multinational companies, this research investigates and especially focuses on these interdependencies (Rezende, 2006, Asmussen et al., 2009).

The philosophy is the foundation of each research process and the underpinned logic of a research project (Sousa, 2010). According to Saunders et al. (2015) the four most common philosophical positions in business and management research are positivism, interpretivism, realism and pragmatism (see appendix 1).

As illustrated in Table 16 (chapter 2.8) beside the fourteen papers which are based on a literature review and the four papers based on qualitative research methods, the remaining papers are based on quantitative and mixed research methods. Evidently, most of the previous studies which are focused on internationalisation and management-decision-making theory are underpinned by the logic of positivism, realism and pragmatism (Asmussen et al., 2009). This is suggested by Rezende (2006) that the quantitative and positivistic philosophical position is the predominant foundation of this research area (Rezende, 2006). In chapter 2.8 and more specifically in Table 18 (chapter 2.8) the critical evaluation of the current literature body is summarized and the weaknesses of the methodologies of the previous studies is shown. With developing a conceptual framework in chapter 2.9, this research introduces new perspectives in the internationalisation theories and seeks to investigate new perspectives like interdependencies between simultaneous international activities in a multinational company as recommended by Rezende (2006) and Asmussen et al. (2009). 
My underpinned beliefs are that the reality is constructed as contextually and subjective bound and not "given" as defined by the positivistic tradition. The aim of my thesis is to discover the probable truth of new perspectives in the context of a real business phenomenon in the reality and how this phenomenon is subjectively and contextually existing in the reality of the experts (Husserl, 1982; Wilding \& Whiteford, 2005; Ryan, 2006; Ormston, Spencer, Barnard, \& Snape, 2014; Lyons, 2015). The contribution to knowledge shall be achieved through focusing on the subjective experiences of people and the interpretations of the world and reality surrounding the studied phenomenon (Sousa, 2010). Therefore, my research proceeds from a phenomenological perspective which underpins the objectives of my research. This shall help me discover new perspectives such as interdependencies between simultaneous decision-making processes of mode switching in a multinational company because the phenomenon is investigated in the reality of the experts and because the research develops a model based on the subjective and contextual experiences of those experts. The phenomenological approach assists me by investigating the entirety of the real-life phenomenon and by understanding what is occurring in the contextually, socially and subjective constructed world of the decision-making process of mode switching. Since I intend to interact with the selected experts and intend to learn from their real life subjective experiences by interpreting, understanding and describing the decision-making process of mode switching within a multinational company in the context of the real business environment, the phenomenological approach is the most appropriate one to answer the "what" and "how" research questions outlined in chapter 1.3 (Wilding \& Whiteford, 2005; Saunders et al., 2015; Silverman, 2015; Creswell, 2018).

For a researcher with a phenomenological perspective the interpretation and reflection process is of importance to ensure quality in the research because both the object of the study and the researcher himself are connected and have a mutual influence on each other through all stages of the research 
process (Cassel \& Symon, 2012). Being the observer, I am part of what is observed. According to Cassel and Symon (2012):

"researcher reflexivity involves think about how our thinking came to be, how a pre-existing understanding is constantly revised in the light of new understanding and how this in turn affects our research"

Therefore, I have reflected all along the research my own role within this study to ensure the awareness of how I have affected the research process and its outcome. As suggested by Cassel and Symon (2012), I have focused on the two key elements that are interpretation and reflection to ensure the sufficient reflexivity within my phenomenological research. During my interpretation process I have recognized interpretation not only as simply being an analysis of facts which reflects the 'reality' but also considered that my interpretations and outcomes are influenced by me, my values and knowledge. During my reflection process, I have focused on myself, on my intellectual and cultural conditions or traditions, each influencing my research project (Cassel and Symon, 2012). Consequently, my reflection process has become some sort of interpretation of my interpretation itself, and only through this approach I ensured the reflexivity of my research. My interpretation process can be seen in section 3.8.1.2 in which I have illustrated the analysing and interpretation process of my collected data. The reflection process and more specifically the way I am informing and influencing the research process is explained in section 3.7.5 in which I emphasize my role in the research process as part of the observed phenomenon.

The literature review of this thesis disclosed the current gaps in the literature body and the limitations of previous studies in this research area (see Table 18, chapter 2.8 ) which are to be closed by answering the research questions. Due to the outlined gaps and limitations of previous studies I define the qualitative data collection methods as being the most appropriate data collection methods to answer the research questions (outlined in chapter 1.3), 
since this research intends to investigate the decision-making process of mode switching by understanding and interpreting the participants experiences in a real-life context (Schutz, 1967; Husserl, 1982; Tuohy et al., 2013).

Based on the conceptual framework, this research evaluates the management decision-making of single mode switching (Objective 2) and explores the influence of the key actor's behaviour and the environment on single mode switches (Objective 2) with the goal to develop the process of management decision-making within a multinational company's internationalisation strategy in a single mode switching process. Finally, the research will use the developed process of management decision-making in a single mode switching process to determine the role of interdependencies between simultaneous decision-making process of mode switching that are existing at the same time (Objective 3 ). The role and integration of each stage of the research process is presented in Figure 29. Adapting the phenomenological beliefs is consistent within research objectives and within the methods which are shown in the following sections (Schutz, 1967; Husserl, 1982; Tuohy et al., 2013). 
Objective 1: Revew Acade mic Literature
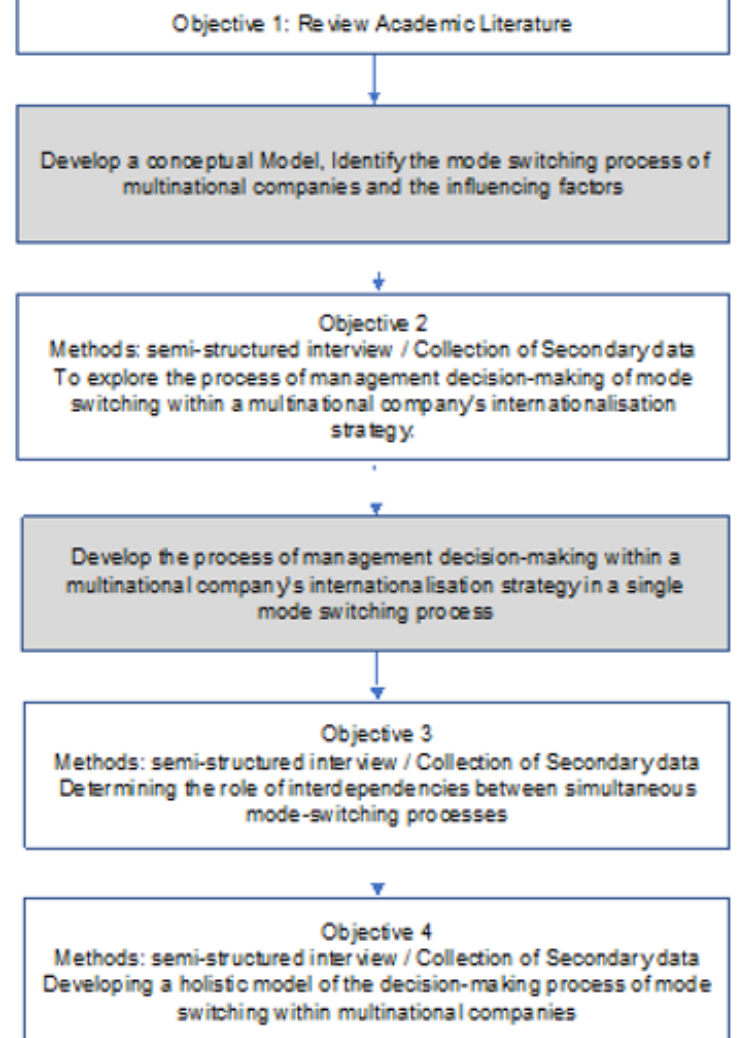

Figure 27: The Research Process 


\subsection{Research Approach}

The selected research approach very much depends on the underpinned philosophical position of a researcher (Sousa, 2010) because many research approaches are connected with specific philosophical positions, e.g. theory testing with deduction and positivism, theory building with induction and interpretivism, explanation of theory with abduction and critical realism or disregarded of theory over practice with pragmatism (Sousa, 2010; Saunders et al., 2015).

As described by Saunders et al. (2015) during the research process the purpose of the research is defined which could be exploratory, explanatory or descriptive. Next to this it is clarified if a (mono, multi or mixed) qualitative (building theories through descriptions and meaning of human experiences, intensive (Easterby-Smith, Golden-Biddle, \& Locke, 2008), quantitative (using a deductive analytical approach to measure predominantly numerical data) or a mixed-method design (combining quantitative as well as qualitative methods) shall be used to achieve the research aim (Saunders et al., 2015).

The conceptual framework is developed and underpinned from the existing literature and the existing theories. The critical evaluation of the existing literature (chapter 2.8) points out that the existing theories do not fit for multinational companies because these theories do not include interdependencies that are existing between simultaneous decision-making processes of mode switching that are occurring at the same time (Rezende, 2006; Asmussen et al., 2009). Consequently, a new theory needs to be generated based on the conceptual framework generated in chapter 2.9 following an inductive research approach (Figure 30) to bridge the current gaps in the literature and to contribute knowledge (Rezende, 2006; Asmussen et al., 2009; Saunders et al., 2015; Dudovskiy, 2018). 


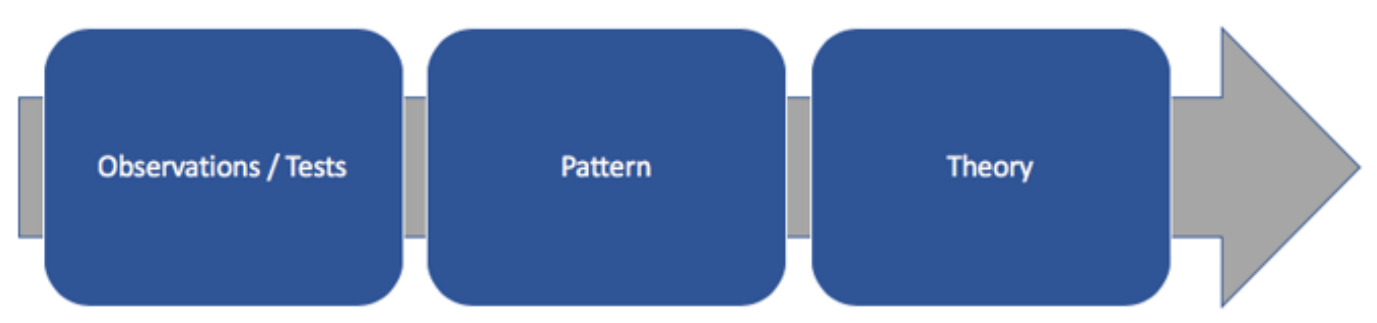

Figure 28: Inductive Research Approach (Dudovskiy, 2018)

I intend to gain an understanding of the meaning managers attach to the phenomenon through a close understanding of the research context (Saunders et al., 2015) as personal behaviours of managers are often influencing factors of the decisions and human beings are the key actors of the investigated phenomenon (Calof \& Beamish, 1995). Following the inductive research approach by developing patterns and a new model based on the qualitative data collection methods which are used to investigate the phenomenon in a real-life context in combination with the phenomenological beliefs builds a credible research design (Schutz, 1967; Husserl, 1982; Tuohy et al., 2013; Saunders et al., 2015).

\subsection{Research Strategy}

According to the literature, (Flyvberg, 2006; Bryman \& Bell, 2011; Saunders et al., 2015) there are several research strategies to conduct a study such as experiments and surveys (mainly used in quantitative research projects), action research, grounded theory, ethnography and case study research. The experiment was not used to conduct this study because this research investigates a phenomenon in a complex and real life context and it would have been difficult to establish the external reflexivity of this real life context in a laboratory environment. The survey was excluded from the possible research strategies because of the quantitative nature of a survey which would not fit to achieve the research aim because the quantiative nature of the previous studies in this research area wes defined as one key gap of the 
existing literature body (see chapter 2.8). An action research was not conducted because this research had not the possibility to actively intervene in the decision-making process of mode switching of the investigated multinational company. The grounded theory was excluded from the possible research strategies because this research is predominantly exploratory rather then descriptive. Ethnography was not conducted because this research was not able to observe the experts while the decision-making process of mode switching occurs but rather learn from the experiences of the experts which they achieved in their business life within the multinational company.

To achieve the research aim of developing a new process model by bridging the current gaps in the literature body and the limitations of previous studies, the research will adopt a multi-method qualitative and a single case study strategy. As supported by other PhD studies (Georgiou, 2014; Jung, 2017), this research adopted the case study approaches of Yin (2015) because the approaches of Yin (2015) are predominantly used for management and business research (Georgiou, 2014; Jung, 2017). Selecting the case study strategy is supported as I am investigating a contemporary phenomenon in a real-life business context (Yin, 2015). Furthermore, the case study strategy is often used if what and how research questions need to be answered and is therefore supported by the research questions of this thesis (Saunders et al., 2015; Yin, 2015). Next to this, I intend to develop my own model of decisionmaking of mode switches which needs an exploratory study and additionally I aim to investigate the interdependencies and relationships between simultaneous processes which is supported by an exploratory study. The exploratory study type is supported by my phenomenological approach as well as by the case study strategy (Wilding \& Whiteford, 2005; Yin, 2015).

To overcome the limitations of previous studies which is explained in the gaps of the literature and chapter 2.8 , I conduct a single case study by focusing on one multinational company because this will allow me to investigate the interdependencies between simultaneous (happening at the same time) 
decision-making process of mode switching and to investigate the developed conceptual framework in a complex real life context (Rezende, 2006; Asmussen et al., 2009). A single case study allows me to learn from the experts who operate based on intimate knowledge within their area of expertise (Flyvbjerg, 2006). Developing the decision-making process model of mode switching in a single case study will build a foundation for application in other organisations and industries (Yin, 2015).

Merriam (2009, p. 40) defined case study research with a simple description:

"an in-depth description and analysis of a bounded system"

The bounded system is defined as a single entity unit with boundaries around and which could be a company, an organisation, a single person, a group of people, an institution, a community or a specific policy.

According to Simons (2009, p. 21$)$ a case study research is defined as:

"an in-depth exploration from multiple perspectives of the complexity and uniqueness of a particular project, policy, institution, programme or system in a real-life context. The primary purpose is to generate in depth understanding of a specific topic, programme, policy, institution or system to generate knowledge and/or inform policy development, professional practice and civil or community action"

There are more definitions of case study research in the literature ( Stake, 1995; Yin, 2015) but although there are several definitions with different emphasis on specific aspects, all of them indicate that case studies are typically investigating complex real-life phenomena within specified boundaries. This fits to the research aim to develop a model of management decision-making of mode switching which considers interdependencies of simultaneous decision-making processes of mode switching because this research develops the model based on the data that is collected in a real-life 
context of a multinational company with qualitative data collection methods (Yin, 2015).

In the literature, authors (Merriam, 2009; Simons, 2009) highlight the key strengths and weaknesses of case study research which are illustrated in Table 20.

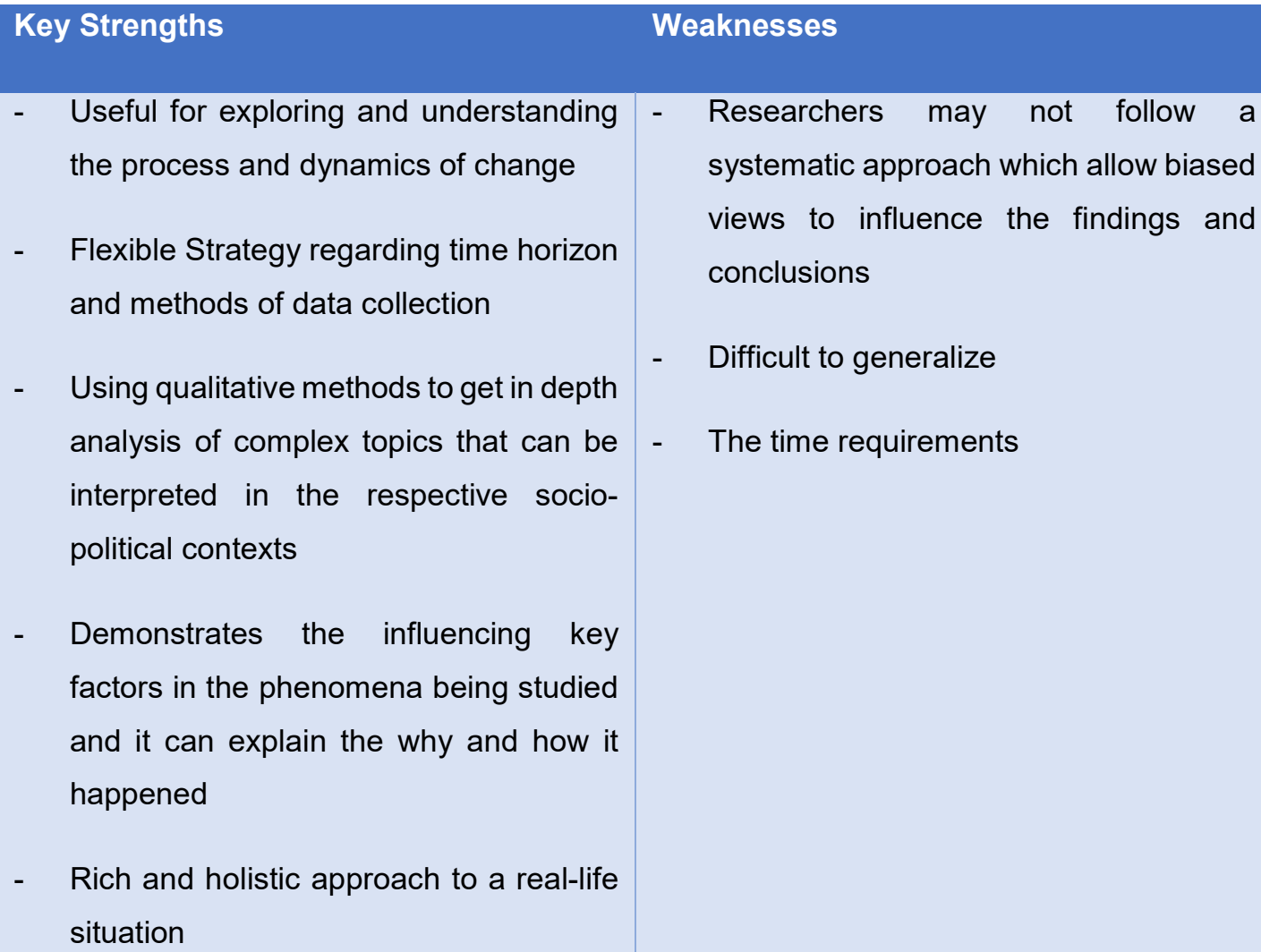

- Rich and holistic approach to a real-life situation

Table 19: Strengths and Weaknesses of Case Study Research (Simons, 2009;

\section{Merriam, 2009)}

Yin (2015) argued that case studies can be generalized to theoretical propositions but not to the universe. According to this, case studies cannot be seen as a representative sample of the entire population but rather an excerpt with the aim to develop, expand or generalise theories which is also suggested by Merriam (2009). This means that this study does not represent a respective sample of the population but rather a specific case from which the information and results are obtained (Merriam, 2009). Therefore, the results and the finally 
developed process model can only explain and contribute knowledge at this level. The extension to any other population or the universe need an additional research (Simons, 2009). As the aim of this research is to understand the multinational firm's management decision-making process of mode switching and the research is not aiming to find a generizable research results which can be extended to the universe, an qualitative in-depth single case study supports building the new model and generating theoretical propositions (Yin, 2015).

\subsection{Time Horizon}

Any research can be conducted within a longitudinal (over time) or crosssectional (snapshot in time) time frame (Cohen, Manion, \& Morrison, 2011; Saunders et al., 2015). Based on that, specific methods are defined and analytical techniques are adopted, suitable to find warranted knowledge and to answer the research questions (Duberley, Johnson, \& Cassell, 2012). This research was conducted in a cross-sectional strategy as only a snapshot in time of the investigated decision-making process of mode switching activities is required because decision-making is defined by the social and environmental conditioning and rational economic factors and are therefore stable over time (Rezende, 2006; Asmussen et al., 2009). Variables and factors that depend on longitudinal results, like implementation challenges or the decision impact on the future performance of the case company are existing, however first the understanding of the process itself and the influencing factors are necessary which is the focus of this study before the longitudinal results of the process can be investigated (Sachse, 2010).

\subsection{Case Study Design}

The research was conducted in Mannheim, Germany as the headquarter of the investigated multinational company is located in this region and all decisions about mode switching are done in the headquarter and to ensure that all participants were interviewed within the same environment (Saunders et al., 2015). The justification of the selected multinational case company is 
given in the following sections of chapter 3.7. Additionally, the location has a 24-hour security service to ensure the safety of the participants and myself (Saunders et al., 2015).

\subsubsection{The Lubricant Industry and the Global Market}

The main purpose of lubricants is the minimization of friction and wear in all kind of applications and specially to separate moving factors. Additionally, lubricants have also, depending on the application, secondary tasks like cooling, sealing, transporting contaminants, cleaning, and protecting the respective surfaces. Generally, lubricants can be divided in the product groups of automotive lubricants (e.g. engine oils), industrial lubricants (e.g. hydraulic fluids), metal working fluids (e.g. for grinding applications), corrosion preventions (e.g. special waxes) and greases (e.g. for bearings). A typical lubricant contains approx. $70-90 \%$ base oils and $10-30 \%$ additives. The main tasks of the additives are to improve the properties of the base oils, decease the disadvantages of the base oils and finally to add properties to the base oils. The main tasks of the base oils are to lubricate, to transport the additives, cooling etc. The most interesting numbers in relation with lubricants is that the studies show that western countries save $0,4 \%$ of their gross domestic product due to the correct application of lubricants (Mang \& Dresel, 2007) which shows the importance of lubricants regarding the cost saving potential within a manufacturing firm.

It is estimated that the global demand for lubricants is approx. 40 billion tons and in Figure 31 this global demand is broken down on the different global regions. 


\section{REGIONAL BREAKDOWN OF THE GLOBAL LUBRICANT MARKET}

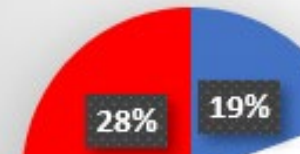

$53 \%$
Europe

Asia-Pacific and rest of the world

- North and South-America

Figure 29: Regional Breakdown of the global lubricant market (Grand View Research, 2020)

With approx. 1.400 lubricant manufacturers the lubricant industry is highly competitive and fragmented (Mang \& Dresel, 2007). Of these 1.400 lubricants manufacturers, 180 are multinational companies according to the definition of this thesis. According do Mang and Dresel (2007) approx. 60\% of the global lubricant demand is supplied by the fourteen biggest lubricant manufacturers which are shown in Table 21.

\begin{tabular}{|c|c|}
\hline $\begin{array}{c}\text { Lubricant Manufacturer } \\
\text { Shell }\end{array}$ & Head Office \\
\hline ExxonMobil & USA \\
\hline BP & UK \\
\hline SINOPEC & China \\
\hline Chevron & USA \\
\hline Lukoil & Russia \\
\hline Fuchs & Germany \\
\hline
\end{tabular}




\begin{tabular}{|c|c|}
\hline Nippon Oils & Japan \\
\hline Valvoline & USA \\
\hline Idemitsu & Japan \\
\hline Conoco Philipps & USA \\
\hline CPC & Taiwan \\
\hline PDVSA & Venezuela \\
\hline REPSOL & Spain \\
\hline Indian Oil & India \\
\hline Agip & Italy \\
\hline
\end{tabular}

Table 20: Largest Multinational Lubricant Manufacturers (Mang \& Dresel, 2007)

The selected lubricant industry seems to be suitable for an in-depth analysis because the products of the industry are mostly commodities which makes the industry comparable to other commodity industries (Seawright \& Gerring, 2008). Next to this, the industry has global demands because you can find applications which need lubricants everywhere in the world (see Figure 31) and therefore, the internationalisation and decision-making process of mode switching is important for this industry (Seawright \& Gerring, 2008).

\subsubsection{Case Selection}

Case selection is the primordial task of case study research, because the respective case has the role to represent a population of cases which are typically larger than the selected case (Seawright \& Gerring, 2008; Yin, 2009). Especially for single in-depth case studies, it is necessary to express why a respective case is used and why this case can be used to represent a bigger population. 
According to Seawright and Gerring (2009), there is still no justified methodological approach of selecting a proper case. But there are the three techniques of random, pragmatic and purposive case selection. Seawright and Gerring (2009) stated that there was an experiment in Monte Carlo where several random case selections were analysed and as a result the randomized case selection often provide unrepresentative cases of the population. The pragmatic techniques in comparison are typically based on mathematical formulas and try to appraise the respective case with selected variables (David, LaPorte, \& Seawright, 2007). The challenge with the pragmatic case selection is that often it is difficult to find parameters which make several cases comparable to each other as most cases are complex and difficult to compare.

This research is based on a purposive selected in-depth case study because this methodological approach fits to the phenomenological position (Yin, 2015). Additionally, the main goal of his research is not to find the absolute truth and a generalizable outcome but rather to discover the probable truth and to investigate what is existing subjectively and contextually in the reality and how the phenomenon is existing in the reality according to the subjective experiences of the experts (Ryan, 2006). Consequently, the purposive selection of the in-depth case study fits to the philosophical position of the research and furthermore to achieve the aim to understand a multinational firm's management decision-making process during their transition between international entry strategies and the reason why these mode switching activities occur. The study will develop a new process model to illustrate and explain this business activity and expand the international management literature base.

According to Yin (2015) there are five reasons of purposive selecting a single case; selecting a critical case to test an existing theory (1), selecting an extreme case or a case with unusual circumstances (2), selecting a common case (3) or if the case provides revelatory (4) or longitudinal (5) purpose. The 
main reason for selecting this case is that it is a revelatory case. According to Yin (2015, p. 130), a single case study is justified if there is

"an opportunity to observe and analyze a phenomenon previously inaccessible to social science inquiry"

As shown in the gaps of the literature in chapter 2.8 , table 18 , there are only a limited number of in-depth analyses of multinational companies in previous studies (Rezende, 2006). One reason for this could be the inaccessibility of the data for external researchers or because the focus of the previous studies was not on developing a new process model but rather to analyse an existing theory (Asmussen et al., 2009). As I am involved as a key actor in the decisionmaking process of mode switching in the selected multinational company, he has the opportunity to get access to an in-depth analysis, it is worth to conduct the single case study because the investigated data will be revelatory (Yin, 2015). This is also suggested by Ishak and Bakar (2014) who developed a sampling frame for qualitative case studies and recommend that a single case selection is justified by a revelatory case is selected. Additionally, Jung (2017) used the same selection approach for a single case study in his PhD thesis. In chapter 3.7.5 the advantages and challenges of being an internal researcher is critically discussed (Unluer, 2012). Another important factor to justify the case selection of a single case study is that the selected case needs to be information rich for the relevant topic (Yin, 2015). The selected multinational company is an information rich single case because it has a long history in the industry, has a global structure and many international activities, is not under the top 5 of the biggest manufacturers which would indicate to be an extreme case but is still within the top 14 of the biggest manufacturers which shows that the company still has a significant position but also averaged position within the industry (Seawright \& Gerring, 2008).

Also, the selected lubricant industry is suitable for an in-depth analysis because the products of the industry are mostly commodities which makes the 
industry comparable to other commodity industries (Seawright \& Gerring, 2008). Next to this, the industry has global demands because you can find applications which need lubricants everywhere in the world (see Figure 31 on page 146). Therefore, the internationalisation and decision-making process of mode switches is very important for this industry, because the lubricant manufacturers needs to establish a global footprint and global network of international activities to meet the global demands of the customers (Seawright \& Gerring, 2008).

\subsubsection{Boundaries of the Case Study}

The research title, questions and objectives provide the organisational and strategical boundaries of the case study which is the lubricant manufacturer shown in Figure 32 (Holding, 2020). The research questions and objectives were internationally stated and based on the holistic lubricant company network (all subsidiaries are included). This case company perfectly matches with the outlined research problem in chapter 1.2, because it represents a multinational company and because the interdependencies between simultaneous (happening at the same time) international activities and the effect that one decision in an international activity can have on another can be investigated in this revelatory single case. The global organisation of the company consists of a number of independent subsidiaries that are geographically segmented. Each subsidiary operates independently but with a Chief Executive Officer (CEO) who is reporting to the management board of the headquarter that consists five managers (Holding, 2020). As all subsidiaries are reporting to the same management board and are navigated and operated from the headquarter, the company is following the organizational model of an international coordinated federation (Bartlett \& Ghoshal, 2000; Harzing \& Van Ruysseveldt, 2004). According to Harzing and Van Ruysseveldt (2004), the multinational companies which follow the international coordinated federation approach typically are coordinated and controlled by the headquarter but still work as independent companies in the 
network (Barlett \& Ghoshal, 2000). Rezende (2006) and Asmussen et al. (2009) explain that interdependencies between the international activities are existing within multinational companies which follow this network approach and therefore the selected multinational company with its global network is suitable to understand the multinational firm's management decision-making process of mode switching and to investigate the interdependencies between simultaneous (occurring at the same time) decision-making processes of mode switching.

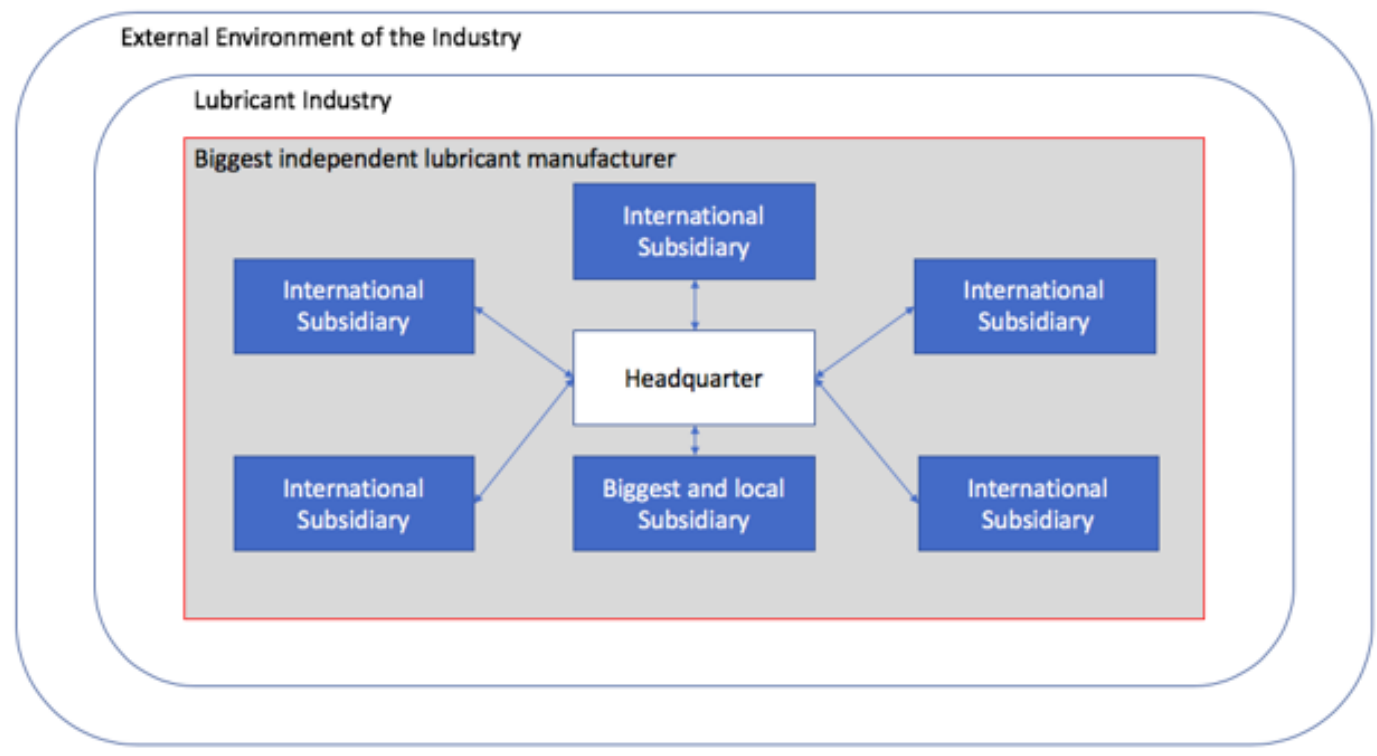

Figure 30: Boundaries of the Case Study

\subsubsection{The Structure and Culture of the Multinational Company}

The investigated multinational company develops, produces and sells a full portfolio of lubricants and related specialties for almost all industries and areas of application (Holding, 2020). The company was founded in Germany and the headquarter as well as the biggest subsidiaries for the respective product groups are still located in Germany (Holding, 2020). Today, the company is one of the world's largest supplier among the lubricant manufacturers with 
subsidiaries in over 45 countries (Holding, 2020). The company contains 58 operational companies all over the world and 33 production plants which means that some of the operational companies are "only" working as sales subsidiaries in the global network of the company. The organizational reporting structure is divided into the regions, Europe, Asia-Pacific, Africa and Northand South America. The executive board of the companies consists of 4 executive bodies and one chairman of the executive board (Holding, 2020). This structure shows that the selected case company fits to the definition of a multinational company according to Bartlett and Ghoshal (2000) and that the case company has established an international coordinated federation structure to manage the business and processes of the company.

According to Harzing and Van Ruysseveldt (2004) a multinational company has a geographic subsidiary management level, a global business management and a top-level corporate management. The operational responsibilities of the international activities of the company can be illustrated as shown in Figure 33. 


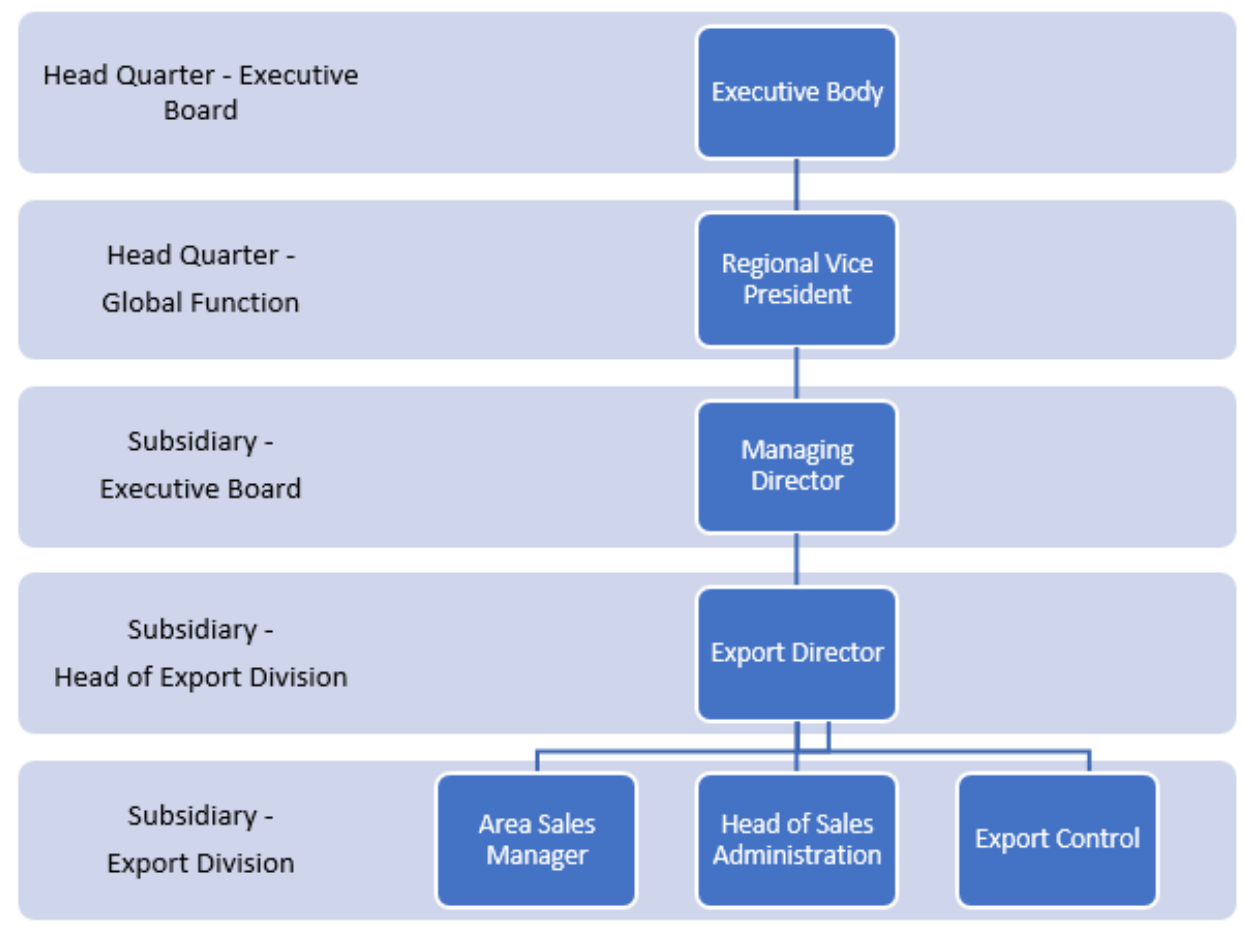

Figure 31: Operational Structure of the Internationalisation Process

There is the executive body who is the top-level corporate manager of the multinational company. In this management role he / she has to manage transnational and global topics and typically needs to balance and integrate diverse and often conflicting interests of different stake holders within the multinational company (Harzing \& Van Ruysseveldt, 2004). The regional sales managers who are responsible for a complete region, e.g. South America, are the next management level of the multinational company and reflect the global business management of the theoretical approach of Bartlett and Ghoshal (2000). These regional sales managers are responsible for the business activities and processes in their region and the respective managing directors of each subsidiary are reporting to their respective regional sales manager. The next management level of the multinational company is the geographic subsidiary management which is headed by the managing directors of the respective subsidiary. The tasks of the managing directors very much intersect with the theoretical approach of Harzing and Ruysseveldt (2004) who explains 
the task of the geographic subsidiary management to balance the national and local interests of the subsidiary with the global and corporate strategy of the multinational company.

Although the case company has defined responsibilities and organisation structure, the management supports and requires a hierarchy-free, open and transparent communication and working environment. Their mission statement of working and deciding together is based on the company values: respect, integrity, reliability, create values and trust (Holding 2020). The special feature of the selected case company is that although being a multinational and globally active company, it still is a family-owned company (more than $50 \%$ of the shares are possesses by one family). Due to this set-up and based on the mission statement, a specific company culture has been developed that supports group decisions and where key actors from different management levels can influence decision-making processes such as the mode switching process. Therefore, I decided to select at least one expert per key actor group to learn from the experiences of different management levels.

Talking about the internationalisation history and journey of the selected multinational company, originally the internationalisation was started from the two biggest German subsidiaries for their respective product groups. Subsidiary 1 is responsible for the specialities in the product portfolio of the company and subsidiary 2 is responsible for the commodity products of the company (Holding, 2020). The global sales of the company in 2019 are broken down according to Figure 34. As the selected multinational company was founded in Germany and the first international expansions started in Europe, most likely according to the UPPSALA model which is introduced in the literature chapter (Johanson \& Wiedersheim-Paul, 1975), the majority and almost $50 \%$ of the global sales are still done in Europe of the multinational company (Holding, 2020). 


\section{REGIONAL BREAKDOWN OF THE GLOBAL Sales}

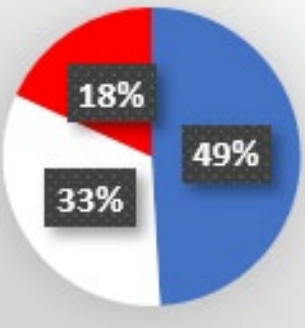

$$
\text { Europe }
$$

Asia-Pacific and rest of the world

- North and South-America

Figure 32: Regional Breakdown of the Global Sales (Holding, 2020)

As the internationalisation of the selected multinational company started in Europe and from the two German subsidiaries in the home country of the multinational company, these two subsidiaries are still handling the international activities of the multinational company with their export divisions. Therefore, the export divisions are the last management level in Figure 33 which are part of the geographic subsidiary management level (Harzing \& Van Ruysseveldt, 2004). Within the export divisions the area sales managers, the head of sales administration and the export control are responsible for the operations in foreign countries and the export director is the head of the division.

Within multinational companies the decision-making processes are managed from the three management levels, geographic subsidiary management level, a global business management and a top-level corporate management (Harzing \& Van Ruysseveldt, 2004). Therefore, I defined the key actors of the decision-making processes of mode switching according to the management structure outlined in Figure 33. In Table 22, the key actors and their responsibilities with the decision-making processes of mode switching is illustrated and summarized. 
Key Actors

Responsibilities within the decisionmaking process of mode switches

\begin{tabular}{|c|c|}
\hline Executive Body & - Taking the final decision \\
\hline Regional Sales Manager & $\begin{array}{l}\text { - Analysing the external and internal } \\
\text { environment of the decision-making } \\
\text { process } \\
\text { - Checking switching motivators in their } \\
\text { region } \\
\text { - Part of the final decision }\end{array}$ \\
\hline Managing Director & $\begin{array}{l}\text { - Analysing the external and internal } \\
\text { environment of the decision-making } \\
\text { process } \\
\text { - Checking switching motivators in their } \\
\text { region } \\
\text { - Preparing the data for the final decision } \\
\text { - Part of the final decision }\end{array}$ \\
\hline Export Director & $\begin{array}{l}\text { - Managing the area sales managers } \\
\text { - Preparing the data for the managing } \\
\text { director } \\
\text { - Gathering the information }\end{array}$ \\
\hline Area Sales Manager & $\begin{array}{l}\text { - Handling the current mode option } \\
\text { - Implementing the new mode option } \\
\text { - Gathering the information }\end{array}$ \\
\hline
\end{tabular}


PhD Thesis Mario Gehrlein

\begin{tabular}{|c|c|}
\hline $\begin{array}{l}\text { Head of Sales } \\
\text { Administration }\end{array}$ & $\begin{array}{l}\text { - Managing the back office of the export } \\
\text { division } \\
\text { - Handling the current mode option }\end{array}$ \\
\hline Export Control & $\begin{array}{l}\text { - Handling the current mode option } \\
\text { - Implementing the new mode option } \\
\text { - Gathering the information }\end{array}$ \\
\hline
\end{tabular}

Table 21: Key Actors and their Responsibilities within the decision-making process

\subsubsection{My Role in the Research and the Reflexivity}

Utilizing a qualitative method for data collection makes it crucial for social researchers to clarify their roles, to make the outcomes of their research credible. Since the observer is part of the observed during a qualitative research, reflecting the role of the researcher and how he / she is informing and influencing the research project is crucial to ensure the reflexivity in a research project. During a qualitative study the researcher take on several member roles within the research setting (Breen, 2007; Mercer, 2007; KarnieliMiller, Stier \& Pessach, 2009; Unluer, 2012). The extreme researcher roles can vary from a complete membership of the group being studied (insider) to a complete stranger (outsider) (Unluer, 2012). In the literature there are several definitions for insider and outsider researcher. Typically, insider researcher are those who study a group of participants to which they belong, while outsider do not belong to the group of participants (Breen, 2007). As I am working as Area Sales Manager in the export division at one of the German subsidiaries of the selected multinational company and therefore being one of the key actors of the decision-making process of mode switches, I have adopted the role of an insider-researcher. Georgiou (2014) his study also supports the use of this approach. 
As explained in table 22 (page 156), in my role as Area Sales Manager, I am usually at the receiving end of the decision process regarding mode switches, and responsible for implementing the decision, made by a strategy team. I have experienced in my career that in some cases, the mode switching decisions within the investigated multinational company has been appeared not to be justified, inconsistent or even irrational for the implementation team, because there was a lack of transparency and communication and it seemed that some decisions might follow the personal interests and behaviours of the managers in charge. This is also supported by Calof and Beamish (1995) who argue that the attitudes of executives often drive internationalisation decisions and not economic factors. For instance, there was a mode switch in a country where our department was working with an external distributor as sales partner. One day, we got contacted by a strategy team to contribute numbers and figures regarding the business that we were having with the partner, but without being informed of the reason or background behind this internal request. In the later stage of the process it turned out that the strategy team was already in contact with our local partner to discuss a possible mode switch, even though we had not been informed during the process but instead received the final decision that we were changing the mode to an own subsidiary in the country. From our perspective the decision itself is or was not the issue but rather that the strategy team only requested numbers and figures from us and kept everything confidential instead of involving the market experts (what our department actually is, being responsible for the market and cooperating with the external partner since decades) in the early stages of the process, in order to profit from our expertise and to possibly get additional and further input for the mode switching decision, seen from another perspective. To us it felt as being excluded on purpose, because we might have given input which could have led the decision in another direction which would not meet the intentions of the individual managers in the strategy team. As a consequence, we had the feeling that the personal behaviours and attitudes of the strategy team prevailed over the transparency and entirety of influencing factors and effects. 
In addition, I experienced that often there are interdependencies between simultaneous international activities and that the mode switching decision in one country affects the international activity in another international activity. For instance the case appeared when our company decided to launch its own subsidiary in a country that this heavily affected our business in a surrounding market with an external distributor, because the distributor feared that one day, our company would also launch a sales subsidiary in his market or that our new sales force in the neighbouring country would affect his market. Our distributor feared that this could increase the competition and that he might lose market share. As this new set-up challenged our already existing partnership with the external distributor in a surrounding country, we experienced that interdependencies are existing between simultaneous decision-making processes of mode switching and that these interdependencies need to be considered and handled in order to find the most appropriate and efficient mode option in a respective country.

I must consider my existing knowledge and my experiences on the investigated phenomenon of the mode switching process during the interpretation process (se section 3.8.1.2) to ensure the reflexivity of my phenomenological research. As shown in my two examples above, my opinion is already biased regarding the mode switching process (objective 2), the way key actors can affect the process (objective 2), whether interdependencies exist or not and how interdependencies are handled (objective 3). Being affiliated to a greater familiarity with the investigated phenomenon (KarnieliMiller et al., 2009), I will ensure that only the data will be considered to explain the phenomenon which will be achieved through this study without bias through previous knowledge and experiences and I will conceptualise myself as a co-investigator which fitting to my phenomenological perspective (Breen, 2007). However, I must reflect on the fact that the interpretation of the collected data is influenced by me as the researcher and consequently also by the existing knowledge that I have (Symon and Cassell, 2012). 
Being an insider-researcher has many advantages as speaking the same insider language, understanding the local values, knowledge and taboos, knowing the formal and informal power structure, and obtaining the right to conduct the research, interview and to get access to all data like records and documents (Unluer, 2012). Furthermore, the possibility to collect the data at any time ensures a continuity of data collection and consequently more trustworthy research data. Also the collection of missing data can easily complete due to close contact between researcher and participants (Mercer, 2007). Finally, knowing the personality of participants and vice versa facilitates the interactions between participants and researcher (Unluer, 2012).

Despite the advantages of conducting an insider-research, some challenges could be faced during data collection and analysis as role duality (colleague/researcher), overlooking routine behaviours, making assumptions about the meanings of events and not seeking clarification, assuming that the researcher knows the participants views and issues, the assumptions of the participants that the researcher already knows what they know and the familiarity to situations could hinder the researcher to see all dimensions of the bigger picture while data collection (Mercer, 2007). Before starting my research, I expressed my role as an internal researcher within the company I work for to ensure that my role is clearly understood by the participants. The disadvantages can be affiliated to the greater familiarity of myself with investigated phenomenon (Karnieli-Miller et al., 2009). I will ensure that only the data will be adopted to explain the phenomenon which will be achieved through the study without bias through previous knowledge and experiences and I will conceptualise myself as a co-investigator which fits to my phenomenological perspective (Breen, 2007).

One of the most critical challenges for an internal researcher is their access to sensitive data and how the researcher handles this data ethically (Unluer, 2010). To be compliant with the privileged information at each stage of the research, I will follow the University of Gloucestershire's Research Ethics 
procedures (see chapter 3.11, research ethics). I will use the material for research purposes only. All information will be anonymous and kept confidential (neither the organization's nor the participant's names will be mentioned) (Mercer, 2007). It will be stored securely and will be deleted when no longer required for research purposes (Saunders et al., 2015). If an interviewee does not want to participate in the research, he / she can withdraw at any point and all information collected will be destroyed.

In qualitative research and especially for insider researcher the power relations between researcher and participants is critically discussed (Karnieli-Miller et al., 2009). According to Reason (1994, p. 42) the relationship between participants and researchers in traditional / quantitative positivism studies is dichotomous, unequivocal, constant and uniform as he stated:

"In traditional research, the roles of researcher and subject are mutually exclusive: the researcher alone contributes the thinking that goes into the project, and the subjects contribute the action or contents to be studied"

The insider researcher conceptualise himself as a co-investigator to develop an equal partnership with the participants as power relation (Karnieli-Miller et al., 2009). This partnership gives the participants the welcoming and nonthreating environment that they are willing to share personal experiences, knowledge and beliefs (e.g. their stories). Additionally, the insider-researcher will empower the participants by re-engaging them after the interview with the additional objectives of strengthening the trustworthiness, accuracy and credibility of the findings (Karnieli-Miller et al., 2009). Any research project follows a development trajectory with different stages (Figure 35). 


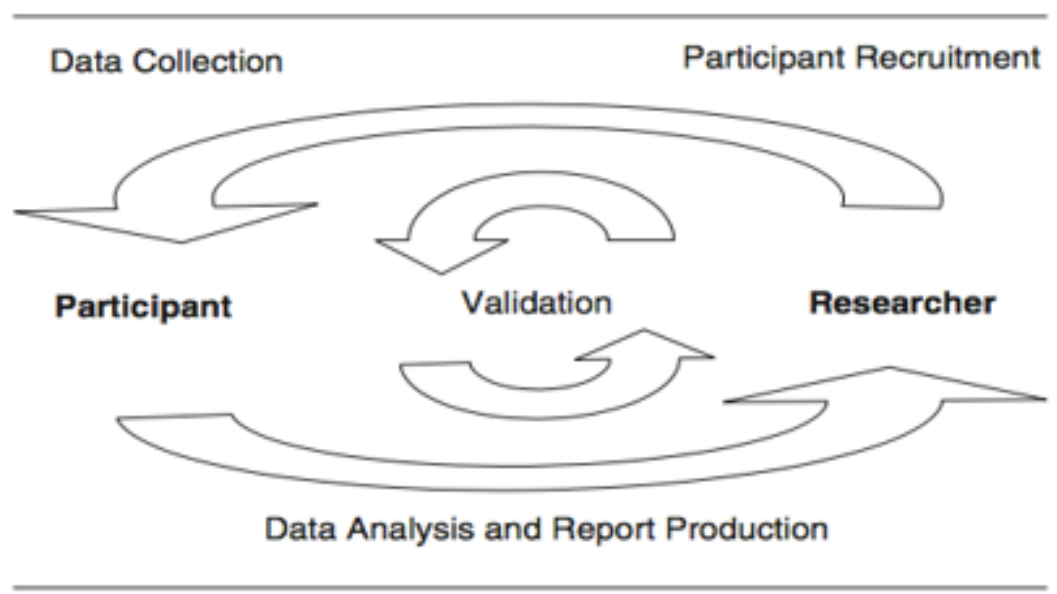

Figure 33: The Flow of Power Relation in Qualitative Research (Karnieli-Miller et al., 2009)

It is important that the power relation between researcher and participant is kept equal in all stages as each stage has a different purpose. Figure 35 summarizes shifts in power relations within a research project and the circular form illustrates that these stages are not linear in qualitative research and can reoccur (Karnieli-Miller et al., 2009; Mercer, 2007). Any researcher has methods to protect their own professional ethics and in parallel to ensure keeping the co-investigator relationship with their participants at any time of the research. An overview of these methods is given in Table 23.

\begin{tabular}{|l|l|}
\hline Timing & Methods \\
\hline Before the Research & - Examine reasons and aims of the study \\
& $-\begin{array}{l}\text { Examine the personal commitment to the } \\
\text { participants } \\
-\end{array}$ \\
& - Present the study in a clear and open way \\
\hline During the Research & - Protect privacy and anonymity \\
& $-\begin{array}{l}\text { Show awareness of the power relation and open } \\
\text { communication }\end{array}$ \\
\hline
\end{tabular}




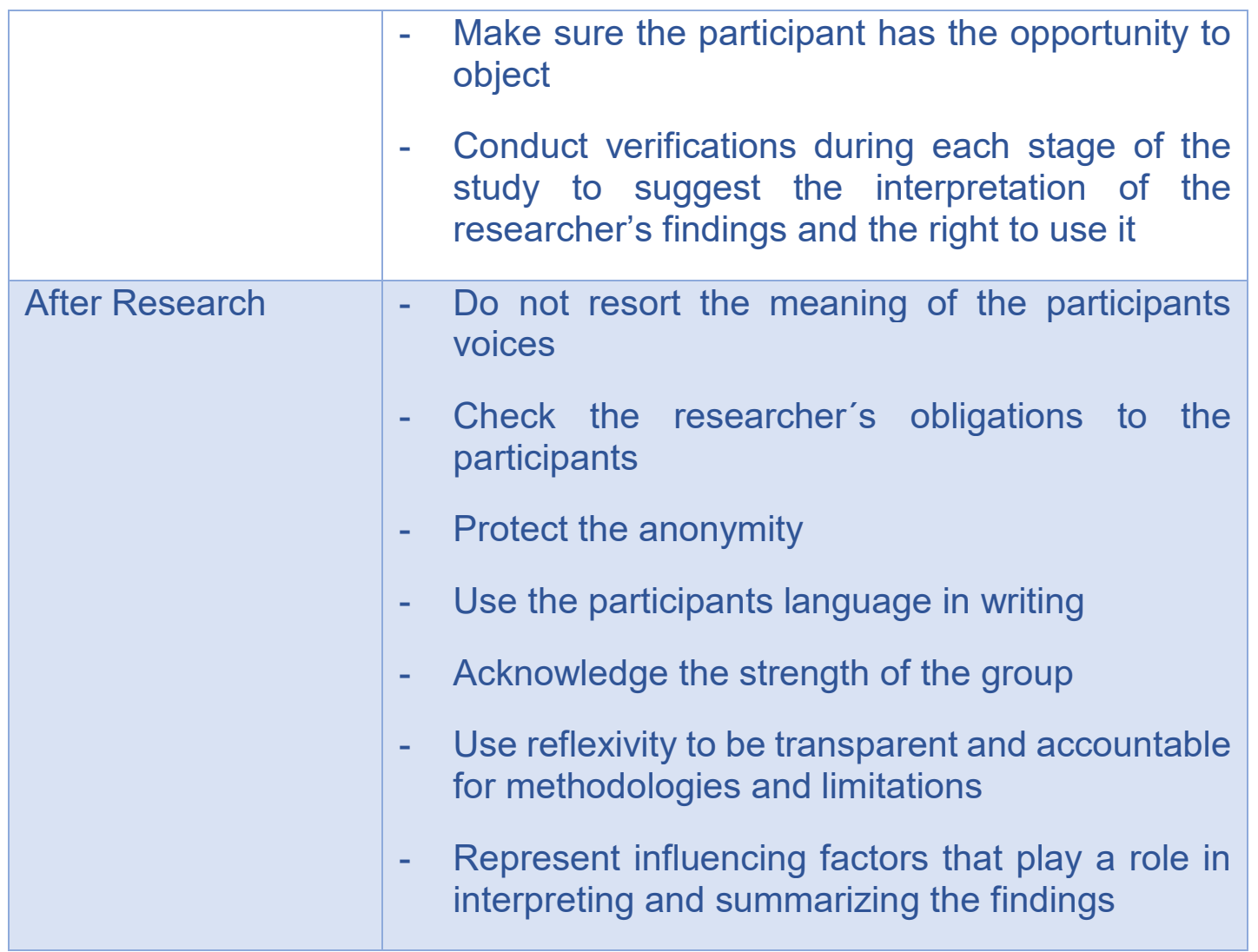

Table 22: Ethical and Methodological Recommendations ensuring the Power Relation between Researcher and Participant (Karnieli-Miller et al., 2009)

Following the above-mentioned paradigms and methods develops a replicable process for future research and a credible approach to meet the research aim (Symon \& Cassell, 2012).

\subsection{Methods}

According to Yin (2015) one strength of data collection in case studies is the opportunity to conduct multiple data collection methods because data collection from different sources is possible. This is also suggested by Geer et al. (2004) in regard to case studies within organisations because they suggest that it is necessary to use different data collection methods to get a deeper understanding of an organisation and its processes (Zhang, 2009). As this research aims to understand the management decision-making process of mode switching within multinational companies and a single case study of a multinational company is selected, two different data collection methods to 
collect evidence is applied to answer the research questions and to achieve the research aim (Zhang, 2009; Geer et al., 2014, Yin, 2015). Yin (2015) argued that using multiple sources ensures that the results of a quailitative study is more credible. According to Merriam (2009), employing multiple sources of data collection is a strategy of qualitative researcher to increase the credibility, reflexivity and quality of the outcome by comparing and crosschecking evidence collected by multiple methods, or by the same methods at different times. In the literature the more widely applied terminology for employing multiple data collection methods is triangulation (Zhang, 2009; Geer et al., 2014; Yin, 2015). By using triangulation, this research has the possibility to complement multiple qualitative data collection methods and to investigate if the data from different sources provide the same or different results (Zhang, 2009). Using the triangulation approach is also supported by Georgiou (2014) and Zhang (2009) in their case studies. During conducting the research the primary data is collected through semi-structured interviews. This technique has the role to collect, to find the first results and to be the main data collection method of this research, while the collection of secondary data through documentation review is used to indicate and triangulate the findings from the semi-structured interviews as much as possible (Zhang, 2009; Yin, 2015). Developing the research methods was based on a review of available data collection methods in the literature. Checking the suitability of these methods was based upon the data required for each research question and phase of the study and my phenomenological stance that influences the suitability of the methods used (King, 2004a; Saunders et al., 2015). The detailled justification for using semi-structured interviews and documentation reviews is defined in the next chapters 3.8.1 and 3.8.2. Due to the high amount of techniques analysed, only the used and relevant options - semi-structured interviews and collection of secondary data - have been discussed in the following sections. 


\subsubsection{Semi-Structured Interviews}

According to Yin (2015), an important technique and source of evidence in a case study are interviews because they provide insightful and deep information of the investigated phenomenon. Generally, personal interviews have several advantages, e.g. it has the potential to overcome poor response rates of questionnaires (Yin, 2015), it is well suited to explore attitudes, values, beliefs and motives (Zhang, 2009), during the interview it is possible to evaluate the credibility of the respondents answer by observing non-verbal factors and it ensures that the respondent is providing by his own and without help (Barriball \& While, 1994). In the literature interviews are suggested as one of the core methods of qualitative research in organizsations because they help to understand and investigate how decisions are made (Symon and Cassell, 2012). Therefore interviews perfectly support answering the research questions outlined in chapter 1.3., because this research is about the management decision-making of mode swithing and how these decisions are made within a multinational organization (Symon and Cassell, 2012). Next to this other $\mathrm{PhD}$ studies also support using interviews as data collection methods (Georgiou, 2014, Jung, 2017; Schröter, 2018).

In the literature, the authors group personal interviews in the categories structured, semi-structured and unstructured interviews (Saunders et al., 2015; Flick, 2017).

In structured interviews, the researcher uses structured set of questions which are predetermined and standardised (identical set of questions for each participant). In this case, the interviewer read out questions and record the answers on a standardised schedule with usually pre-coded answers. Due to this set-up the answers typically can be quantified because the same questions are asked. Therefore, the structured interview is called quantitative research interview (Saunders et al., 2015). According to Saunders et al. (2015) structured interviews are recommended for studies with a descriptive research purpose because the structured set of questions and the possibility to quantify 
the answers of the participants helps identifying general patterns. Objective 2 of this research is to explore the process of management decision-making of mode switching within a multinational company's internationalisation strategy. Therefore, this research has predominantly a exploratory research purpose and the structured interview approach is excluded.

The unstructured interview is the opposite as it is informal (Saunders et al., 2015). This means, that there is no standardised list of questions that the interviewer intend to discuss but rather a clear idea and research topic about which apsects need to be explored in the interview (Flick, 2017). An unstructured interview technique is typically used if the research purpose is exploratory because the unstructured nature of the interview encourages the experts to speak freely about their experiences regarding a respecitve phenomenon in a specific context (Zhang, 2009). Between these extreme positions, researchers have developed semi-structured interviews (Flick, 2017; Saunders et al., 2015). I will have a list of themes and main questions that are covered during the semi-structured interview but the direction and content of the interview can vary from interview to interview (Symon and Cassell, 2012). Selecting the interview strategy often depends on the purpose of a research as shown in Table 24 (Saunders et al., 2015; Flick, 2017).

\begin{tabular}{l|l|l|l|} 
& \multicolumn{1}{l}{ Exploratory } & \multicolumn{1}{c|}{ Descriptive } & Explanatory \\
\hline Structured & & $\mathrm{xx}$ & $\mathrm{x}$ \\
\hline $\begin{array}{l}\text { Semi- } \\
\text { Structured }\end{array}$ & $\mathrm{x}$ & $\mathrm{xx}$ \\
\hline Unstructured & $\mathrm{xx}$ & \\
\hline & $\mathrm{xx}=$ more frequent, $\mathrm{x}=$ less frequent & \\
\hline
\end{tabular}

Table 23: Use of different interview strategies depending on the purpose of the research (Saunders et al., 2015) 
The purpose of this research is exploratory as objective 2, 3 and 4 of this thesis is to explore the management decision-making process of mode switching, the interdependencies that are existing between simulataneous management decision-making processes of mode switching and to develop a new process model which shows the exploratory purpose because a particular problem is investigated in a specific context to gain familiarity with the phenomenon in the reality (Zheng, 2009). Therefore, according to the literature the semi-structured or unsructured interview technique is most suitable to achieve the outlined research objectives and to answer the research questions in chapter 1.3 (Saunders et al., 2015).

I will adopt semi-structured, qualitative interviews to explore the process of management decision-making of mode switching within a multinational company as the semi-structured interviews ensures a qualitative credibility of the research project because a trustworthy report and thick description of the interview concept, main questions and key topics are given (Symon and Cassell, 2012; Lyons \& Coyle, 2015; Silverman, 2015). Furthermore, using semi-structured interviews in business and management research is supported by other studies (Georgiou, 2014; Jung, 2017). Additionally, authors suggest qualitative studies should point out and develop a clear research design (Sykes, 1991; Saunders et al., 2015; Flick, 2017) which enables other researchers to reproduce the collected data and to ensure that there is no lack in the research process (Saunders et al., 2015). Conducting a semi-structured interview with a clear research process and design will ensrue this reproducability and consequently the credibility of this research (Symon and Cassell, 2012). To ensure this reproducability of the interviews, the design of the semi-structured interview is clearly illustrated and it is explained how the semi-structured interviews will be conducted in Appendix 4. The design, procedure and outcome is explained in chapter 4 in detail.

The main limitations of qualitative research and in particular of semi-structured interviews are related to the trustworthiness, reflexivity and representation of 
a research study and its results (Symon and Cassell, 2012; Tuohy et al., 2013; Husserl, 1982; Schutz, 1967). If these aspects are not considered by the researcher, this could implicate that the quality of the research suffers (Symon and Cassell, 2012) and therefore chapter 3.10 defines how the quality in this qualitative research is ensured.

According to Sykes (1991, p. 8), it is possible to achieve a high level of quality in qualitative and semi-structured interviews if they are conducted carefully:

"The main reason for the potential superiority of qualitative approaches for obtaining information is that the flexible and responsive interactions which is possible between interviewer and respondent(s) allows meanings to be probed, topics to be covered from variety of angles and questions made clear to respondents"

One key to conducting successful interviews and to overcome the quality research issues of semi-structured interviews, is careful preparation (Saunders et al., 2015; Flick, 2017). According to Saunders et al. (2015), there is a check list which ensures that a researcher is well prepared and that a credible and reproduceable data collection is possible. This check list is illustrated in Appendix 3.

\subsubsection{Conducting the semi-Structured Interviews}

\subsection{Data collection Phase}

The procedure of the semi-structured interviews follows the research design which is rolled out in the previous chapters. After defining the sample size (see chapter 3.9) within the single case, I contacted the purposive selected experts via email. The used email text is shown in Appendix 10 of this thesis. As attachments of the email,I sent the participants the privacy notice of the University of Gloucestershire as well as the participant information sheet which is issued by me (see Appendix 5). Providing the participants, the necessary information before taking part of a research is crucial for several reasons. First 
of all, the participant information sheet explains the individual participant what will happen to them in case they agree to take part of the study (Michaelson et al., 2014). Additionally, the participant can weigh up the advantages and disadvantages as well as the risks and benefits of participation (Michaelson et al., 2014). Finally, the participant information sheet gives me and the participant the insurance that everything is documented from a legal perspective (Michaelson, 2014; Saunders et al., 2015). Based on the available examples of participant information sheets in the literature like the participant information sheet of the Oxford University Hospitality NHS Foundation Trust (University, 2019) and according to the research ethics handbook of the university of Gloucestershire (2020), I developed the participant information sheet in Appendix 5. This participant information sheet contains a consent form which is signed by each participant and myself to indicate that the participants agree to take part in the study and that I fulfil my obligations of the consent form (University of Gloucestershire, 2020).

After the email was sent out, I received feedback from all purposively selected participants in an appropriate time frame and scheduled the 15 interviews accordingly (the justification of the sample size and selection of the experts is discussed in chapter 3.9). All 15 participants take part in the research and signed the consent form at the beginning of the interview. Each interview was made face to face and took between 45 and 80 min which is an appropriate time frame for semi-structured interviews (Newcomer, 2015). For conducting the semi-structured interviews, I created a design for the interviews which contains the main topics and main questions that need to be focused during the expert interviews (Saunders et al., 2015). According to Newcomer (2015) and Georgiou (2014) creating a design for conducting the semi-structured interviews is recommended to ensure the credibility of the research. I grouped the interviews and the interview design in four parts; the introduction, the first main part of the interview with the focus on the decision-making process of single mode switches, the second main part of the interview with focus on the 
decision-making process of multiple mode switches and the interdependencies and final comments and conclusions from the participant. Grouping the interview design into different main parts and topics is recommend by Newcomer (2015) and was carried out by Georgiou (2014) in his study.

\section{Part 1: Introduction}

In this part of the interview, I went through the participant information sheet which I sent to the participant via email before the interview. The main focus in this part was on establishing a trustful and good interview environment, explaining the participant his rights, what will happen with his data, the anonymity and confidentiality. The first part of the interview was finished, when the participant finally agreed to get electronically audio recorded and when the participant gave his permission to conduct the interview and sign the informed consent form.

\section{Part 2: The first main part of the interview with the focus on the decision- making process of single mode switches}

In this part of the interview, tl focused on the conceptual framework level 1 which is illustrated in Figure 26 (page 120) of this thesis and on the decisionmaking process if only one mode switch is considered. The themes were developed according to the findings of the literature review, the test interviews, the research questions and the research objectives. Regarding the research objectives the focus of the second part of the interview was on Objective 2 of this research:

Objective 2: To explore the process of management decision-making within a multinational company's internationalisation strategy.

The main themes in this part of the interview are extrapolated from the objective 2 of this thesis; the respective steps of the decision process, the influencing factors, the key actors and especially their influence on the process 
because of their experiences and personal behaviour and finally the rational decision within the process.

For conducting this part of the interview, I prepared some example questions in the design of the interview (see Appendix 4) which was created based on the research questions and objectives of this thesis. Depending on the flow of the interview and the answers of the participants, I added some questions or adjusted the existing example questions according to my needs (Georgiou, 2014; Newcomer, 2015).

\section{Part 3: The second main part of the interview with the focus on the decision-making process of multiple mode switches}

In this part of the interview, I focused on the finalized conceptual framework which is illustrated in Figure 27 of this thesis and on the decision-making process if multiple mode switches are considered at the same time. The themes for the interview design were developed according to the findings of the literature review, the research questions and the research objectives. Regarding the research objectives the focus of the second part of the interview is on Objective 3 and 4 of this research:

Objective 3: To determine the role of interdependencies between simultaneous mode switching processes.

Objective 4: To build a model of management decision-making during a process of mode switching which considers interdependencies of simultaneous internationalisation processes within a multinational company.

The main themes in this part of the interview are extrapolated from the objective 3 and 4 of this thesis; the interdependencies between simultaneous international activities, the transfer and influence of best practices and the global export strategy of multinational companies. 
For conducting this part of the interview, Iprepared some example questions in the design of the of the interview (see Appendix 4) which I created based on the research questions and objectives of this thesis. Depending on the flow of the interview and the answers of the participants, I added some questions or adjusted the existing example questions according to my needs (Georgiou, 2014; Newcomer, 2015).

\section{Part 4: Final comments and conclusion}

In the last part of the interview I give the participants the opportunity of final comments or further contribution that the participant intends to provide. Additionally, I ask the participants for secondary data which might give a contribution to my topic and for recommendations regarding additional contacts of possible experts that I could interview. Last but not least lexpressed again my thanks to the participants and closed the interviews (Georgiou, 2014; Newcomer, 2015).

This structured procedure of conducting the semi-structured interview ensures the replicability and credibility of this study and that I focused on the main topics during the interviews (Georgiou, 2014; Newcomer, 2015; Saunders et al., 2015).

\subsection{Transcribing the Audio-Recorded Data}

In the next step of the semi-structured interview procedure, Itranscribed the interview audio data of each interview. As the mother language of the participants and myslef and the company language of the investigated multinational German company is German, I decided to conduct the interviews in German. This ensures that the replies and the input of the participants are not limited to any language barriers and that I can build a trustful and positive environment with the participants. As conducting translation in qualitative research become more interest in the literature and research, lalso considered the challenges that could arise with translation regarding credibility and quality 
of qualitative studies. To ensure the quality and credibility of the translation of the interview transcripts, I followed a translation process that is supported and recommended from many authors in the literature (Beaton, Guilemin \& Ferrant, 2002; Weeks, Swerisson \& Belfarge, 2007; Regima, Naidoo \& Pilkington, 2010; Bureau, 2019).

1. Determination of the relevance and context

2. Forward-translation of the research instruments (i.e. topic guides)

3. Backward-translation

4. Examination of the translated meaning in both source and target languages, and then finally

5. Revisiting the whole process to get similar interpretations

In the first step of the translation process I get familiar with the German transcripts and identified topics and themes. This process steps are also in line with the selected thematic analysis concept which is selected from me to analyse the data of this research (Regima, Naidoo, \& Pilkington, 2010). Step 2, 3 and 4 are done several times from me to ensure that no topic, meaning or input is lost from the participants. The last step of the translation process shall illustrate that the whole process is a cycle and iterative. Consequently, I have done this translation process several times and at different points of the project to ensure that no information and input is lost or misinterpreted by me. The final step of transcribing the audio-recorded interviews was to anonymize the information about the participant and the information about the investigated company (like company name) to fulfil the consent information form (Beaton, Guilemin \& Ferrant, 2002; Weeks, Swerisson \& Belfarge, 2007; Regima, Naidoo \& Pilkington, 2010; Bureau, 2019).

\subsubsection{Analysing the Interview Transcripts}

Reviewing the literature regarding analysing and interpretation of evidence collected from qualitative research shows that there are no general accepted rules and processes and therefore the task of analysing qualitative data is 
challenging for each researcher (Robson, 2002; Gray, 2009; Merriam, 2009; Bryman \& Bell, 2011; Yin, 2015). One possible approach analysisng qualitative data is the thematic analysis which will be adopted by me to answer my research questions and to achieve the aim of this thesis because using thematic analysis with phenomenology as underpinned philosophical position has a long history in research, especially because thematic analysis are focusing on the participants subjective experiences (Robson, 2002; Gray, 2009; Merriam, 2009; Bryman \& Bell, 2011; Symon \& Cassell, 2012; Yin, 2015). Furthermore, conducting the thematic analysing technique is supported from the PhD studies of Sefiani (2013) and Khondokar (2018).

The thematic analysis is a process approach to identify patterns and themes within qualitative data in an inductive way (Maguire \& Delahunt, 2017). The aim of a thematic analysis is not only to summarize the data but rather to interpret the qualitative data and make sense of the findings (Rosenthal, 2016; Maguire \& Delahunt, 2017). In the literature, there are different approaches to conduct thematic analysis (e.g. Boyatzis, 1998; Alhojailan, 2012; Javadi \& Zarea, 2016) and therefore, there are different perspectives about the nature of thematic analysis and especially the difference to qualitative content analysis (Vaismoradi, Turunen \& Bondas, 2013). I decided to use one of the most influential approach in social sciences (Maguire \& Delahunt, 2017) from Braun and Clarke (2006) who developed a 6-step framework which is very clear and usable, e.g. this approach is used by AlQathani (2016) in his PhD thesis. The 6-step framework is illustrated in Figure 36. Those six steps of the framework explain the interpretation process of my research. To ensure its reflexivity, I have done a reflection loop after each framewok step of the interpretation process in which I have thought about whether and how my interpretation of the data might be influenced by my personal experineces and by the existing knowlegde (explained in the descriptions of the single framework steps). With this reflexivity appraoch, I have ensured that my findings were supported and coming from the data only although the 
interpretation is directly influenced by me, being the observer which is typical for qualitative and phenomenological research (Breen, 2007; Symon and Cassell, 2012).

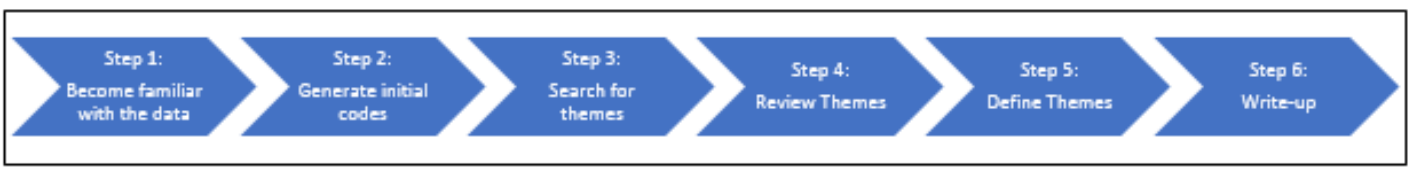

Figure 34: 6-step framework of thematic analysis (Braun \& Clarke, 2006)

\section{Step 1: Become familiar with the data}

The first step in each qualitative analysis, including thematic analysis, is reading and re-reading the transcripts of the qualitative data (Maguire \& Delahunt, 2017). During this step, it is recommended to do the first notes in the transcripts and write down the first impressions because this helps to become familiar with the data (Rosenthal, 2016).

This step has been done by me from the beginning by transcribing the audiodata and translating the data by himself. After becoming familiar with the data in German and finishing the iterative translation process, the research moved to step 2 of the thematic analysis.

\section{Step 2: Generate initial codes}

In this step the collected data is organised in a systemtic way. This step converts the massive body of data into small lumps of meaning. Braun and Clarke (2006) differ between a so called top-down, theoretical thematic analysis in which the coding is done according to the research questions of a research and the bottom-up, inductive thematic analysis in which the initial codes and systematic structure is driven by data itself (Saldana, 2009). This research adopts the inductive thematic analysis according to his outlined research approach in chapter 3.4 to find initial codes, themes and patterns in the interview transcripts (Saunders et al., 2015). 
Using the inductive approach while reading and re-reading the interview transcripts, I generated the initial codes (32 codes) and a first list of possible codes which are represented in more than one interview like,

- $\quad$ Short-Cut Decisions

- Incremental Process

- Starting Impulse

- Market analysis

- Business Plan

- Influencing Factor

- Interdependencies

- Personal Behaviour

- Key Actors

- Global Strategy

- etc.

The full list of initial codes can be seen in Appendix 6 of this thesis. Having developed the final list of codes, I have reflected whether my interpretation and the identified codes reflect the totality of the collected data and interview transcripts.

Step 3: Searching for themesl have a wide list of 32 different codes. Within process step three of the framework, sorting the respective codes to potential themes and collecting the relevant data extracts of the respective codes to the sorted theme is the main goal (Saldana, 2009). In this process step, the purpose is to analyse and interpret the chosen codes and trying to combine several codes to one theme. To do so, I have different methods, like mindmapping, concept maps, tables, etc. that help to visualize the codes and make it easier to group the respective codes to a themes (Braun \& Clarke, 2006). For conducting this process step, I used concepts maps to organize the themes of my project and to maintain the meaning of the interview data (Delay, 2004). Using concept maps has several advantages. The content and information of an interview transcript is huge and therefore the richness of the meanings can be lost (Braun \& Clarke, 2006). Using a concept map helps to 
maintain the complex and richness of the meanings because a good overview is given and the concept maps illustrates the connections between the defined themes (Delay, 2004). Typically, transcripts showing the interview data in a linear format and its original form while the concept maps visualize the themes within the interview data as interconnected and in hierarchicalformats. This is more analogous of how humans are conducting interviews and discussing concepts or processes in the reality and therefore using concept maps, perfectly fits to my philosophical position as interpretivist (Delay, 2004). The biggest advantage of concept maps is the reduction of data volume to show the interconnections of themes and to illustrate interdependencies and comparisons of the themes (Braun \& Clarke, 2006). The major disadvantage of concept maps is their complexity and that unfamiliar readers or participants of the research process could have challenges in identifying the linkages and the interdependencies between the themes. I ensure to level this disadvantage by writing a detailed narrative about each theme and interconnection in chapter 4 of this thesis (Braun \& Clarke, 2006).

The result of this process step is illustrated in Appendix 7: First Concept Map of this thesis. Having developed the final concept map, I have reflected, whether my interpretation and the investigated connections between the themes and codes reflect the totality of the collected data and interview transcripts.

\section{Step 4: Reviewing themes}

In this step of the framework, I refine the identified themes of process step three. By reviewing, interpreting and reflecting the identified themes of the previous process step it could happen that themes are combined with eachother, that themes are broken down in several main themes or that an 
identified theme is evaluated as not being an important theme and is deleted from the list (Braun \& Clarke, 2006). According to Patton (1990) the data within themes should be evaluated according to a dual criteria of internal homogeneity and external heterogeneity which means that the data within one theme should cohere meaningfully and the data between themes should be differentiated clearly. By reviewing the themes, the data extracts have been collected in a separate Excel file, the so-called list of codes and has categorized each data extract according to the theme, subtheme and the respective codes. As an example, Table 25 shows an extract of the list of codes. A more holistic extract of the codebook is shown in Appendix 11.

\section{Global Strategy}

\begin{tabular}{|c|c|c|c|}
\hline Participant & Quote & Sub theme & Code \\
\hline 1 & $\begin{array}{l}\text { The localization of individual products in } \\
\text { China, for example, has been going on } \\
\text { for } 3 \text { years now and why is it taking so } \\
\text { long? We still have to fly in products } \\
\text { from Germany to China, and of course } \\
\text { that is very expensive. These are topics } \\
\text { that are discussed, even if it concerns } \\
\text { only some, but all of them have the } \\
\text { Global Head open and can contribute } \\
\text { their part, even if you do not have } \\
\text { everything down to the detail of the } \\
\text { product of the previous production, the } \\
\text { future production, why the transfer is so } \\
\text { difficult, how are the market differences. }\end{array}$ & Supply-Chain & $\begin{array}{l}\text { Global } \\
\text { Production } \\
\text { network }\end{array}$ \\
\hline
\end{tabular}

Table 24: Example Extract of the List of codes

For creating the list of codes, the interview transcripts are colour coded according to the selected main- and sub-themes while each colour is used for one main theme, as illustrated e.g. in Appendix 9.

The review process of the candidated themes can be grouped into two levels. In the first level, the I am reviewing the themes on the level of the data extracts. 
In this context I am looking for coherent patterns within the coded extracts of each theme (Guest \& MacQueen, 2012). The selected themes are revised until I have created a thematic map in which each theme is adequately reflecting the respective coded extracts (Braun \& Clarke, 2006). The second level of reviewing the selected themes is a similar process to the first level but the reviewing process is related to the entire data set. At this level, the research investigates if the selected thematic map is reflecting the meanings and interpretations of the entire data set and the quality of the individual themes in relation to the data set (Guest \& MacQueen, 2012). Finally, there are two reasons for re-reading the whole data set. First, I am checking if the candidated themes work in relation to the entire data set and second, if any additional information or data has been missed in the previous coding steps (Braun \& Clarke, 2006). It is important to mention at this point that data coding and creating themes can go on until the smallest part is reached. Therefore, it is very important to consider the saturation level of coding and at what stage the themes are selected appropriate and an additional coding is only a kind of finetuning and nuances are added to the list of codes or concept maps (Braun \& Clarke, 2006). The saturation level was considered as reached when each code was grouped into a theme or subtheme and no complete new codes were identified in the data set (Braun \& Clarke, 2006) which means that all important quotes of the experts were selected from the interviews, coded and grouped according to the identified themes.

At the end of phase 4 I have a concept map which tells the overall story of the data set and have an overview of how the themes are connected with each other. This concept map is illustrated in Appendix 8.

\section{Step 5: Defining and naming themes}

In this process step of the framework, the research defines and refines what shall be presented in the analysing chapter and in parallel the coded data extracts are analysed within the single themes. According to Braun and Clarke 
(2006), defining and refining means to investigate the essence of the individual themes and to investigate the major aspects of the coded data which the respective theme capture.

Braun and Clarke (2006) group the themes within their framework in semantic and latent themes. Semantic themes are defined as (Braun \& Clarke, p. 84, 2006):

„....within the explicit or surface meanings of the data and the analyst is not looking for anything beyond what a participant has said or what has been written."

Latent themes are defined as (Braun \& Clarke, p. 84, 2006):

„... starts to identify or examine the underlying ideas, assumptions and conceptualisations - and ideologies - that are theorised as shaping or informing the sematic content of data"

This study intends to identify semantic as well as latent themes in the collected qualitative data as the interest is not only in interpreting the explicit surface meanings but rather the interrelations beyond what has been said and consequently, interpreting and explaining the findings. At this point, it is essential not just to paraphrase the data content but rather to investigate and interpret the content behind the coded data (Lyons \& Coyle, 2015).

As a result of step 5, Ideveloped a short summary of my concept map to give the reader an overview of the selected main- and subthemes in Figure 37. 


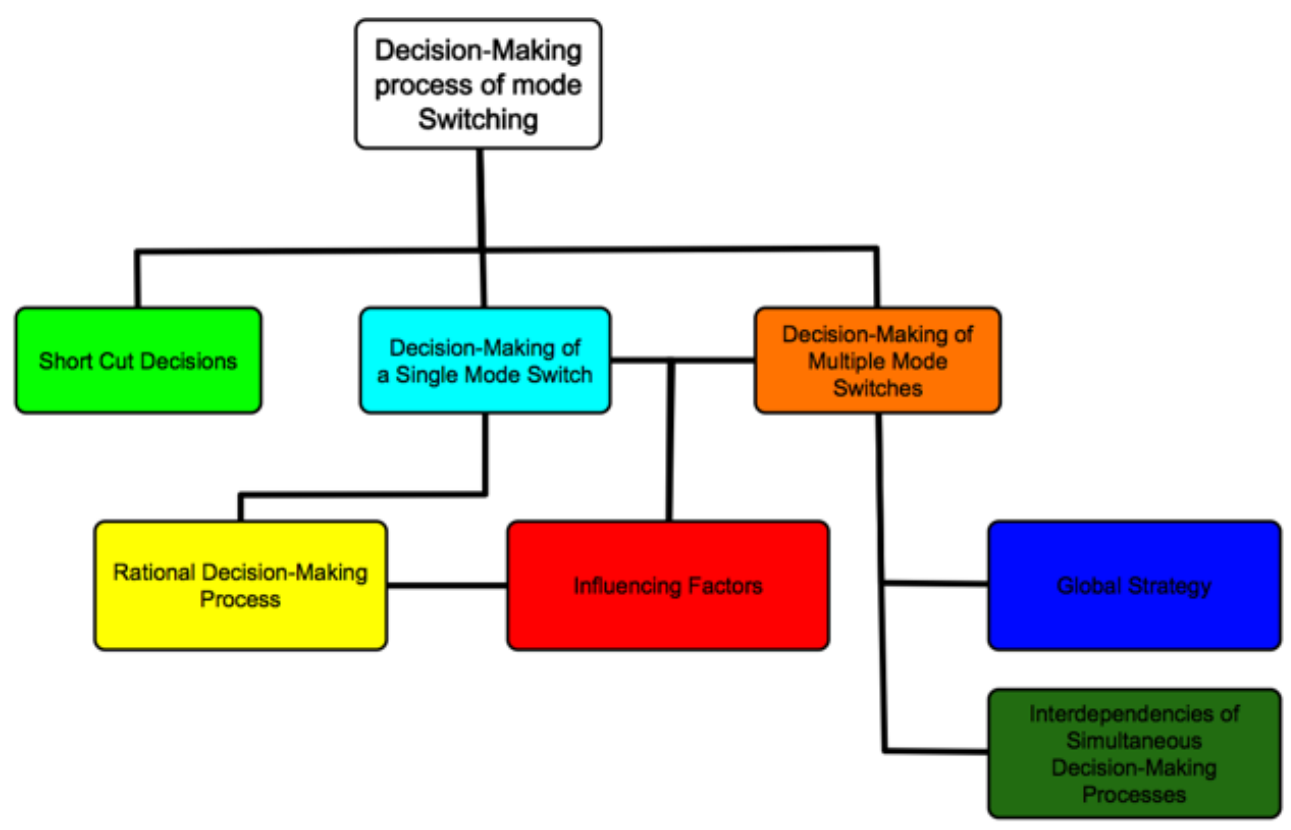

Figure 35: General Overview of the Concept Map

The final result of the concept map after process step 1-5 is the holistic concept map in Appendix 11 of this thesis. This is the final framework step of my interpretation process. Consequently, I reflected the interpreted findings and checked if my finalized concept map and code book reflect the totality of my data set by cross-checking the interview transcripts with the interpreted findings in my visualisation tools (concept map and code book).

In the last phase of this process step, I have to write a detailled analysis of each individual theme (Lyons \& Coyle, 2015). The detailled analysis of each theme answers the research questions and the research considered how the individual theme is fitting into the story of the entire data without overlapping the individual themes too much (Braun \& Clarke, 2006). Consequently, the detailled analysis is focused on the theme itself but also considers the relations and interdependencies between the themes.

\section{Step 6: Producing the report}


In the last process step, I am producing a final report of the individual detailed theme analyses of the previous step based on the holistic concept map and the list of codes with the categorized data extracts (Appendix 11), The report needs to be a concise, coherent, logical, non-repetitive and interesting analysis which includes the data extracts and is within and across the selected themes (Saldana, 2009). In this research project, the identified themes and their connection to each other build the foundation to finally identify how the interdependencies of simultaneous international activities affect the decisionmaking process, by focusing on the personal behaviour of the management and organizing them into clusters (Thomas, 2006; Lyons, 2015). By producing a narrative account between the interplay of the interpretative activity of me and the experiences of the participants words, I will develop my model (Smith, 2004; Thomas, 2006;. As details and experiences of individuals can also give deeper insights to significant aspects of the general, the developed model will contribute theoretical knowledge to the literature of decision-making in the context of mode switching and particularly how interdependencies between simultaneous international activities are resolved (Thomas, 2006; Lyons, 2015).

Last but not least, it is necessary to point out that the 6-step framework, illustrated in Figure 36, is an iterative process and many steps need to be done in parallel and at the same time. Consequently, I went through several iterative loops until I achieved the final concept map and list of codes which are attached as Appendix to this thesis and which build the foundation of the next sections and the outcome of this research project (Braun \& Clarke, 2006).

\subsubsection{Collection of Secondary Data}

Some authors argue that using secondary data in a case study additionally to complement primary data, e.g. collected through semi-structured interviews, has advantages in comparison to studies which are only using primary data because secondary data is already existing and can be re-evaluated before 
usage (Zhang, 2009, Grant, Berg \& Cable, 2014; Yin, 2015). This study collects secondary qualitative data to triangulate as much as possible data and results from the semi-structured interviews because triangulation is suggested for case study research by many authors in the literature to ensure that the results of the case studies are credible and trustworthy (Zhang, 2009, Grant, Berg \& Cable, 2014; Yin, 2015). That case studies use data triangulation and multiple data collection methods to make the study outcomes more credible and trustworthy is shown in the studies of Zhang (2009), Georgiou (2014) and Grant, Berg and Cable (2014) who use documentation reviews to support the results and data from their interviews.

Georgiou (2014) recommends in his study to use documentation reviews from the investigated company as secondary data source if the research is focused on a single case company and if the accessibility to the organizational documents is possible (e.g. as an internal researcher). Next to this, Yin (2015) argues that using documentation reviews in case studies is the most important source of secondary data to triangulate the data and results from interviews, because the data can be reviewed repeatedly, the documents are not specifically created for the case study and therefore are completely independent, they can cover many events and useful insights and details of events. According to Yin (2015) there are the following weaknesses of documentary reviews. First, organizational documents are difficult to access. Secondly the documents in general can be of limited quality in regard to credibility (whether the document consists mistakes), representativeness (is the document typical?), authenticity (is the document original) and meaning (is the document clearly understandable?). The first weakness according to Yin (2015) is not applicable for this research because I have the access to internal organizational documents due to my role as an internal researcher (Breen, 2007; Mercer, 2007; Karnieli-Miller, Stier \& Pessach, 2009; Unluer, 2012). According to Bryman and Bell (2011), the second weakness, mentioned by Yin (2015) in regard to documents in general is not applicable for organizational 
documents if they are selected and received from the investigated company of a case study because these organizational documents most likely fulfil all quality criteria in regards to credibility, authenticity, representativeness and meaning. However, Bryman and Bell (2011) argue that instead of evaluating the quality of the organizational documents, the relevance and justification of using the organizational documents for answering the research questions and achieving the research objectives needs to be ensured. Therefore, this study justifies and explains in chapter 3.8.2.1, why the respective organizational documents are included and how they support the research to answer the research questions and to achieve the research objectives outlined in chapter 1.3.

As in the general theoretical literature (Yin, 2015) and in recent studies (Zhang, 2009; Georgiou, 2014; Grant, Berg \& Cable, 2014), the usage of organizational documentation reviews is suggested to triangulate as much as possible data and results from the primary data collection method (e.g. interviews) this study uses documentation reviews from the investigated company to triangulate the findings from the interviews best possible and to find new results if possible, to answer the research questions. These documents include written materials like notices, correspondence, minutes of meetings, reports of shareholders, diaries, transcripts of speeches and administrative, emails and public records (Bowen, 2009; Saunders et al., 2015).

Georgiou (2014) and Grant, Berg and Cable (2014) got access to the organizational documents in their studies by asking their experts and participants during the interviews to provide them interesting and necessary documents if possible because getting the organizational documents from the experts ensures that documents with a high and relevant value for the study is preselected (Georgiou, 2014; Grant, Berg and Cable, 2014). Therefore, following the semi-structured interviews, I asked the participants to provide me organizational documents which are relevant (in the opinion of the participants) in regard to the management decision-making process of mode switching. I 
ensure that the data are treated confidential and the participants do not have to provide the documents if they don't want to.

\subsubsection{Conducting the Documentation Review}

After each semi-structured interview, I asked the respective participant if he/she can provide any organizational documents which are relevant (in the opinion of the participants) in regard to the management decision-making process of mode switching. As a result, the experts provided 6 documents for this research project. The overview of the documents is shown in Table 26.

\begin{tabular}{|c|l|}
\hline Number & \multicolumn{1}{c|}{ Name of Provided Document } \\
\hline $\mathbf{1}$ & Business Pan of a mode switching process in Europe \\
\hline $\mathbf{2}$ & Example of a customer transfer sheet \\
\hline $\mathbf{3}$ & Market segment analysis \\
\hline $\mathbf{4}$ & Press release about a mode Switch in Africa \\
\hline $\mathbf{5}$ & Press release about a possible mode Switch Middle East 1 \\
\hline $\mathbf{6}$ & Press release about a possible mode Switch Middle East 2 \\
\hline
\end{tabular}

Table 25: Provided Documents for the Documentation Review

Some documents were provided from more than one participant, some participants have provided two documents and some participants have not provided any document. Table 27 shows an overview of the documents which are provided per participant.

\begin{tabular}{|l|l|}
\hline Participant & Provided Documents \\
\hline Participant 1 & 5, 6 \\
\hline Participant 2 & 1 \\
\hline Participant 3 & - \\
\hline Participant 4 & - \\
\hline Participant 5 & 1 \\
\hline Participant 6 & - \\
\hline Participant 7 & 2 \\
\hline Participant 8 & 2 \\
\hline Participant 9 & 1,3 \\
\hline Participant 10 & 4 \\
\hline Participant 11 & 1 \\
\hline
\end{tabular}




\section{Participant 12}

Participant 131

Participant $14 \quad 2,4$

Participant 15

Table 26: Provided Documents per Participant

Document 1 is an example for a business plan of a mode switching process in Europe and has 103 pages. This document is suitable for further analysis and was provided by the experts because it shows a business plan that was the basis for the management decision-making process of a mode switch in a respective country and gives credible insights about the influencing and determining factors of the decision process. This document contributes useful results and outcomes to achieve objective 2 of this research because it shows which determining factors are used within the investigated company for the decision-making process of mode switching.

Document 2 is a customer transfer sheet in an excel format and has 7 spreadsheets. This document was provided by the experts because it shows an example of which information and what kind of information is shared within the multinational company if a business is transferred from one subsidiary to another as a result of a mode switch. This document helps to answer the second research question of this study because business transfers within subsidiaries are a result of the interdependencies between simultaneous decision-making processes of mode switching (as discussed in chapter 4.2.3.1).

Document 3 is an example for a market segment analysis and has 3 pages. The experts provided this document because the market analysis was explained as important process step of the management decision-making process. Therefore, this document contributes knowledge to achieve objective 4 of this research because the market analysis is defined as one process step of the new model which is developed in this study (see chapter 4.2.1.1.2). 
Document 4 is a press release of the multinational company about a mode switch decision in Africa. This document was provided by the experts because within the press release the chief executive officer of the investigated company talks about the reasons for switching the mode in the respective country. This document contributes useful results and outcomes to achieve objective 2 of this research because it shows which influencing factors are existing within the investigated company for the decision-making process of mode switching.

Document 5 and 6 are articles of two different German newspapers which are about a possible mode switch in Middle East of the multinational company. These documents were provided by the experts because within the documents the management board of the investigated company talks about the reasons for switching the mode in the respective countries. These documents contribute useful results and outcomes to achieve objective 2 of this research because they show which determining factors are used within the investigated company for the decision-making process of mode switching.

\subsubsection{Analysing the Documentation Review}

For analysing the organizational documents provided by the experts, this research follows the approach conducted by Grant, Berg and Cable (2014), because they did a business research within real organizations using semistructured interviews and organizational documents as secondary data to triangulate the findings and results from their interviews. Furthermore, Grant, Berg and Cable (2014) used the thematic analysis approach to analyse their interview transcript, as it is conducted in this research. Following this approach, the organizational documents are analysed according to the predefined codes, themes and subthemes from the developed concept map of the semi-structured interviews, shown in Appendix 8 (Bowen, 2009). Consequently, I am using the organizational documents to triangulate the findings from the semi-structured interviews best possible and to find new results if possible (Gran, Berg \& Cable, 2014). Both methods complement 
each other and build a robust and justified method approach to conduct this research based on my phenomenological and for achieving the research aim (Grant, Berg \& Cable, 2014; Yin, 2015; Saunders et al., 2015).

\subsection{Sampling}

Selecting the participants of a research study is called sampling (Manen, 2014). Originally, sampling comes from quantitative research in which the term sample refer to an empirical sample as a subgroup of the population with the aim of finding empirical generalization (Manen, 2014). However, according to Manen (2014, p.352), there is an alternative understanding of the term "sampling" which is suitable for qualitative research:

"But the term sample can be related back to the French root word example, which has paradigmatic significance, as has been pointed out with reference to ..."

\subsubsection{Sampling Methods}

Sampling is achieved through probability or non-probability sampling methods (Silverman, 2014). In a probability sampling method, the researcher selects respondents at random using data bases via a systematic, cluster or stratified approach (Saunders et al., 2015). If databases are unavailable, research can use a voluntary, purposive, convenience, quota or snowball technique in a non-random method which is called non-probability sampling (Bryman \& Bell, 2011).

Within a phenomenological position, a non-probability method is desirable to select experienced experts for in-depth studies (Gentles, Charles, Ploeg \& McKibbon, 2015). Especially, in combination with a case study research, purposeful sampling is promoted by the literature (Gentles, Charles, Ploeg \& McKibbon, 2015). For example, Yin (2011, p. 311) defines purposeful sampling as: 
"The selection of participants or sources of data to be used in a study, based on their anticipated richness and relevance of information in relation to the study's research questions"

Following a non-probability purposeful sampling method, is therefore underpinned by the philosophical position and research strategy of this research because this research is underpinned by a phenomenological research position and is conducting a single case study (Yin, 2015; Saunders et al., 2015). Additionally, Georgiou (2014) and Jung (2017) supports using purposeful sampling methods for their case studies.

\subsubsection{Sample Size and Process}

According to Robinson (2014) there is a four-point approach of purposeful sampling in qualitative research as shown in Table 28 , which this study follows.

\begin{tabular}{|c|c|c|c|}
\hline & Name & Definition & Key decisional issues \\
\hline $\begin{array}{l}\text { Point } \\
1\end{array}$ & $\begin{array}{l}\text { Define a } \\
\text { sample } \\
\text { universe }\end{array}$ & $\begin{array}{l}\text { Establish a sample universe, } \\
\text { specifically by way of inclusion } \\
\text { and / or exclusion criteria }\end{array}$ & $\begin{array}{l}\text { Homogeneity vs. } \\
\text { heterogeneity, inclusion } \\
\text { and exclusion criteria }\end{array}$ \\
\hline $\begin{array}{l}\text { Point } \\
2\end{array}$ & $\begin{array}{l}\text { Decide on a } \\
\text { sample size }\end{array}$ & $\begin{array}{l}\text { Choose a sample size or sample } \\
\text { size range, by taking into account } \\
\text { what is practical and what is ideal }\end{array}$ & $\begin{array}{l}\text { Ideographic (small) vs. } \\
\text { nomothetic (large) }\end{array}$ \\
\hline $\begin{array}{l}\text { Point } \\
3\end{array}$ & $\begin{array}{l}\text { Devise a } \\
\text { sample } \\
\text { strategy }\end{array}$ & $\begin{array}{l}\text { Select a purposive sampling } \\
\text { strategy to specify categories of } \\
\text { person to be included in the } \\
\text { sample }\end{array}$ & $\begin{array}{l}\text { Stratified, cell, quota, } \\
\text { theoretical strategies }\end{array}$ \\
\hline $\begin{array}{l}\text { Point } \\
4\end{array}$ & $\begin{array}{l}\text { Source the } \\
\text { sample }\end{array}$ & $\begin{array}{l}\text { Recruit participants from the } \\
\text { target population }\end{array}$ & $\begin{array}{l}\text { Incentives } \\
\text { incentives, } \\
\text { sampling } \\
\text { advertising }\end{array}$ \\
\hline
\end{tabular}

Table 27: Four-point approach to qualitative sampling (Robinson, 2014) 


\section{Point 1: Sample Universe}

In the first step of the four-point approach of Robinson, the sample universe needs to be defined according to the inclusion and exclusion criteria of the researcher as illustrated in Figure 38.

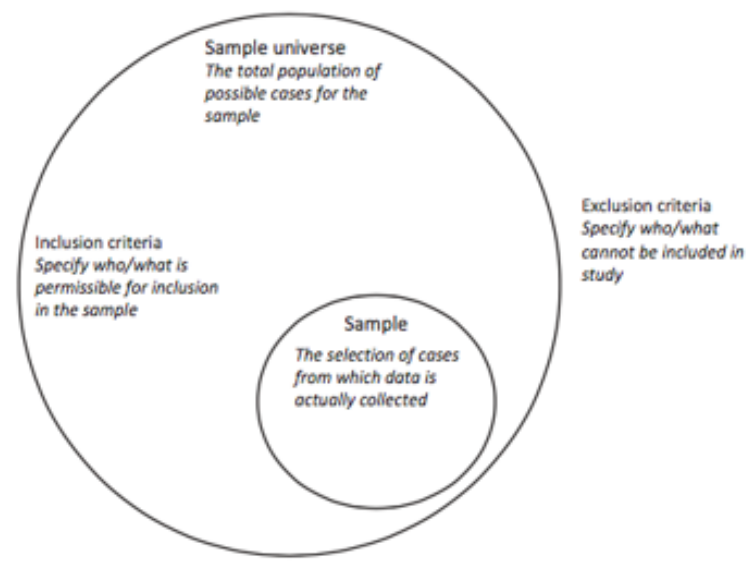

Figure 36: Sample Universe (Robinson, 2014)

As the current academic literature is limited to understanding only individual entry mode switching actions across a range of firms or a single transition between strategies (Amussen et al., 2009; Sachse, 2010) and because international organisations mode switching actions take place as a series of interrelated activities (interdependencies) and do not exist as independent actions as prior research has focussed upon, the aim of this research is to understand a multinational firm's management decision-making process during their transition between international entry strategies and the reason how these mode switching activities occur. Therefore, I decided to focus on multinational companies within one industry to develop a new process model to illustrate and explain this business activity and expand the international management literature base. This focus results in inclusion and exclusion criteria to define the sample universe in Table 29. 
Company size

Industry
Non

companies

All other industries multinational Multinational Companies

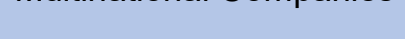

Lubricant Industry

Table 28: Inclusion and Exclusion Criteria of the Sample Universe

Consequently, the sample universe contains all companies which pass the inclusion and exclusion criteria which I defined.

\section{Point 2: Deciding on the Sample Size}

The selected sample size can vary from single case studies to large-scale interview projects in qualitative research. Both extreme positions can have their advantages and disadvantages which are discussed in the literature (Robinson, 2014; Saunders et al., 2015). Due to the limits of the current literature body of the investigated research theme and aim of this research is to understand the decision-making process of a multinational company during their transition between international entry strategies, I decided to focus on one multinational company and consequently on a single case study which is also explained in chapter 3.4. Georgiou (2014) also investigated a single multinational case company in his research about the decision-making process of entry mode options.

\section{Point 3: Selecting a Sample Size:}

Due to my current position as an Area Sales Manager in the largest independent lubricant manufacturer, it is possible to interview the key actors who are involved in the decision-making process of mode-switches within the selected multinational company and therefore the investigated multinational company is a revelatory single case (see chapter 3.7.1) and it is justified to select this company as single case (Guenzi, 2011; Flick, 2017).

The data collection phase includes secondary data analysis (objective 1), primary data collection phase (objective $2-4$ ) and secondary data collection through documentary of the case company (objectives $2-4$ ), as shown in 
Table 32. The participant recruitment for the primary data collection (objective 2 - 4) followed a purposive (homogenous) sampling technique based on my experiences with the investigated mode switching process of the company I work for (Saunders et al., 2015).

The research questions and objectives address the current research gap outlined and develops a model to understanding how managers respond and resolve the interdependencies of simultaneous internationalisation activities (Silverman, 2015; Creswell, 2018). To explore the individual experiences of managers, the research will adopt a single case study strategy. Within a phenomenological perspective this seeks context-dependent knowledge formed through the experiences of expert's activities (Flyvbjerg, 2006). In Table 32 the specific techniques and sampling sizes are indicated for the respective research objectives. A single phenomenological case study allows me to learn from the experts who operate based on intimate knowledge within their area of expertise (Flyvbjerg, 2006). Focusing on one multinational company will allow me to overcome the limitations of previous research and understand the interdependencies of activities within a transition process (Rezende, 2006; Asmusen et al., 2009). Therefore, I can collect data from most relevant key decision-makers (shown in Table 30) within an adequate time frame and consequently a relevant, credible and justified sample is indicated (Georgious, 2014). The number of interviews per key actor group is dependent on the total number of employees per key actor group, e.g. each of the German subsidiaries has one Managing Director, and on the number of employees who accepted to be interviewed in this research per key actor group (Georgiou, 2014). Table 30 displays the selected amount of interviewees per key actor group. Additionally, Table 30 shows the company affiliation and the experiences of each interviewee (if there is more than one interview per group, the interviewees are indicated with letters). 


\begin{tabular}{|c|c|c|c|}
\hline Key Actors & $\begin{array}{l}\text { Number of } \\
\text { Interviews }\end{array}$ & $\begin{array}{l}\text { Company } \\
\text { affiliation (in } \\
\text { years) }\end{array}$ & $\begin{array}{c}\text { Experiences with the } \\
\text { decision-making process of } \\
\text { mode switching }\end{array}$ \\
\hline Executive Body & 1 & $>20$ & $>20$ \\
\hline $\begin{array}{c}\text { Regional Sales } \\
\text { Manager }\end{array}$ & 3 & $\begin{array}{l}A:>10 \\
B:>20 \\
C:>3\end{array}$ & $\begin{array}{l}\mathrm{A}:>5 \\
\mathrm{~B}:>15 \\
\mathrm{C}:>3\end{array}$ \\
\hline Managing Director & 2 & $\begin{array}{l}A:>10 \\
B:>15\end{array}$ & $\begin{array}{l}\mathrm{A}:>5 \\
\mathrm{~B}:>10\end{array}$ \\
\hline Export Director & 2 & $\begin{array}{l}A:>10 \\
B:>10\end{array}$ & $\begin{array}{l}A:>10 \\
B:>10\end{array}$ \\
\hline Area Sales Manager & 5 & $\begin{array}{l}A:>10 \\
B:>15 \\
C:>5 \\
D:>2 \\
E:>5\end{array}$ & $\begin{array}{l}\mathrm{A}:>10 \\
\mathrm{~B}:>5 \\
\mathrm{C}:>2 \\
\mathrm{D}:>2 \\
\mathrm{E}:>5\end{array}$ \\
\hline $\begin{array}{l}\text { Head of Sales } \\
\text { Administration }\end{array}$ & 1 & >20Th & $>20$ \\
\hline Export Control & 1 & $>20$ & $>20$ \\
\hline Sum & 15 & & \\
\hline
\end{tabular}

Table 29: Number of interviews per key actor group

As illustrated in Table 30, most of the selected experts have been working for the case company for more than 10 years and many of them have at least five or ten years of experiences in the mode switching process. This shows and underpins the long-time experience of the selected key actors within the selected case company and in the mode switching process in particular. The exact number of years is not indicated for each key actor to ensure their anonymity within the multinational company. There are differences to be seen 
between the time of experiences of the experts with the mode switching process and their years of company affiliation because some of the key actors have been working at other positions which are not linked to the mode switching process before their current position.

One of the most discussed topics within the general qualitative methods literature on sampling is the saturation point (Lincoln \& Guba, 1985; Morse, 1994, 1995, 2007; Sandelowski, 1995). In the literature, saturation is defined as reaching a point of informational redundancy within the research where additional data collection provides little or no new contribution to the study. In this case, saturation is labelled as data saturation (Gentles et al., 2015). Saturation is the main criterion to determine when a sufficient sample size is achieved in qualitative research (Glaser \& Strauss, 1967; Lincoln \& Guba, 1985; Glaser, 1992; Morse, 1995; Charmaz, 2003; Merriam, 2009;). A benchmark that determines when a sufficient sample size is reached, is given by Cohen, Kahn and Steeves (2000; p. 56).

"The scientifically important criterion for determining sample size for the hermeneutic phenomenological researcher is the intensity of the contact needed to gather sufficient data regarding a phenomenon or experience. This intensity is measured in both length of time it takes for an event to occur...and how often a participant should be contacted to understand the changes undergone."

According to Symon and Cassell (2012) the recommended sample sizes depending on the nature of study are given in Table 31.

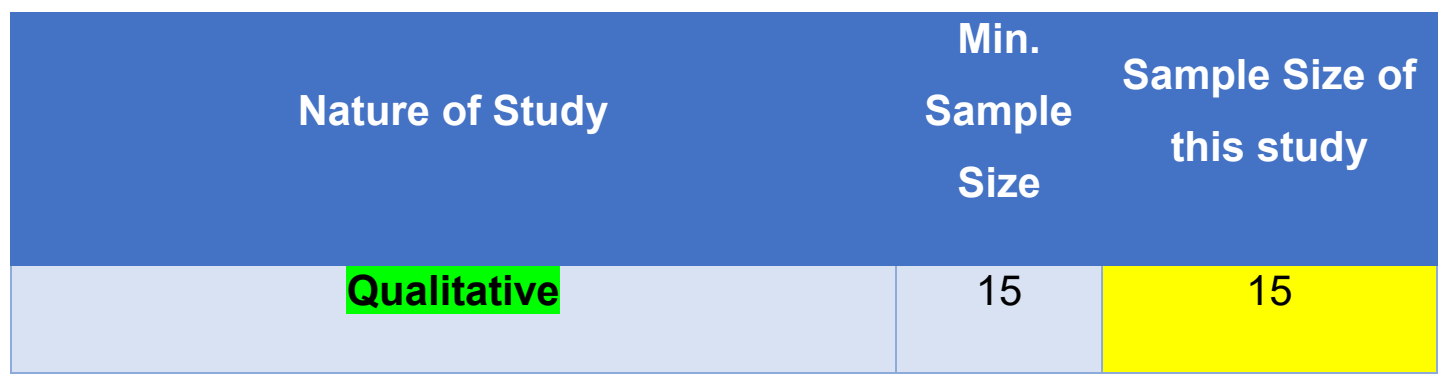




\begin{tabular}{|c|c|}
\hline \multicolumn{1}{|c|}{ Interviews } & $5-25$ \\
\hline Ethnographic & $35-36$ \\
\hline Grounded Theory & $20-35$ \\
\hline Phenomenological & $5-25$ \\
\hline Considering a homogeneous population & $4-12$ \\
\hline Considering a heterogeneous population & $12-30$ \\
\hline
\end{tabular}

Table 30: Recommended Sample Sizes

This research is underpinned by a phenomenological philosophical position and is a qualitative study that is conducting interviews as primary data collection method. Therefore, the green highlighted natures of research in Table 32 need to be considered for this research according to Symon and Cassell (2012). As illustrated in Table 32 the selected sample size of this study is in line with the recommended samples sizes of Symon and Cassell (2012) considering the nature of this study. Next to this, Zhang (2009) and Georgiou (2014) who did their PhD studies in the same research area as this research and also used case studies only conducted 12 (Zhang, 2009) and 8 (Georgiou, 2014) interviews. Consequently, as the theoretical theories in the literature (Symon \& Cassell, 2012) and recent studies in the same research area of this research and with the same research strategy (Zhang, 2009; Georgiou, 2014) recommend or use a smaller sample size, the selected sample size of 15 interviews is justified and a credible saturation level is achieved. Furthermore, due to the boundaries of the selected case study and the focus on one multinational company, I can collect data from at least one person per key actor group in an adequate time frame and consequently a relevant, saturated and justified sample is supported (Manen, 2014; Robinson, 2014).

\section{Point 4: Sourcing Sample}


I used study advertising by contacting the key actors within the company I work for via email to get the key actors and experts of the decision-making process as participants of my study (Robinson, 2014). 


\begin{tabular}{|c|c|c|c|c|c|}
\hline Objectives & Data Type & \multicolumn{2}{|c|}{ Techniques } & Justification & $\begin{array}{l}\text { Sample Size and } \\
\text { Justification }\end{array}$ \\
\hline 1 & \multicolumn{5}{|c|}{ Secondary Review of Academic Literature } \\
\hline $2-4$ & Secondary & $\begin{array}{l}\text { Purposive } \\
\text { Sampling }\end{array}$ & $\begin{array}{l}\text { Secondary data } \\
\text { - If they help to answer the re } \\
\text { - If the benefit of th } \\
\text { - If I am }\end{array}$ & $\begin{array}{l}\text { me experts were used: } \\
\text { objectives } \\
\text { ir use is higher than their costs } \\
\text { allowed to use them }\end{array}$ & $\begin{array}{l}\text { Emails, minutes of } \\
\text { meetings which are } \\
\text { provided by the interview } \\
\text { participants. }\end{array}$ \\
\hline $2-4$ & Primary & $\begin{array}{l}\text { Purposive } \\
\text { Sampling }\end{array}$ & $\begin{array}{l}\text { Self-Selection (based on my } \\
\text { experiences with the investigated } \\
\text { mode switching process within the } \\
\text { company I work for) }\end{array}$ & $\begin{array}{l}\text { Due to the boundaries of the selected case } \\
\text { study and the focus on one multinational } \\
\text { company, I can collect data from all relevant } \\
\text { key decision-makers within an adequate } \\
\text { time frame and consequently a relevant, } \\
\text { valid and justified sample is indicated. }\end{array}$ & $\begin{array}{l}15 \text { semi-structured } \\
\text { interviews with the key } \\
\text { decision makers of the } \\
\text { investigated phenomenon. } \\
\text { Point of Saturation is } \\
\text { reached, as most key } \\
\text { decision-makers have } \\
\text { participated. }\end{array}$ \\
\hline
\end{tabular}

Table 31: Sampling strategies adopted for each objective (Saunders et al., 2015; Silverman, 2014 


\subsection{Quality in qualitative research}

The quality of qualitative research is often discussed in the literature and by researchers and there are different views on that subject (Robson, 2002; Gray, 2009; Merriam, 2009; Bryman \& Bell, 2011; Symon \& Cassell, 2012). The evaluation criteria for quality in qualitative research are very much connected with respective philosophical position of a researcher. According to Denzin and Lincoln (1994) there are different positions regarding the quality of qualitative research.

While positivists and quantitative positions belief that the evaluation criteria for the quality of a research are internal validity, external validity, reliability and objectivity the phenomenological and qualitative position argue that qualitative research needs a set of individual and seperate criteria for evaluating the quality of the research because the underpinned beliefs are different (Symon \& Cassell, 2012). Accroding to Kopola and Suzuki (1999) the main evaluation criteria for qualitative researchr are trustworthiness, reflexivity and representation. However, according to Symon and Cassell (2012), qualitative research is very much diverse and therefore there is no general list of elements which determines if the necessary quality in qualitative research is reached. Symon and Cassell (2012) belief that qualitative researchers need to draw on the elements which are most relevant for their research and using the right elements is a learning process (Symon \& Cassell, 2012, p. 220):

"the creative brilliance of qualitative methods, like any interpretive art, is learned through practice and apprenticeship. While rules and guidelines are helpful, if it were really as straightforward as 'eight simple criteria', there would be no magic, no surprises, and therefore no genius."

As I have based my research design on a phenomenological and qualitative approach, I also intend to evaluate the quality of my research according to Denzin and Linclon (1994) and with the evaluation criteria of trustworthiness, 
reflexivity and representation. These evaluation elements are also defined and explained by Symon and Cassell (2012) and conducted by Jung (2017) in his PhD study.

\section{Trustworthiness}

For many researchers trustworthiness is the primary criterion for evaluating the quality of qualitative research which requires that elements of "good practice" are carried out in the research process (Lincoln \& Guba, 1985; Kopola \& Suzuki, 1999). Consequently, the transparency of the researcher throughout the ressearch process is the foundation for the quality of each qualitative research project (Riggs, 2015). According to Stiles (1993), there are the key elements (a) disclosure of the researcher's orientation, (b) intensive and prolonged engagement with the material, (c) persistent observation, (d) triangulation and (e) and deep discussions about the findings, to ensure that trustworthiness is given by the research process. I intend to follow and include these key elements in my research process to ensure the trustworthiness of the research design, approach, process and finally the outcomes. I have fully disclosed my orientations, previous knowledge about the topic and my role in chapter 3.7.4. In chapter 3.8.1.2, I disclosed my inductive thematic analysis process and consequently showed intensive and prolonged engagement with the data. Due to the iterative approach of the thematic analysis process, a persistent observation of the material is ensured. By using a multi-method qualitative approach I use documentation reviews to indicate the findings of the semi-structured interviews and to ensure data triangulation. Last but not least the deep discussion about the findings is ensured in chapter 5 of this thesis.

\section{Reflexivity}

As I am the central part of the research process and in developing the interpretations and outcomes of the research, reflexivity is an essential part for ensuring quality in a qualitative research project. According to Kopola and 
Suzuki (1999), the commitment to reflexivity requires that the research topic, design and process together with my personal experiences and bias are critically evaluated throughout the entire research process. There are three types of reflexivity (Wilkinson, 1988), personal, functional and disciplinary reflexivity. I intend to ensure the quality of my qualiative research project by commiting to the three types of reflexivity. I acknowledge that my personality, personal interests and personal values influence the research process and my final contribution to knowledge. This research ensures the functional reflexivitiy by investigating the research process continously and by being transparent regarding my assumptions, values and biases. For ensuring the disciplinary reflexivity, I will critically evaluate and analyse the selected methodology of the research process.

\section{Representation}

The represenation of the findings and outcomes of a qualitative research is essential because it is not just about writing up but rather being a part of the research process and sometimes it even constitutes findings (Denzin \& Lincoln, 1994). Regarding the quality of qualitative research, the representation of the findings plays a decisive role because the presentation style and how I present my results is very much influenced by my personality. Therefore it is so important to include narrative and personal information about me in the research project in order to give the reader a chance to evaluate my representation. Following the concepts of Lincoln and Guba (1985) ensures that I am representing my final research outcome in high quality. These concepts include credibility, transferibility, dependability, confirmability and authenticity. For achieving a credible representation of the final outcome, I will present the experiences of the participants. Within the representation of the research findings, I will discuss the transferabilty of the outcomes by comparing the results with the current literatur body. By explaining the research process, design and approach very deeply, clearly and transparent, I will show the dependability and that a replicable research process is ensured. 
I will relate the outcomes and contributions to the extracts of the participants and will link the results to the data to ensure the confirmability of his representation. By investigating the research topic from different view points, the rearcher will write the representation of his contribtuion to knowledge in an authentic and transparent way (Kopola \& Suzuki, 1999; Symon \& Cassell, 2012).

\subsection{Research Ethics}

The ethical approval for the research project was obtained by the university of Gloucestershire because the RD1 of this research was approved. The ethical approval is necessary to protect the participants of the research project and the finally approved RD1 document is attached to this thesis in appendix 12. Following the guidelines of the research ethics handbook of the University of Gloucestershire ensures that the given ethical approval of the RD1 is maintained in this research project (Gloucestershire, 2020).

Before the research project was started I had to get the ethical approval of the company I work for as I did the research project as an internal researcher (see chapter 3.7.5). For getting the approval of the company I discussed the research problem and project with my direct manager. After getting the approval of my manager to do the research project as a part-time student, I discussed the research problem and project with the managing director of the selected case company and finally got the approval from the managing director to conduct the study as internal researcher under the requirement of ensuring the anonymity of the firm and the participants (Georgiou, 2014). Ensuring the anonymity was ensured through disguising the names of the participants and the investigated company in the interview transcripts. All interviewees and Isigned the informed consent form in appendix 5 of this thesis. This internal approval process within the selected multinational company is illustrated in appendix 12 of this thesis. 


\subsection{Chapter Summary}

Chapter 3 of this thesis presents the methodological approach, research strategy and finally the research design outlined for the research project. Based on the research questions and objectives, I decided to adopt a phenomenological and interpretive philosophical position to achieve the aim of his project. Following the research onion of Saunders et al. (2015), I have developed the research design illustrated in Figure 39.

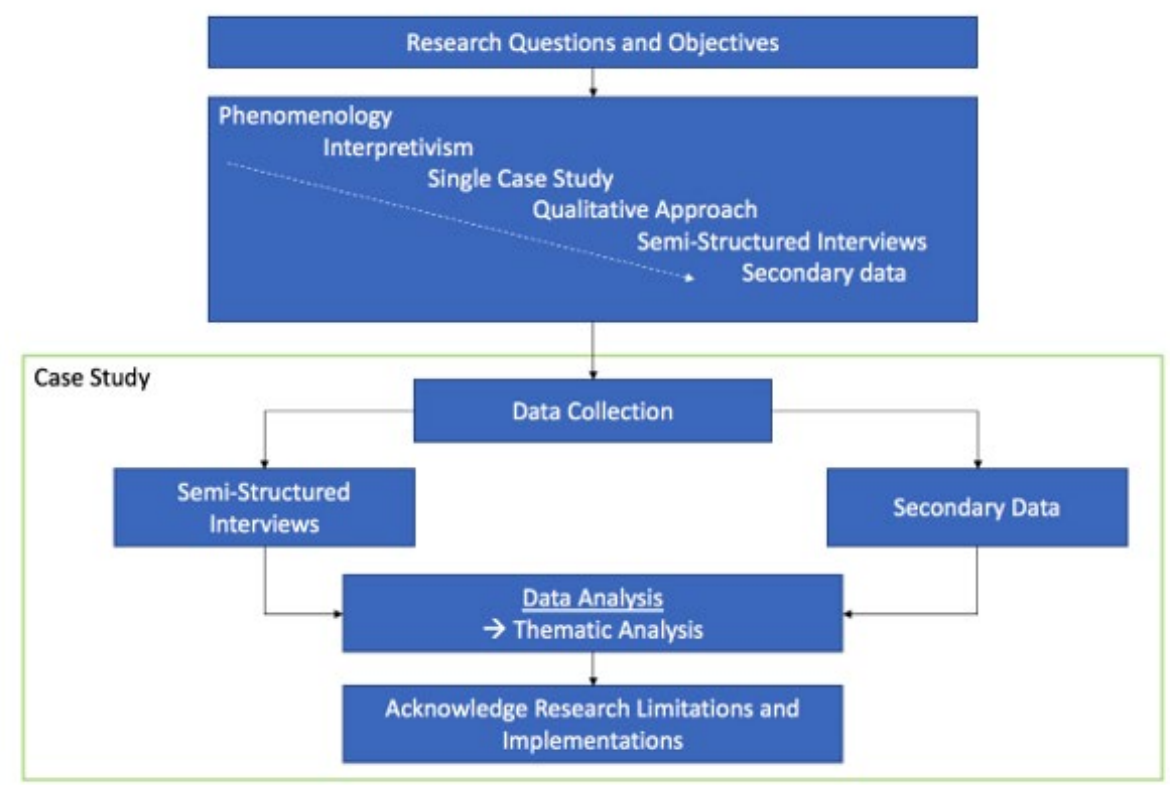

Figure 37: Research Design

I am using an inductive approach according to Dudovskiy (2014) by conducting an in-depth single case study to observe and find patterns on which he can build a new theory in form of a process model of the decision-making process of mode switching within multinational companies. As I am working as an area sales manager in the export division within one of the biggest lubricant manufacturers, he has access to data which were inaccessibly for previous researcher. Therefore, I selected this revelatory case company to do my indepth analysis (Yin, 2015). The selected multinational company is an information rich single case because it has a long history in the industry, has 
a global structure and many international activities, is not under the top 5 of the biggest manufacturers which would indicate to be an extreme case but is still within the top 14 of the biggest manufacturer which proof that the company still have a significant position but also averaged position within the industry (Seawright \& Gerring, 2008).

As data collection methods, I am using two qualitative methods. The semistructured interviews are the main method and have the role to collect data and to find the first results, while the collection of secondary data through documentation review is used to support and triangulate the findings from the semi-structured interviews. Consequently, both methods complement each other and build a robust and justified method approach to conduct this research and for achieving the research aim. For sampling the experts for the interviews, I used the purposeful 4-point selection approach from Robinson (2004) and selected 15 experts from the case company. The saturation level of the sample size is justified according to the recommended samples sizes of Symon and Cassell (2012) related to the qualitative and phenomenological nature of this study and by other $\mathrm{PhD}$ studies which are related to the same research design. For analysing the collected data of the interviews, I use the inductive 6-step framework of thematic analysis from Braun and Clarke (2006) to build the model of the decision-making process and to achieve the research aim. The data from the documentation reviews are used to triangulate the results from the interviews.

Last but not least, research ethics are discussed and through the evaluation criteria of trustworthiness, reflexivity and representation the quality of this qualitative research project is ensured. 


\section{Analysis and Findings}

\subsection{Introductory Comments}

The purpose of this chapter is to present the findings from this research and to outline the core data and extracts from the dataset that contributes to the development of the model. The chapter is sectioned into three parts. Firstly, I identified the key themes and findings per theme using the inductive thematic analysis technique in the transcribed data from the semi-structured interviews. The identified themes and their connections are illustrated in a concept map, which can be seen in Appendix 8. Secondly, I develop my model based on the previous presented findings. Last but not least, I analysed the documents which I received from the participants by using predefined codes, themes and subthemes from the developed concept map of the semi-structured interviews. Consequently, I am using the documentation review to support and triangulate the findings from the semi-structured interviews. Both methods complement each other and build a robust and justified method approach to conduct this research based on my phenomenological beliefs and for achieving the research aim.

\subsection{Findings from the Interviews}

The findings from the interviews are grouped according to the main themes that are identified from the inductive thematic analysis process which is explained in the previous chapter (chapter 3.8.1.2). The overview of the main themes which were identified in the interview transcripts is illustrated in Figure 40. 


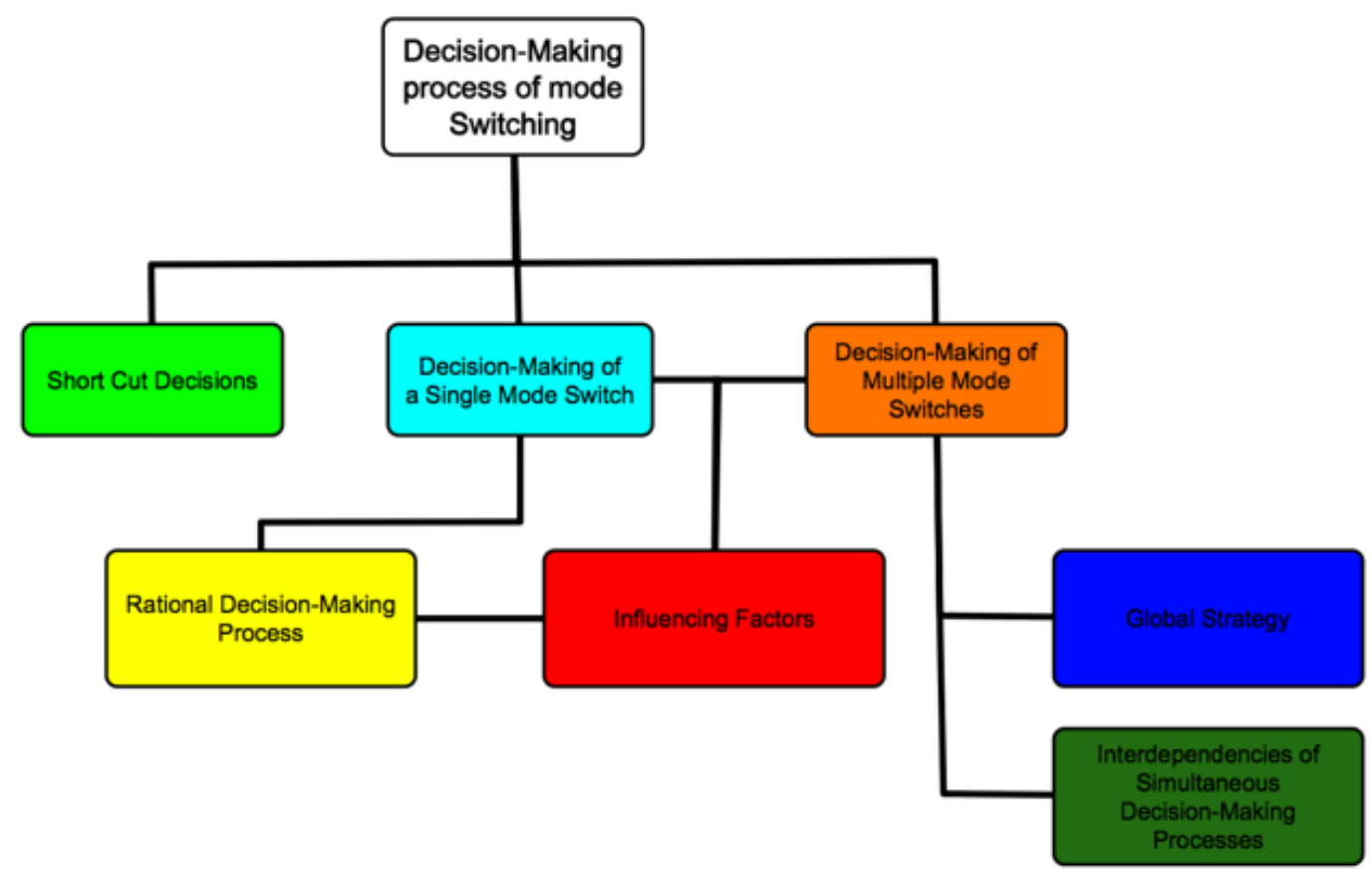

Figure 38: Summarized concept map

(The colours and shapes in the figure are only provided to make them more readable and do not have a specific meaning)

The three main themes which build the foundation of the findings are short-cut decisions, the decision-making process of a single mode switch and the decision-making process of multiple mode switches. I found out that there are three set-ups of the decision-making process of mode switching within the multinational company. First, there is a decision-making process of a single mode switch which means that the multinational company decides about a possible mode switch in one international market. Secondly, there is a decision-making process of multiple mode switches which means that within the multinational company, there are decision-making processes about mode switching in several international markets at the same time (multiple simultaneous mode switches). These decision-making processes of switching the mode in several markets at the same time are connected and impact each other (interdependencies). And last but not least, there are short-cut decisions which do not follow a structured decision-making process but rather are 
intuitive and a decision is made at short notice. The following sections are grouped according to the identified main themes (the three set-ups of the decision-making process) and the findings per main theme are presented. The sub sections of the main themes are structured according to the identified sub themes which represent the suggested process steps of each set-up of the decision-making process of mode switching and the respective influencing factors of the process set-ups. The connections between the suggested sub themes and process steps are presented in section 4.2.1.3 and 4.2.3.3 in which I develop my models of the decision-making processes of mode switching within multinational companies.

\subsubsection{Decision-Making Process of a Single Mode Switch}

As sub themes of the decision-making process of a single mode switch, I identified the themes rational decision-making process and influencing factors. The identified main and sub themes are in line and fit to the literature chapter and the conceptual framework level one in Figure 26 (page 120). The conceptual framework level one is focused in the inner loop on the rational decision-making process from the switching motivators through gathering information, evaluation process and the final decision step and additionally is focused on the influencing factors around the rational decision-making process such as the external and internal environment as well as the influence of the key actors in the conceptual framework. In the following sections, the researcher illustrates the findings of the sub themes and finally develops his model of the decision-making process of a single mode switch in section 4.2.1.3.

\subsubsection{Rational Decision-Making Process}

Figure 41 shows an extract of the holistic concept map which contains all subtopics and codes that are connected with the main theme rational decisionmaking process which is highlighted in dark yellow. These subtopics and codes indicate the single process steps of the rational decision-making 
process and which factors impact the single process steps of the rational decision-making process.

The sub themes are highlighted in light yellow and are inside rounded rectangle; situational analysis, starting impulse, incremental process, strategic process, decision-making and mode options. The codes are highlighted in grey and are inside octagons; good commercial performance, dissatisfaction with performance, changes within an existing partner, personnel, business, competitor and politics. The colours and shapes in the figure are only provided to make them more readable and do not have a specific meaning.

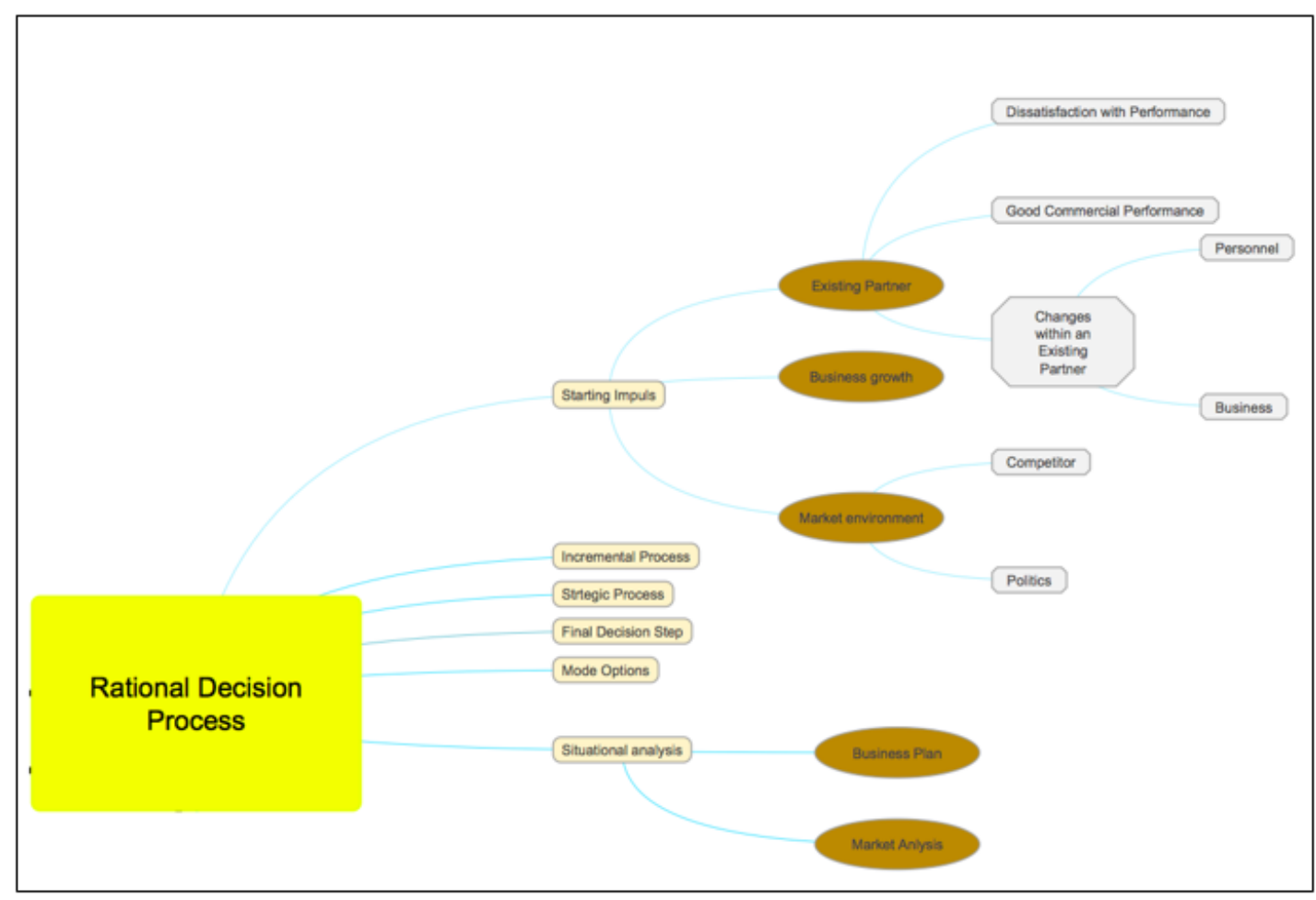

Figure 39: Extract of the Concept Map_Rational Decision Process (The colours and shapes in the figure are only provided to make them more readable and do not have a specific meaning)

The orange highlighted themes which are inside ovals can be defined as additional sub-sub themes or as groups of codes. Due to the fact that some of these sub-themes are used as codes because they do not have additional subgroups, I define the orange highlighted ovals as groups of codes. 


\subsection{Starting Impulse}

As I intends to present my findings of the data set regarding the decisionmaking process of mode switching, I start with the findings of the sub theme starting impulse because the data from the expert interviews show that the starting impulse can be conceptualized as the starting point of the investigated process. According to the data set and the experts there are three types of starting impulses which could start the rational decision-making process; an existing partner of the multinational company, the business growth intention and the market environment of the multinational company. Looking at the only internal factor that could be a starting impulse according to the data set, participant 2 states:

"It was clear that if you want to achieve even more market share and market penetration, you have to change the set-up."

This statement of participant 2 underpins that there are internal growth intentions within the investigated multinational company which are indicated as the starting impulse for the rational decision-making process to think about a mode switch in a respective market and country. This is also suggested by participant 6 who mentions:

"Of course, if we want to grow the holding market share to 2-3\% in South America, what do we have to do in those countries? We had to answer the questions if it is absolutely essential that we set up a local subsidiary, or is a distributor sufficient, or does one have to have a local production site?"

This statement additionally indicates that the rational decision-making process of a mode switch in a country or a region can be started because of the strategic goal and the long-term growth intentions of the multinational company. Last but not least the internal starting impulse of strategical and long-term growth intentions is supported by participant 3 : 
"Yes, the process was clearly driven internally. But it was also clearly driven

by our long-term strategy of gaining market share, achieving long-term growth and achieving significant business potential in countries where we are underrepresented."

Also, this statement indicates that the starting impulse of the rational decisionmaking process can be driven internally, and the main driving force is the intention of long-term business growth and to gain as much as possible of the local market share.

Besides the internal starting impulses of the rational decision-making process the experts and data set express external starting impulses that can happen which are the starting point of the rational decision-making process. These external starting impulses are grouped into the existing partners and the market environment of the multinational company. According to the participants there are two types of external partners. The independent thirdparty partners like distributors who are responsible for a respective market as mentioned from participant 5:

"There are other examples where we have lost distributors due to age, because the owners did not continue and had no successors."

This statement of participant 5 explains that a partnership with an external distributor can end because the distributor is going out of business, e.g. because the owner does not continue. If the distributor is stopping his business the multinational company has to develop a new strategy for the respective market and may implement a mode switch. Consequently, the external thirdparty partner could be the starting impulse for a mode switching process.

Additionally, to the independent partners, there are joint venture partners, as stated by participant 2 : 
"At some point, the goals of our joint venture partner, the officially communicated goals, were no longer the same as the holding's officially communicated goals. “

As stated by participant 2, changed strategical goals at the joint venture partner could also be the starting impulse for the mode switching process. The starting impulses which can occur from external partners (either from independent partners or from joint venture partners) can be grouped in dissatisfaction with the performance of a partner, good commercial performance of a partner and finally changes that are going on within an external partner. Participant 5 stated that the dissatisfaction of the multinational company with the performance of one of their partners can be a starting impulse for the decision-making process of a mode switch:

“...that we usually exchanged old non-performing distributors..."

A rather similar statement is given by participant 11 :

"Second, that the company is not satisfied with the performance in a respective market but rather sees a much higher potential in a market and therefore decides to handle this market with an own sales force to achieve a higher market share."

These statements illustrate that a non-performing partner in a respective market can be a reason and consequently a starting impulse for the multinational company to do a mode switch.

But not only poor performance of an external partner can be a starting impulse but rather a very good performance of an external partner can be considered as a starting impulse according to Participant 11 :

"First, that a respective sales partner in a market performs very well and therefore the company decides to acquire the partner or launch an own 
sales subsidiary because the sales partner proved that the respective country has a high potential."

The same participant suggested that good as well as bad performance of an existing external partner can be a starting impulse of the decision-making process, but he also states that the positive performance of an external partner is the stronger starting impulse:

"Although there are two possible scenarios, the positive performance scenario definitely has the bigger impact on the mode switching decision."

The positive performance of external partners as starting impulse is also indicated by participant 14 :

"I guess or I believe that at that time we had a very strong local partner in the market who had a very good market access, also to the big international companies...

... Finally, having a strong local partner which were acquired was a nice ad-on and perfect match due to his structure, employees and market access."

Consequently, many participants support that the performance of an existing external partner can be a starting impulse either as positive performance or as negative performance.

According to the participants and the data set, the last starting impulse that could occur from an external partner, are personnel or business changes within the existing partner. Participant 2 explains an example in which a business change within an external partner become the starting impulse for the multinational company to start the decision-making process: 
"At some point, the goals of our joint venture partner, the officially communicated goals, were no longer the same as the holding's officially communicated goals."

A rather similar statement is given by participant 4 :

"And so yes, because the joint venture partner itself, especially in this smaller European country, has emancipated itself, is no longer technologically dependent on us today or was no longer dependent on us at the time of termination."

Both statements indicate that a business change within an external partner either it is a change of the long-term strategic goals (as explained in the first statement of participant 2) or it is a change in the set-up of internal departments (as illustrated by the second statement of participant 4), can occur as starting impulse for the multinational company to begin the decision-making process.

Beside the business changes, also the personnel changes within an external partner can be a starting impulse, as mentioned by participant 5 :

"There are other examples where we have lost distributors due to age, because the owners did not continue and had no successors."

Consequently, there could happen changes within an external partner which act as starting impulses for the multinational company either because of personnel changes or because of business changes.

The last code group of the sub theme starting impulse is the market environment in which I grouped the codes in competitor and politics.

According to participant 1 , the competitors or their behaviour or changes within the competitors can be a starting impulse of the decision-making process of mode switches, as he stated: 
"The story was so, uh, the family or conglomerate had a joint venture with a competitor which was a very well-known brand ...

... You have to say, the Saudis had $70 \%$ of the joint venture, so the local investors and $30 \%$ had the competitor, but the brand came from the competitor. And the dissatisfaction, the details are unimportant, I think, but the dissatisfaction was so great that the local family intended to find a new partner and then everyone came, the Shells, the Castrols, the Elfs, etc., all known names wanted to take this market in their hands, because the competitor apparently flies out and takes over this $30 \%$."

Also, participant 2 raised the topic of competitors who trigger the starting impulse of the decision-making process:

"Finally, if the competitor did not address this itself, it was still triggered by their behaviour, e.g. by the aggressive competition in Germany."

Both statements show that the situation at a competitor can act as starting impulse for the multinational company either because a former partner of the competitor finish the partnership or because the strategy and behaviour of a competitor is changing. It is evident that changes within competitors can cause market adjustments and changes to which the multinational company has to react and might change its mode option.

The last starting impulse that I identified in the data set is the politics and with politics, I mean the political situation in a country, laws and the politicians themselves. Participant 1 gives an example how the political situation in a country or market can trigger the decision-making process of the multinational company:

"We had a local subsidiary in both countries and sold it because it was no longer manageable. In one of the countries we had death threats against the manager, who was a local citizen and didn't dare leave the 
house. There was corruption, fraud, intrigues and everything you can imagine."

This example shows that the politics can be the starting impulse of the decision-making process and the outcome of the process could even be to quit a market completely, but the politics can also occur as starting impulse and the outcome is completely different. As stated by participant 4 , the politics can work as starting impulse that the multinational company decides to enter into a market with an own subsidiary:

"However, there are always the tendencies of protectionism, in which a country tries to protect its own economy in such a way that it makes it more difficult for imported products to compete with local producers. If such a change is foreseeable, then we are already of the opinion that we must rather set up our own company in order to be perceived there as a local competitor."

According to this statement of participant 4, a political decision e.g. regarding the import and export regulations can trigger and consequently can be the starting impulse for the decision-making process of mode switching because the political circumstances within a country require a specific mode to be implemented. If this mode is not implemented yet, the multinational company has to switch.

Finally, the sub theme starting impulse shows that there are several and different factors that could occur as starting impulse of the decision-making process of mode switches for the multinational company. Figure 41 gives a good overview of the starting impulses in form of the respective codes in the concept map.

\subsection{Situational Analysis}

According to the findings of the data set, the next step of the rational decisionmaking process is gathering information. This process step is identified as one 
theme in the thematic analysis of the rational decision-making process as illustrated in Figure 41. As gathering information also includes the data analysis step, I wanted to proceed with the subtheme data analysis which I identified from the collected data set as the next step of the decision-making process.

The first code and step of the data analysis is identified as the market analysis. This market analysis can be grouped in quantitative market analysis and qualitative feasibility analysis of a market. Participant 9 gives an example of data that is analysed in the quantitative market analysis:

"Additionally, in Chile it can be said that more than 400 open gears are working in the mining industry. The defined goal was to lubricate $10 \%$ of the open gears with our products after 3 years. As a result, if the customer uses our products for open gears, other products are usually also used for other lubrication points."

A similar statement is stated by participant 6 :

"Subsequently, I obtained statistics on the South American lubricants market in order to be able to estimate the market potential."

Hence, the quantitative market analysis is focused on getting as much as possible validated and statistical data about the market volumes in total and if possible, per business segment of the multinational company to develop a holistic and coherent picture of the market. Consequently, the quantitative market analysis is one part of the data analysis process step. The inter-step which is typically done before the quantitative market analysis is conducted and which is also part of the data analysis process step, is the qualitative feasibility market analysis as described by participant 4 :

"When we now say that we are talking about a market in the European Economic Area in the narrower sense, i.e. within the EU, Scandinavia. Then certain questions do not arise. There are no questions about the 
marketability of our products, there are no questions about the availability of raw materials, there are no questions about embargoes or imports. Therefore, in such a case, the market-related and financial evaluation is more in the foreground."

The participant explains with his statement that prior to the quantitative and financial market analysis, the due diligence or feasibility of a market needs to be checked and if there are any factors that could be a showstopper for the decision-making process. E.g. if a market is located protected from authorities or due to embargos, the multinational company does not enter into this market regardless of the size and the quantitative figures of the market. The participant also suggests, that this is depending on the region of the country, e.g. in an economic stable region like Europe with similar local laws, the feasibility market analysis is less important.

The next step of the data analysis is the collection of the data and to create the decision foundation which is identified as business plan in the data set. The findings regarding the business plan can be categorized into the existence of a business plan, the format of a business plan and finally the content of a business plan. Concerning the existence of a business plan as foundation for the final decision in the mode switching process there are different opinions of the experts in the data set. Participant 2 for example states:

"Sometimes I had the feeling that we at the holding had set up national companies without looking at economic aspects."

A rather similar statement is given by participant 13:

"I would like to see it sometimes simply more backed up with hard facts. You can't prove everything with figures and some things are also in the qualitative area and how do I quantify them? I agree with anyone who uses that as a counterargument. But I lack the link to say what I want to achieve and what means I make available." 
Both expert doubt that the multinational company always have the quantified foundation for a decision of mode switches in form of a business plan, but both also relativize their statement as they say "sometimes". As a result, they also indicate that there are decisions with a business plan as foundation but there are also some decisions which are made without a business plan and detailed quantified analysis. The existence of a business plan as foundation of the final decision of a mode switch is suggested by participant 2 who states:

"We were given the task by our managing director to draw up a business plan with the working hypothesis "Establishment of a national company in a small country in Europe". This business plan then required various analyses such as market, product and competition analysis. We carried out a complete P\&L calculation for the national company on the basis of a full cost calculation and thus virtually simulated the complete national company with all costs incurred."

And by expert 12:

"A business plan is usually created...

... So, a decent market and competition analysis, the analysis of the market entry barriers, where are potential customers, etc."

Consequently, most of the decisions about a mode switch are based on a detailed business plan and some decisions are made without a business plan. These decisions which are not made based on a detailed business plan and which I identified as short-cut decisions are the main focus of chapter 4.2.2.

Regarding the format of a business plan my findings are that no blueprint or business plan starting template is existing in the multinational company but rather that depending on the decision-maker the business plan can look differently. This is indicated by participant 6: 
"It is important for me to mention that there was no template or best practice for creating the basis for the final decision, but that I was given a free choice by our CEO and was able to create the decision basis myself."

After clarifying the existence of a business plan and the format of a business plan, I intend to show the findings regarding the content of a business plan. Participant 7 suggests that a business plan should contain qualitative as well as quantitative aspects, although he also points out that the quantitative factors are finally more important for the decision:

"It definitely should be a mixture of both, quantitative as well as qualitative factors. I think that the business plan and the final decision is mainly based on quantitative and measurable factors."

A similar statement is given by participant 9:

"Therefore, to come back to your question, it was a combination of qualitative and quantitative aspects that finally formed the basis for the decision."

Participant 12 explains that there are qualitative as well as quantitative variables in a business plan and that the qualitative factors are the foundation for the quantitative analysis. Hence, the qualitative factors are the foundation and the quantitative variables are the decisive basis for the decision:

"Basically, in addition to the pure numbers, the question is asked how to get to the numbers and basic assumptions have to be made. And the basic assumptions must also be described...

...The qualitative considerations of how to gain business in which regional market and in which market segments with which customers, through which product range and in which period. You always have to 
think about this. This means that it is a mixture of qualitative and quantitative factors."

As a result, I can summarize my findings regarding the business plan that the multinational company uses business plans as decision foundation, without a fixed format as blueprint but rather a format that differs from case to case and which is depending on the responsible manager and that the business plans contain qualitative (e.g. the market structure as the existing market segments of the target market) as well as quantitative aspects (e.g. cash flow calculation or profit and loss calculation).

\subsection{Final Decision Step}

The last process step of the rational decision-making process which was found as a sub theme is the final decision step of the process. The findings of this theme can be grouped into findings about the decision-makers and the decision parameters. Several participants state that the final decision about a mode switch in a respective country is in the responsibility of the regional management, as for example participant 7:

"These decisions are typically done by the regional sales manager who is responsible for a respective region."

As the regional management is located at the head quarter of the multinational company, the final decision is made by the head quarter and as the regional management is reporting to the executive board directly, the executive board is also involved into the final decision. This is suggested by participant 9 :

"Finally, the decision is made by our holding company."

And participant 4:

"In this case, the decision-makers are first and foremost the regional managers for the regions, who are not necessarily located directly with the Executive Board" 
Although the final decision is made by the regional management, the managers try to involve their colleagues, get their input and to find a consensus before doing the final decision. This is supported by participant 3 :

"Um, in the end it was made in the region, so by me, of course in close consultation in the house with for example my managing director colleagues in Europe, from where there were a lot of deliveries to this country e.g. from France, Germany and Italy."

The second part of the sub theme final decision step is about the decision parameters, determinants and decisive factors of why the decision-makers are doing a specific decision. One of the findings in this regard is that the multinational company does not have fixed decision parameters or determinants which they use for a final decision. This is stated by participant 4:

“We don't have any hard decision parameters, where we say, if you don't jump over this hurdle, then it won't work. We are not there. So you can already say that it is a case-by-case approach where you try to make the individual case fair. If you say a ROI in a mature country, you can say for a large investment, say 6-7 years, we feel comfortable with the decision. But this does not mean that we reject the same investment decision in another country because the ROI is 8 years. So you can say that we are agile or at least we are not stuck in such decisions."

The finding of this statement is clearly that the final decision about a mode switch is an agile and case by case process. The multinational company decides each case based on different parameters and determinants. This does not mean that the process until coming to the point of final decision is always different. This is also indicated by the statements of other participants. For example, participant 6 states: 
"The decisive factors were certainly the qualitative reasons rather than the simplified profit and loss calculation. The profit and loss calculation was prepared and accepted and not turned around and adjusted three times."

While participant 6 mentions that the qualitative parameters play the decisive factors of this specific example, participant 10 states:

"Yes, I think that's how it happens, and I think that the holding is very much focused on quantitative factors. If I think about the decisions within the holding, I have the feeling that often the decisions are made with as less risk as possible and on the long-term."

As final outcome of the final decision step sub theme it can be summarized that the final decision is made by the top management which is responsible for a region, however they try to involve all key actors of the process into the decision-making and that the decision parameters and determinants can vary from decision to decision and from case to case.

\subsection{Mode Options}

The different mode options which are existing within the multinational company are the decision options for the decision-makers. I found out that as higher the capital investment of a mode option is as higher is the possible management control of a company. The management control is for the multinational company also a decisive factor which is explained in the next chapter with the influencing factors. The findings of the data set are that the multinational company is using several mode options to serve its global and foreign markets like export, licensing, contractual agreements, joint ventures and wholly owned subsidiaries. The extract of participant 12 shows these mode options:

"So from this point of view you can say that there are different mode options for a country and that there is the possibility to support a country and the customers via the export department directly from Germany, or 
I do the business via a trading partner, possibly with the aim to buy the business of the dealer at some point and to establish a local national company."

The first mode option with the smallest investment and management control is exporting which is also stated by participant 12. The next higher level is establishing a distributor with an official contract. Another possible mode option that the multinational company have is licensing which is between the contractual agreements and a joint venture regarding the factor's management control and capital investment, as stated by participant 1:

"That means we have gone one step further. Between the distributor and our own company or joint venture, we brought this joint venture in making. For the sake of completeness, there was no put option, only a call option."

This means that the multinational company developed their own mode which is a joint venture in making because they have always the option to buy a part of the partner's company. Therefore, this licensing mode option is between contractual agreements and joint ventures according to the parameter's management control and capital investment.

The last possible mode option that has the highest capital investment and the highest management control level is the own subsidiary either as sales subsidiary or as local subsidiary with its own production. This is also indicated by participant 7:

"I have made the experiences that typically the holding is expanding and growing in their markets globally and therefore the main mode switch that happens is changing for an existing set-up with a third-party dealer to an own sales subsidiary and often the holding has acquired one of their previous distributors in the past." 


\subsection{Incremental Process}

Following the inductive thematic analysis process, I identified the incremental process as a sub theme in the data transcripts of the participants. Behind this sub theme, there are data transcripts which focus on the complete process, the process flow and timing of the afore discussed process steps. Participant 10 states that there is no incremental process but rather a rolling process as many steps run in parallel:

"Therefore, it is more a rolling process, because the analysis starts far before the decision-making process of mode switches, so many steps run in parallel. As there are many mode options for the final decision, there are also many analyses which need to be done in parallel. "

The participant also points out that the process can include the analysis of more than just one new mode option and this already explains, why the process cannot be incremental but rather is rolling because if the analysis step for one mode option is finished, the analysis step of a second mode option just begin. Participant 11 suggests with his statement:

"All in all, I think there is no incremental and straight on process of the decision-making process of mode switching because there are many influencing factors and actions which are not foreseeable and therefore cannot be controlled, e.g. the cancellation of a distributor or the concentration on a certain business filed."

The participant means that the process is so complex and there are many influencing factors (which are discussed in the next chapter) that the decisionmaking process cannot be incremental but rather many process steps are iterative and needs to be done at the same time. Therefore, the outcome of this sub theme is that the decision-making process even if we are talking about the rational decision-making process within the multinational company is not incremental but rather a rolling and cycled process. 


\subsection{Strategic Process}

The last sub theme of the rational decision-making process was identified because I found in the data sets many codes and data of the participants in which they are talking about the decision-making process of mode switching as strategic process and the long-term goal behind the process. Participant 6 explains very well how the strategy for a specific region is developed within the multinational company and that there are strategic and long-term concepts before the final decision-making process of a specific country or mode option is done:

"Before the final decision was made, I introduced our CEO in a three pager about the strategy and my ideas for South America, in Power Point Slides, which I used later to discuss with the other subsidiaries as well...

... The three slides show what was the actual situation in 2016 when I arrived, what is the status in mid-2018 after the foundation of our new subsidiary and what is my outlook until 2023. Finally, it was about taking the map and exploring the goal that in the next 3-4 years at the latest a local subsidiary will also exist in two additional countries. In which form these local subsidiaries will be founded, whether as a joint venture or from the ground up, with a production site or not, has not yet been discussed, as this question does not yet arise."

As explained by the participant, there is a strategic factor inside the decisionmaking process and the long-term goals are considered in the process which means that the first thoughts about a decision can start by far earlier than the official decision-making process of mode switches starts.

Participant 3 also suggests that there are strategic elements behind the decision-making process of mode switches which play a decisive role in the process: 
"The strategy of how we do business in individual countries often has, in a way, a revolutionary development. Things that we may have done

10 years ago in a different way, where we were more opportunistic, we are now making much more focused and targeted."

The participant also explains that the strategic direction can be adjusted and changed over the years. Consequently, the rational decision-making process of single mode switches is part of a strategical process which is happening on a global and regional strategic level within the multinational company. This is a first indication that the decision-making process of a single mode switch is integrated into a global strategical network of a multinational company and consequently the several decision-making processes of mode switching are happening at the same time within the multinational company. These simultaneous decision-making processes exert interdependencies which is an aspect that I have considered in chapter 4.2.3.

\subsubsection{Influencing Factors}

Figure 42 shows an extract of the holistic concept map which contains all subtopics and codes that are connected with the main theme influencing factors, highlighted in dark red. I found out within this theme that there are factors (external, internal and circumstances) which influence the decisionmaking process at several stages and significantly drive the final decision.

Some starting impulses from the rational decision-making processes (which are explained in the previous chapter 4.2.1.1) are overlapping the influencing factors as for example, the business growth intention of the multinational company as well as the changes within existing external partners. I decided to keep these two sections separated because the starting impulses are very much related to the rational decision-making process and are "only" the starting point of the decision-making process while the influencing factors can have an impact on the decision-making process at any time and process step. Consequently, each influencing factor can be a starting impulse because the 
influencing factors act at each stage of the process but not each starting impulse is an influencing factor because the starting impulses are clearly defined as starting point of the decision-making process. I will bring both sections together in chapter 4.2 .1 .3 by integrating them into my model of decision-making processes of a single mode switching.

The sub themes of the influencing factors are highlighted in light red and are inside rounded rectangle; external, internal and circumstances / opportunities. The codes are highlighted in grey and are inside octagons; market, market barriers, culture, accessibility, availability of employees, local legal requirements, due diligence, security of raw material supply, export control regulations, competitors, politics, reputation, partners, personnel due diligence input personal changes key actors, market, customer structure, size, market share, economy, tax, competitors, complexity costs, cultural effects, local proximity to the customers, controlling the market strategy, personal interests, personal behaviour, bonus \& provision system, critical mass, financial possibility, cannibalisation and expansion strategy. The colours and shapes in the figure are only provided to make them more readable and do not have a specific meaning. 


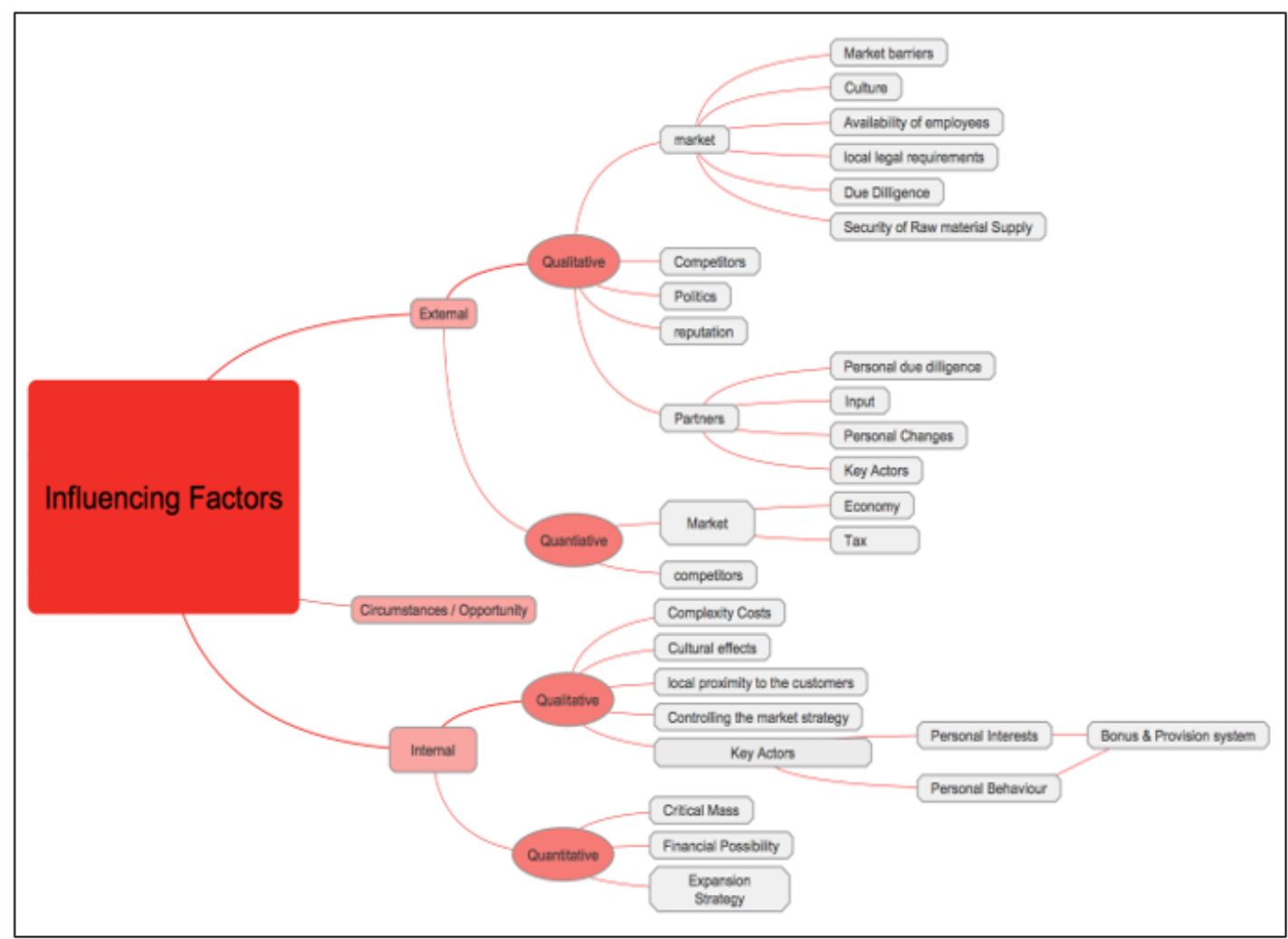

Figure 40: Extract of the Concept Map_Influencing Factors (The colours and shapes in the figure are only provided to make them more readable and do not have a specific meaning)

The mid red highlighted themes which are inside ovals can be defined as additional sub-sub themes or as groups of codes. To be consistent with the definition of the previous chapter these ovals are defined as group of codes.

\subsection{External influencing factors}

According to my findings, the external influencing factors can be grouped into qualitative and quantitative external influencing factors. The extract of the qualitative external influencing factors is shown in Figure 43. 


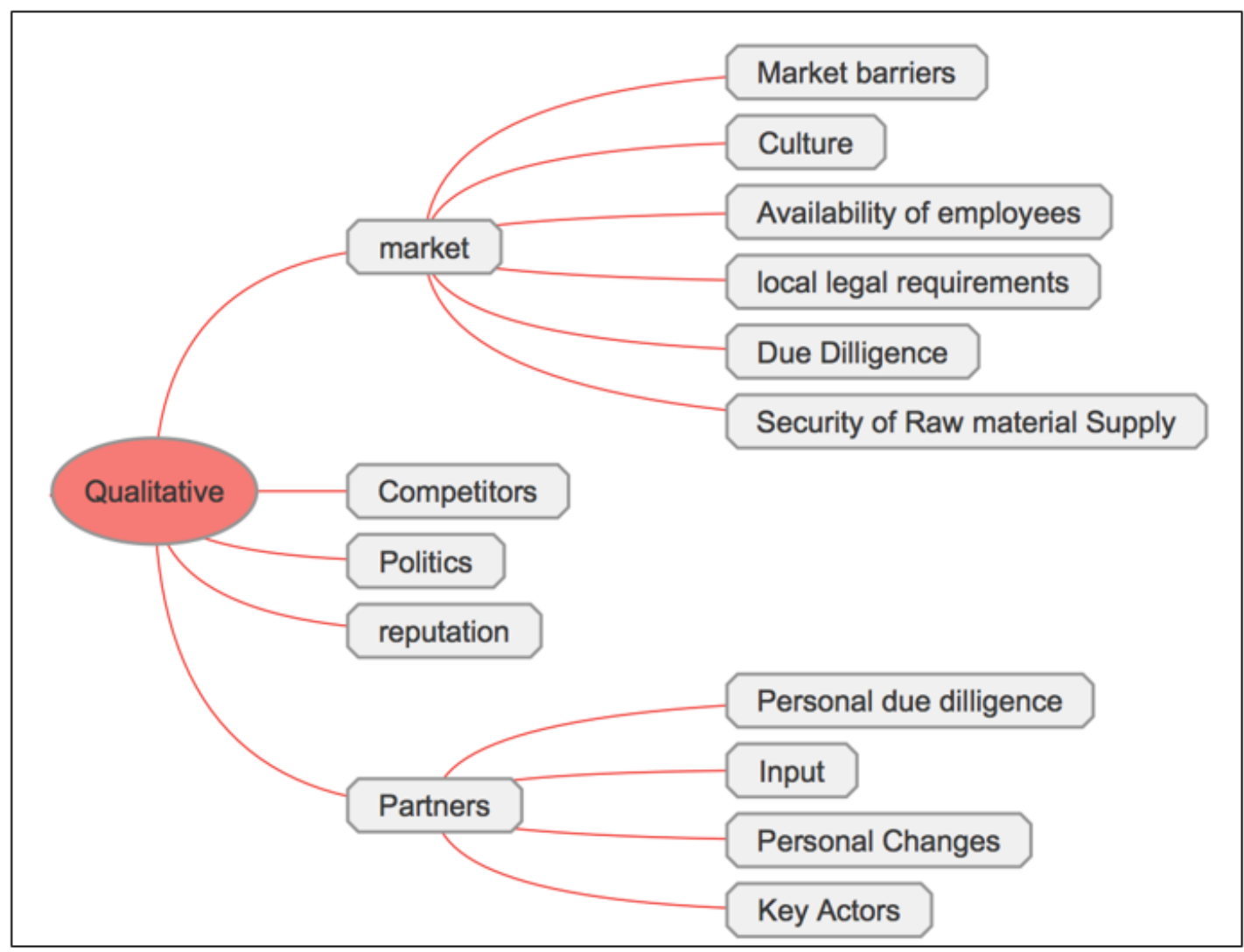

Figure 41: Extract of the Concept Map_Qualitative external influencing factors (The colours and shapes in the figure are only provided to make them more readable and do not have a specific meaning)

First code of the qualitative external influencing factors is the code group market which contains the codes, market barriers, culture, availability of employees, local legal requirements, due diligence and the security of raw material supply.

As mentioned by participant 6 the existing or changing market barriers can be the decisive influencing factor of a decision-making process of a single mode switch:

"It was clear to me that the decision of launching an own local subsidiary is mainly caused by the lowest possible entry barriers. These entry barriers were decisive for me in the end. For me, entry barriers are, basically quite simple, there is a vertical oil industry in the country, so 
local oil is produced. The fact is that, as a rule, countries where oil is extracted are very protectionist about imports, while countries without oil extraction are logically more dependent on oil imports. This means that there are fewer restrictions on competition."

The participant indicates with his statement that the market barriers can have an influencing effect on the decision-making process at any time of the process and additionally that in his point of view the market entry barriers are coming from the industrial set-up of a country and furthermore e.g. from the fact if a country extracts oil and has refineries.

Another qualitative external influencing factor that I found in the data set is the market culture in a country. For example, participant 10 raised the point that:

"Cultural influencing factors, e.g. that people of specific countries prefer to do business with local subsidiaries as they work in the same time zone and speak the same language. But on the other side there are also people of specific countries which prefer to work with foreign people, e.g. from Germany than with local people. The same is happening regarding the label "MADE IN GERMANY". There are countries and regions in which the customers are looking for "MADE IN GERMANY" products and are willing to pay a higher price and on the other side there are countries and regions in which the customers are only looking for the cheapest priced products."

Consequently, the culture of a market and country can influence the decisionmaking process of a mode switch because the new mode should consider the cultural factors regarding the responsible people who are working in a country, e.g. if a country should be supplied from Germany directly or via a local subsidiary, and also regarding the brand culture of a market and how the supply-chain to a market or country needs to be designed to implement it best possible to fit the cultural conditions and the customer requirements of a local market. In summary, during the decision-making process the multinational 
company needs to consider that the chosen final mode option fits to the local cultural aspects and set-up of the respective market.

An additional qualitative external influencing factor can be the availability of finding local employees if the possible new mode option requires local employees. This is a challenge that the multination company often has during the decision-making process of mode switching as suggested by participant 5 :

"The sticking point in many countries so far has been that they have found it incredibly difficult to find people who have the skills to do business, either because they don't have a foundation on which to build, or because they don't understand it at all. Um, that hasn't been so critical in the USA and Brazil, but in China, for example, it's very critical."

The participant explains that the lack of finding employees for a local mode option could have two reasons, first because they do not have the respective educational background to learn the lubricant business or second because they have the education but do not understand the lubricant business. The participant also indicates that this is dependent on the country and consequently it depends case to case if this influencing factor needs to be considered in the decision-making process.

Another big qualitative external influencing factor which is getting increasingly important in the chemical industry and consequently also in the lubricant industry, is the local REACH${ }^{1}$ requirements in a country or market. These local legal requirements have an enormous impact on the decision-making process, as suggested by participant 5 , because depending on the REACH requirements either the importing company, e.g. the distributor, or the exporting company, e.g. the multinational company, has to ensure that the products are REACH confirm:

\footnotetext{
${ }^{1}$ European regulations and laws regarding chemicals
} 
"But REACH and legal changes, these are just a few of the things I've heard about, and they can definitely influence the decision-making process."

Consequently, depending on the REACH requirements and which company is responsible for ensuring the $\mathrm{REACH}$ conformity of the products, the multinational company will choose between the mode options.

Last but not least the multinational company needs to consider the due diligence of a market or country as qualitative external influencing factor in order to ensure that the multinational company can do business in the respective country according to their code of conduct. One topic that is always critical in a country or market regarding due diligence is corruption. This finding is suggested by participant 4 :

"What are the customers accessible to us, what is the market accessible to us, because not every market is accessible to us due to corruption."

And participant 5 indicates it as well:

"The country we are looking at, is first and foremost a politically stable country. Uh, with relatively little corruption in South America. So, there were the general conditions to determine whether we could operate as a holding with our own national subsidiary here."

Consequently, the decision-making process of a mode switch is influenced by the due diligence of a market or country because the due diligence check of the respective country or market has an influencing effect on the final mode options that can be used to ensure that the multinational's code of conduct is fulfilled. E.g. the multinational company will not enter into a foreign market with an own subsidiary if the local business is dominated by corruption because this is against the code of conduct of the multinational company. 
The last influencing factor that is grouped into the market code group is the security of raw material supply. This influencing factor only occurs if the mode switch to an own local production in a country is an option as mentioned by participant 4:

"In this country we were always on the road as importers with our own company. However, the big decision to change the processing strategy in this market was actually our own production. This was the milestone for us, because we became another player with our own production. There, completely different questions arise for the time being."

In case that the multinational company intends to open up an own production plant in a foreign country the security of raw material supply needs to be ensured. That this is not always the case is explained by participant 4:

"And the second big issue with the import of raw materials from Europe and if we have access to locally available base oil. So, base oil, where we say technically, yes, there is a read across and that is there, but they sell us base oil for local production in the first place, because often you are perceived differently in markets than competitors, whether you are a pure importer or suddenly also a local producer, i.e. we need base oil. That was also an intensive examination to look at, if we find local suppliers, who also actually sell us the base oils and the answer at the beginning was No."

Although this influencing factor comes only into play if the multinational company thinks about an own production plant in a foreign country, it is still an important influencing factor because if the security of raw material supply is not ensured this could be a showstopper for the final mode switch decision of launching an own production plant in a respective country.

The next finding regarding external qualitative influencing factors is the impact of competitors on the decision-making process of a mode switch. As stated by 
participant 7, a decision of a competitor can have an influencing effect on the decision-making process of the multinational company:

"Next to this it could be triggered by a decision of the competitors, e.g. if the competition is launching an own production plant. This could push or motivate us to start the mode switching process to stay competitive with the cost advantage, advantage of a faster supply chain, etc. with the competition."

In this example the strategy shifts of a competitor to build an own production plant in a country and consequently putting more efforts and focus into a market could influence the decision-making process of the multinational company. Because the multinational company risks to lose market share if it does not adjust its strategy according to the new set-up of the competitors.

Another qualitative external influencing factor can be the politics and with politics I mean the political situation in a country, laws and the politician themselves. One example is given by participant 10 :

"So, e.g. political changes regarding a respective country. For example, that due to the embargo of the US regarding a critical country, the holding is not supplying to this country anymore."

With this example the participant definitely shows an extreme and worst-case scenario because due to the political decision, the multinational company needs to stop business and consequently exit from a market. There are also fewer extreme examples and cases in which the political situation even supports a mode switch decision, as suggested by participant 4 :

"Of course, this is also an opportunity for us, if we make an investment decision for a country, to contribute to the local content of our main customers. This sometimes also makes the decision easier for us, because we are then regarded as a local supplier, even if the technology 
we use is still of German or European origin and is used locally in production in this country to qualify as a local supplier."

In this example the participant explains that there are countries in which local companies have the political requirement to purchase a specific part of their raw material from other local manufacturers. If they do not fulfil this requirement, they have to pay a fee. Therefore, it is a sales argument if you are producing locally for the customers and this political requirement supports the decision of launching an own production plant in such a country.

Another finding in the data set is the reputation of the multinational company as qualitative external influencing factor which can direct the final decision step and the whole decision-making process. I discovered that according to the experts, the multinational company also considers the impact of a mode decision on the local reputation in a market or country. Participant 4 explains an example of how this influencing factor is considered during the decisionmaking process:

"Many lubricant manufacturers who are importers in a foreign market are the ones who actually bring technologically sophisticated products into the market that the local players do not have. If lubricant suppliers like us and other competitors also, we make the market entry into such a developing country, then we must be careful that we do not suddenly become a local player in the narrow sense, because then the technology leadership is lost."

With this example the participant intends to explain that the local brand recognition is very important for the multinational company and that the selected mode option can have an impact on this. Therefore, the brand positioning and the reputation in a local market is a decisive influencing factor for the multinational company. While participant 4 is focused on ensuring that a mode switch does not have a negative impact on the local reputation of the 
multinational company, participant 8 shows the chances and benefits that a mode switch can have on the local reputation:

"This means that the brand is of course marketed more strongly by a local subsidiary and the existing market potential is tried to be covered best possible."

Both statements show that the local reputation in a market or country and the effect that a mode switch could have, is definitely considered by the managers during the decision-making process of mode switches because the local reputation and brand recognition is an important factor regarding the competition advantage of a company.

The last group of codes regarding qualitative external influencing factors are the external partners who can have an impact on the decision-making process. External partners can have an impact on the decision-making process and I found out that the input of the partner can influence the decision-making, the key actors at the external partner, personnel changes within the partner and last but not least the personnel due diligence of the partner.

One of the main influencing factors of external partners is their possible input into a partnership. The multinational company always considers this possible input before doing the final decision of a mode switch, as suggested by participant 1:

"You really have to think about it, in most cases it is the local expertise and the network that we have seen in many countries in one market. Customer contacts, faster approvals, renting warehouses, it's all easier, accountants have a system, etc."

With this statement the participant explains that in most cases the multinational company hope to get local market expertise and an easier market entry process as input from an external partner while other market entry steps like 
the supply-chain or the logistics itself are not a big challenge. Additionally, he states:

"If I don't need any of this and I can do it alone, or I find a good distributor in Nigeria, then I start alone and have $100 \%$ of this company and done." Consequently, the multinational company is not afraid to switch its mode or enter into a market by themselves if there is no external possible partner who can contribute necessary and beneficial input to a partnership.

Second influencing factors, that external partners could have on the decisionmaking process of the multinational company is the behaviour of the key actors of an external partner. If for example the multinational company intends to take over an existing partner and build an own subsidiary it is a decisive factor if the former key actors of the partner stay on board or not, as mentioned by participant 12:

"This is possible if the owner of the trading partner remains on board and, for example, acts as managing director of the local subsidiary. Then he has a motivation to contribute something and can contribute his expertise. This was possible in the case of the eastern Europe country, but it was not possible in the Nordics, for example, as the managing director, as the former owner, was no longer available."

As mentioned by the participant, keeping the former key actors on board after acquiring an external partner is a decisive and important factor for the success of the mode switch due to the experiences of the key actors. Therefore, the key actors of an external partner can have an influence on the decision-making process of mode switching at the multinational company with his decision if he intends to stay with the multinational company or if he intends to leave the board.

An additional influencing factor that has been discovered which is also connected with the key actors of an existing partner, is the impact of personnel 
changes within an existing partner, e.g. within a joint venture partner. As the partnerships are often built on personal relationships, such personnel changes can have a big influence on the relationship and consequently can influence a decision-making process of mode switching as well. This is suggested by participant 4 who states:

"But when it comes to generational succession and the people involved change, then this bond, the personal bond is different and then such discussions are often more difficult because the joint venture partner approaches the matter much more soberly and rationally."

As explained by the participant, a personnel change within the management of an external partner can change the relationship in a partnership very much and this could cause challenges, e.g. in a joint venture if the personal trust and connection is not existing anymore. Therefore, personnel changes at external partners are found as external qualitative influencing factors of the decisionmaking process.

Last but not least there is the personal due diligence of an external partner that could influence the decision-making within the multinational company. This means that the multinational company always do due diligence checks of their possible external partner before they, e.g. launch a joint venture with a partner.

"We screened the potential partner and made our picture of whether this partner would fit into the holding. So, it was a personal due diligence. This was done because it was the idea to launch a joint venture with the existing partner."

Consequently, the result of the due diligence test of an external partner can have an impact and can influence the final decision about a mode switch because it could be a showstopper for the multinational company if the external partner would not pass this due diligence test. 
According to my findings, the second part of the external influencing factors are the quantitative external influencing factors. The extract of the quantitative external influencing factors is shown in Figure 44.

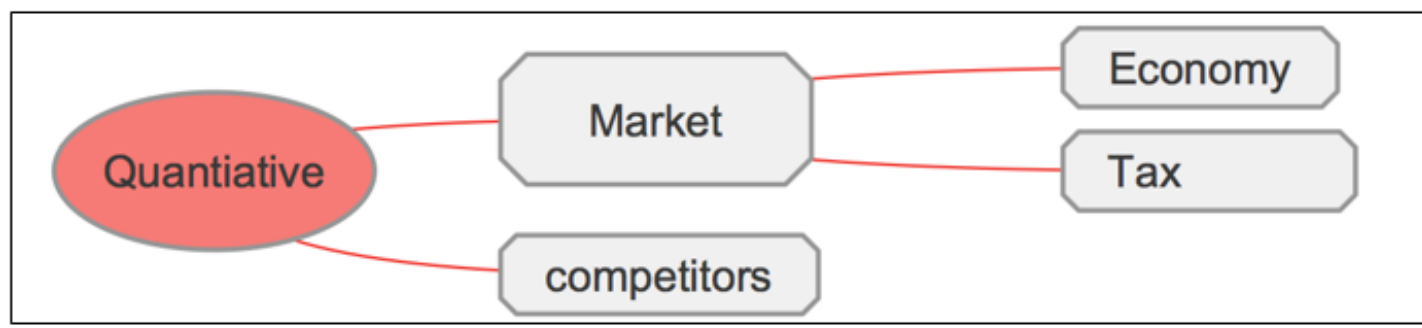

Figure 42: Extract of the Concept Map_Quantitative external Influencing Factors (The colours and shapes in the figure are only provided to make them more readable and do not have a specific meaning)

The extract of the quantitative external influencing factors shows that many codes are the same as with the qualitative external influencing factors. The differences are the data and extracts behind the codes while the qualitative influencing factors are focused on non-measurable factors that could influence the decision-making process, the quantitative influencing factors are focused on factors that can be measured and calculated based on numbers and figures as suggested by participant 7 :

"It definitely should be a mixture of both, quantitative as well as qualitative factors."

I split the quantitative and qualitative influencing factors because I found out that there are differences between them.

Starting with the market and the quantitative influencing factors that it could have on the decision-making process. Participant 1 explains the relevance of taxes and import duties as influencing factor with the following comment:

"So we have high export barriers, sometimes 25 or even $30 \%$, but if there are a lot of imports, the market pays the price and it is often the case that when one is locally produced, the customs barriers are really 
raised in order to protect this local producer, so this interaction was there, even if we already had customs duties in many markets...

... I have also seen many factories, mostly outside the holding, where the choice of location was decided on the basis of tax advantages. That is mostly wrong."

As explained by the participant, local taxes and import duties have only a limited influence on a decision about a mode switch because the circumstances are typically the same for all players in the market and consequently the market price is adjusted accordingly. He also indicates that tax reasons are typically not decisive factors of the multinational company for doing a decision. The only exception which he explains, if markets protect their local manufacturers with extraordinary high import duties that in this case the multinational company may need to react and think about a mode switch. Consequently, very high import duties could be an influencing factor on the decision-making process. This means that if the import costs for the products of the multinational company are extraordinarily high, it is more beneficial for the company to launch its own production within a market rather than importing the products from other production plants of the multinational company. As a result, the import duties can direct the final decision step of the mode switching process.

The second influencing factor that has been discovered and which is connected with the external market, is the economic situation in a market which can drive the final decision-making step and can be the decisive factor for the decision. Participant 14 states that market growth can be the decisive factor which finally directs the final decision of a mode switch at the multinational company:

"I think the final and most important factor was the growth potential that was identified for the market. So, I think the market potential of this 
respective country was the decisive factor for changing the mode in the market."

Next to the market growth, also the existing companies and customers in a market can influence the decision of a mode switch, as explained by participant 12:

"This country was known as a country and a market because many large companies relocated their production there for cost reasons. Low cost country as keyword. Ergo, it was already clear for us for a long time that this high potential exists, and the potential has also grown."

Consequently, the economy of a market does have a big influencing effect on the decision-making process of mode switching within the multinational company. In this regards the economic situation is the key word and includes many variables as growth rates, growth potential, customers in the market, etc. This means that the more attractive from an economic point of view a market is the more is the intention of the multinational company to switch to a mode with a high management control like an own production plant or own sales team in a respective market.

Last but not least the competitors have been identified as external quantitative influencing factor. The participants suggest that the competitors can influence the decision-making process of the multinational company if they increase significantly their market position. For example, participant 11 explains that if a competitor increases his competitive advantages and consequently the market share of the competitor raises significantly, this influences the decisionmaking process of mode switches at the multinational company:

"Special increase of the competitive advantage of one of the competitors in a foreign market, which means that one competitor is strengthening his positions and is winning additional market shares. 
Due to this my company has to react in order to avoid losses in regard to market shares."

As the market share can be measured, this influencing factor is categorized as external quantitative influencing factor.

\subsection{Circumstances / Opportunities}

Besides the external and internal influencing factors I discover additional influencing factors besides the external and internal influencing factors of the decision-making process within the multinational company that can be grouped in the sub theme circumstances and opportunities. With opportunities I mean the fact that sometimes the decision-making process of a mode switch is influenced by an opportunity that appear, as explained by participant 1 :

"In one country, for example, we have a lubricant expert who has researched and looked into who might be an option, found an investor who had nothing to do with lubricants, but had a pile of money to do with it. Both then came to us and said we could do something together. This was also done and the whole thing was 15 years ago now and is a huge cooperation. In this case, this is also an external factor, because opportunity comes to us and opportunity plays a huge role. "

As stated by the participant this influencing factor could also be grouped as external influencing factor but due to the fact the circumstances and opportunity can show up internally as well as externally of the multinational company, I decide to keep the circumstances and opportunities as separate sub theme. That the circumstances can also change internally, is shown by participant 4 and his statement:

"From today's point of view we would never make this decision that way and ähm, because we have other financial possibilities, because we would certainly not make such a joint venture today without our brand taking place on the market and so there is a situation where you can 
make decisions, where you would like to work on a market differently again, simply because the main parameters that seemed right or important at the time are evaluated differently today."

This statement from the participant clearly shows that the circumstances and, in this case, the internal circumstances of the multinational company can change over time and can therefore influence the decision-making process and even decisions which are made in the past could be evaluated differently on a later stage.

Consequently, the overall circumstances which might be the result of all influencing factors and the opportunities that show up from time to time can have an impact on the decision-making process of mode switches and therefore are identified as influencing factors that need to be considered in this research project.

\subsection{Internal Influencing Factors}

Analogous to the external influencing factors that I grouped into quantitative and qualitative external influencing factors, I found out that the internal influencing factors can be grouped into qualitative and quantitative internal influencing factors as well. The extract of the qualitative internal influencing factors is shown in Figure 45.

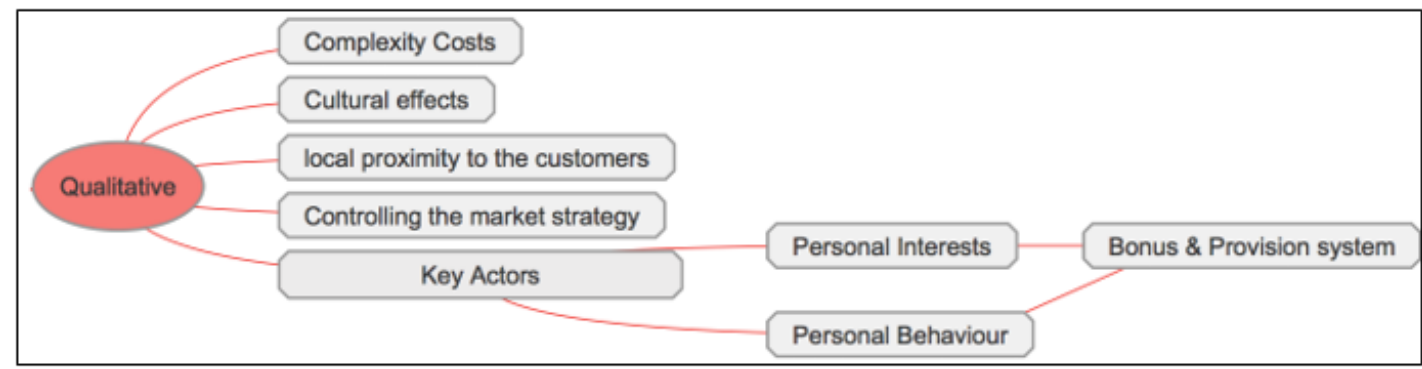

Figure 43: Extract of the Concept Map_Qualitative Internal Influencing Factors (The colours and shapes in the figure are only provided to make them more readable and do not have a specific meaning) 
The influencing factor that has been found in the data set and which is categorized in the sub theme qualitative internal influencing factors is complexity costs. According to the experts, the complexity costs are definitely considered in the decision-making process of mode switches, but this kind of costs are difficult to quantify and therefore they are grouped as qualitative factors. As example, participant 1 talks about a case in which the complexity costs were the reasons for doing a decision although the project team was not able to quantify and evaluate them before:

"That's how it was there and that's where I also worked in terms of ownership, okay, if it doesn't matter whether we do something or do nothing, then we do it now because we have the feeling and there were some that regardless of what is calculated there, it's worth closing one of the plants. That's what we did, and it was really worth it, because all the complexity was gone. That is not so easy to quantify. Complexity costs are huge, but how huge is that?"

So, although the complexity costs are difficult to quantify and evaluate, they are a qualitative influencing factor which is considered in the decision-making process of the multinational company as shown in the given example of participant 1.

The next internal influencing factor which can drive the decision-making process of mode switching is the cultural aspects which is considered internally. As already discussed in the previous section about the external influence of cultural aspects, internal cultural aspects can also have an influence into which direction the final decision of the process goes. For example, due to the existence of the external cultural influences of a country, the multinational company prefers to hire managing directors for a respective subsidiary who are natives, as suggested by participant 4 :

"Perhaps regional managers who are responsible for a region, but a national company is typically always managed by a native" 
As a result, internal cultural aspects could influence the decision-making about a mode switch if for example the multinational company does not find a suitable native managing director for a possible new subsidiary, launching and own new subsidiary in a respective market could be a risk that the manageability of the new mode is not ensured.

The next influencing factor that is found and categorized as internal qualitative factor, is the local proximity to the customers which is one of the main strengths of the multinational company according to the participants. The importance for the multinational company of this point is expressed by participant 4 :

"Well, we have had many cases because we as a company are convinced that our strengths lie in our local proximity to the customer and that our local proximity to customers enables us to score points with international and global customers in particular, because this really makes us a global supplier. That's why the question of market strategy arises so often".

The participant underlines that the local proximity to customers is one of the main strengths of the multinational company and therefore the aim of achieving this local proximity can influence the decision-making about a mode switch. As this local proximity is not quantifiable, this influencing factor is a soft and qualitative factor. A similar statement is given by participant 7 :

"Maybe, the wish to be closer to the market and the customers in a respective country. Of course, we have our distributors in the local market, but it is not the same as it would be with own salespeople in a foreign market. So, it could be a marketing aspect and the intention to be closer to the customers."

Consequently, the aim of being closer to the customers can be the decisive factor of switching the mode, e.g. from a distributor to an own sales subsidiary, 
and therefore I intendto consider this influencing factor as one finding of the data set.

One key finding of the data is that the intention of the multinational company to control the market strategy in a respective country is an influencing factor for the decision-making process of mode switches. For example, participant 3 states:

"Exactly, and this is about defining the market segments that you want to work on, it is about what my pricing looks like that I want to establish in the market, I can only suggest this to a dealer, but not decide for myself."

The Participant explains in this statement that in the mode option of having a distributor or external partner in a country, the multinational company can only work as a consultant but do not have a direct management control in the country. Participant 8 explains on the other side the comfortable situation that the multinational company has with an own subsidiary in regard to management control:

"However, I can imagine that the holding might set up a local subsidiary in one country in order to have more influence on the business locally in that respective country...

... However, I think the most important point is that your local subsidiary can be managed much better than a local independent dealer."

Hence, the intention of the multinational company to have as much as possible management control in a respective country or market regarding defining the sales and marketing strategy, is one of the influencing factors for the decisionmaking process.

The last internal qualitative influencing factor that I found is the influence of the internal key actors at the multinational company on the decision-making 
process of mode switching. My first finding in this regard is that within the multinational company there are key actors who have opposite interests and goals regarding a decision about a mode switch. This is, for example, shown in the statement of participant 7 :

"Because if the mode is switching from a distributor in a country to an own sales subsidiary, the business is not handled from the Export Department anymore but rather from the Intercompany sales department who is handling all global sales between the subsidiaries. That's why the Export Department do not have an interest in pushing the mode switching process."

As explained by the participant, a mode switch can cause business losses for some internal departments and therefore such decisions are not always in the interest of all key actors of the multinational company. A similar point of view is shown by participant 10 :

"No, the export division does not benefit from a mode switch if e.g. an own sales subsidiary is launched because then the export division has to transfer the existing business in a country to the own sales subsidiary. Therefore, the regional sales manager is pushing the process as he / she is focused on the development of the region and not specifically on single markets."

Also, this participant explains the opposite interests of key actors in the decision-making process of mode switches. As the key actors of the decisionmaking process have different interests, the process is also influenced by this personal interest and by the behaviour of the key actors which is suggested by the statement of participant 14 :

"Everyone has their responsibilities somewhere and therefore personal interests which are often determined by the different objectives. Of course, all this does not make things easier." 
I also find out the main reason and foundation for the personal interests of the key actors. According to participant 7, the existing bonus system within the multinational company is one driver for personal interests of the key actors and consequently one influencing factor of the decision-making processes of mode switching:

"Yes, of course due to the bonus system for the reached targets but this can also be grouped as personal interests."

Participant 3 also indicates that the monetary system and provision system of the multinational company has an impact on the personal interests of the key actors and as a result is an influencing factor of the decision-making process of mode switches:

"It will certainly also be an intensive monetary system, even if it may not be significant in individual cases, but then it will be a matter of principle and perhaps also a small part of the commission. Of course, there are people who fight to the last for it."

Consequently, the personal interests and behaviours of the key actors are important influencing factors of the decision-making process and I need to consider them as findings of the data set. As the monetary bonus and salary system of the multinational company seems to be one of the drivers for these personal interests, these systems are indicated as influencing factor within the data set as suggested by participant 7 :

"Yes, of course due to the bonus system for the reached targets but this can also be grouped as personal interests."

Coming to the second part of the internal influencing factors, the quantitative influencing factors. The extract of the quantitative internal influencing factors is shown in Figure 46. 


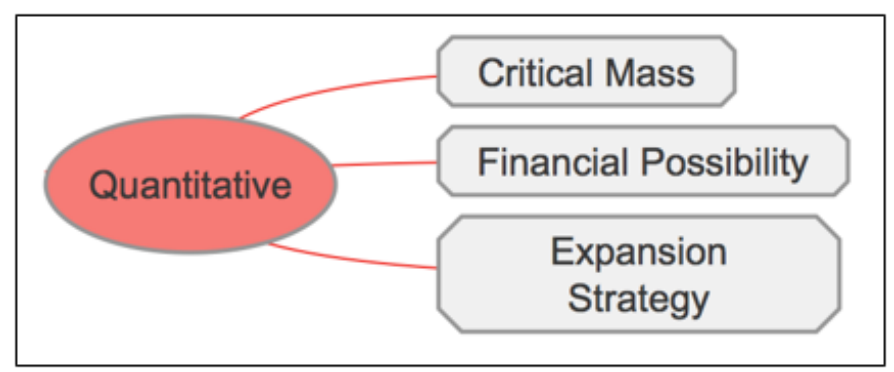

Figure 44: Extract of the Concept Map_Quantitative Internal Influencing Factors (The colours and shapes in the figure are only provided to make them more readable and do not have a specific meaning)

The first internal influencing factor that is quantifiable is the question about an existing critical mass within the multinational company which triggers a decision within the mode switching process which is indicated from participant 12:

"This certainly requires a critical mass. This is perhaps also a question that the Executive Board could answer well, if we are not in a position to achieve at least one million euros EBIT with a national company within a reasonable period of time, the question already arises as to whether the high expenditure associated with operating a company is justified."

With critical mass the expert means if there are explicit defined borders regarding sales volumes or turn-overs which need to be reached for switching from one mode to the other, e.g. establishing an own sales subsidiary in a market instead of working through distributors in the market. Participant 1 indicates that such critical masses exist within the multinational company but that these critical masses are more thumb values and no insurance that a decision is made if these values are reached in a country:

"So, there are a few thumbs values. If I want to build a plant, oil starts at 4,000 tons and it's just not worth below that. With grease it starts at 500-800 and you don't have to start below that. That's what I tell my 
people, we don't have to talk about it, honest announcement, before you don't have it as sales volumes. Of course, there is such a thing."

Hence, these critical masses are influencing factors, especially for the local employees who are working on the decision-making process of mode switches and these critical masses can act as motivators, but they are not carved fixed but rather flexible and can be adjusted case by case.

Another internal quantitative influencing factor that $I$ found is the financial possibility of the multinational company to switch a mode. According to participant 4 , the financial possibility of the multinational company to do an investment is definitely an influencing factor of the final decision:

"In this country we were already almost ready to do something, but then we rejected due to the global economic and financial crisis in 2008 and 2009 and then actually needed a second attempt to open up the market and that actually worked quite well."

The participant explains with an example during the world-wide economic crisis in 2008 and 2009, that depending on the financial possibilities some mode switches are not done or are postponed to a later point in time. A similar statement is given by participant 13 :

"It was always clear in the discussion that we ourselves in the working group assumed that in the current economic situation, setting up one's own business on the basis of the business plan was not an option."

Also, in this example the decision not to switch the mode or not to launch an own sales subsidiary was influenced by the financial possibilities of the multinational company at that time.

The last internal quantitative influencing factor that I have discovered, is the expansion strategy which the multinational company follows. This strategy influences the decision-making process of mode switching because each 
strategical decision within the multinational company is aligned with this goal of long-term expansion, as stated by participant 3 :

"At the holding we are interested in long-term developments and perhaps do things where we only see the return in many years..."

\subsubsection{Model Integration: Decision-Making Process of a Single Mode Switch}

It is evident from my findings about the theme rational decision-making process that one part of the decision-making process of mode switching is a rational process. Based on the findings about the theme rational decisionmaking process and influencing factors, I developed the model in Figure 47 which illustrates the model and the connections between the identified sub themes.

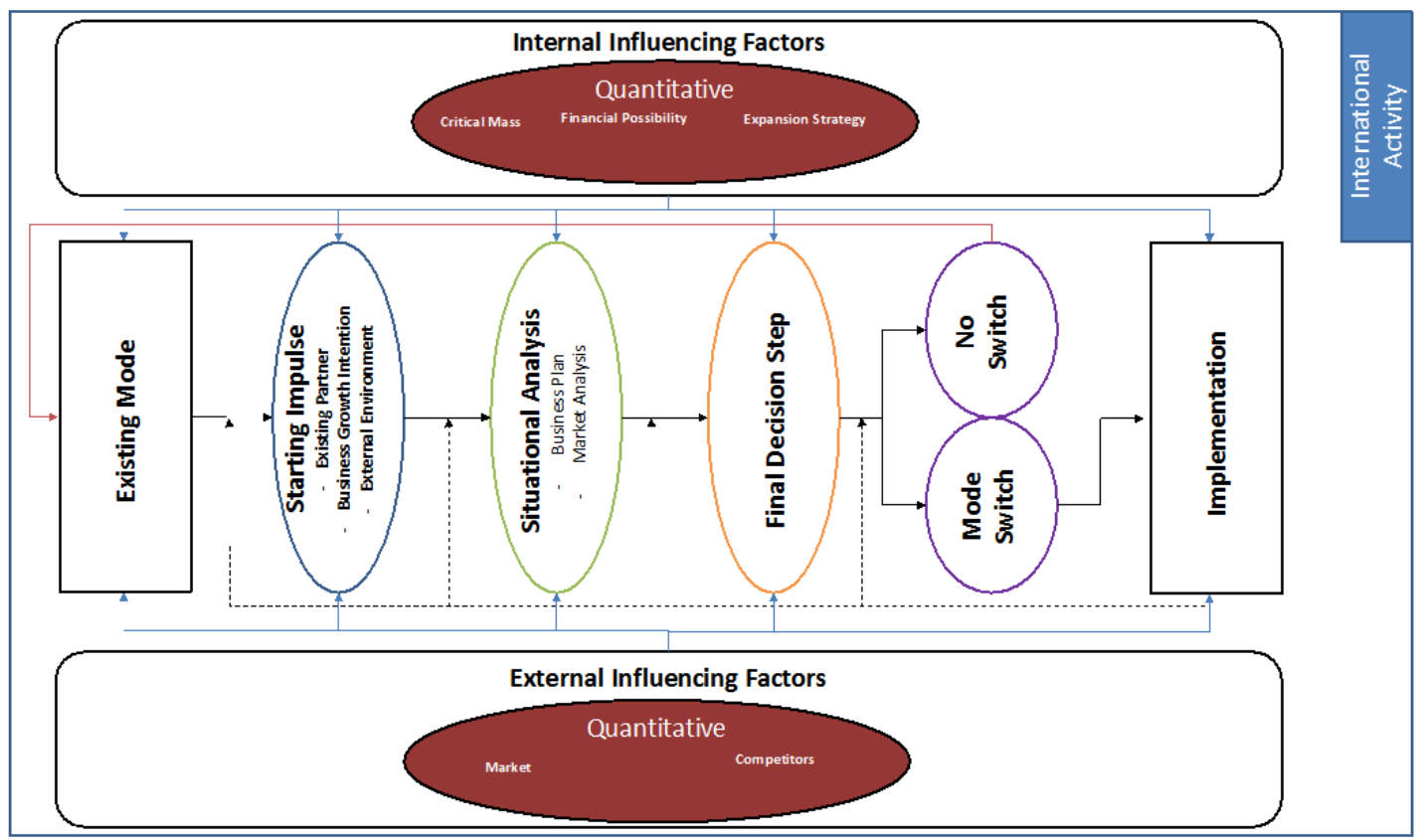

Figure 45: Model of the Rational Decision-Making Process of a single mode switch (The colours and shapes in the figure are only provided to make them more readable and do not have a specific meaning)

The process starts with an existing mode in an international activity because if no mode is existing in a foreign country, the multinational company cannot 
switch the mode in this country but rather needs to think about the market entry strategy.

The process starts with the starting impulses which are illustrated in the blue ellipse. I found out that the starting impulse of the decision-making process can come from the external or internal environment. In the internal environment, I identified the intention of the multinational company of longterm and strategic business growth which can be the starting impulse of the process. In the external environment, the general market environment can cause the start of the process, as e.g. the competitors in the market or the politics in a country. Next to the general market environment, also the existing partners in a respective country can occur the starting impulse because of their performance (good or bad) or because of ongoing changes within the partner.

The next step of the process is the situational analysis which is shown in the green ellipse. The situational analysis starts with the market analysis and gathering information about the respective market and country. In this step, the multinational company starts with analysing the due diligence or feasibility of a market and if there are any factors that could be a showstopper for the decision-making process. If this is suggested, the multinational company is conducting a quantitative market analysis to collect as much as possible quantitative data from the market. In the second step of the data analysis, the multinational company is developing a business plan which builds the basis for the decision-making process in the next process step.

The final decision step which is the next process step is illustrated in the orange ellipse. The findings of this sub theme were that the decision is mainly made by the holding company of the multinational company and respectively by the regional responsible managers. Additionally, I found out that there are no fixed decision parameters in the multinational company, e.g. that a mode switch needs an ROI of 5 years, but rather each decision is evaluated separately and case by case. Depending on the final decision of the 
management, there are two options for the next step of the process (shown in the purple ellipse). First if the management decides not to switch the mode, the process is going back to the beginning and the existing mode option in the respective market (red arrow from in Figure 47). Second decision option for the management is to switch the current mode option and if the management decides to switch, the process is proceeding and finishing with the implementation of the new mode option.

Next to the individual process steps of the rational decision-making process, I found out that there are external and internal influencing factors which can influence the decision-making process at any time. As I show in the first step of the model integration only the rational decision-making process, Figure 47 contains only the identified quantitative internal and external influencing factors because the rational decision-making process is not dependent on qualitative factors but rather on value analysis (Vasconcelos, 2009). As external quantitative influencing factors I found out that the economic situation and the tax regulations of the respective market can influence the decision-making process which are both quantifiable. Next to this, also the competitors can influence the decision-making process with quantifiable factors, e.g. if the competitor is increasing his market share in a respective country significantly. As internal quantitative influencing factor I found out that the critical mass which the multinational company achieves with the existing mode can influence the process, the financial possibility of the company can influence the mode switching decision and finally that the quantified expansion strategy, e.g. a respective market share in a region, can influence the decision-making process.

One of my findings was that the decision-making process of mode switching is not an incremental process but rather a circled or rolling process because many process steps need to be done in parallel or several times. Therefore, I included the dotted arrows in his model which should illustrate the possible cycles. 
As I found out that there are more influencing factors of the decision-making process and because the participants suggested that the decisions within the multinational company are not only based on quantitative numbers but rather also on qualitative factors, it is evident that the model shown in Figure 47 is not the final model for the decision-making process of a single mode switch. Therefore, I have extended the rational decision-making process conceptualized in Figure 48 by the qualitative influencing factors and by the influencing factor, opportunities and circumstances. The finalized model of the decision-making process of a single mode switch which I developed based on the findings of my research project, is shown in Figure 48. The influencing factor category "opportunities / circumstances" overlaps the "quantitative" and "qualitative" influencing factors categories, because opportunities / circumstances can consist both qualitative and quantitative influencing factors. As the categories of the influencing factors (qualitative, quantitative and opportunities / circumstances) can evolve from outside (external) and inside (internal) the organisation both directions of impact are illustrated in the model separately.

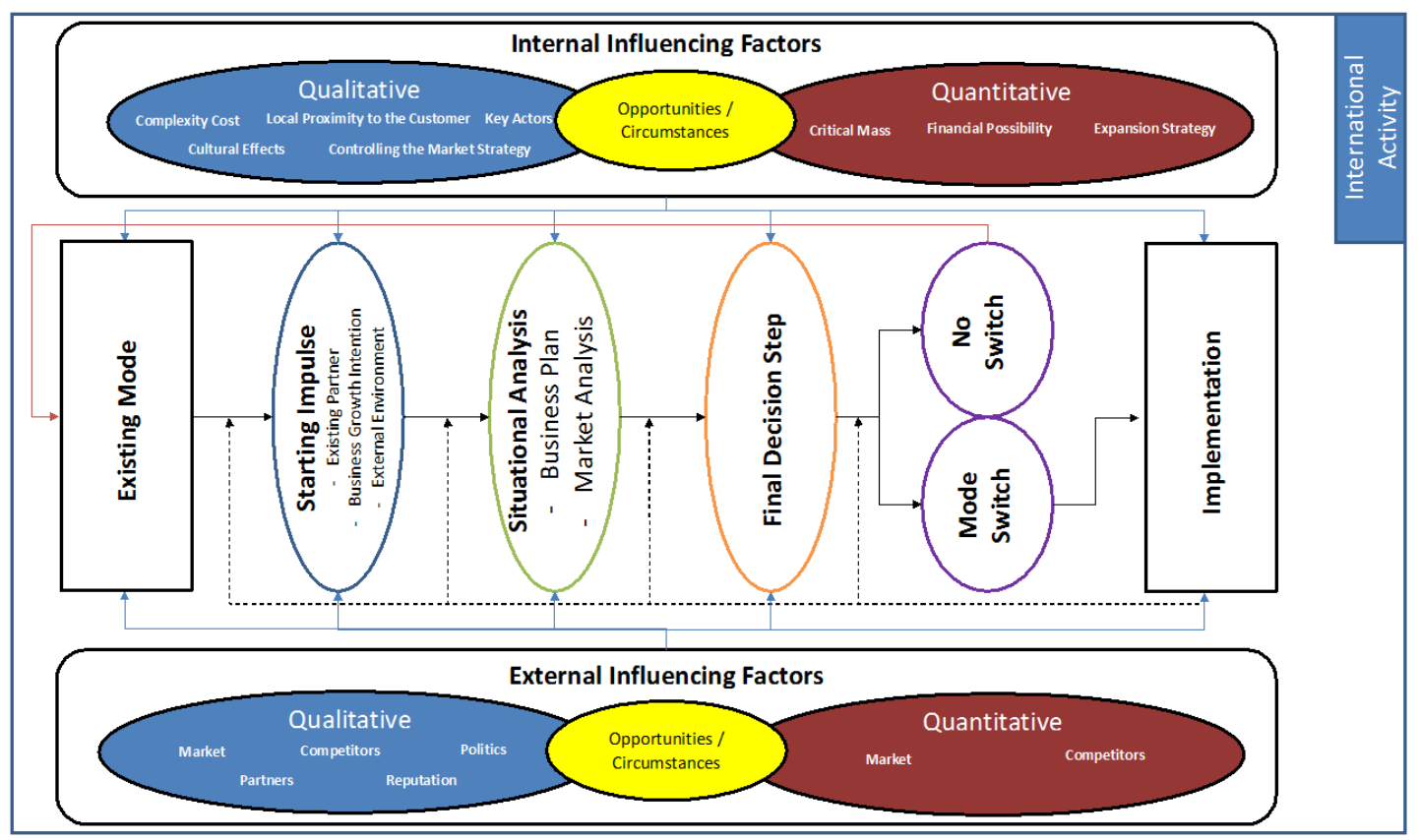

Figure 46: Final Model of the decision-making process of a single mode switch 
As internal qualitative influencing factors I found out that the several factors can influence the decision-making process. The complexity costs which are difficult or impossible to quantify can influence as well as the intention of the company to increase the local proximity to the customers. Additionally, the intention of the multinational company to control the local market strategy and being independent in the decisions and the cultural effects which means if the multinational company can select internal managers for a respective mode options from their internal resources and if these managers fits from the cultural perspective and cultural acceptance in a respective market, can influence the decision-making process at various stages. Last but not least, the key actors of the process can influence due to their personal interests and personal behaviours can influence the decision-making process at various stages. I found out that the personal interests and behaviour of the managers are mainly related to the respective salary and bonus system which is established at the multinational company.

I found out that the market as well as the competitors can also be qualitative external influencing and not only quantitative. In this regard I included the influencing factors which are not quantifiable and coming from the market and the competitors. If a Competitor, for example changes his market strategy and build an own production plant in a country, this can influence the decisionmaking process of the multinational company. The qualitative factors coming from the market are e.g. the existing market barriers like import restrictions, the culture and due diligence of a market like the existence of corruption, the local legal requirements, the availability of local employees and finally the security of raw material supply in case the launch of an own production facility is considered. Another external qualitative influencing factor can be the politics, e.g. if the politicians declare embargos against respective markets, this influence the decision-making process. Last but not least the external partners can qualitative influence the decision-making process, e.g. because 
the key actors at the partner are changing or because a possible external partner fails the personnel due diligence test of the multinational company. Finally, the last identified qualitative external influencing factor is the reputation that the multinational company has and intend to have in a respective market which could influence the decision-making process in various steps.

As final internal and external influencing factor I found the circumstances and opportunities which could influence the decision-making process at different stages. The circumstances and opportunities can be external or internal and qualitative or quantitative. Therefore, I established an own category for them. An external opportunity that could influence e.g. the decision-making process is that a possible new joint venture partner is contacting the multinational company with a developed business plan and a proposal of establishing a joint venture together. This opportunity is coming from external and contains qualitative as well as quantitative factors. An internal circumstance that could influence the decision-making process is for example if the financial possibilities and the marketing strategy for establishing the own brands in the markets change over time. The participants explained this with an example in which the multinational company started a joint venture in the past and this joint venture has not promoted the own brands of the multinational company but rather has established an own and separated brand. The reason for going into this joint venture were the limited financial possibilities of the multinational company at that time. This example shows that internal circumstances can influence the decision-making process at various stages.

Hence, I have developed a model, based on my findings which is conceptualized and illustrated in Figure 48. This model reflects the conceptual framework level 1 in Figure 26 and does not consider or explains the interdependencies between simultaneous decision-making process of mode switching. The model which considers these interdependencies and can be conceptualized as decision-making process of multiple mode switches is developed in chapter 4.2.3.3. 


\subsubsection{Short-Cut Decisions}

I find out during the data analysis that the participants also talks about shortcut decisions and decisions which are not following a strategic and defined process but rather are done in short-term, very flexible and intuitive. Figure 49 shows the sub themes which I identified in connection with the main theme short-cut decisions.

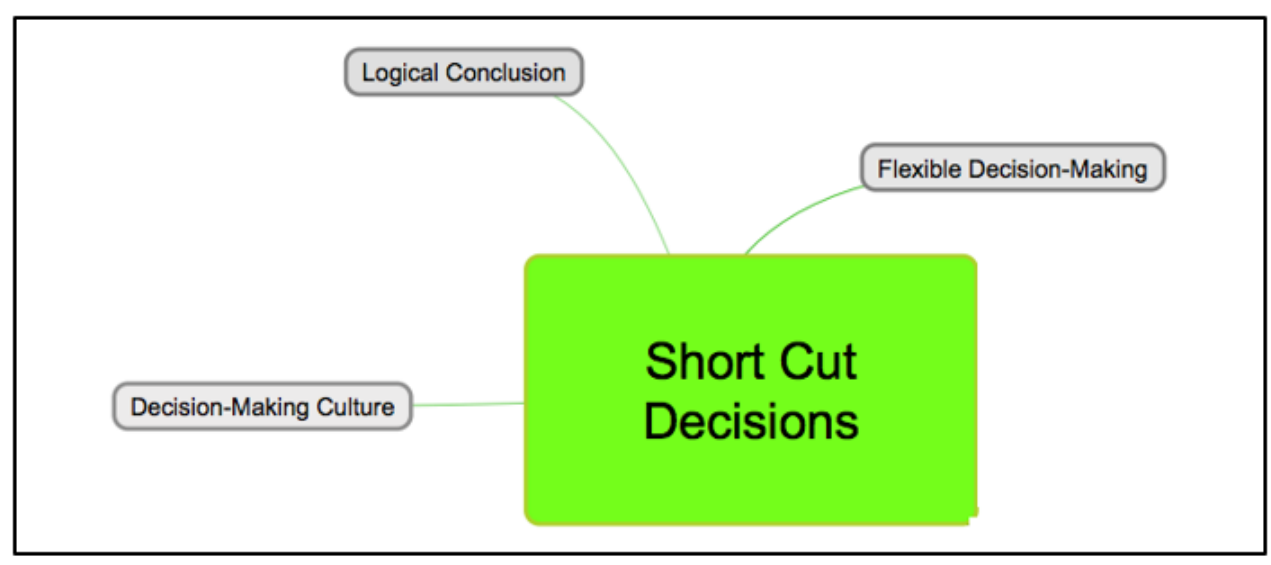

Figure 47: Extract of the Concept Map_Short-Cut Decisions (The colours and shapes in the figure are only provided to make them more readable and do not have a specific meaning)

My first finding regarding short-cut decisions is that the multinational company is in some cases very flexible about how the decision-making process should look like and especially regarding how detailed the analysis are carried out, as described by participant 12 :

"When a decision has to be made at short notice, you usually have more difficulties for a qualitative in-depth preparation and evaluation."

This flexibility of decision-making is also explained by participant 1 :

"So, we at the holding are not documentary. When it's about shortcuts." Consequently, my finding is that indeed the multinational company is sometimes bypassing the defined decision-making process of mode switching and is doing short-cut decisions even if the decision is about a mode switch. 
One reason for this short-cut decisions is mentioned by participant 12 who explains that some projects come up with an opportunity which requires a fast reaction and decision:

"But in some projects, there is not enough time if you reach for an opportunity that just arises."

Hence, the limited decision time can be a reason for short-cut decisions.

My next findings which I categorized in the sub themes logical conclusions and low risk, are other reasons for the multinational company to do short-cut decisions. For example, participant 6 explains an example in which the decision is based on a logical conclusion without a detailed analysis:

"On the basis that there was a certain market potential in the country of south America and that the corresponding high-margin product segments have a high potential in which our brands could be well placed, it was justified that a local subsidiary in this country would make sense."

This example shows that there are short-cut decisions regarding switching a mode in a country without a detailed and in-depth analysis. Participant 12 explains for which cases the multinational company uses the defined decisionmaking process and for which cases the multinational company is using shortcut decisions:

"I think it's interesting to look at the cases where there wasn't an easy and clear decision. Or where the reasons are not obvious, either that it is not worth it, the market is too small or the market entry barriers are too high or crystal clear, the market potential is large and I have to enter the market or need a local company locally. The cases where you are in-between may be the more interesting cases, because the management has to meet here and discuss, why there are reasons to react in one way or the other." 
Consequently, the participant indicates that there are easy and logical decisions and cases which can be handled with short-cut decisions and on the other side there are the more complex and diverse cases and decisions which follow the defined decision-making process of mode switching.

My last finding regarding short-cut decisions is that the decision-making culture changed in the multinational company during the last year regarding short-cut decisions as described by participant 14 :

"In the past, when the world was bigger and there were more white spots, a lot was decided much faster and more on the qualitative feeling of the managers."

A similar statement is given by participant 8 :

"Well, I think in recent years and especially now in the current example in Europe, the decisions are prepared very intensively and only a few decisions are made as short-cut decisions."

According to participant 7 , this change of the decision-making culture is related to the global alignment of the multinational company and to the learning process:

"Well, now that I think about it, I think that in the past many decision were made ad-hoc within the holding and not based on the explained process, but this will change now because the management board intends to establish an aligned strategical process. Consequently, the holding is on the way from a multinational company to a global aligned company without silo approaches within the group."

Consequently, my findings show that although there are less short-cut decisions, they are still important in the decision-making process of mode switching and that due to the global alignment of the multinational company, the decision-making process of mode switching is getting increasingly in focus 
and of importance for the multinational company by becoming a part of the global strategy.

\subsubsection{Decision-Making Process of Multiple Mode Switches}

As sub themes of the decision-making process of multiple mode switches which reflects the finalized conceptual framework in Figure 27, I identified the themes interdependencies and global strategy. The finalized conceptual framework is focused on the interdependencies between decision-making processes and how simultaneous decision-making processes of mode switches are interacting and influencing each other. Consequently, the finalized conceptual framework is focusing on the global set-up of a multinational company and therefore the sub theme global strategy is also overlapping the conceptual framework and is contributing to reach the objectives of this research project.

\subsubsection{Interdependencies of Simultaneous Decision- Making Processes}

Figure 50 shows an extract of the holistic concept map which contains all subtopics and codes that are connected with the main theme interdependencies of simultaneous decision-making processes, highlighted in dark green.

The sub themes are highlighted in light green and are inside rounded rectangle; external, internal, handling of interdependencies, role of interdependencies and learning process. The codes are highlighted in grey and are inside octagons; market responsibility, production transfer, scale effects, business transfer, availability of resources, best practices of experiences, return on market entry investments, competition, support structure, know-how transfer, cross-selling, cultural interdependencies, political level, personal level, politics, partner, exports, local, free trade areas, sales structures, removing country boarders and establishing global segments, 
democratic decisions, report system, local entrepreneurship vs. global alignment, global company goals, global alignment, moderating, opportunities coming from other decisions, brand reputation, know-how transfer, international customers.

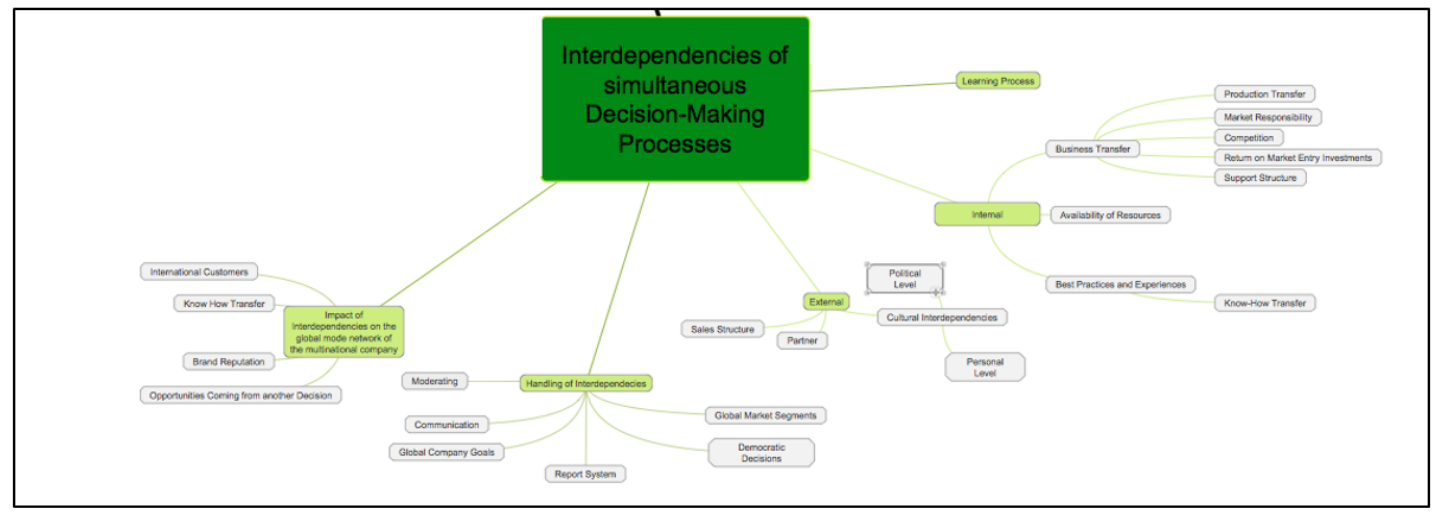

Figure 48: Extract of the Concept Map_Interdependencies of Simultaneous DecisionMaking Processes

(The colours and shapes in the figure are only provided to make them more readable and do not have a specific meaning)

\subsection{Internal Interdependencies}

An extract of the internal interdependencies of simultaneous decision-making processes is shown in Figure 51. 


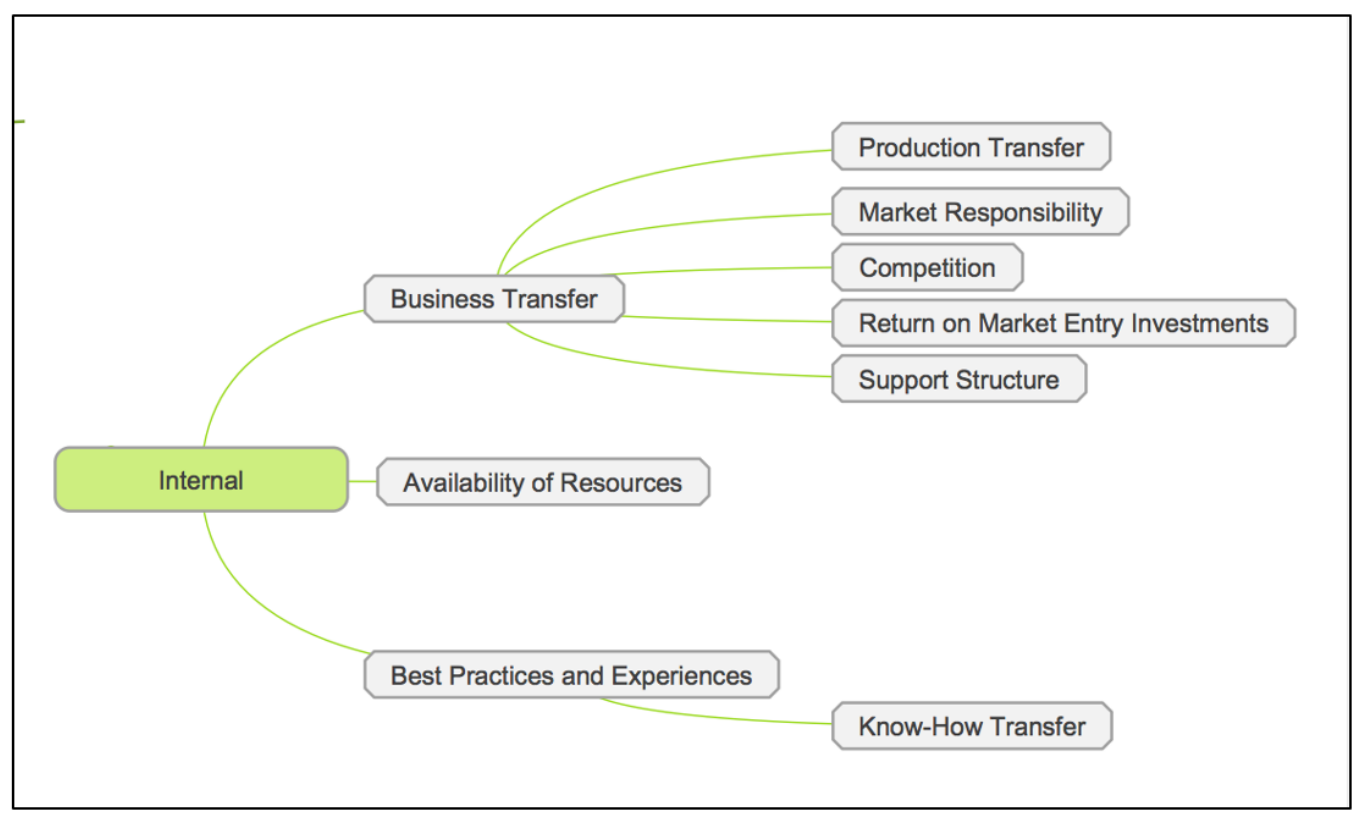

Figure 49:Extract of the Concept Map_Internal Interdependencies of Simultaneous Decision-Making Processes

(The colours and shapes in the figure are only provided to make them more readable and do not have a specific meaning)

The first interdependency that I found out in the area of internal interdependencies is that switching a mode in a respective market can cause business transfers within the multinational company. The sub theme business transfer is connected with the codes market responsibilities, production transfer, competition, return of market entry investments and support structure because all of these codes are related to a business transfer within the multinational company. A general example of such a business transfer that is happening due to the interdependency with the mode switch decision in a respective country is shown by participant 5 :

"Let us take an eastern European country as an example. I thought that there is really only about the business that goes through the distributor. But it has an effect on surrounding subsidiaries because they had to transfer the business they had previously done in this country," 
The participant gives an example in which the mode switch in a respective country from a distributor to an own sales force is influencing the surrounding subsidiaries because they have to transfer their business that they have in the respective country. This example is about the business that is existing in the country in which the mode switch is taking place. A similar situation can arise regarding the market responsibilities of surrounding countries although they are not directly connected with the country in which a mode switch is happening. It is explained by participant 4 who states that if the multinational company is switching the mode in a country, they are also checking the situation in the surrounding countries and the respective region:

"So that's definitely the case and we make decisions with a view to the respective market, but then we also always try to find out what that means for the previous processing in the market and for the market processing for perhaps adjacent markets, if we set such a stone and we say we now ram a flag in there and perhaps we can help this flag to serve the other markets better."

Consequently, switching the mode in one country can have an impact on the business in this respective country and additionally on the responsibilities of surrounding countries within the multinational company, e.g. that a new established subsidiary in a region also supplies the surrounding countries which were supplied before via the export departments from Germany, as suggested by participant 7:

"Yes, there are definitely interdependencies between simultaneous international activities and these activities influence each other and are related and interrelated to each other. So, it could happen that a subsidiary in country $A$ is supplying to country $B$ where no subsidiary is existing but where the export department has a long-term established partner."

The next interdependency which is similar to the change of market responsibility but a little bit more specific and therefore identified as separate 
code, is the transfer of productions which means that a product is not produced in Germany and shipped to a local subsidiary anymore but rather that the local subsidiary is producing the product by themselves because they have established an own production plant and consequently have switched their mode from sales subsidiary to own production subsidiary. As described by participant 2, typically the first mode switch in a country is from an external partner to an own sales subsidiary which has no interdependency regarding the supply-chain or the production location:

"In other words, uh, the first step was the business transfer to the local subsidiary. The goods will continue to come from Germany for the time being."

But after this first step, the multinational company often does the second step of an own production plant in the respective foreign country and this decision of switching the mode from sales subsidiary to own production plant interacts with other mode decisions and market responsibilities in surrounding countries, as stated by participant 2 as well:

"But the second step is often the local production, so that the costs for transport are no longer incurred and that the local subsidiary can skim off the maximum margin itself and has a corresponding capacity utilisation...

... In other words, the construction of a production plant or the expansion of a production plant also has interdependences with the surrounding markets and can lead to competition within the national companies."

Consequently, especially the mode switch to an own production subsidiary in a foreign market has interdependencies with other international activities in surrounding countries because it could cause the market responsibilities for some countries are switching within the multinational company.

Another topic that is related to the interdependencies and the business transfers within the multinational company is the return of market entry 
investments. I found out that the managers who have to transfer a business, have one major concern regarding a business transfer and this concern is the return of their investments which they spent to develop a market, country or business, as stated by participant 9 :

"Basically, the holding Group does not have any regulations, or they are not known to me that investments made by a national subsidiary are returned to that subsidiary if the subsidiary has to transfer a business..."

The participant points out in his statement that there is a lack of returning the investment to a subsidiary which developed a business or market after the subsidiary has to transfer a business.

The last point that is related to the interdependencies and the business transfers is the support structure of the multinational company which is affected by the decisions regarding mode switching. If a subsidiary like the German subsidiary transfers a business to a local sales subsidiary, the support structure of the German subsidiary for this business and market changes as suggested by participant 4:

"The functions that another national company assumes for this market are changing. Today it may have been a sales function and a technical function, both are no longer needed because the local subsidiary then carries them out. There it limits itself to the supply function, to a coordination, when it comes to pricing with international customers, that there is an agreement." Consequently, there is an interdependency between the decision about a mode switch and the strategical support structure of the multinational company or at least of the subsidiary which needs to transfer business due to a respective mode switch in a country. The result of this adjustment of support structure can be that some employees need new responsibilities and tasks as explained by participant 5 : 
"For example, they had to think about what they would do with the employees who had previously managed the business in this country. If this is on a larger scale, I might have to give this person a completely new job or retrain him."

The last internal interdependency which is categorized in the code group of business transfer is the competition between subsidiaries within the multinational company. I found out that there is competition between local subsidiaries and especially regarding export markets which means regarding markets in which the multinational company do not have an own subsidiary yet. Participant 1 explains how the situation of the export markets is existing:

"But if you look closely now, you will also find the English, the Spanish, the Italians, etc. in this trace. In the end, everyone is trying to sell their goods to Africa. It is difficult to get everything in order, because in some countries we have up to three distributors who are all looked after by the holding company in South Africa but were not acquired from South Africa."

A similar statement regarding the existence of such competition between the local subsidiaries is given by participant 7 :

"Yes, e.g. it could happen that a local subsidiary in country $A$ is quoting products to a distributor in country $B$ although this distributor is already working with the export department of the German subsidiary since many years. Finally, this results in a competition at the same customer and the results are decreasing prices for the customers and lost margin for the whole group."

The participant also shows in his statement the consequences of this internal competition and the negative effects of margin loss for the multinational company. Hence, the global export set-up is changing with each decisionmaking process about a mode switch and there is an interdependency between the decision-making process of one mode switch and the decision- 
making process of other international activities and decision-making processes because changing the mode option in a country could cause increasing competition within the multinational company and more specifically between subsidiaries. As a consequence of this increasing internal competition, the multinational company could lose margin because the subsidiaries are competing with the same products at the same customers.

Another internal interdependence is existing between multiple decisionmaking processes of mode switching is the availability of resources. In the discussions with the participants, I found out that there are two type of resources within the multinational company. First the financial resources and second the resources of manpower and employees. Participant 4 explains that the availability financial resources of the multinational company is typically not limited:

"Of course, we have the luxury that we have no financial restrictions if these are associated with investments...

... Of course, we do. So, our growth target is more in the foreground and that we want to develop the markets."

As the financial investment which is needed for the decision about one mode switch does not affect the availability of financial resources for a simultaneous decision-making process, the financial resources are consequently no interdependency between simultaneous and parallel multiple decision-making processes. But on the other side, I found out that the availability of human resources is an interdependency between simultaneous decision-making processes. Participant 12 states:

"You concentrate on the things that promise the most success and are the most attractive. And we've talked about interdependencies, and that's certainly also an interaction, in a time when, for example, our 
export department is taking care of the current project in central Europe, it can't take care of other issues...

... I think that is a legitimate question. But the strategic value of having a solution, how do we do the marketing in this country, it was worth concentrating on it for a certain time."

Although the multinational company is typically not limited regarding the financial resources, there is a limitation regarding the availability of human resources and consequently the decision-making process of a mode switch is connected and an interdependency exists between multiple and simultaneous decision-making processes of mode switching because if employees are working for the key actors of one decision-making process, their time for simultaneous decision-making processes is limited, as explained by participant 12. Hence the interdependencies between multiple decision-making processes that I found out, is the availability of internal human resources at the multinational company.

The last internal interdependency that I found out, is the necessary know-how transfer which is related to the decision of a mode switch in a respective country. Participant 13 explains this interdependency in his statement as follows:

"That brings this topic with it, but we have to transfer competences. So not only our products, but really a part of the know-how."

Consequently, each decision about a mode switch is interdependently connected with the decision about business transfers and with the know-how transfer strategy because the know-how transfer is necessary for the multinational company to coordinate globally and to keep the existing businesses going as indicated by participant 8 :

"I just want to point out again that I think it is the most important point, also regarding the current initiative, that more open, transparent and simple 
global information is exchanged and that global issues are better coordinated."

\subsection{External Interdependencies}

An extract of the external interdependencies of simultaneous decision-making processes is shown in Figure 52.

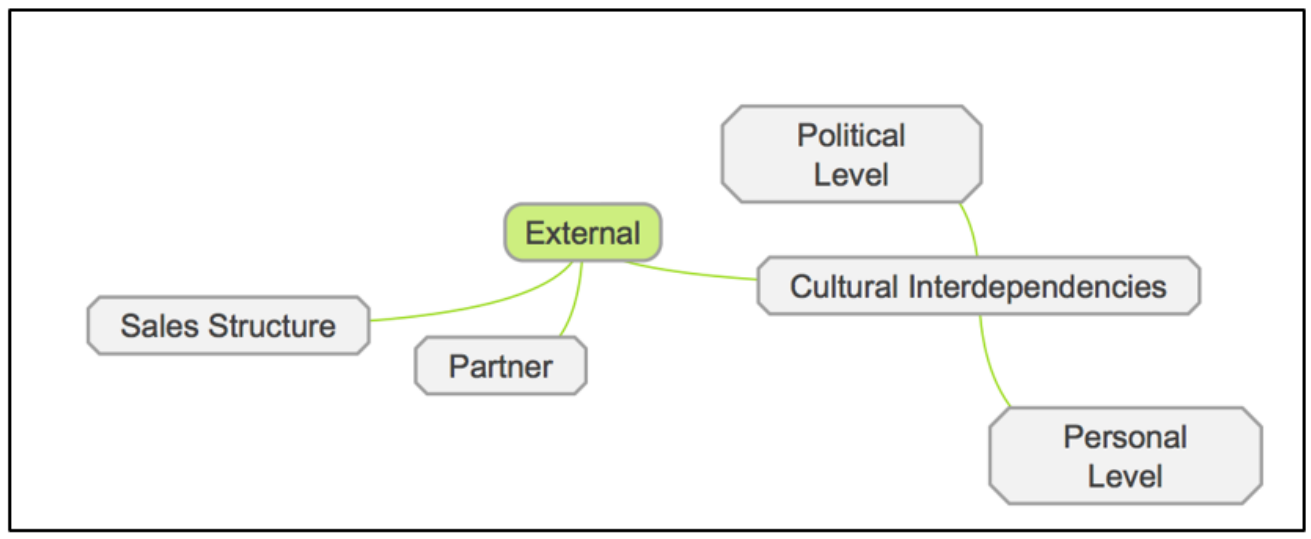

Figure 50: Extract of Concept Map_External Interdependencies of Simultaneous Decision-Making Processes

(The colours and shapes in the figure are only provided to make them more readable and do not have a specific meaning)

The first external interdependency that I found out, is the cultural interdependencies which can exist on political level or on a personal level. On a political level there are the cultural interdependencies between countries, as explained by participant 8 :

"I can imagine that cultural differences in certain regions can have a great influence on the surrounding countries. For example, there are certainly countries from which it would be impossible to serve surrounding countries with a local subsidiary because the cultural differences between the countries are simply too great."

Consequently, a decision about a mode switch in one country, e.g. to launch an own sales subsidiary has interdependencies with the decision-making process in surrounding countries due to the cultural interdependencies, 
because customers from the surrounding countries could fear to be transferred to this new subsidiary because from a cultural and political perspective, they do not want to work together with this subsidiary, as explained by participant 10:

"Additionally, there could be cultural influencing factors that local dealers may not fear to lose customers to a new launched subsidiary but rather to be handled via the new subsidiary in future which is may located in a country with other cultural background and due to historical reasons, the distributor does not intend to do business with such cultures and countries."

Hence, the decision about a mode-switch in one country is interdependently connected with the decision-making process in surrounding countries and as a result there are cultural interdependencies between multiple decision-making processes.

These cultural interdependencies can also exist on a personal level as explained by participant 1 :

"I can send young dynamic people to China, if I send young dynamic people to Saudi Arabia, he will fail because of age. If I now would send you there as a new regional manager, then you will not be seen by many, because they sort by age and next maybe by weight. Different rules apply there."

Consequently, besides the cultural differences and interdependencies between countries and on the political level, there are also cultural interdependencies on the personal level.

The next external interdependency in the data set of the participants is the sales structure which is joining the multinational company in case of an acquisition. A possible mode switch in a respective country can be the acquisition of a competitor. Acquiring a competitor to do a mode switch in a respective country has interdependencies with simultaneous decision-making 
processes of mode switching in other countries of the multinational company if the acquired competitor has a sales structure which affects more countries. Participant 3 explains the situation which could happen because of an acquisition:

"Until 2015, we had individual dealers there who looked after the business. And as part of an acquisition of a competitor, we took over a complete business area. With this acquisition, we also took over 7 national subsidiaries, three of which existed in the north east countries of Europe. If we had not taken over these with the acquisition, we would certainly not have had a national subsidiary in the north east countries of Europe even today. In other words, based on our strategic view, we would not have established a national subsidiary there."

As stated by the participant the acquisition of a competitor was done to strengthen the position of the multinational company in a respective business area. This business area originally has not included the north east European countries because the multinational company was represented by local distributors in this region has not intended to do a mode switch in these countries. But due to the acquisition and the existing sales structure of the competitor, the decision to acquire the competitor and to switch the mode in a respective country or region has the interdependency with the decision-making process of mode switches in the north European countries.

The last external interdependency between multiple decision-making processes are the existing partners. If the multinational company for example decides to start a joint venture with a partner and consequently decides to switch the mode in a respective country this can have an impact or drives a decision process which happens simultaneously (interdependencies between multiple decision-making process of mode switching) in other countries if the partner is also interested to work together with the multinational company in other countries than agreed in the joint venture, as explained by participant 4 : 
"Where the joint venture partners then say, let us open up these markets together in markets that are not or insufficiently developed, even under our brand, which is excluded in today's contracts. Of course, we have great reservations about this, because we say why should we open up a market with a joint venture partner when we can actually do it ourselves and they say why not, it worked well after all and let's take this success and continue."

Consequently, the decision to switch the mode to a joint venture in one country can have an impact on the decision-making process of mode switches in other countries if the joint venture partner is interested in extending the cooperation in other markets as well. Next to joint venture partners, the decision to switch a mode in one country, can also affect distribution partners in surrounding markets as indicated by participant 10 :

"Consequently, this could have the impact that distributors around a country in which the holding is launching a subsidiary are fearing to lose customers and are not happy with the decision of the holding to launch a new subsidiary."

Hence, the decision of switching the mode in one country can influence the international activities in the surrounding countries and as a result there are interdependencies between simultaneous decision-making processes.

\subsection{Impact of Interdependencies on the global mode network of}

\section{the multinational company}

Next to the interdependencies itself and what kind of interdependencies are existingl also found out which role the interdependencies have in the simultaneous decision-making processes of mode switching and in the global network of the multinational company. I summarized these findings in the sub theme role of interdependencies. 


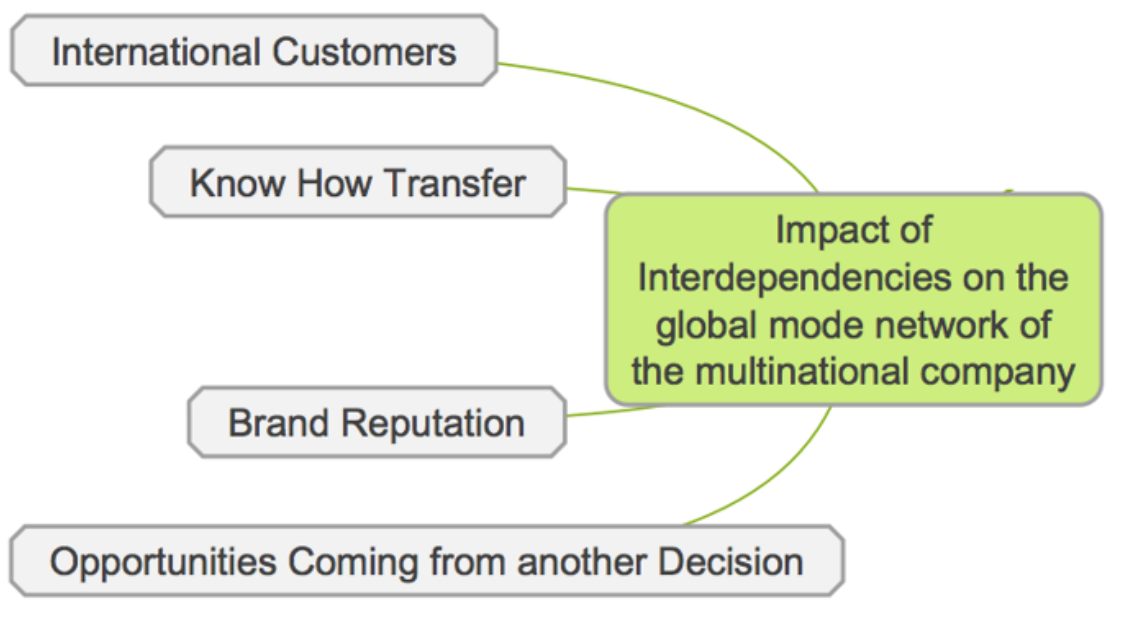

Figure 51: Extract of Concept Map_Impact of Interdependencies on the global mode network of the multinational company

(The colours and shapes in the figure are only provided to make them more readable and do not have a specific meaning)

My first finding is that the interdependencies between decision-making processes plays an important role for the multinational company regarding international customers. Due to the globalisation and as the countries have more and more interdependencies, as discussed in the previous section, also the customers are getting more and more internationalised and want to get served globally at the same level. As the multinational company intends to serve these international customers best possible, the role of interdependencies is getting very important, as explained by participant 3 :

"Firstly, there are customers who are active regionally in different countries. If I can look after the customer differently in country $A$, it can very well be that this will also give me new options for looking after the internationally active customers in other countries."

As explained by the participant, a mode switch in one country that gives the multinational company the opportunity to win an international customer in this country has interdependencies with additional business that the multinational company can do with this customer in other countries. Consequently, the 
interdependencies are very important for the multinational company in the decision-making process of mode switching as the customers are getting more and more internationalised and consequently increasingly connected globally.

Although the multinational company is aware of the interdependencies and their role regarding the international customers, I also found out that some key actors of the decision-making process of mode switching believe that the interdependencies do not have the high priority role that they should have within the multinational company. According to participant 2, often one decisive factor is missing which should also be the role of interdependencies within the multinational company. The participant thinks that the know-how transfer in the decision-making process of mode switching is not established sufficiently:

"All this knowledge was not asked for in the process and it was not asked what is being done in the country. To the best of my knowledge, the responsible persons were not asked for an interview where they talked about it and tried to get knowledge from the export department."

The participant explains that due to the set-up of the export division, they are very much affected from the interdependencies between international activities and are expert in their countries and regions. According to the participant these experts or at least their knowledge is needed to handle the decision-making process of mode switching. Consequently, the role of interdependencies within the multinational company should be important enough that the multinational company involves the experts from the different departments who are affected by this interdependencies.

Another role that the interdependencies have is the impact on the global brand reputation. As the markets are getting more and more open, marketing is no longer a local or country specific topic but rather the marketing activities are influencing surrounding markets and even the global market. This is also explained by participant 14 : 
"I also think that the establishment of a local national subsidiary in a region can give a corresponding marketing boost and thus the surrounding countries can also benefit, and the degree of brand awareness can be greatly increased locally in a region."

The last role of interdependencies which I finds out is the opportunities which are coming from other decisions about switching a mode. Participant 12 gives an example of an opportunity that can arise from a simultaneous decisionmaking process:

"In the past, we have also acquired new subsidiaries through acquisitions. If we were to buy a company now that has a few national companies, it could also be that we would get a national company where we do not yet have one."

Consequently, the decision to switch the mode in a respective market, e.g. by acquiring a competitor, could give the multinational company the opportunity to switch the mode in another country as well, because the acquired competitor does have a subsidiary in this country. This shows that both decision-making process of the countries are interdependently connected with each other.

As a result, I want to point out that beside the existence of the interdependencies between multiple and simultaneous decision-making processes of mode switches, I also find out that the interdependencies have a significant role regarding the global brand reputation, the know-transfer, the handling of international customers within the multinational company and additionally that due to the existence of interdependencies the multinational company gets opportunities from time to time which are coming from one decision and can trigger another decision. Therefore, it is very important for the global success and performance of the multinational company to consider the interdependencies and to handle them. 


\subsection{Handling of Interdependencies}

The study found out that many interdependencies are existing between simultaneous decision-making processes and that the interdependencies plays an important role regarding global aspects within the multinational company. Furthermore, the participants point out how the multinational company is handling these interdependencies. The handling options can be categorized in moderating, establishing global market segments, global alignment, democratic decisions, report systems and local entrepreneurship vs. global alignment (as shown in Figure 54).

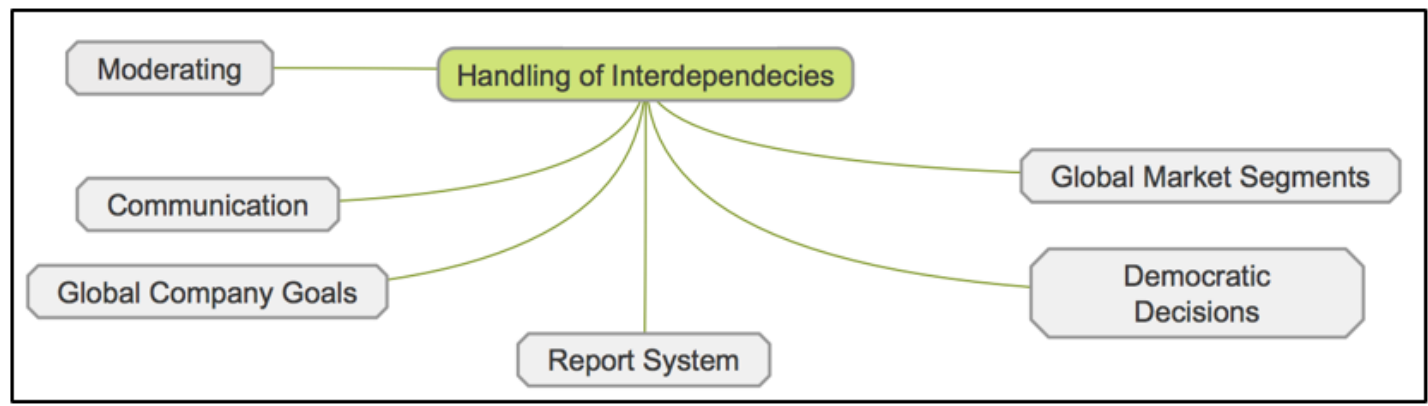

Figure 52: Extract of Concept Map_Handling of Interdependencies (The colours and shapes in the figure are only provided to make them more readable and do not have a specific meaning)

I find out that the multinational company intends to moderate the existing interdependencies by discussing decisions like mode switches in a global management committee. This committee is dealing with strategic decisions and topics as explained by participant 1 :

"We primarily deal with strategic issues, but also with communication within the overall network. How can I say relieve."

As stated by the participant, with such a committee, the multinational company intends to handle important decisions with a global and holistic perspective and consequently to handle for example the interdependencies between simultaneous decision-making processes of mode switches. 
Another way to handle the interdependencies is the establishment of global market segments for the multinational company which are looking at the specific market segment from a global perspective and without the local country boundaries. This shall ensure that the interdependencies between markets and countries are eliminated and that international and global customers of a respective market segment can be supported best possible and according to their specific needs. This option is explained by participant 1 with the example of the cement industry:

"A segment, e.g. a cement plant in China, is no different from a cement plant in Canada or the USA. If I know what they need and I know how their language works and which chess pieces they have and typical problems, then I can talk to them much better and get along with them much better."

Also, participant 2 suggests that the multinational company is more and more focusing on business segments and is categorizing their business more specifically:

"Currently, a process is being driven by the holding that all sales departments worldwide are grouping their business into certain business segments."

This strategy shift is not only driven by the decision-making process of mode switching but is definitely one option for handling the interdependencies between decision-making processes of mode switching which happen at the same time in different countries.

Another finding that I identified regarding how the multinational company handles interdependencies is communication. Participant 8 explains an example in which several subsidiaries are working in the same market but with a focus on different market segments. Although there are many interdependencies between the market segments, the involved managers are handling the situation very well as they improved the communication: 
"It might be, for example, that in one country we are only active in the automotive sector and a local subsidiary is only active in the industrial sector. In this regard, it of course makes sense and the interdependencies can be used to cover all business segments in a country from industrial sectors to automotive sectors via different subsidiaries. But communication is very important here."

This example can be transferred to the interdependencies between simultaneous decision-making process of mode switching in different countries because the internal and external interdependencies between market segments and countries are overlapping in many points, like the availability of internal human resources or the know-how transfer between subsidiaries. Ensuring an open and transparent communication within the key actors and managers of the multinational company helps to handle the existing interdependencies in the global network of the multinational company.

An additional finding is that the salary and provision system can be used to handle interdependencies which is categorized in the code of global company goals because typically provisions or bonus are connected with the achievement of specific goals. So, the definition of the company goals from a global perspective can help the multinational company to handle interdependencies. According to participant 13, this is currently not happening at the multinational company:

"But with a salary system that does not promote the fact that there is anything of importance outside this local market, I cannot, of course, create a basis for saying that we all have the highest global interest, even if that could mean for me personally that I would have an impairment in my local market."

The participant explains that a salary system that does not promote global company goals or the global company success does not help to motivate managers to think globally or outside of their country responsibility and 
consequently these managers do not consider the interdependencies which their decision could have with other international activities or decisions. Participant 5 suggests that and gives a recommendation regarding bonus system that would fit better for handling the global set-up of the multinational company and as a result also the interdependencies:

"And I know Systems from my history, where companies had three types of goals, their own goals, divisional goals and overall company goals. Then you always had a mixture and it was clear that if I wanted this bonus, I had to work properly in all three parts."

It is a system which includes different type of goals that a manager is focusing on different business areas and not only on his specific business area.

Next to the global company goals, I find out that the global report system can help the management of the multinational company to handle interdependencies. Participant 3, for example, explains a current gap in the report system which causes that the regional vice presidents do not have to consider all interdependencies between the countries in their regions:

"Ähm, no these countries are not in the reporting of the regional vice president. But his responsibility and the management function also include this, but he is not directly responsible for a dealer business that we have in a country without a national subsidiary. But the managing directors of the national company all report directly to him."

The participant shows that in the current reporting system, the regional vice presidents are not responsible for the export markets which means for the markets where the multinational company does not have an own subsidiary. Consequently, the regional vice president does not have to consider or handle the interdependencies which one decision in a market could have with the export markets in his region. This can be considered as a gap regarding handling the interdependencies between decision-making processes. 
Participant 4 supports that this is a gap in the current reporting set-up and thinks about closing this gap:

"For the countries that belong to a region, it is of course an exciting idea, because then it is perhaps the export strategy or the decision, so to speak, that I only export to this country, I also attribute to the regional vice president, because it is a conscious decision not to make a country representation of one's own so far. But this would perhaps significantly reduce the feeling of well-being and the desire of regional vice president to add this value themselves, but for which exports would either have to come from another national company in the region or to set up their own national company."

Consequently, closing this reporting gap could not only improve the handling of interdependencies within the multinational company but rather reduces the internal competition which is explained and discussed as one of the biggest internal interdependencies which is existing within the global network of the multinational company.

Last but not least democratic decisions are identified to help handling interdependencies within the multinational company. Due to the internationalisation and globalisation the amount of interdependencies will increase and as expressed by me in the previous sections, these interdependencies can have positive as well as negative effects for some managers. Therefore, democratic decisions and the procedure of a democratic decision is very important for the multinational company because there is almost no decision which does not have any negative effect on a manager of the process. According to participant 1 , this is exactly the way which the multinational company is going right now:

"I think when people get used to making collective decisions and are responsible for them and can't say we voted tenth and I was against it, so it's none of my business. If I'm against it, I have to make myself audible and 
not just put one vote against nine others, but tell people we'd rather not vote yet because I have a huge problem here and you have to learn that, practice it and I think the systems allow that."

Consequently, democratic decisions require that the managers are discussing a decision from different directions and ensure that the interdependencies between decision-making processes are considered best possible.

\subsection{Learning Process}

The last finding within the theme of interdependencies is the sub theme learning process because I identified that many participants explain the decision-making process of mode switching as a learning process. The reason for that is that the participants express the interdependencies in form of transferring best practices from a one decision about mode switching to another decision-making process of mode switching, as for example participant 4:

"I can now not fully negate that when I entered into the small European market, the extremely high cost level for my own organisation was more of a counter element for me. We say, of course, that we have the confidence to do something in this country, because it is a high-price country and everything is safe, everything is good. But building your own team, setting up your own organisation, etc. naturally leads to start-up losses and that was exactly the same in Scandinavia."

In this example the participant explains that he learned something from the negative experiences of a previous mode switch decision and is transferring this knowledge to an actual decision-making process. Consequently, there is an interdependency between the previous decision about the mode switch in country $A$ and the actual decision-making process of a switch in country $B$.

Also, participant 12 suggests that the multinational company is in a continuous learning process: 
"We are on the way to becoming a company that believes in many ways already like a group, but in many areas still rather multinational. So, we conduct certain business in a secure, group-like manner, while others are more decentralized and multinational. But also, the changes in industrial customers, who are going into the area of standardisation, will force us to act more group-like in this area as well."

As explained by the participant, the multinational company is on a journey of becoming a global company as some businesses are already handled on a global level while parts of the multinational company are still decentralized and multinational. One part of this learning process is the interdependencies between decision-making processes of mode switching as explained by participant 4 because the key actors of the process will learn from the positive and negative examples from previous decision-making processes and will transfer best practices to handle the complex process of multiple and simultaneous decisions:

"To a certain extent, of course, experience or what experience means, positive and negative experiences, such as myself in a comparable market and I would say Scandinavia and the case of the smaller European country, does not play a very different role."

\subsubsection{Global Strategy}

Within the sub theme global strategy, I categorized all findings that are related to the decision-making of mode switching but also have a global and strategical perspective on the multinational company. Hence, this sub theme is more about the global structure and strategy of a multinational company and the findings focuses on interactions between this global set-up and the decisionmaking process of mode switching. Figure 55 shows an extract of the holistic concept map which contains all subtopics and codes that are connected with the main theme global strategy, highlighted in dark blue. 
The sub themes are highlighted in light blue and are inside rounded rectangle; export strategy, company culture, reporting systems, matrix organisation, supply chain, synergies, local entrepreneurship and decision alignment. The codes are highlighted in grey and are inside octagons; global production network and production as own entity.

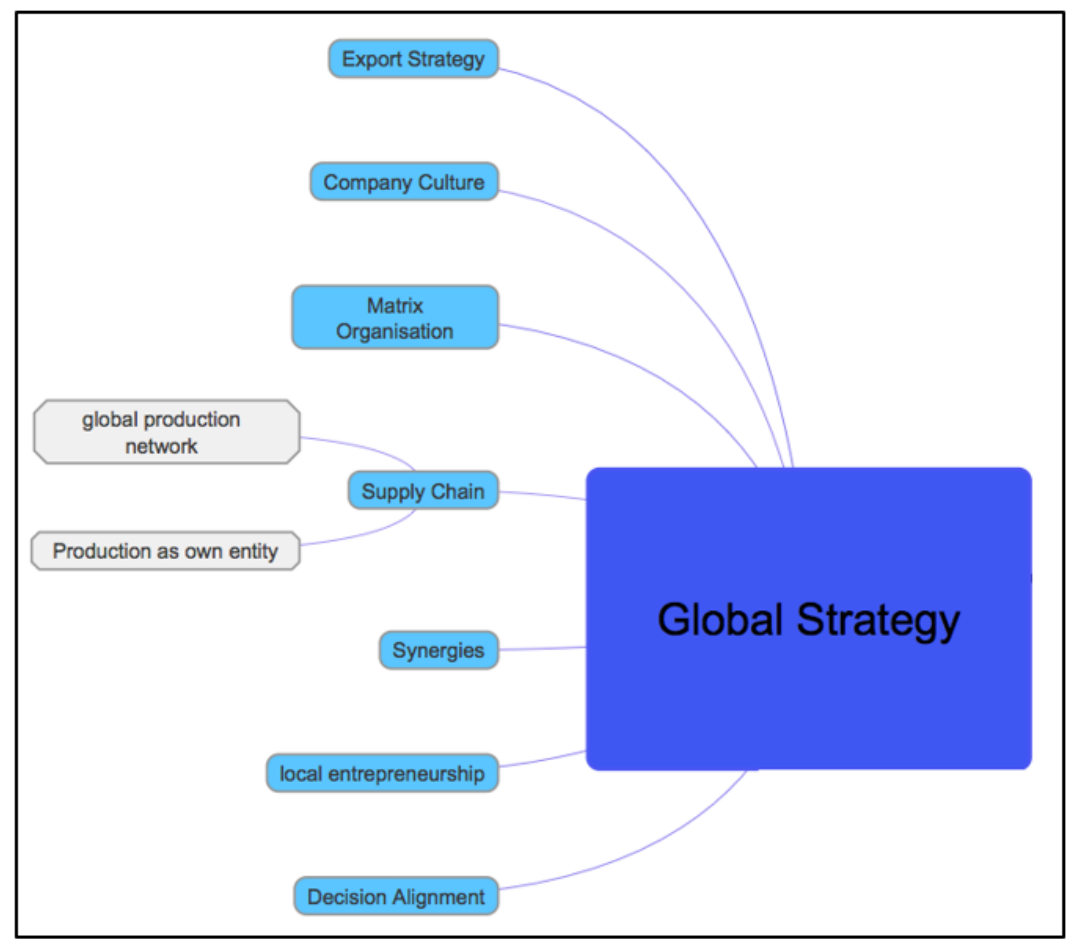

Figure 53: Extract of the Concept Map_Global Strategy (The colours and shapes in the figure are only provided to make them more readable and do not have a specific meaning)

The first finding in the sub theme of global strategy is that the multinational company does not have a global export strategy. With global export strategy, I mean a sales strategy for all countries where the multinational company does not have an own subsidiary either as production or as sales subsidiary. This is suggested by participant 4 :

“So today, if we are honest with ourselves, we don't have a global export strategy. So, we have more of a Wild West way, according to the motto, whoever thinks he can conquer a market should do so." 
A similar statement is given by participant 2 :

"The global export strategy of the holding looks like there is no global export strategy, which is bad from my point of view."

According to participant 14 , the multinational company is aware of this strategy lack and intends to close it:

"There is certainly room for improvement in this respect. There is currently also the current initiative of the holding, which is pushed globally by the board and involves all employees and finally the slogan of the project is "act global" which already says that the holding wants exactly to go this way to a global strategy, which of course also includes internationalisation and global export."

The participant mentions a strategic initiative which is currently going on within the multinational company to focus on the global strategy and act more as a global company. A global export strategy is included in this initiative.

Participant 7 points out a possible solution to bridge the strategic gap of a missing global export strategy:

"In my opinion, maybe a global export division could help to align the global processes of the holding, which means that only one export division will exist in the holding company which will be responsible for all countries world-wide where we do not have an own subsidiary"

This solution is founded on a global export division within the multinational company that is responsible for all countries where the multinational company does not have a subsidiary and consequently this division can roll out a global sales strategy for the respective markets.

The next finding in the theme of global strategy is that according to participant 3 , the culture of the multinational company has changed over the last 10 years: 
"If we were to go back 10 years, when other responsible people were still in export roles, this would have been unthinkable in some stages, or would have triggered extreme resistance. This is a sign that the company's culture is also changing and that it is clear that optimising one's own area of responsibility is not the right thing to do. But it is definitely a critical element for success and if you ask why, of course because people don't see the whole company, but sometimes their own area and also their own egoism, you have to say."

As explained by the participant, the company culture is a decisive factor for working successfully on a global scale within the multinational company. A company culture in which each manager is only looking into his area of responsibility is a challenge and is not contributing to a global strategy. The change of company culture which is explained by the participant shows that the multinational company is putting the global strategy and the intention to act as a global company more and more in focus. Participant 13 describes this new company culture as democratically structured:

"Because the holding leadership culture is very democratically structured. That's what I would call it. Things are discussed on an equal level and also discussed until a common sense has been found."

This democratic structured company culture ensures that different aspects are discussed on an equal level and consequently the decision-making processes include the consideration of diverse interdependencies.

I also find out how the multinational company has adjusted their organisational form that it fits to the new company culture and the intention to act more globally. The Multinational company is today organized as a matrix organization, as explained by participant 2 : 
"In principle, there are the national companies, which are vertically more or less set up as silos, and horizontally virtual cross-country divisions are introduced, which are supposed to form a kind of matrix organisation."

Consequently, the matrix organisation is built on the local subsidiaries which are pretty much focused on their local markets and on the horizontal crosscountry and global divisions which are virtually looking at the multinational company from a global perspective. A similar set-up is shown by participant 4 :

"It is basically a matrix organization. We live more and more in the matrix and yet we assign the entrepreneurial design to the regional or local subsidiary. Together with the global functions and the divisions, this determines our actions."

Another finding is that the participants raised several times the topic of supply chain strategy in the context of global strategy and therefore identified the supply chain as sub theme in this area. In the current supply-chain set-up, each sales division is directly connected to a production facility. This is something which participant 2 for example would like to change:

"My personal opinion is that I would probably separate the production and distribution strategies. I think a global sales strategy would have to be established and I would assign the global sales strategy to one person, including regional managers and including sales managers."

The participant also explains the reason for his opinion:

"As an export department we do not have the possibility to sell products from other national companies at all but can only access the German portfolio. In other words, we are working as a silo and cannot access the global production network of the other manufacturing plants."

Although the multinational company has a global production network, the local sales division do not have the entire access to this network which limits their 
possibilities. Therefore, separating the production networks from the sales divisions and establishing a global production network as well as a global sales division would be a benefit for the multinational company according to the participant. Participant 6 also has this position regarding the global supply chain:

"So, we should set up a production company and a trading company, as some competitors do. Then it would not be decisive where a product is manufactured, because there is a global allocation of which plant manufactures which products."

This participant not only points out that competitors already have this separation of production and sales, he also states that this separation is a decisive factor of being a global company. According to the information of the participants using the existing synergies of the multinational company is one of the decisive topics in the theme of global strategy. Participant 9 thinks that using these synergies and bundling resources like a global production network would leverage the business and consequently the competitive advantage of the multinational company enormous:

"I think that such a global bundling would have a very big leverage on the business. Such topics have been pushed forward for many years."

Although the multinational company has established the new matrix organisation structure and the company intends to act more globally in the future, I find out that the local entrepreneurs, more specifically the local subsidiaries and managing directors, still have the decision power in the multinational company which could cause conflicts in the new company structure and culture. This phenomenon is explained by participant 5 :

"The second side is that it is the philosophy of the holding that the local Managing Directors have the power of decision. This is the conflict as far as the achievement of goals is concerned. The even stronger matrix 
doesn't make this any better. We can, of course, enter our ideas and suggestions. But we are dependent on the final decision and approval of the local management."

This has an effect on the decision-making processes of mode switching because even if the managers look on the multiple simultaneous decisionmaking processes on a global scale and intend to consider the interdependencies between them, if the final decision is not accepted or made by the responsible managers in the country or region, it can cause challenges within the multinational company because the decisions are made on a local scope and not on a global level. Also, participant 13 sees improvement opportunities in this regard with his statement:

"Uh, I would just say that there has to be an alignment in the goals and in the strategy. So I think it's very good to give people the degrees of freedom they need when it comes to implementation and to say that as entrepreneurs they have the necessary freedom to shape things, because it's motivating and you should use this potential and not deprive yourself of it. But if I am a group that operates globally, then I must expect the holding to be interpreted and executed in the same way everywhere."

The participant points out the importance of still giving the local managers the degree of freedom regarding implementing their strategy locally but there needs to be a global alignment regarding the global company goals which also the local entrepreneurs and managers needs to follow. This position is supported by participant 7 who mentions that this is the last step of the multinational company of becoming a global aligned company with aligned decisions:

"I would say that the holding needs to do this final step from a multinational company to a global aligned company without silos and clear rules and regulations of how such decision-making process of mode switches are handled." 
The participant also states the importance of the decision-making process of mode switching in this regard which shows that this decision-making process is part of the global strategy and is connected with the current initiative of the multinational company to act more global aligned. As this global alignment leads to the situation that even more decision-making processes of mode switches will be interrelated and connected with each other, the interdependencies and handling of these interdependencies will become even more important as suggested by participant 14 :

"And in this context your topic fits in very well."

\subsubsection{Model Integration: Decision-Making Process of Multiple Mode Switches}

Following the conceptual framework development, the research questions, the research objectives and my findings, this chapter has the focus on extending the developed model of the decision-making process of a single mode switch (from chapter 4.2 .1 .3 ) by the interdependencies between multiple and simultaneous decision-making processes of mode switching and developing a model which contains these interdependencies.

My first finding regarding the interdependencies between simultaneous decision-making processes of mode switching was, that these interdependencies are existing and that they can grouped into external and internal interdependencies.

As internal interdependencies I identified the factors business transfer, availability of resources and best practices which could affect and influence the decision-making process. With best practices I mean the know-how transfer and transfer of best practice experiences that the management of the multinational company has made in another decision-making process and these experiences (positive as well as negative) are affecting the decisionmaking of the management in a respective other process. The research 
identified human resources as limited resource within the multinational company and therefore the usage of human resources in one decision-making process of a mode switch can influence the simultaneous decision-making process. Finally, the factor business transfer means that most mode switches occur the transfer of businesses within the multinational company from one sales division to another. This business transfer can take place in the respective market where the mode switch takes place but additionally also in surrounding markets. Consequently, the mode switch in a respective country can cause changes in the surrounding markets and therefore I conclude that there are interdependencies between simultaneous decision-making processes of mode switching which are existing due to business transfers.

As external interdependencies I identified the factors of cultural interdependencies, partners and sales structures which could influence the decision-making process of a mode switch. With sales structure I mean that if the multinational company is e.g. acquiring a competitor business because they intend to do a mode switch in a respective country or region, they typically also acquire an existing sales structure of other regions which was not the main target of the original acquisition and mode switch. This existing sales structure of the other regions or countries which needs to be integrated into the multinational company can influence a simultaneous decision-making process of mode switching if the simultaneous process is conducted in this respective region. With partners I mean that if the multinational company decides to switch the mode in a respective market to a joint venture and the joint venture partner intends to extend the business relationship in other markets besides the joint venture markets, this could influence simultaneous decision-making processes if the simultaneous process is about a market or country which the joint venture partner would like to focus on. Last but not least, there are cultural interdependencies. This means that if the multinational company switches the mode in one country, this could have influences on the surrounding countries and consequently on the decision-making process in 
these countries because of the cultural interdependencies on the political level between the countries because the respective countries are not working with each other. Such situation can occur e.g. in the middle east.

As a result, and according to my findings the interdependencies between simultaneous decision-making process of multiple mode switches are influencing factors of each decision-making process of a single mode switch and can be grouped as internal and external influencing factor. The difference between interdependencies and the other influencing factors (qualitative, quantitative, opportunities/circumstances) is that the interdependencies emerge from decision-making processes of mode switching which are running simultaneously (at the same time) while the other influencing factors (qualitative, quantitative, opportunities /circumstances) emerge either from the external environment or the remaining internal environment of the multinational company. Therefore, I added the identified interdependencies to the developed model of the previous chapter and conceptualized the first level model of decision-making process of multiple mode switches in Figure 56. 


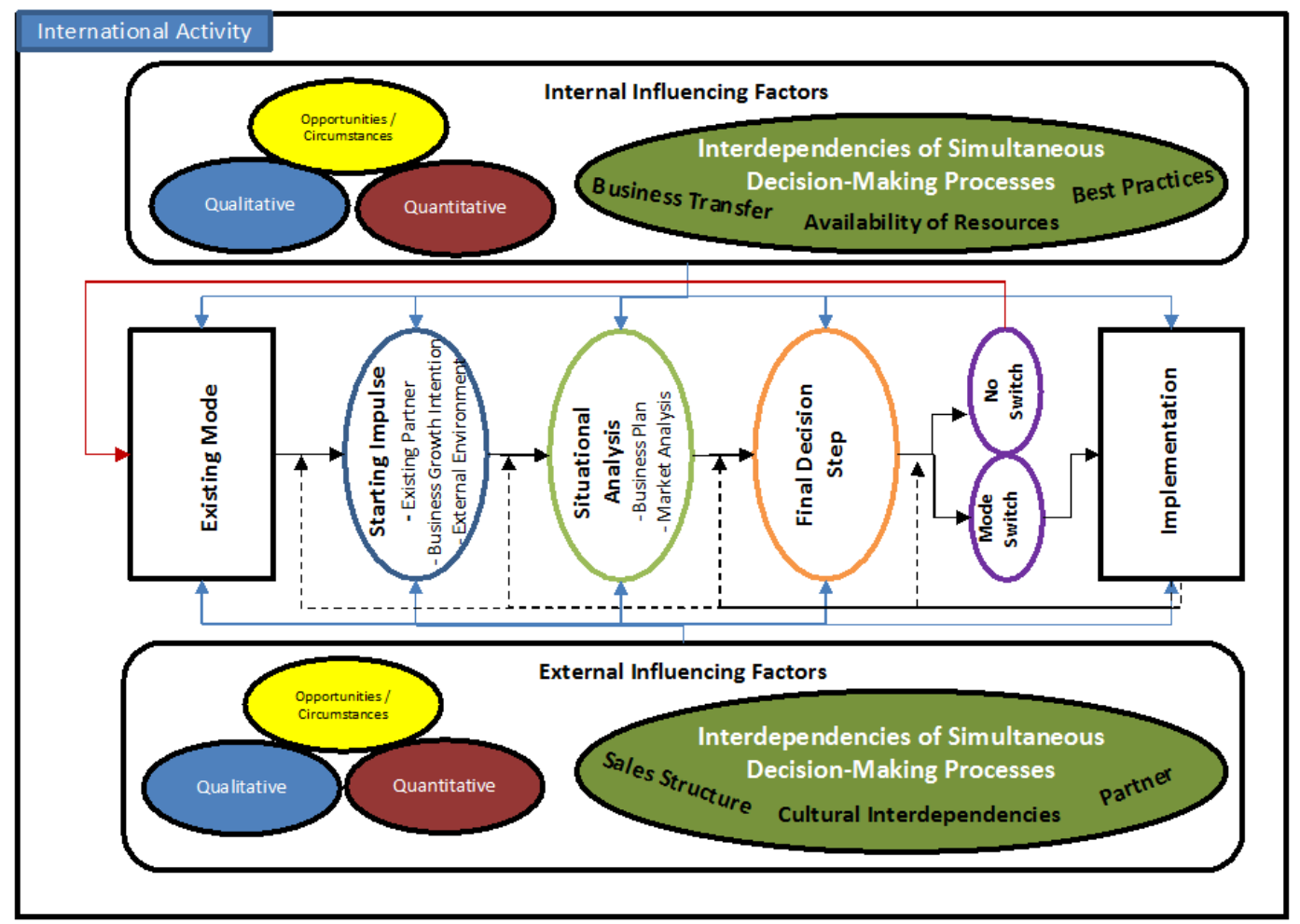

Figure 54: First Level Model of the Decision-Making Process of Multiple Mode Switches (The colours and shapes in the figure are only provided to make them more readable and do not have a specific meaning)

I call the model in Figure 56 the first level model of the decision-making process of multiple mode switches because for the final model of the decisionmaking process of a multinational company, I extend the model in Figure 56 by the additional findings regarding the handling of interdependencies, the shortcut decisions and the global strategy. By including these aspects and adding them to the first level model, I developed my final model of simultaneous decision-making processes of multiple mode switches within a multinational company which is conceptualized in Figure 57 (page 293).

My findings show that there are still short-cut decisions regarding the mode switches within the multinational company. They can happen because of the limited time that might be available for the final decision and therefore the multinational company is flexible regarding the decision-making process and to short the process down because otherwise such short -term decision which 
could be beneficial could be missed. Additionally, the detailed decision-making process could be bypassed if the decision follows a logical conclusion and if there are no doubts about the success of a decision. Therefore, I added the possibility of short-cut decisions and bypassing the detailed decision-making process in the final model which is illustrated with the purple arrow in Figure 57.

Regarding the handling of interdependencies, I found out that the multinational company has managers with global functions which are focused on looking at the multinational company and the processes from a global perspective to handle interdependencies between markets, countries and processes, including the simultaneous decision-making processes of multiple mode switches. These global functions try to establish a global strategy by open and transparent communication, by moderating critical topics and discussions, by global reporting system and global company goals, by doing democratic decisions and finally by implementing global market segments which are not bounded to national or regional boarders but rather concentrate on a specific market segment from a global perspective.

According to my findings, the global strategy which influences the simultaneous decision-making processes of multiple mode switches within a multinational company contains several factors as the export strategy, the company culture, matrix organisation, the supply-chain, synergies, the local entrepreneurship and aligning the decisions.

I found out that the multinational company does not have a global export strategy which has a negative impact on handling the interdependencies because there is a global competition between subsidiaries regarding the export markets which increases the internal interdependencies which could occur in regard to a business transfer. Regarding the company culture, I found out that it is a decisive factor for working successfully on global scale within the multinational company. A company culture in which each manager is only 
looking into his area of responsibility is a challenge and is not contributing to a global strategy. My major finding was that the company culture has changed within the multinational company over the last years and that the multinational company is putting the global strategy and the intention to act as a global company more and more in focus which has a positive effect on handling the interdependencies between simultaneous decision-making processes of mode switching.

In order to align the multinational company more globally and to ensure that interdependencies between simultaneous decision-making processes are handled and considered, the multinational company has established a matrix organisation that is built on the local subsidiaries which are pretty much focused on their local markets and on the horizontal cross-country and global divisions which are virtually looking at the multinational company from a global perspective. I found out that this matrix organisation was a first step of the multinational company of getting a global company but that still the globally aligned decisions are missing because the local entrepreneurs (managing directors of local subsidiaries) still do the final decision. As the local entrepreneurs cannot have the global and borderless view on the decisionmaking processes the missing global decision alignment and the strong local entrepreneurs can have a negative impact on handling the interdependencies between simultaneous decision-making processes of mode switching.

Last but not least the final factor within the global strategy which influences the decision-making process of mode switching is the global supply chain and using the synergies within the production network of the multinational company. Although the multinational company has a global production network, the local sales division do not have the entire access to this network which limits their possibilities. Therefore, separating the production networks from the sales divisions and establishing a global production network as well as a global sales division would lead to more independent decision-making processes about business decisions because they are made from a sales 
perspective only. This would reduce the interdependencies between simultaneous decision-making processes of multiple mode switches and would make the handling of those easier because the decisions would not affect the production network which is currently one of the major internal interdependencies regarding the business transfers.

Hence, I have developed a final model of simultaneous decision-making processes of multiple mode switches within a multinational company which is shown in Figure 57 and also showed some possible improvements that were found out for the investigated multinational company. 


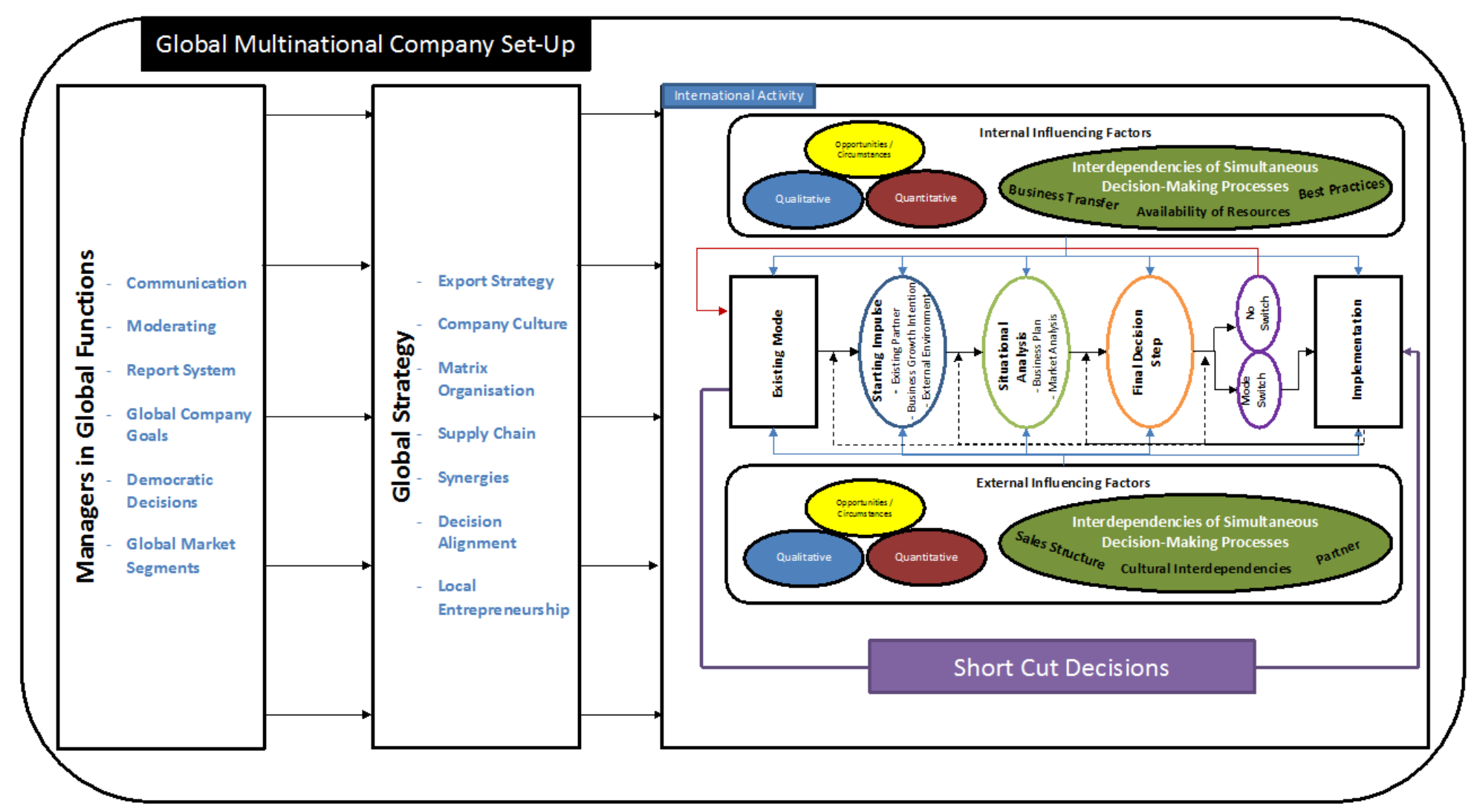

Figure 55: Final Model of Simultaneous Decision-Making Processes of Multiple Mode Switches within a Multinational Company (The colours and shapes in the figure are only provided to make them more readable and do not have a specific meaning) 


\subsection{Documentation Review}

For analysing the documentation reviews I used the identified themes of the inductive thematic analysis process of the interview transcripts. In the following chapter I show the results and findings from the review of documents which triangulate and support the findings from the semi-structured interviews.

\subsubsection{Rational Decision Process}

As document 1 is an example of a business plan for the decision-making process of a mode switch within the multinational company, this document provides valuable insides regarding the rational decision-making process and the sub theme data analysis and business plan. According to the findings from the semi-structured interviews the findings are categorized according to the code's existence of a business plan, the format of a business plan and finally the content of a business plan. As document 1 supports, the multinational company is using business plans for their decision-making process of mode switching. Regarding the format of the business plan, my findings in the semistructured interviews were that there is no general blueprint existing within the multinational company. This either can be supported by document 1 nor can be falsified by document 1 because the business plan provided with document 1 is just one example of a business plan which was developed within the multinational company. The table of content shows that there are quantitative as well as qualitative factors are considered in this business plan. As an example of the quantitative factors, I show chapter 10 of the business plan:

\section{Financial Plan}

10.1 Volumes and Turn-Over

10.2 Product Costs

10.3 Sales Costs

10.4 Costs for Administration.

10.5 Additional Costs and Incomes 
The content list of chapter 10 shows that the business plan contains the quantitative analysis of the new mode option which shall be implemented as final result of the decision-making process. This quantitative analysis includes the detailed costs and income perspective which result in a comparison and summary of a P\&L and Break-Even Analysis.

An Extract of chapter 6 and 8 of the respective business plan shows examples of qualitative aspects which are considered in the business plan:

\section{Marketing Strategy}

\section{1 „Promotion“ - Positioning}

\section{Personnel and Organisation}

\subsection{Management Principles}

\subsection{Managing Director and Key Personnel}

In chapter 6 the project team has mainly focused on the marketing strategy and the strategy to position the brand of the multinational company within the targeted market. In chapter 8 the project team did a recommendation regarding the management principles which are important for a new subsidiary in this respective market and which recommendations they have concerning the key managers like managing director.

Additionally, the business plan also shows insights about the market analysis which is one of the sub themes of the data analysis of the rational decisionmaking process which I have been identified during the interviews. Chapter 3 of the business plan shows an overview of the topics which were investigated for the market analysis: 


\section{The Lubricant Market}

\subsection{Potentail Market Segments}

\subsection{Market Potential}

\subsection{Customers}

\subsection{Business Cases}

\subsection{Competitor Analysis}

In the first section the project team has defined the respective market segments which are existing in the market as e.g. the cement industry. In the next section, they have calculated the market potential per marked segment to know the complete market potential of the interesting segments. In section 3 of the chapter, the project team has analysed the existing and possible customers of the target market and especially which customer structure is existing in the country. In the next section they have thought about possible business cases which could be implemented in the new market. With business cases the project team means the mode option that the multinational company has to switch to in the respective market. As, according to document 1 , this business plan had the proposition of evaluating the mode option of an own sales subsidiary in the respective market, the project team has only focused on this mode option and has not included other possible business cases. The last chapter of the market analysis is the competitor analysis which includes qualitative as well as quantitative aspects. In this context, the project team defined the analysis factors quality, prices and service and evaluated each competitor according to these factors with the following scheme:

\begin{tabular}{|l|l|}
\hline Value & Meaning \\
\hline $\mathbf{0}$ & No Competition \\
\hline $\mathbf{1}$ & Weak Competition \\
\hline $\mathbf{2}$ & Medium Competitions \\
\hline
\end{tabular}




\begin{tabular}{|l|l|}
\hline $\mathbf{3}$ & Strong Competition \\
\hline NA & No information available \\
\hline
\end{tabular}

Table 32: Competitor Evaluation Criteria_Business Plan Example

Consequently, the project team has evaluated each competitor according to these factors and as a result the multinational company had a competitor positioning map for each market segment.

Document 3 also provides input related to the sub theme data analysis of the rational decision-making process. This document is provided by participant 9 and is a detailed market analysis regarding one specific market segment. This document contains the following contents:

1. Sales history in the respective market segment of the target market

2. Overview of the market shares of the multinational company and the competitors

3. Qualitative description of the market situation

4. Key Account Customers and customer structure

5. Possible mode options for the respective market

Consequently, the detailed market segment analysis provided in document 3 contains similar topics like the market analysis in the business plan of document 1 . Section 3 of the table of content above shows that the detailed market segment analysis contains qualitative data as well. Hence, although I found out that there is no blueprint for a business plan existing within the multinational company, the key topics of the two example documents regarding market analysis are rather similar. According to participant 9 who provided document 3 , this document was issued by product managers who are specialists for the specific market segment and as a foundation for a business plan.

In Document 4 which contains a press release about a mode switch of the multinational company in Africa, I found interesting data and information about the sub theme starting impulses within the main theme rational decision- 
making process. The document, for example, contains a statement from the managing director of the new established subsidiaries:

"The distributors have done an excellent job in building the companies brand in their countries and the timing is now right for the company to take an equity stake in the businesses."

This statement shows that the good performance of the existing external partners can occur as starting impulse for the rational decision-making process as I found in the data analysis of the interview transcripts.

Additionally document 4 contains a statement from the CEO of the multinational company which is also categorized in the sub theme of starting impulses:

"This will supply markets in Africa and is also part of our current global growth initiative investing in existing and new plants focused on capacity increase in line with advanced technology."

This statement suggests that the general business growth intention from the multinational company can be one decisive starting impulse of the rational decision-making process. I identified the same findings in the data set of the semi-structured interviews.

Document 5 and 6 contain two separate articles from well-known German newspapers (Handelsblatt and FOCUS). Both articles are from 2012 and about the rumours that the one of the joint venture partners of the multinational company intends to sell their joint venture shares because of the financial crisis in the middle east. Consequently, the input and extracts from these two documents indicate my findings of the interview transcripts that the external partner as well the market environment or economic situation of a market can be the starting impulse for the rational decision-making process. 


\subsubsection{Influencing factors}

In Document 4 which contains a press release about a mode switch of the multinational company in Africa, I found interesting data and information about the theme influencing factors. The document, for example, contains a statement from the regional vice president:

"Customers in these countries, who require lubricants and services in fields like mining, commercial vehicle fleets, general industry, agriculture, food and beverage, consumer products and other specialty applications will benefit locally from even stronger lubricants focus supported by international resources."

This extract triangulates the internal qualitative influencing factor and the code word "local proximity" to the customers which I identified and defined in the thematic analysis of the semi-structure interviews. This statement of document 4 additionally suggests and triangulates that one of the influencing factors of the multinational company for a mode switch is the argument for a better local proximity to the customers.

\subsubsection{Interdependencies of simultaneous Decision-Making Processes}

Document 2 "customer transfer sheet" is related to the subtheme business transfer and know-how transfer which I have identified in the theme of interdependencies of simultaneous decision-making processes of mode switching. This customer transfer sheet was issued by the German subsidiary that transferred a business due to the mode switch in a Scandinavian country to an own sales subsidiary. The customer transfer sheet is in a excel format and contains the following 7 spreadsheets:

\footnotetext{
- General information

- Articles list

- Business figures 2015

- Business figures 216
} 
- Actual Price list

- Price list history

- Marketing support

The spreadsheet general information contains the contact information about the order handling process with the respective customer like the payment conditions, delivery conditions, account overview, etc. The article list shows all products which the customer has purchased from the multinational company in the history of partnership, the spreadsheets business figures 2015 and 2016 contain the volumes and turn-over figures of the respective business years, the pricelists spreadsheets contain all prices which have been quoted to the customer in the past and the last spread sheet shows if the customer receives a marketing bonus. Consequently, the customer transfer sheet mainly contains quantitative information and information about the administrative order handling process with the customer. The customer transfer sheet does not include any qualitative or in-depth information and experiences from the responsible sales manager about the customer relationship or important factors that need to be considered by working with this customer. Participant 7 and 8 who provided methis customer transfer sheet also indicated that there was no further exchange regarding this business transfer besides the customer transfer sheet which indicates the statement from participant 2 from the data analysis of the interview transcripts:

"All this knowledge was not asked for in the process and it was not asked what is being done in the country. To the best of my knowledge, the responsible persons were not asked for an interview where they talked about it and tried to get knowledge from the export department."

Consequently, there is a lack regarding handling the interdependencies within the global mode network of the multinational company because the managers and experts of a respective market are not involved deeply enough in the final decision of mode switching. 


\subsection{Chapter Summary}

This chapter presents the findings from the research and outlined the core data and extracts from the dataset that contributes to the development of the model and for achieving the research objectives.

In the first part of this chapter, I used an inductive thematic analysis approach to identify the themes, sub themes and codes of the semi-structured interview data set. I colour coded each interview transcript to highlight which data extract from the interview is used for analysis and to which theme the extract belongs. These highlighted data extracts were summarized in a list of codes (Appendix 11) and categorized per theme. Based on the inductive thematic analysis I developed a concept map (Appendix 8) which shows the identified themes, sub themes, codes and their connection to each other. As result I identified the main themes short cut decisions, decision-making of a single mode switch and decision-making of multiple mode switches. As sub themes I identified the rational decision-making process, the influencing factors, the global strategy and the interdependencies of simultaneous decision-making processes (Figure 40). The findings per theme and sub theme were shown in this chapter and the chapter is structured according to the main and sub themes.

Based on my findings, Ideveloped the final model of my thesis which is shown in Figure 57. I developed the final model step by step. First, I developed the rational decision-making process based on my findings and extended the rational decision-making process by the qualitative influencing aspects which were found in the dataset to finally develop the decision-making process of a single mode switch which only considers one international activity within the multinational company. Second, I extended the developed model of a single mode switch with the findings regarding the interdependencies which are existing between simultaneous (happening at the same time) decision-making processes within multinational companies. Last but not least I developed my final model in Figure 57 by including his additional findings regarding the handling of interdependencies, the short-cut decisions (intuitive decisions) and 
the global strategy. By including these aspects, I developed my final model for simultaneous decision-making processes of multiple mode switches within a multinational company which is conceptualized in Figure 57 and related to the final conceptual framework in Figure 27.

In the second part of this chapter, I analysed the documents provided by the participant by using the predefined themes, sub themes and codes of the semistructured interviews. Consequently, I am using the documentation review to support and triangulate the findings from the semi-structured interviews. Both methods complement each other and build a credible and justified method approach to conduct this research based on my phenomenological beliefs and for achieving the research aim and objectives. 


\section{Discussion}

\subsection{Introductory Comments}

This chapter discusses the research findings by comparing the results which are presented in the previous chapter with the existing theories and knowledge of the current literature body which is outlined in chapter 2 of this thesis. This chapter is structured according to the result chapter (chapter 4). First the results of the three set-ups of the decision-making process of mode switching within the multinational company (short-cut decisions, the decision-making process of a single mode switch and the decision-making process of multiple mode switches) are compared to the theories regarding decision-making. Second the contribution and differences of the new developed model to the existing theories are shown. In the last section of this chapter, I illustrate the research propositions which I found as statements in context of my concept and integrated model of decision-making process of multiple mode switches.

\subsection{Comparison with Literature}

\subsubsection{Decision-Making Process of a Single Mode Switch}

In this section the findings and results regarding decision-making process of a single mode switch are discussed with the existing theories of the literature body. The findings regarding the decision-making process of a single mode switch are summarized in Figure 48 (page 252). The purpose of this section is to show how objective 2 of this research is achieved.

\subsubsection{Rational Decision-Making process}

One of the first findings of this decision-making process was that a rational decision-making process exists within the multinational company which contains the process steps, existing mode, starting impulse, situational analysis, final decision step and implementation. This result is supported by Albaum and Duerr (2008) and Sachse (2010) who explain in their study that 
rational decision-making processes of mode switching are existing in organizations and contain the process steps, problem identification, gathering information, generating alternatives, evaluation of alternatives, decision and transition. As shown in the comparison of the single process step in Table 34, the identified process steps of the rational decision-making process of mode switching are supported by the authors in the literature (Albaum \& Duerr, 2008; Sachse, 2010, Luoma \& Martela, 2020).

\begin{tabular}{|c|c|}
\hline $\begin{array}{c}\text { Rational Process Steps of the } \\
\text { literature } \\
\text { Problem identification }\end{array}$ & $\begin{array}{c}\text { Rational Process Steps of this } \\
\text { research }\end{array}$ \\
\hline $\begin{array}{c}\text { Gathering information, generating } \\
\text { alternatives and evaluation of } \\
\text { alternatives }\end{array}$ & Situational Analysis \\
\hline Decision & Final decision step \\
\hline Transition & Implementation \\
\hline
\end{tabular}

Table 33: Comparison of the rational process steps of the literature and this research

As supported in Table 34, this research found in the collected dataset the same process steps for the rational decision-making process of mode switching as it is suggested in the literature. However, while the theoretical model of Albaum and Duerr (2008) and the model of Sachse (2010) is an incremental and step by step approach, the developed model of this research shows (see Figure 48 (page 252)) that the decision-making process of mode switching within the investigated multinational company is more a cycled and iterative process. Therefore, this study contributes new perspectives to the decision-making process of mode switching within multinational companies.

Next to the finding that a rational decision-making process of mode switching is existing within the multinational company which is supported by the 
literature, this research found new perspectives regarding the rational decision-making process of mode switching because this research identified the specific quantitative influencing factors which are the decision determinants for the respective process steps. These new perspectives per process step are discussed in the following sub sections.

\subsection{Starting Impulse}

I found out that the existing external partner, the growth intention of the investigated company and the external market environment can be the starting impulse to launch the rational decision-making process of mode switching.

The results of this study that the external environment of the investigated company can be a starting impulse for the decision-making process of mode switching is supported by Sachse (2010) and is shown in his model of mode switching in Figure 11.

The agency theory (Welch et al., 2007; Metsola et al. 2020) as well as Sachse (2010) in his study support the findings of this research that third party distributors can have an inlfuencing effect on the internationalisation decisions of a firm. Within the literature the agents are typically defined as external partners of the company (Welch et al., 2007; Metsola et al. 2020). However, new perspectives were identified because this research found out that next to the external third party partners, e.g. distributors, also joint venutre partners can influence the decision-making process of mode switching. In this regards, the ressearcher especially found out that changed strategic goals at the joint venture partner can be a starting impulse for the multinational company to switch the mode. Consequently, on the one side this research triangulates and supports the key aspects from the agency theory with its findings regarding the influencing effects that external partners can have on the decision-making process of mode switching. However, on the other side the findings of this research extend the current literature body of the agency theory by the aspect that existing joint venture partners of the multiantional company can also 
influence the decision-making process of mode switching as external partner and furthermore this research found additional and new influencing factors that have not been considered in the agency theory, e.g. the growth intention of the multinational company.

Dunning (2000) supports the finding of this research that the growth intention of the multinational company can be the starting impulse for starting the decision-making process of mode switching, because Dunning (2000) argues that the firms' performance in an international activity determines if a mode switch is occuring or not. However, the developed model of this research also schows that there are additional starting impulses for the decision-making process of mode switching, e.g. the existing external partner or the market environment. Therefore, the findings of this research extends the knowlegde of the OLI paradigm of Dunning (2000) and shows that not only the performance of an international activity drives the decision regarding internationalisation as it is suggested in the OLI paradigm by Dunning (2000) (Yaw \& Keon, 2020).

\subsection{Situational Analysis}

This research found out that the process step of situational analysis contains the market analysis of a respective international activity and that the possible decision alternatives are evaluated with a business plan which builds the basis for the final decision step within the multinational company.

Sachse (2010) supports the findings of this research regarding the situational analysis because Sachse (2010) defines the situational analysis in his research as the evaluation process of the mode switching alternatives. Sachse (2010) suggests that based on a detailed market analysis an evaluation process starts which considers the transaction costs and the economic potential of a mode switching option. Therefore, the findings of this research that a business plan with an economic analysis of the respective decision 
alternatives is developed based on a detailed market analysis is supported by the literature.

The theory of transaction cost which was developed by Coase in 1937 and further investigated and adjusted by Williamson $(1975,1985)$, was the first traditional approach that I described in my literature review chapter. This approach is focusing on the costs which emerge in context of an international activity of a firm. This means that a decision, e.g. to enter into a market or to switch a mode in a respecitve market are made based on the emerging costs of the available alternatives. According to the transaction cost theory, a firm would decide always for the decision with the lowest emerging costs (Coase, 1937; Calveras \& Orfila-Sintes, 2019). That the emerging costs play an important role in the decision-making process of mode switching within a multinational company is shown by my findings. The data analysis step of the rational decision-making part of the process in which the multinational company typlically develops a business plan for the respective mode switching decision normally contains a profit and loss calculation. This profit and loss calculation considers the emerging costs of mode switching alternatives. Consequently, the aspects of the transaction cost theory are supported by my findings and included in the developed model. However the developed model of this research provides a more holistic view and contributes theoretical knowledge because the decision determinants are not limited to the emerging costs only, as it is within the transaction cost theory, but rather is extended by profit asepcts as well as qualitative influencing factors which gives a more transparent and more comprehensive picture of the phenomenon.

\subsection{Final Decision Step and Mode Options}

As supported by Sachse (2010) I found out that regarding the final decision step the investigated multinational company has the decision options to continue with the current mode option or to make a mode switch. 
At the beginning of the literature review about mode switching, I show the entry mode options which are existing in the current literature body and which are explained by previous studies. According to the literature and the systematic literature review, the mode options are differentiated by the level of capital investment and by the level of possible management control of the respective company, as illustrated in Figure 12. The higher the capital investment of a mode option is the higher is the possible management control of a company. The management control is for the multinational company also a decisive factor. The findings of the data set is that the multinational company is using all mode options which are discussed in the literature chapter (chapter 2) like export, licensing, contractual agreements, joint ventures and wholly owned subsidiaries. However, I also found out that the multinational company used a mode option which is not described in the literature review of chapter 2 , a joint venture in making. The joint venture in making means that the multinational company signs a contract with an external third-party distributor and this contract gives the multinational company the right to acquire a certain number of shares of the distributor at any time. Therefore, the multinational company defines this mode option as a joint venture in making because with signing the contract, the multinational company still operates with the distributor, but they clearly mention their intention and their right to change this set-up to a joint venture inside the contract. This finding contributes knowledge to the theory of entry options which is outlined in chapter 2.6.1.1 because this mode option was not explained and discussed before in the literature.

Next to the entry mode options, I also describe the existing theories of the market entry process in chapter 2.6.1.2. As I previously explained $r$, this process is the preceding and necessary process which takes place before the decision-making process about mode switching can take place because the multinational company needs to act in a respective foreign market with a previous selected mode option before the multinational company can switch the mode. One of the newest and may be most influential studies regarding 
the market entry process is from Georgiou (2014) who developed a process model for the market entry process. This process model is illustrated in Figure 13 (page 73) of this thesis. Although, Georgiou (2014) has not analysed the mode switching process but rather the market entry process, he showed in his findings that there is an operational and strategical lens in the decision-making process of a multinational firm. This research illustrate the same aspects in the final model in Figure 57 where the global strategy and managers in global functions influence the decision-making process of mode switching by setting the global guidelines, standards and boundaries for the process. Hence, the results of Georgiou (2014) and the findings from this research overlap and the aspects of the strategical and operational lens or level need to be considered in decision-making processes of multinational companies.

\subsection{Revisiting Research Objective 2}

The outlined objective 2 of this research project is to explore the process of management decision-making of mode switching within a multinational company's internationalisation strategy. The discussion of the research results in chapter 5.2.1.1 regarding the rational decision-making process shows that many elements of the developed rational decision-making model of mode switching of the investigated multinational company (see Figure 47 (page 249)) are supported from the literature. However, the discussions also show that the developed model in Figure 47 (page 249) of this research contributed new aspects. The developed model of rational decision-making process of mode switching within the multinational company in Figure 47 (page 249) and the summary of the result discussions regarding the rational decision-making process of mode switching in Table 35 supports that objective 2 of this research is achieved. 


\begin{tabular}{|c|c|c|c|c|}
\hline & $\begin{array}{c}\text { by the } \\
\text { literature }\end{array}$ & & & \\
\hline $\begin{array}{l}\text { Structure and individual } \\
\text { process steps of the } \\
\text { rational decision-making } \\
\text { process }\end{array}$ & $x$ & & $\begin{array}{c}\text { Albaum \& } \\
\text { Duerr, 2008; } \\
\text { Sachse, 2010; } \\
\text { Luoma \& } \\
\text { Martela, } 2020\end{array}$ & 5.2.1.1 \\
\hline $\begin{array}{c}\text { External Environment as } \\
\text { starting impulse }\end{array}$ & $X$ & & Sachse, 2010 & 5.2.1.1.1 \\
\hline $\begin{array}{l}\text { Joint Venture partners as } \\
\text { possible external partner } \\
\text { that act as a starting } \\
\text { impulse }\end{array}$ & & $X$ & $\begin{array}{l}\text { Welch et al., } \\
2007\end{array}$ & 5.2.1.1.1 \\
\hline $\begin{array}{c}\text { There are additional } \\
\text { possible starting } \\
\text { impulses next to the } \\
\text { growth intention of a firm }\end{array}$ & & $x$ & Dunning, 2000 & 5.2.1.1.1 \\
\hline $\begin{array}{c}\text { A detailed market } \\
\text { analysis and business } \\
\text { plan is the basis for the } \\
\text { final decision }\end{array}$ & $x$ & & Sachse, 2010 & 5.2.1.1.2 \\
\hline $\begin{array}{l}\text { Transaction costs are } \\
\text { not the only determinant } \\
\text { for doing the final } \\
\text { decision }\end{array}$ & & $X$ & $\begin{array}{c}\text { Williamson, } \\
\text { 1975 \& 1985; } \\
\text { Calveras \& } \\
\text { Orfila-Sintes, } \\
2019\end{array}$ & 5.2.1.1.2 \\
\hline Entry Mode options & & $X$ & $\begin{array}{c}\text { Georgiou, } \\
\text { 2014; Glowik, } \\
2020\end{array}$ & 5.2.1.1.3 \\
\hline
\end{tabular}

Table 34: Summary of Result Discussion_Rational Decision-Making Process 


\subsubsection{Influencing Factors}

As shown in the developed model of the management decision-making process of a single mode switch in Figure 48 (page 252), this research found out that there are external and internal influencing factors which impact the outcome of the decision-making process at different steps. An additional finding was that there are influencing factors that include external and internal elements and therefore are identified as circumstances and opportunities that can impact the decision-making outcome. The following sections discuss which elements are supported by the literature and which new perspectives were found by the results of this research.

One theory that supports the findings of this research regarding the internal and external influencing factors is the threelevel approch of Swoboda (2002). This model contains three levels which are influencing the internationalisation process of a firm, as illustrated in Figure 23 (page 106). The first level is grouped into internal and external environmental factors which are seen as the stimuli of international development. The main determinants of the primary level are the country portfolio, the operation mode and the transfer of value creation. The primary level is defined as the foundation and guiding principles of the internationalisation process and to develop internationalisation pathways. The secondary / basic level are the changes of structure, processes and culture within a company that occur due to the internationalisation pathways. Depending on the developed pathways, the company is creating its new configuration regarding processes, culture and structure (Swoboda, 2002; Schmid \& Morschett, 2020). According to this model the main influencing factor of the decisions regarding internationalisation are the external and internal environment of the decision-making process of mode switching. This elements are supported by the findings of this research regarding the influencing factors. As illustrated in Figure 57 (page 293) the influencing factors of the decisionmaking process of mode switching are divided into external and internal influencing factors. However, the findings of this research also show that there 
are external and internal interdependencies which can be categorized as influencing factors but which emerge not from the internal or external environment but rather emerge from simultaneous decision-making processes of mode switching which happen at the same time. These interdependencies which are existing within multinational companies are not considered within the three level approach and therefore the developed model in Figure 57 (page 293) contributes theoretical knowledge regarding the interdependencies between multiple mode switches within multinational companies.

\subsection{External Environment}

The first finding regarding the external influencing factors was that these can be grouped into quantitative, qualitative and circumstances influencing factors Figure 48 (page 252). Georgiou (2014) and Sachse (2010) support that there are quantitative as well as qualitative influencing factors that impact the final decision outcome. However, these studies do not define circumstances/opportunities as influencing factors of the external environment although I found out that such circumstances/opportunities can impact the final decision of mode switching (see chapter 4.2.1.2.2). Therefore, this study contributes new perspectives on the aspect of external influencing factors in context of external opportunities that can arise outside of the organization, e.g. that a new potential external partner contacts the multinational company to do a mode switch in a respective market.

Finding qualitative influencing factors that impact the decision-making process of mode switching shows that indeed there is a rational decision-making process (as discussed in chapter 5.2.1.1) but the rational perspective is extended by qualitative elements that also impact the decision outcome because qualitative influencing factors have been found. According to Albaum and Duerr (2009) and Luoma and Martela, 2020 these qualitative influencing factors are part of intuitive decision-making. Albaum and Duerr (2008) developed an integrated multi-level model (which is shown in chapter 2.5) 
which integrates the rational as well as the qualitative and intuitive decisionmaking as shown in Figure 9 (page 59). This model supports the findings from this research that there is a rational decision-making process of mode switching and qualitative influencing factors that impact the decision outcome as well. However the model of Albaum and Duerr (2008) only defines subordinated external qualitative influencing as environment and key actors (see Figure 9 (page 59)) and does not define the specific influencing factors inside the subordinated groups. Therefore, this research contributes new perspectives regarding the external qualitative influencing factors by defining the influencing factors specifically. As shown in the model in Figure 48 (page 252), I found the following specific external qualitative influencing factors, market (e.g. the availability of well-educated employees in the respective market), competitors (e.g. if a competitor changes his market development strategy), politics (e.g. if the politics announce an embargo for a respective country), cultural effects (e.g. if people from one country do not want to work with a specific other culture), reputation (e.g. if the multinational company decides which mode option results in the best reputation in the respective market).

One theory that supports the findings reagding the external influencing factors of this research is the network perspective approach which is based on social exchange and resource dependency theories (Sharma \& Blomstermo, 2003). The main focus in this approach is on non-hierachical systems in which firms invest to improve and strengthen their position in global networks (Sharma \& Blomstermo, 2003). Especially the inter-organisational and inter-personal relationships in the global network play a decisive role (Chetty \& Blankenburg Holm, 2000; Li, et al., 2004; Luoma \& Martela, 2020). The aspects of the network perspective approach are suggested by the findings of this research because I found several external influencing factors which affect the decisionmaking process of mode switching, such as the politics, the external partners or the competitors. This shows that the global network around the multinational 
company plays a decisive role within the developed model in Figure 57 (page 293). However, the developed model also shows that there are additional aspects and infleuncing factors which need to be considered in the context of the decision-making process of mode switching and therefore the developed model contributes additional perspectives to the current literature body and extend the knowledge regarding the network perspective approach

\subsection{Internal Environment}

Analogues to the findings of the external environment, the first finding regarding the internal influencing factors was that these can be grouped into quantitative, qualitative and circumstances influencing factors Figure 48 (page 252). Georgiou (2014) and Sachse (2010) support that there are quantitative as well as qualitative influencing factors that impact the final decision outcome. However, these studies do not define circumstances/opportunities as influencing factors of the external environment although I found out that such circumstances/opportunities can impact the final decision of mode switching (see chapter 4.2.1.2.2). Therefore, this study contributes new perspectives on the aspect of internal influencing factors in context of internal circumstance that can change inside of the organization and can influence the decision outcome.

Regarding the internal quantitative influencing factors, this research found out that the financial possibilities and the expansion strategy influence the decision outcome and that there is a critical mass which is the decisive factor of mode option selection (see chapter 4.2.1.2.3). Georgiou (2014) and Sachse (2010) supports with his model that the financial possibilities and the expansion strategy or intention to grow influence the decision outcome. However, both studies do not define that there is a critical mass which means that there are explicit defined borders regarding sales volumes or turn-overs which need to be reached for switching from one mode to the other, e.g. establishing an own sales subsidiary in a market instead of working through distributors in the 
market. Therefore, this research contributes additional perspectives regarding the internal quantitative influencing factors regarding the decision-making process of mode switching.

Analogues to findings of the external influencing factors, this research found qualitative influencing in the group of internal factors as well. Finding qualitative influencing factors that impact the decision-making process of mode switching shows that indeed there is a rational decision-making process (as discussed in chapter 5.2.1) but the rational perspective is extended by qualitative elements that also impact the decision outcome because qualitative influencing factors have been found. According to Albaum and Duerr (2009) and Luoma \& Martela (2020) these qualitative influencing factors are part of intuitive decision-making. Albaum and Duerr (2008) developed an integrated multi-level model (which is shown in chapter 2.5) which integrates the rational as well as the qualitative and intuitive decision-making as shown in Figure 9 (page 59). This model supports the findings from this research that there is a rational decision-making process of mode switching and qualitative influencing factors that impact the decision outcome as well. However the model of Albaum and Duerr (2008) only defines subordinated internal qualitative influencing factors as environment and key actors (see Figure 9 (page 59)) and does not define the specific influencing factors inside the subordinated groups. Therefore, this research contributes new perspectives regarding the internal qualitative influencing factors by defining the influencing factors specifically. As shown in the model in Figure 48 (page 252), I found the following specific internal qualitative influencing factors, complexity costs (e.g. costs that are not quantifiable), cultural effects (e.g. hiring people for the subsidiaries in a market that works in regards to the cultural aspects), controlling the market strategy (e.g. if the multinational company intends to have a high control on the market strategy, a mode option which provides this high control is necessary). One key finding of this research that contributes new perspectives is the influence of key actors on the management decision- 
making process of mode switching. I found out that the personal behaviour typically influences the decision-making process of mode switching which is supported by Albaum and Duerr (2008), Georgiou (2014) and Luoma and Martela (2020). However, this research found out that the personal interests which are mainly dependent on the bonus and provision system of the individual managers defines the personal behaviour of managers which contributes new perspectives and knowledge to the decision-making process of mode switching.

\subsection{Revisiting Research Objective 2}

The outlined objective 2 of this research project is to explore the process of management decision-making of mode switching within a multinational company's internationalisation strategy. The discussion of the research results in chapter 5.2.1.2 regarding the influencing factors of the management decision-making process of mode switching shows that some elements of the influencing factors of the investigated multinational company (see Figure 48 (page 252)) are supported from the literature. However, the discussions also show that the developed model in Figure 48 (page 252) of this research contributed new aspects.

The developed model of decision-making process of a single mode switch within the multinational company in Figure 48 (page 252), the summary of the result discussion in table Table 35 (chapter 5.2.1.1.4) and the summary of the result discussions regarding the influencing factors of the decision-making process of mode switching in Table 36 shows that objective 2 of this research is achieved.

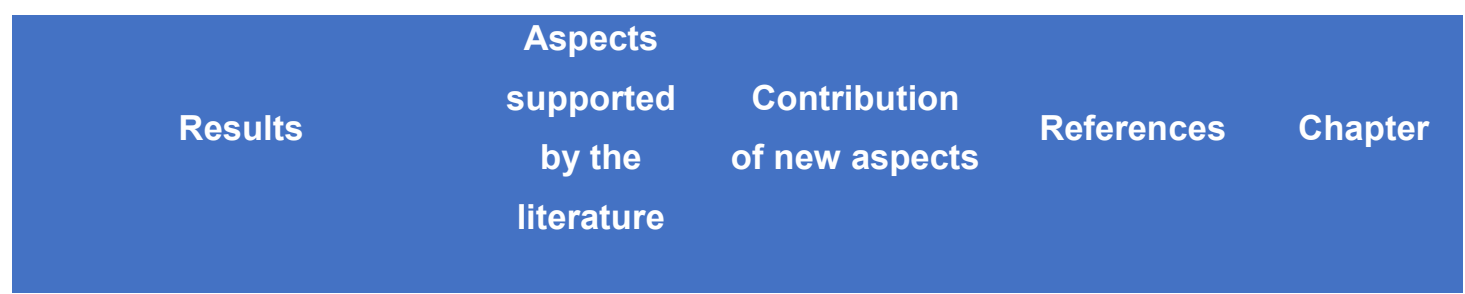




\begin{tabular}{|c|c|c|c|c|}
\hline $\begin{array}{l}\text { Opportunities and } \\
\text { circumstances as } \\
\text { additional external and } \\
\text { internal influencing } \\
\text { factors }\end{array}$ & & $x$ & $\begin{array}{c}\text { Sachse, } 2010 \\
\text { Georgiou, } \\
2014\end{array}$ & $\begin{array}{l}5.2 .1 .2 .1 \\
5.2 .1 .2 .2\end{array}$ \\
\hline $\begin{array}{l}\text { Finding qualitative } \\
\text { external and internal } \\
\text { influencing factors }\end{array}$ & $X$ & & $\begin{array}{c}\text { Albaum and } \\
\text { Duerr, } 2008 \\
\text { Luoma and } \\
\text { Martela, } 2020\end{array}$ & $\begin{array}{l}5.2 .1 .2 .1 \\
5.2 .1 .2 .2\end{array}$ \\
\hline $\begin{array}{l}\text { Specifically defining the } \\
\text { internal quantitative } \\
\text { influencing factors }\end{array}$ & & $X$ & $\begin{array}{c}\text { Sachse, } 2010 \\
\text { Albaum and } \\
\text { Duerr, } 2008 \\
\text { Georgiou, } \\
2014\end{array}$ & 5.2.1.2.2 \\
\hline $\begin{array}{l}\text { Defining the } \\
\text { determinants for the } \\
\text { personal interests and } \\
\text { behaviour of managers }\end{array}$ & & $X$ & $\begin{array}{l}\text { Sachse, } 2010 \\
\text { Albaum and } \\
\text { Duerr, } 2008 \\
\text { Georgiou, } \\
2014 \\
\text { Luoma and } \\
\text { Martela, } 2020\end{array}$ & 5.2 .1 .2 .2 \\
\hline
\end{tabular}

Table 35: Summary of Result Discussion_Influencing factors

\subsubsection{Short-Cut Decisions}

During the data analysis, I found out that the participants also talked about short-cut decisions and decisions which are not following a strategical and defined process but rather are done in short-term and very flexible (see chapter 4.2.2). Previous studies (Albaum \& Duerr, 2008; Sachse, 2010; Georgiou, 2014) have not included the possibility of short-cut decisions into their process models but rather have defined the decision-making processes as incremental 
and strategical step-by-step processes. However, the findings of this study show that my developed model contains new aspects which have not been considered yet, e.g. by the multi-level model of Albaum and Duerr (2008). First, the model of Albaum and Duerr (2008) was illustrated as incremental process with clearly defined process steps as seen in see Figure 9 (page 59). The model of this thesis in Figure 57 (page 293) shows that within multinational companies short-cut decisions which do not follow a strict and constant step by step approach but rather an intuitive nature needs to be considered because for some decisions a firm does not have the time to follow an incremental and step-by-step approach. Therefore, the new developed decision-making process model about mode switching contributes knowledge to the current literature by this aspect and contributes knowledge for achieving the research objective 2 of this thesis.

\subsubsection{Decision-Making Process of Multiple Mode Switches}

In this section the findings and results regarding the decision-making process of multiple mode switches are discussed with the existing theories of the literature body. The findings regarding the decision-making process of multiple mode switches are summarized in Figure 57 (page 293). The purpose of this section is to show how objective 3 and 4 of this research is achieved.

\subsubsection{Interdependencies}

The first finding of this research regarding interdependencies was that the experts of this study explained that within multinational companies there are existing interdependencies between simultaneous (happening at the same time and in parallel) decision-making processes of mode switching. This is supported by Rezende (2006),Asmussen et al. (2009) and Belderbos et al. (2020) who argue that multinational companies are structured as loosely coupled network and within this network and between simultaneous decisionmaking processes of mode switching there are interdependencies that influence the outcome of a decision process. However, Rezende (2006) and 
Asmussen et al. (2009) has not defined what kind of interdependencies are existing and how these interdependencies are managed. Therefore, this research contributes new perspectives and knowledge to the management decision-making process of mode switching within multinational companies by defining the interdependencies between simultaneous decision-making processes and how these are handled within a multinational company.

As shown in the final model of this research in Figure 57 (page 293), this research found out that the interdependencies can be defined as additional internal and external influencing factors.

The internal interdependencies were specifically defined as business transfer, availability of resources and best practices. The results of this study show that simultaneous decision-making processes of mode switching influence each other because the processes are competing concerning the available resources within the multinational company (e.g. the available human resources). Therefore, the decision-making process of mode switching in one international activity can have an impact on the available resources for simultaneous decision-making processes. Furthermore, the findings show that there are internal interdependencies between simultaneous decision-making processes because the multinational company transfers knowledge and best practices between the decision-making processes. The UPPSALA model (Johanson \& Wiedersheim-Paul, 1975; Belderbos et al., 2020) assumes that the internationalisation activities occur incrementally and that a firm extend their internationalisation activities and commitment with increasing market knowledge (Johanson \& Wiedersheim-Paul, 1975; Belderbos et al., 2020). Consequently, although the UPPSALA model was the first process model, it already explains that there are interdependencies between decision-making process of mode switching within a firm because a firm increases its knowledge from time to time and can transfer this gained knowledge of one mode switching process to another. Although, the UPPSALA model is one of the most influential process models of the internationalisation literature it does 
not fit to the organizational set-up of a multinational company because the model does not include all perspectives that were found and defined by final model of this research in Figure 57 (page 293), e.g. the global structure of a multinational company as an influencing factor is not included (Rezende, 2006; Asmussen et al., 2009; Hollensen, 2017; Belderbos et al., 2020). Therefore, the final developed model Figure 57 (page 293) contributes new perspectives to the literature body and the UPPSALA model. Another theory that supports that knowledge transfer is an interdependence between simultaneous decision-making processes of mode switching is the path dependency model. Most of the internationalisation models define the learning process as a cumulative, path-dependent ( Hutzschenreuter et al., 2007). Consequently, the foundation for the further development of internationalisation is given by the accumulated knowledge in the past (Hutzschenreuter et al., 2007; Sune, 2018). This view of the path dependency model is supported by the findings of this research because the know-transfer and transfer of best practices from one decision-making process of mode switching to another have been found and categorized as internal interdependency within a multinational company. However, the path dependency is limited to this historical based and knowhow transfer view and does not consider other aspects like the internal influencing factors of a firm e.g. the growth intentions of a multinational company or the changing global strategy of multinational company. As the developed model in Figure 57 (page 293) considers these aspects, it contributes new and further knowledge to the literature body of internationalisation. Last but not least, this research found out that often a mode switching decision results in a business transfer from one subsidiary to another subsidiary within the multinational company. If one of these subsidiaries are in parallel working in a decision-making process of mode switching, these simultaneous decision-making processes can influence each other. 
The external interdependencies were specifically defined as sales structure, partner, cultural interdependencies. One interdependence that can influence the decision-making process is an external sales structure that is acquired together with a mode switch decision in one country, e.g. if the multinational company decides to acquire a competitor to strengthen its position in one respective market, it happens that this competitor also have additional subsidiaries in other markets which are acquired as well. Therefore, this acquisition which is mainly occurred because of one key market impacts the decision-making processes in other international activities. Another external interdependence that can occur is that the existing external partners react on a mode switch decision that the multinational company is doing in another country. E.g. if the multinational company switches in several countries from the external partner to an own sales force this could cause that other external partners stop working with the multinational company because they fear to be exchanged from a local subsidiary of the multinational company in their domestic market as well in future. These findings have not been supported by the theories of the literature body.

I also found out why the independencies need to be included in the decisionmaking process of mode switching within multinational companies because the interdependencies impact the international success of the multinational company and to work more efficiently. I found out that the multinational company has an increasing number of international customers that needs to be served. These international customers are also multinational companies that are connected in a network and therefore the multinational company needs to involve the interdependencies between international activities into the decision-making process of mode switching to ensure that the multinational customers can be served and that the brand reputation is not suffering because the multinational company does not manage and handle the interdependencies between their international activities (e.g. that the multinational company builds a global price list for all their international 
activities that work together with one multinational customer). Last but not least, this research found out that if the multinational company manages and includes the interdependencies between simultaneous decision-making processes, the multinational company benefits from the know-how transfer between the decision-making processes because positive and negative experiences can be shared and transferred. As previous studies have not (or only limited) focused on the interdependencies between simultaneous decision-making processes, this study contributes additional perspectives to the field of decision-making processes of mode switching within multinational companies (Rezende, 2006; Asmussen et al., 2009; Belderbos et al., 2020).

As the investigated multinational company is aware of the impact that interdependencies have on the decision-making process and the negative impact that they can have on the decision outcome and performance of the multinational company if they are not included, the experts explained how the multinational company is managing and handling interdependencies. This research found out that the multinational company uses the following techniques to handle interdependencies, moderating (discussing mode switching decision in global committees), global market segments (establishing global market segments that are focusing on the international customers without country boarders), communication (transparent communication with all key actors within the decision-making process), global company goals (aiming to align the company goals and reducing provision and reporting systems that support personal interests) and democratic decisions (ensuring that all key actors are involved that a common strategy is outlined). As previous studies have not focused on the interdependencies between simultaneous decision-making processes, this study contributes additional perspectives regarding how the interdependencies are handled to the field of decision-making processes of mode switching within multinational companies (Rezende, 2006; Asmussen et al., 2009; Belderbos et al., 2020). 


\subsubsection{The final model}

In this section the research compares the remaining elements of the final developed model Figure 57 (page 293) that have not discussed in the previous chapters. In Figure 58, the last remaining elements which are discussed and compared with the literature are highlighted.

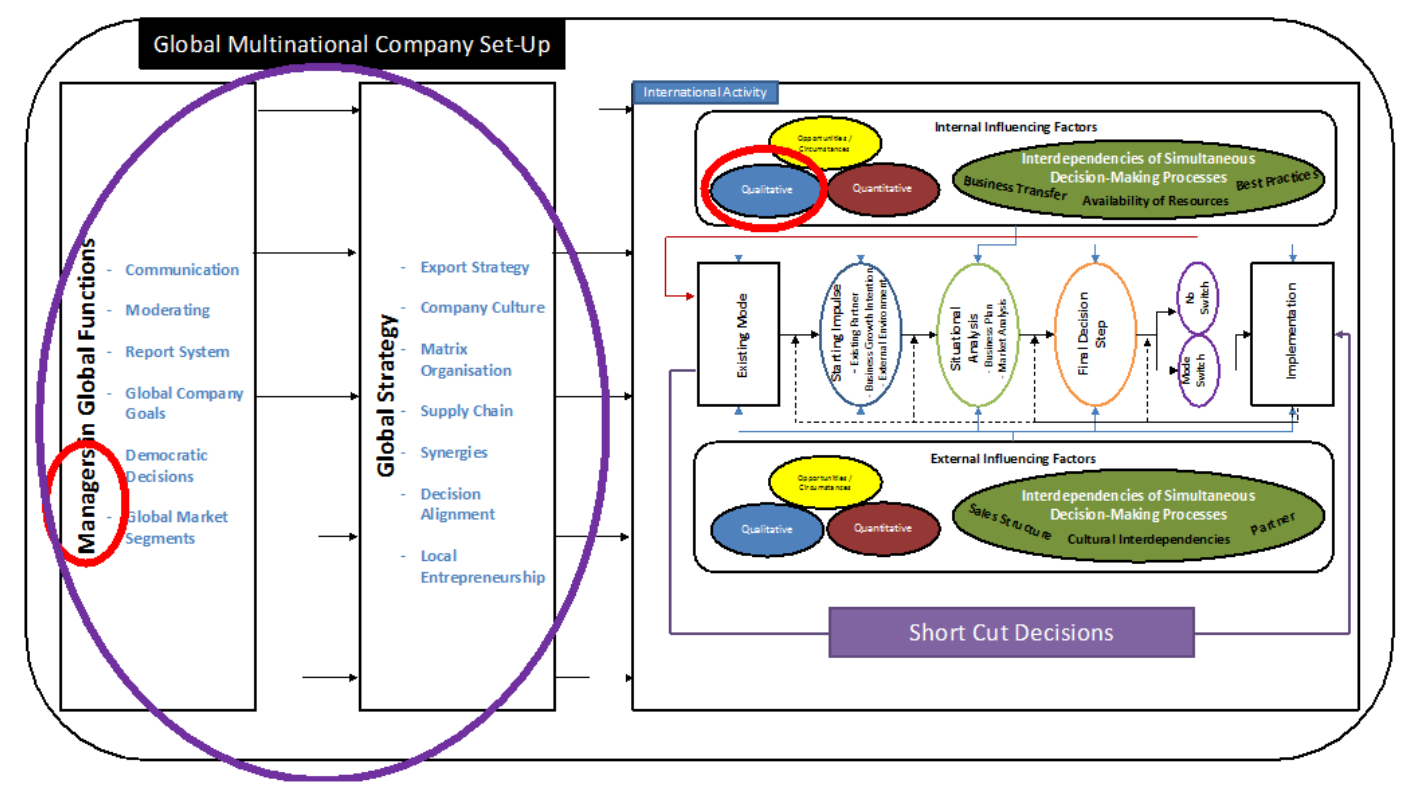

Figure 56:Highlighted remaining elements of the final model (The colours and shapes in the figure are only provided to make them more readable and do not have a specific meaning)

One finding of this research is the impact and influence of the global strategy and set-up of the multinational company on the decision-making process and on handling the interdependencies between simultaneous decision-making processes, highlighted in the purple ellipse in Figure 58. As the decisionmaking process of mode switching is part of the global set-up and global strategy of the multinational company it is evident and a key finding of this research that the process is influenced by the global managers as well as by the global company strategy. This finding of the global viewpoint of a multinational company is partly supported by the competition oriented and strategic appproach (chapter 2.7.1.4) because this approach explains that an 
internationally active firm has build an organizational set-up to balance the local responsiveness which means the neccessarity to adopt to the local hostcountry conditions and the global integration which means to find a globally standard approach which they can follow within its international activities (Hollensen, 2017). Consequently, according to the competition-oriented model the organizational structure of a multinational company can influence the mode switching process because it underpins and is the basis for each international activity (Hollensen, 2017). The findings of this research and the developed model in the purple ellipse in Figure 58 supports that the organizational structure of a multiantional firm is an important influencing factor of the decision-making process of mode switching because the global strategy and the managers with global functions set the global standards and guidelines for the process within the multinational company. Furthermore, the organizational structure of the multinational company can also influence the decision-making process of mode switching as internal environment of the firm. Therefore, the current literature body with the competition oriented and strategic approach supports the findings of this research that the organizational structure of a firm influences the decision-making process of mode switching (Sachse, 2010). However, the strategic approach is limited to these aspects only while the developed model of this research extends the current literature body with further findings, e.g. regarding the decision-making process itself and its other influencing factors, like the external environment of the firm or the key actors. Consequently, the strategic approach contributes interesting and important asepcts to the literature about the decision-making process of mode switching but does not provide a process model for mode switching processes within multinational companies as this research does.

The last element that this research discusses and compares with the literature body are the key actors of the decision-making process of mode switching within multinational companies (highlighted in red ellipses in Figure 58). By developing the final model, this research found out that the managers influence 
the developed process model at two levels. First, on the operational level of the decision-making process in which the key actors of the process are influencing the decision-making process with their personal interests and behaviours as internal qualitative influencing factor. Second, the key actors which are managers with global management functions are influencing the decision-making process of mode switching because they are defining the global set-up and the global strategy of the multinational company which is one of the decisive factors for handling the interdependencies between simultaneous decision-making process of multiple mode switches and influences the decision-making process of a mode switch. These aspects and elements are special for multinational companies and show one gap of the current literature body which does not provide a process model of mode switching which can be sufficiently used for multinational companies (Rezende, 2006; Asmussen et al., 2009; Belderbos et al., 2020). The important role of entrepreneurs and their attitudes as managers is often emphasized in the literature within the international entrepreneurship research. (Jones \& Coviello, 2005; Kümmerle, 2005; Oviatt \& McDougall, 2005; Engelen, Heinmann \& Brettel, 2009; Luoma \& Martela, 2020). According to Young, Dimitratos and Dana (2003), resources, competences and capabiliites of the actors within a company are the most decisive factors in the internationalisation process of a firm. According to the findings of this research, I can support the key elements of the international entrepreneurship research because in the developed model in Figure 57 (page 293) the key actors and their personal behaviour and interest are a decisive influencing factor of the decision-making process of mode switching. However, the developed model and findings also show that there are numerous additional influencing factors especially within a multinational company, e.g. the internal and external interdependencies with other decision-making processes which are running in parallel and therefore the developed model in Figure 57 (page 293) contributes theoretical knowledge to the literature body of internationalisation by providing 
a holistic model of the decision-making process of mode swithing for multinational companies.

Next to the international entrepeneurship model, the model of Albaum and Duerr (2008) also describes the key actors as influencing factors of the decision-making process, however, does not show how the different key actor groups of a multinational company influence the decision-making process because the model does not distinguish in different key actor groups. While the theoretical model of Albaum and Duerr (2008) illustrates that the key actors are influencing the decision-making process of mode switching, the findings of this research explain which role the key actors play within the decision-making process and where and how the key actors influence the process. Consequently, this research contributes knowledge to this aspect of the literature of decision-making.

Comparing the finalized conceptual framework in Figure 27 (page 125) which was developed on the systematic literature review with the final model of simultaneous decision-making processes of multiple mode switches within a multinational company in Figure 57 (page 293) gives a good summary of this section. There are several new aspects which are found and integrated in my new developed model in comparison to the conceptual framework. First of all, the single process steps like data analysis and starting impulses are described more precisely and detailed in the new developed model. The various influencing factors of the process are clearly structured, explained and separated from each other. The impact of the key actors, their personal interests and behaviours on the decision-making process are highlighted in the new model. The interdependencies of simultaneous decision-making processes are considered, structured and integrated into the new model. I found out that in some cases the multinational company is using short-cut decisions and have therefore included this option into the final model of the process. The handling of the interdependencies and the set-up of the multinational company is considered and explained by the managers in global 
functions and finally the impact of the global strategy on the simultaneous decision-making process of multiple mode switches is integrated in the developed model because it was one of my findings (Figure 57, page 293).

\subsubsection{Revisiting Research Objective 3 and 4}

The outlined objective 3 of this research project is to determine the interdependencies and their role between simultaneous mode switching processes. The objective 4 of this research is to build a model of management decision-making during a process of mode switching which considers interdependencies of simultaneous internationalisation processes within a multinational company. The discussion of the research results in chapter 5.2.2 and 5.2.3 regarding the short-cut decisions, the interdependencies and the final model of this research shows that some elements from the research findings (Figure 57 (page 293) are supported from the literature. However, the discussions also show that the developed model in Figure 57 (page 293) of this research contributed new aspects. The final developed model of the decision-making process of mode switching within a multinational company Figure 57 (page 293) and the summary of the result discussions regarding the decision-making process of multiple mode switches in Table 37 shows that objective 3 and 4 of this research are achieved.

\begin{tabular}{|c|c|c|c|c|}
\hline Results & $\begin{array}{c}\text { Aspects } \\
\text { supported } \\
\text { by the } \\
\text { literature }\end{array}$ & $\begin{array}{l}\text { Contribution } \\
\text { of new aspects }\end{array}$ & References & Chapter \\
\hline $\begin{array}{c}\text { Existence of } \\
\text { interdependencies } \\
\text { between simultaneous } \\
\text { decision-making } \\
\text { processes of mode } \\
\text { switching }\end{array}$ & $x$ & & $\begin{array}{l}\text { Rezende, } \\
2006 \\
\text { Asmussen et } \\
\text { al. } 2009 \\
\text { Belderbos et } \\
\text { al., } 2020\end{array}$ & 5.2.3.1 \\
\hline
\end{tabular}




\begin{tabular}{|c|c|c|c|}
\hline $\begin{array}{l}\text { Specific definition of the } \\
\text { external and internal } \\
\text { interdependencies }\end{array}$ & $x$ & $\begin{array}{l}\text { Rezende, } \\
2006 \\
\text { Asmussen et } \\
\text { al. } 2009 \\
\text { Johanson \& } \\
\text { Wiedersheim- } \\
\text { Paul, 1975 }\end{array}$ & 5.2.3.1 \\
\hline $\begin{array}{l}\text { The impact of the } \\
\text { interdependencies on } \\
\text { the performance of a firm } \\
\text { and the decision-making } \\
\text { process }\end{array}$ & $X$ & $\begin{array}{l}\text { Rezende, } \\
2006 \\
\text { Asmussen et } \\
\text { al. } 2009\end{array}$ & 5.2.3.1 \\
\hline $\begin{array}{c}\text { Handling the } \\
\text { Interdependencies }\end{array}$ & $x$ & $\begin{array}{l}\text { Rezende, } \\
2006 \\
\text { Asmussen et } \\
\text { al. } 2009 \\
\text { Belderbos et } \\
\text { al., } 2020\end{array}$ & 5.2.3.1 \\
\hline $\begin{array}{c}\text { Two level approach of } \\
\text { the key actors }\end{array}$ & $X$ & $\begin{array}{c}\text { Albaum and } \\
\text { Duerr (2008) } \\
\text { Young, } \\
\text { Dimitratos and } \\
\text { Dana (2003), } \\
\text { Luoma and } \\
\text { Martela, } 2020\end{array}$ & 5.2.3.2 \\
\hline $\begin{array}{l}\text { Influence of the global } \\
\text { company structure }\end{array}$ & $X$ & $\begin{array}{l}\text { Hollensen, } \\
2017 \\
\text { Belderbos et } \\
\text { al., } 2020\end{array}$ & 5.2.3.2 \\
\hline
\end{tabular}

Table 36: Summary of Result Discussion_Decision-Making process of multiple mode switches

\subsection{Research Propositions}

In this section, I intend to summarize the main contributions to theoretical knowledge by formulating research propositions to underline the novelty of the findings. 
Proposition 1: In the global network of a multinational company, simultaneous and multiple mode switches can occur between existing interdependencies. Those interdependencies can be categorized as external and internal influencing factors of the decision-making process of mode switching and therefore can have an impact on the final decision at each stage of the process model.

Previous studies (Rezende, 2006; Asmussen et al., 2009) have only indicated that there are interdependencies existing between multiple mode switches within multinational companies but have not defined the interdependencies in a specific context, their nature and their impact on the decision-making process of mode switching. The novelty in my findings is that my data set has shown and explained what interdependencies between multiple mode switches are and how the interdependencies are influencing the decisionmaking process of mode switching within multinational companies. This is illustrated in my finalized process model Figure 57 (page 293) in which I have shown the interdependencies as external and internal influencing factors of the decision-making process.

Proposition 2: In order to handle multiple mode switches and the interdependencies between them, multinational companies must establish managers with global functions to build a global strategy for their company. The global strategy supports handling the interdependencies between multiple mode switches because the global function managers do not consider each mode switching process as a stand-alone decision but consider instead how the multiple mode switching processes are connected and influenced by each other within the global network of the multinational company.

This proposition is supported by my finalized process model Figure 57 (page 293) in which I have illustrated the elements of the global strategy of a multinational company being developed by the managers with global functions. The novelty of my findings lies in the fact that previous studies have not 
considered the global structure and strategy of multinational companies, but have instead focused on the decision-making process of mode switching as a separate and stand-alone process within a company. In contrast to that the model I developed includes the global structure and strategy of multinational companies.

Proposition 3: There are two types of managers who can influence as key actor the decision-making process of mode switching at different management levels. Firstly, there are the operative managers who are directly working within the decision-making process and who accompany each single process step. Secondly, there are the managers with global functions who influence the decision-making process of mode switching by developing the global strategy of a multinational company and by handling the interdependencies within the global network of the multinational company.

This proposition is underpinned by my findings because the final developed model contains the key actors at two levels in Figure 57 (page 293). First the key actors of the decision-making process it-self who are influencing the process according to their personal interests and secondly the managers in global functions who are influencing the global strategy and global set-up of the multinational company, which influences the process. The novelty of my findings lies in the fact that the key actors of the decision-making process within multinational companies can be categorized in two management levels.

Proposition 4: The decision-making process of mode switching within multinational companies also includes the option of bypassing the step-by-step decision-making process and taking a short-cut decision if the project timeline is limited or if the decision can be made intuitively.

The analysis, interpretation and discussion of my collected data demonstrate this proposition, since the option of bypassing the step-by-step decisionmaking process of mode switching is reflected by my data set and explained in section 4.2.2. This bypassing option was not mentioned in previous studies 
which focused on the strategical step-by-step decision-making process of mode switching within companies.

\subsection{Closing the gaps of the literature}

An overview of how the outcome and findings of this research project have closed the gaps in the current literature body is outlined in column closing of the gap in Table 38. The first gap of the literature which was closed by this thesis is the identification and systematic analysis of the existing gaps in the current literature about this research area. This was closed by Table 38 . The second gap which I closed, is that the research was conducted in a single case study of a multinational company with the result of developing a model of management decision-making of mode switching in the context of a multinational company which was missing in the current literature body. The next gap of the current literature body that was closed by this research by answering question 2 and achieving objective 3 , is that the influence of interdependencies between simultaneous decision-making process of mode switches have not been considered in the literature yet. Last but not least the outcome of this research closed the gap by achieving objective 2 and 4 , that in the current literature there is only a limited understanding about the influence of manager's behaviour and external environment on the decision-making process of mode switching in a multinational company. And finally, the literature review process has not shown a model of management decisionmaking during a process of mode switching which considers interdependencies of simultaneous internationalisation processes within a multinational company in the current literature body. This gap I closed through 
developing the new process model for multinational companies in Figure 57 (page 293).

\begin{tabular}{|c|c|c|c|c|}
\hline Literature Gap & $\begin{array}{l}\text { Achieved } \\
\text { Through }\end{array}$ & Objectives & $\begin{array}{c}\text { Summary of the } \\
\text { Gap }\end{array}$ & $\begin{array}{l}\text { Closing of } \\
\text { the Gap }\end{array}$ \\
\hline $\begin{array}{l}\text { Identify research } \\
\text { gaps to position } \\
\text { the research } \\
\text { problem }\end{array}$ & Chapter 2 & 1 & Table 18 & $\begin{array}{l}\text { Table 40, } \\
\text { column } \\
\text { "closing of } \\
\text { the Gap" }\end{array}$ \\
\hline $\begin{array}{l}\text { A Decision-Making } \\
\text { process of mode } \\
\text { switching for } \\
\text { multinational } \\
\text { companies }\end{array}$ & Case Selection & 2 & $\begin{array}{l}\text { Most of the papers } \\
\text { pay little attention } \\
\text { to multinational } \\
\text { companies but } \\
\text { rather on medium- } \\
\text { sized, small } \\
\text { companies, born- } \\
\text { global companies } \\
\text { or the company } \\
\text { characteristic is } \\
\text { not defined }\end{array}$ & $\begin{array}{l}\text { This gap is } \\
\text { closed by this } \\
\text { research as I } \\
\text { conducted a } \\
\text { single case } \\
\text { study and } \\
\text { selected a } \\
\text { multinational } \\
\text { company as } \\
\text { single case } \\
\text { and achieved } \\
\text { objective } 2 \text { of } \\
\text { this research } \\
\text { project. }\end{array}$ \\
\hline $\begin{array}{l}\text { The influence of } \\
\text { interdependencies } \\
\text { between } \\
\text { simultaneous } \\
\text { international } \\
\text { activities on the } \\
\text { decision-making } \\
\text { process of mode } \\
\text { switching }\end{array}$ & $\begin{array}{l}\text { Case Selection } \\
\text { and Data } \\
\text { Collection } \\
\text { Methods }\end{array}$ & 3 & $\begin{array}{l}\text { The previous } \\
\text { Studies are mainly } \\
\text { focused on sveral } \\
\text { companies and } \\
\text { only on one } \\
\text { international } \\
\text { activity per } \\
\text { country. } \\
\text { Consequently, } \\
\text { these studies do } \\
\text { not consider that } \\
\text { there are }\end{array}$ & $\begin{array}{l}\text { This gap is } \\
\text { closed by } \\
\text { answering } \\
\text { research } \\
\text { question } 2 \\
\text { and } \\
\text { achieving } \\
\text { objective } 3 \text { of } \\
\text { this research } \\
\text { project. }\end{array}$ \\
\hline
\end{tabular}




\begin{tabular}{|c|c|c|c|c|}
\hline & & & $\begin{array}{c}\text { simultaneous } \\
\text { internationalisation } \\
\text { processes within a } \\
\text { multinational } \\
\text { company }\end{array}$ & \\
\hline $\begin{array}{c}\text { The influence of } \\
\text { manager's } \\
\text { behaviour and } \\
\text { external } \\
\text { environment on the } \\
\text { decision-making } \\
\text { process of mode } \\
\text { switching in a } \\
\text { multinational } \\
\text { company }\end{array}$ & $\begin{array}{l}\text { Philosophical } \\
\text { Position and } \\
\text { Data } \\
\text { Collection } \\
\text { Methods }\end{array}$ & 2,4 & $\begin{array}{l}\text { Most of the } \\
\text { studies are based } \\
\text { on quantitative } \\
\text { philiosophical } \\
\text { positions or } \\
\text { literature reviews } \\
\text { which restrict the } \\
\text { findings and } \\
\text { interpretations to } \\
\text { statistical } \\
\text { validation, } \\
\text { analytical } \\
\text { rationality, } \\
\text { context- } \\
\text { independent } \\
\text { knowledge and } \\
\text { rules }\end{array}$ & $\begin{array}{l}\text { This gap is } \\
\text { closed by } \\
\text { answering } \\
\text { research } \\
\text { question } 1 \\
\text { and } \\
\text { achieving } \\
\text { objective } 2 \\
\text { and } 4 \text { of this } \\
\text { research } \\
\text { project. }\end{array}$ \\
\hline $\begin{array}{l}\text { Building a model of } \\
\text { management } \\
\text { decision-making } \\
\text { during a process of } \\
\text { mode switching } \\
\text { which considers } \\
\text { interdependencies } \\
\text { of simultaneous } \\
\text { internationalisation } \\
\text { processes within a } \\
\text { multinational } \\
\text { company }\end{array}$ & $\begin{array}{c}\text { Research } \\
\text { Strategy, } \\
\text { Methodological } \\
\text { Approach and } \\
\text { Methods }\end{array}$ & 4 & $\begin{array}{l}\text { Although, the } \\
\text { literature about } \\
\text { decision-making } \\
\text { processes has } \\
\text { payed more } \\
\text { attention to } \\
\text { intuitive decisions } \\
\text { and integrated } \\
\text { models, most of } \\
\text { the decision- } \\
\text { making studies } \\
\text { related to mode } \\
\text { switching or }\end{array}$ & $\begin{array}{l}\text { This gap is } \\
\text { closed by } \\
\text { developing } \\
\text { the new } \\
\text { process } \\
\text { model, by } \\
\text { anwering } \\
\text { research } \\
\text { question } 1 \\
\text { and } \\
\text { achieving } \\
\text { objective } 4 \text { of }\end{array}$ \\
\hline
\end{tabular}




\begin{tabular}{|c|c|}
\hline internationalisation & this research \\
are domiated by & project. \\
rational decision- & \\
making processes, & \\
rules and & \\
parameters &
\end{tabular}

Table 37: Closing the Literature Gaps

\subsection{Chapter Summary}

Chapter 5 has discussed the core findings of this research project by comparing the findings and results of chapter 4 with the concepts, theories and approaches outlined in the systematic literature review of chapter 2 . Discussing the core findings with the current literature body showed the contribution to knowledge of this research and how the research objectives were achieved.

Objective 2 of this research to explore the process of management decisionmaking of mode switching within a multinational company's internationalisation strategy, was achieved through the final developed model in figure 57 (page 293). With the new developed process model, this study has explored the process of management decision-making of mode switching within multinational companies because the process structure and the single process steps are clearly defined. In comparison to the current literature the developed process model contains the following new aspects:

- Joint Venture partners as possible external partner that act as a starting impulse

- There are additional possible starting impulses next to the growth intention of a firm

- Transaction costs are not the only determinant for evaluating the decision alternatives

- New entry mode option

- Opportunities and circumstances as additional external and internal influencing factors

- Specifically defined internal quantitative influencing factors

- Defining the determinants for the personal interests and behaviour of managers 
In the final developed model in figure 57 (page 293), the study defined the role of interdependencies between simultaneous decision-making process of mode switching because the interdependencies are defined as additional external and internal influencing factors. Therefore objective 3 , to determine the interdependencies and their role between simultaneous decision-making processes of mode switching, is achieved.

Objective 4 of this study, to build a process model of management decisionmaking for mode switching which considers interdependencies of simultaneous internationalisation processes within a multinational company is achieved with the final developed model in figure 57 (page 293).

In comparison to the current literature the developed process model contains the following additional new aspects regarding the achievement of objective 3 and 4:

- Specific definition of the external and internal interdependencies

- The impact of the interdependencies on the performance of a firm and the decisionmaking process

- Handling the Interdependencies

- Two level approach of the key actors

- Influence of the global company structure

Las but not least, the discussion chapter and the comparison of the results with the existing theories and concepts of the literature shows that all objectives of this study are achieved and that the identified gaps of the literature are closed. 


\section{Conclusions}

\subsection{Introductory Comments}

This chapter closes the thesis and the research project by presenting the final conclusions, revisiting the research questions, aim and objectives and explains how these have been achieved. The core findings of the research are presented as a summary in the chapter of contribution to knowledge in which I demonstrate the contribution to theory and practice of my research project. I finally closes the thesis by showing the research limitations and with presenting the recommendations for further research project in this research area.

\subsection{Revisiting the Research Questions and Aim}

I outlined in the first chapter three research questions to explore the research topic and to achieve the overall research aim:

The aim of this research is to understand the multinational firm's management decision-making process of mode switching, the influencing factors of the decision-making process and the reason how these mode switching activities occur. The study will develop a new process model to illustrate and explain this business activity and expand the international management literature base.

In the following section, I point out how and where the research questions have been answered in this thesis.

\section{Question 1}

What is the process of management decision-making for mode switching in a multinational company's international activity?

By using the single case study methodology and exploring a specific case of a multinational company in the lubricant industry in depth, the research question 
1 has been answered with the developed model which is illustrated in Figure 59. The data for the development of this process model have been collected through semi-structured interviews and documentation reviews and have been analysed by using thematic analysis.

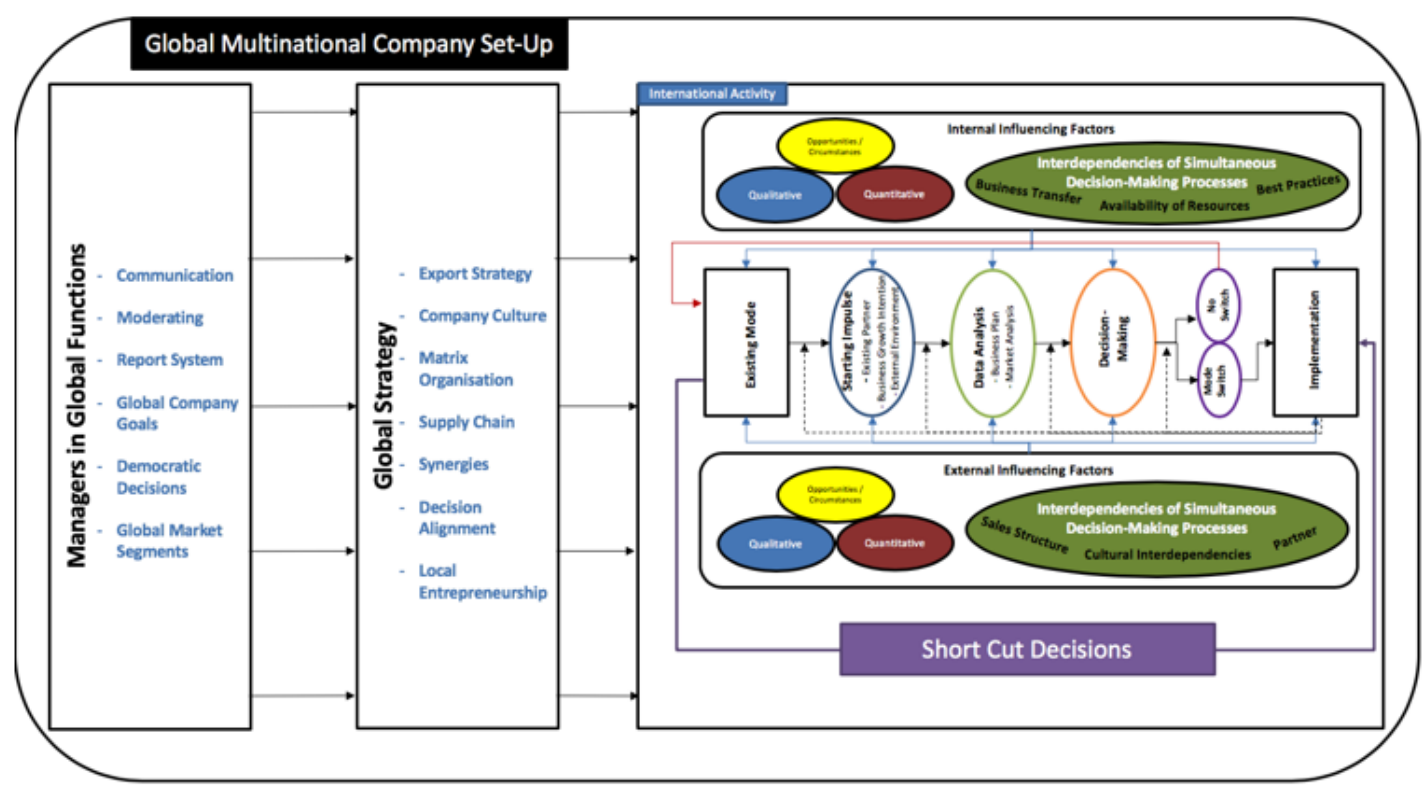

Figure 57: Final Model of Simultaneous Decision-Making Processes of Multiple Mode Switches within a Multinational Company (The colours and shapes in the figure are only provided to make them more readable and do not have a specific meaning)

The process model of decision-making has an inner loop which reflects the rational part of the decision-making process in which a very structured process with clearly defined process steps have been found. This inner loop is not an incremental process but rather a rolling process in which the single process steps are conducted in parallel and if necessary, in an iterative loop which is illustrated with the dotted arrows in the process model. The rational inner loop of the process is influenced by external and internal influencing factors which include qualitative, quantitative aspects as well as the interdependencies of simultaneous (happening at the same time) decision-making processes. Including the external and internal environment of the decision-making process shows that the developed process model is an integrated multi-level decision- 
making model as illustrated by Albaum and Duerr (2008) in the literature review chapter Figure 9 (page 59) of this thesis. As additional process option I found out that the multinational company could bypass the detailed decision processes and can be made short-cut if the decision follows a logical conclusion and if there are no doubts about the success of a decision or if the multinational company has no time to run through the detailed analysis process and needs to do a short-cut decision to take an opportunity. Therefore, I added the possibility of short-cut decisions and bypassing the detailed decision-making process in the final model which is illustrated with the purple arrow the new intuitive aspect and nature of the process.

One key influencing factor that I identified is the key actors who are influencing the developed process model at two levels. First, on the operational level of the decision-making process in which the key actors of the process are influencing the decision-making process with their personal interests and behaviours as internal qualitative influencing factor. Second, the key actors which are managers with global management functions are influencing the decision-making process of mode switching because they are defining the global set-up and the global strategy of the multinational company which is one of the decisive factors for handling the interdependencies between simultaneous decision-making processes of multiple mode switches.

\section{Question 2}

What are the interdependencies at play when decision-making processes for mode switching occur simultaneously?

As a result, and according to my findings the interdependencies between simultaneous decision-making process of multiple mode switches are influencing factors of each decision-making process of a single mode switch and can be grouped as internal and external influencing factor. Therefore, I added the identified interdependencies to the developed model which is shown in Figure 59. The internal interdependencies that I found, can be grouped into 
the sub themes business transfer, availability of resources and transfer of practices. The external interdependencies were grouped in the category's sales structure, cultural interdependencies and external partners. The detailed description of the interdependencies is given in chapter 4.2.3.1.

\section{Question 3}

How are the interdependencies of simultaneous internationalisation processes managed within the decision-making process of mode switching?

I finds out that many interdependencies are existing between simultaneous decision-making processes and that the interdependencies play an important role regarding global success and performance within the multinational company. Furthermore, this study identified how the multinational company is handling these interdependencies. The handling options can be categorized in moderating, establishing global market segments, global alignment, democratic decisions, report systems and local entrepreneurship vs. global alignment.

I found out that the multinational company intends to moderate the existing interdependencies by discussing decisions like mode switches in a global management committee. With this committee, the multinational company intends to handle important decisions with a global and holistic perspective and consequently to handle for example the interdependencies between simultaneous decision-making processes of mode switches.

Another way to handle the interdependencies is the establishment of global market segments which shall ensure that the interdependencies between markets and countries are eliminated and that international customers can be supported best possible from a global perspective and according to their specific needs.

Another finding is that the communication within the multinational company can be a decisive determinant for handling interdependencies successful. As 
identified in the previous research questions, one key internal interdependency is the business transfers that occur in a country due to the mode switch in another country. These business transfer can cause internal competition between several sales divisions because the long-term market responsibility is not clearly defined, and mode switches and its interdependencies can force such internal challenges and competition. I found out that a clear and transparent communication strategy during the mode switching processes can help to handle the interdependencies much easier.

An additional finding is that the salary and provision system can be used to handle interdependencies which is categorized in the code of global company goals because typically provisions or bonus are connected with the achievement of specific goals. Consequently, global company goals can help the managers to handle the interdependencies between simultaneous decision-making processes because the global company goals can balance the positive and negative interdependencies that simultaneous processes can have and this balance ensures that the final decisions of the simultaneous processes help to achieve the overall global company goals and the isolated goals which support the single decision processes are subordinated. In this context, I found out that the global company goals can only support handling the interdependencies if the salary and bonus system is in line with the promoted global company goals to motivate managers to think globally or across their country and responsibility boarders. One of my key findings in this aspect is that the multinational company currently do not link the global company goals with the individual bonus and salary system of the key actors which is evaluated as negative impact on handling the interdependencies from the participants and consequently identified as possible improvement in future.

As the global report system is used as evaluating technique if the individual key actor and manager has contributed his part to achieve the global company goals, it is evident that the global report system enables the management to monitor the achievement of the global company goals and consequently can 
contribute to handle the interdependencies appropriate. In this regard I identified a gap in the global reporting system of the multinational company because the regional vice presidents do not have to consider all interdependencies between the countries in their regions as they are not responsible for the export market in their regions but rather for all countries where a local subsidiary is established. Consequently, the regional vice president does not have to consider or handle the interdependencies which one decision in a market could have with the export markets in his region. This can be considered as a gap regarding handling the interdependencies between decision-making processes. Consequently, closing this reporting gap could not only improve the handling of interdependencies within the multinational company but rather reduces the internal competition which is explained and discussed as one of the biggest internal interdependencies which are existing.

The final aspect which helps handling interdependencies according to the findings of my thesis is democratic decisions. Due to the international growth of the multinational company and the globalisation of the world economy the amount of interdependencies within the multinational company will increase and these interdependencies can have positive as well as negative effects for some key actors. Therefore, democratic decisions and the procedure of a democratic decision is very important for the multinational company because there is almost no decision which does not have any negative effect on a key actor of the process. Consequently, democratic decisions require that the key actors are discussing a decision from different directions and ensure that the interdependencies between decision-making processes are considered best possible. 


\section{Research Aim}

By answering the research questions I outline that the overall research aim was achieved in this $\mathrm{PhD}$ thesis because I extended the understanding about the multinational firm's management decision-making process of mode switching, the influencing factors of the decision-making process and the reason how these mode switching activities occur. Additionally, the study developed a new process model in Figure 57 to illustrate and explain this business activity and expand the international management literature base. Hence, the overall research aim has been achieved and is outlined in this $\mathrm{PhD}$ thesis.

\subsection{Revisiting the Research Objectives}

The research questions and the developed process model have been achieved through the following objectives:

Objective 1: To conduct a review of literature to position the research within the current internationalisation and management literature and identify key gaps where a meaningful contribution could be made.

Objective 2: To explore the process of management decision-making of mode switching within a multinational company's internationalisation strategy.

Objective 3: To determine the interdependencies and their role between simultaneous decision-making processes of mode switching.

Objective 4: To build a process model of management decision-making for mode switching which considers interdependencies of simultaneous internationalisation processes within a multinational company.

\subsubsection{Literature Review (Objective 1)}

To achieve objective 1, I have conducted a systematic literature review. Based on this analysis I identified the current gaps of the literature body (Table 18, page 119) and the conceptual framework in Figure 27 (page 125) has been 
developed which outlines the core elements of the school of internationalisation, the market entry decisions, the mode switching and the decision-making literature body. The overview of the literature gaps and consequently the results of objective 1 are summarized in Table 18 (page 119).

\subsubsection{Preliminary Research (Objective 2 and 3)}

To achieve objective 2 and 3 of this thesis, I have conducted semi-structured interviews and documentation reviews. The findings were identified using an inductive thematic analysis approach as analysis technique and for the presentation of my findings I used a concept map and a list of codes (see Appendix $8 \& 14)$. The achievement of objective 2 and 3 is shown in the answers of research question 1 and 2 and is illustrated in the final process model in Figure 57 (page 293).

\subsubsection{Model Building (Objective 4)}

Based on my findings to achieve the research objectives 2 and 3 which are outline in chapter 4 of this thesis, I discussed the findings and developed a new model of simultaneous decision-making processes of multiple mode switches within a multinational company in chapter 5 which is illustrated in Figure 57 (page 293). This new process model includes the interdependencies between simultaneous (occurring at the same time) decision-making processes and consequently objective 4 is achieved by providing a model for the decision-making process of mode switching within multinational companies and explained in this $\mathrm{PhD}$ thesis. The core findings of the research project are summarized in chapter 5.3 by outlining the research propositions.

\subsection{Contribution to Knowledge}

The outcome and findings of this research project propose theoretical and practical contributions to knowledge which are outlined within this section. 


\subsubsection{Theoretical}

The core contribution of the findings and outcome of this research project is the extended understanding about the multinational firm's management decision-making process of mode switching, the influencing factors of the decision-making process and the reason how these mode switching activities occur which is outlined in my new developed process model to explain this business activity and expand the international management literature base.

The detailed contribution to knowledge of the new process model can be shown by a comparison of the new developed model in Figure 57 (page 293) and the conceptual framework in Figure 27 (page 125). In Figure 60 I highlighted with red ellipses the core contributions to knowledge of the new developed model which are gaps in the conceptual framework.

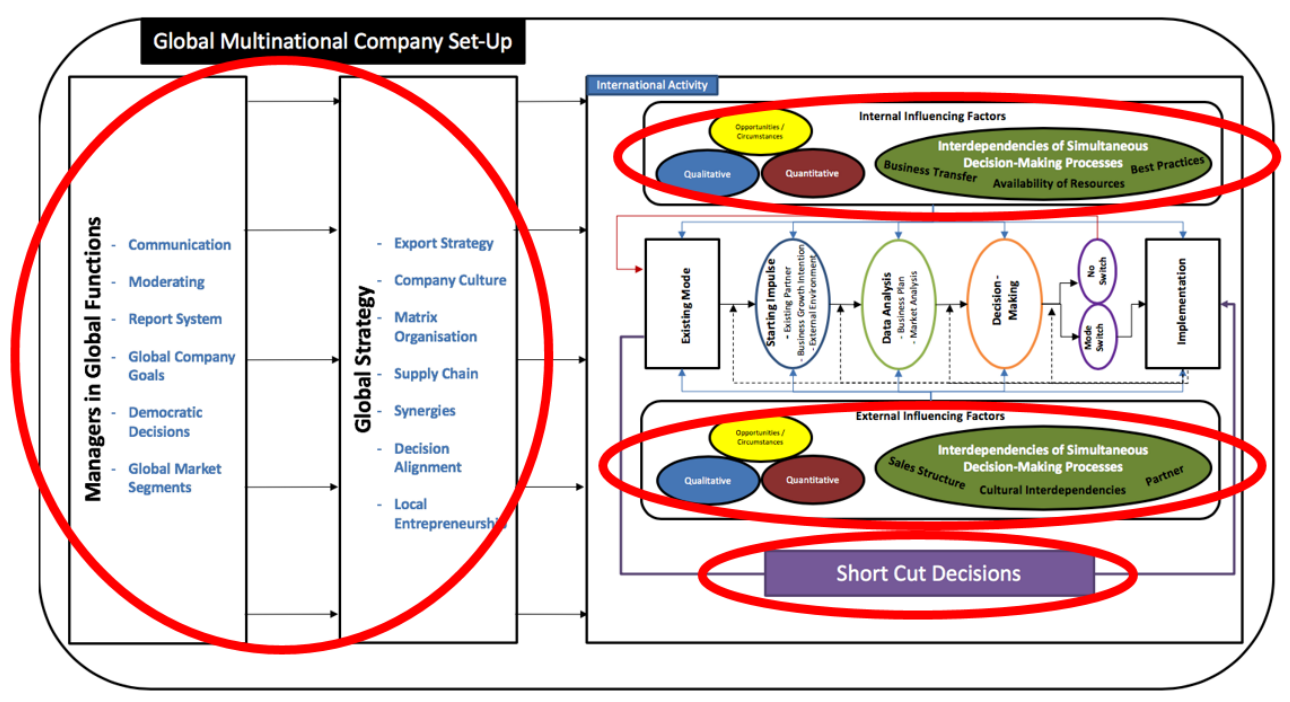

Figure 58: Highlighted Contribution to Knowledge in the New Process Model (The colours and shapes in the figure are only provided to make them more readable and do not have a specific meaning)

First of all, the various influencing factors of the process are clearly structured, explained and separated from each other. While in the conceptual framework the influencing factors are only separated in external and internal environment and additionally the influencing factors are not defined or named, the new 
process model describes and names the influencing factors more clearly and additionally shows the influence of the interdependencies of simultaneous decision-making processes. Consequently, the new process has not only extended the influencing factors by additional main influencing groups like the interdependencies but rather also extended the knowledge and the understanding about the previous known influencing factors of the external and internal environment by showing examples in the data set.

Another key contribution to knowledge of the new process model is the impact of the key actors who are influencing the developed process model at two levels. First, on the operational level of the decision-making process in which the key actors of the process are influencing the decision-making process with their personal interests and behaviours as internal qualitative influencing factor. Second, the key actors which are managers with global management functions are influencing the decision-making process of mode switching because they are defining the global set-up and the global strategy of the multinational company which is one of the decisive factors for handling the interdependencies between simultaneous decision-making process of multiple mode switches. While the conceptual framework only illustrates that the key actors are influencing the decision-making process of mode switching, the findings of this research explain which role the key actors play within the decision-making process and where and how the key actors influence the process.

While the conceptual framework only shows that there are interdependencies between simultaneous decision-making processes of mode switching, the new process model considers, structures and integrates the interdependencies into the new model as part of the internal and external influencing factors which also explains the role of the interdependencies within the process. Consequently, as contribution of knowledge, the new process model shows the existence, the structure and role of the interdependencies in the decisionmaking process of mode switching. 
Last but not least, I found out that in some cases the multinational company is using short-cut decisions (the purple highlighted arrow in figure 60) and has therefore included this option into the new process model. This aspect has not been considered in the current literature body and the conceptual framework and consequently is a contribution to theoretical knowledge.

Finally, one of my core findings was the impact and influence of the global strategy and set-up of the multi-national company on the decision-making process and on handling the interdependencies between simultaneous decision-making processes. This impact and influence is included in the new process model by the managers with global management functions and the global strategy which is defined by the management and is discussed in detail in chapter 5.2.3.2 As the decision-making process of mode switching is part of the global set-up and global strategy of the multinational company, it is evident that the process is influenced by the global managers as well as by the global company strategy. This finding of the global viewpoint of a multinational company was not considered in the conceptual framework and is consequently a contribution to theoretical knowledge.

As final summary of the contribution to knowledge I close the gaps of the literature outlined in chapter 2.8 of this thesis (critical evaluation of the existing literature body) in chapter 5.4 with Table 38 (page 333).

\subsubsection{Practical}

The practical contribution of this research project is an approach and model for multinational companies which can be used to establish their decisionmaking process of mode switching within their global company set-up or to support companies which are on their journey to become a multinational company. As the developed model in Figure 57 (page 293) considers the interdependencies between simultaneous international activities and can be used for multinational companies, following the guidelines of the developed model can help managers to avoid increasing complexity, costs, not using 
synergistic effects to increase the efficiency and finally that a mode switch needs to be reversed due to a lack of success which causes wasting resources. Next to this the model helps managers to find the most appropriate mode option for a respective foreign market during the mode switching process, because the model gives managers the understanding of which influencing factors need to be considered in their final decision and ensures that no important decision determinants are forgotten. Using the most appropriate mode option in a foreign market helps to maximize the profit of a multinational company in this respective market.

Additionally, my findings show examples of possible improvements for the investigated multinational company regarding the handling of the interdependencies between simultaneous (happening at the same time) decision-making process of mode switching and regarding the global strategy of a multinational company. These examples can contribute knowledge to multinational companies which are struggling with similar challenges. For instance, the global reporting system that the regional vice president do not report the achievements of the export markets in his region, the missing global export strategy or the global company goals in combination with an aligned bonus system have been identified as gaps in the global strategy of the investigated multinational company and can contribute practical knowledge to multinational companies.

\subsection{Research Limitations}

All research studies have certain limitations due to the selected methodology and due to the inherited nature of a topic (Merriam, 2009). Qualitative studies and especially case studies are mainly criticised regarding the generalizability (Merriam, 2009). However, the proponents of the case study methodology argue that the outcome of case studies can be generalized to theoretical propostions and the aim of case studies is not to generalize to a population or to the universe (Yin, 2015). This means that a case study does not represent 
a respective sample of the population but rather a specific case from which the information and results are obtained (Merriam, 2009). This argument is supported by Stake (1995) and Yin (2015) who state that the major goal of a case study is particularization and not generalization. As previously discussed, in chapter 3.7.3 where the case study boundaries are defined, this research study is limited to one of the biggest lubricant manufacturer and its global mode switching process. Therefore, the developed process model can only explain and contribute knowledge at this level. The model could be applied and evaluated in other settings and provide key considerations essential to achieving this.

This thesis was designed in a cross sectional single case study approach with the aim to answer specific research questions and to achieve the objectives of the study. According to this design the decision-making process of mode switchding have been analysed and investigated within one multinational company and useful insights have been gained. Due to the limitations of a cross sectional design, the connections between the final decision and any implementation challenges or the decision impact on performance related topics are beyond the scope of this project. It is evident that these connections and influencing effects are interesting as well and a longitudinal study would be able to contribute knowlegde in this regards and help to improve the overall understanding of the decision-making process of mode switching.

\subsection{Recommendation for Further Research}

A natural extension of further research on the decision-making process of mode switching may be carried out in other multinational companies in the lubricant industry.

Additionally, the findings and outcomes of this research could be empirically tested with inclusion of multiple variables in a number of companies of the lubricant industries or in a number of other industries. 
In this research project, I conducted a single case study by investigating one multinational company. The objective of this thesis was consequently not to use the findings which can be generalized universally, but also single case studies are beneficial for generalisations to theoretical propositions and for specific systems according to Yin (2015). Therefore, the collection of additional and further evidence is required before the findings and outcome can be a universal generalization which can be provided either within the same industry as this study or across several industries.

The research area of mode switching is very complex and a various number of different variables and influencing factors have an impact on the decisionmaking process. It is evident that there are further aspects and variables which have not been the main focus of this research project as for instance the connection between the decision-making process of mode switching and the performance of the multinational company in general and between the decision-making process and the performance of the multinational company in a respective country in which the mode switch shall occur.

This is a short summary of further research project that could be conducted further to this thesis.

\subsection{Concluding Comment}

The presented chapters of this thesis outlined that the $\mathrm{PhD}$ research project contributes theoretical and practical contribution to knowledge. The developed new process model in Figure 57 (page 293) illustrates and explains the business activity of mode switching of a multinational company and expand the international management literature base. Due to the globalisation and the increasing trend of companies to internationalize and of small companies to get multinationals, this research area will get increasingly attention and focus for future research. An important contribution to theoretical knowledge has been presented by closing outlined literature gaps which have been identified with a detailed literature review process. The practical contribution of this 
research project is an approach and model for multinational companies which can be used to establish their decision-making process of mode switching within their global company set-up or to support companies which are on their journey to become a multinational company.

Table 39 presents a summary of objective achievements.

\begin{tabular}{|c|c|}
\hline Objectives & Achievement \\
\hline 1 & Fully \\
\hline 2 & Fully \\
\hline 3 & Fully \\
\hline 4 & Fully \\
\hline
\end{tabular}

Table 38: Summary of Objective Achievement 


\section{List of References}

Agarwal, S. (1994). Socio-cultural distance and the choice of joint ventures: A contingency prospective. Journal of International Marketing, 2 (2), 63-80.

Ahlstrom, D., \& Bruton, G. (2010). International Management, Strategy and Culture in the Emerging World. South-Western: Cengage Learning.

Albaum, G., \& Duerr, E. (2008). International Marketing and Export Management. Harlow: FT Prentice Hall.

Alholjailan, M. I. (2012). Thematic Analysis: A critical review of its process and evaluation. West eastern journal of social science, 1 (1), 39-47.

AlQahtani, F. N. K. (2016). Identifying the critical factors that impact on the Development of Electronic Government using TOE Framework in Saudi E-Government Context: A Thematic Analysis. Unpublished PhD thesis, De Montfort University, Leicester.

Anastasia. (2018). Clever ISM. Retrieved from https://www.cleverism.com/qualitative-andquantitative-data-collection-methods/

Anderson, O. (1997). Internationalisation and Market Entry Mode: A Review of theories and. Management International Review, 37, 27-42.

Araujo, L., \& Rezende, S. (2003). Path dependence, MNCs and the internationalisation process: a relational approach. International Business Review, 12 (6), 719-737.

Arksey, H., \& O'Malley, L. (2005). Scoping Studies: towards a methodological framework. International Journal of Social Research Methodology, 1 (8), 19-32.

Arntd, J. (1986). Paradigms in consumer research: a review of perspectives and approaches. European Journal of Marketing, 20 (8), 23-40.

Ashan, M. \& Wyk, J. (2018). Going Past Entry Mode: Examining Foregin Operation Mode Changes at the Strategic Business Unit Level. Journalof Managerial Issues.

Asmussen, C. G., Benito, G. R., \& Petersen, B. (2009). Organizing foreign market activities: from entry mode choice to configuration decisions. International Business Review, 18 (2), 145-155

Aveyard, H. (2014). Doing a Literature Review in Health and Social Care (3rd ed.). Berkshire: McGraw-Hill Education. 
Axinm, C. N., \& Matthyssens, P. (2002). Limits of Internationalization Theories in an unlimited world. International Marketing Review, 19 (5), 436-449.

Baker, W. E. \& Grinstein, A. (2019). The Impact of Entrepreneurial Orientation on Foreign Market Entry. the Roles of Marketing Program Adaption, Cultural Distance, and Unanticipated Events. Journal of International Entrepreneurship, 18, 63-91.

Bank, T. W. (2019). Worldbank. Retrieved from https://data.worldbank.org/indicator/NE.EXP.GNFS.ZS

Baretto, A., \& Da Rocha, A. (2001). Patterns of internationalization of Brazilian firms and the decision to establish subsidiaries abroad. In C. N. Axinn, \& P. Matthyssens (Eds.), Reassesing the Internationalization of the Firm (pp. 79-131). Bingley: Emerald Group Publishing Limited.

Barlett, C. A., Birkinshaw, J., \& Ghoshal, S. (2004). Transnational Management. New York: McGraw Hill.

Barreto, I. (2010). Dynamic Capabilities: A Review of Past Research and an Agenda for the Future. Journal of Management, 36 (1), 256-280.

Barriball, K. L., \& While, A. (1994). Collecting data using a semi-structured interview: a discussion paper. Journal of Advanced Nursing, 19, 328 - 335.

Bartlett, C. A., \& Ghoshal, S. (1989). Managing across boarders: the transnational solution. Boston: Havard Business School Press .

Bartlett, C., \& Ghoshol, S. (2000). Going Global: Lessons from Late Movers. Harvard Business Review, March / Arpil, 132-142.

Beaton, D., Guillemin, F., \& Ferranz, M. (2002). Recommendations for the cross-cultural adaption of health status measures. Rosemont, IL: American Academy of Orthopedic Surgeons.

Becker, M. (2005). Controlling von Internationalisierungsprozessen. Wiesbaden: Gabler.

Belderbos, R., Tong, T. W., \& Wu, S. (2020). Portfolio configuration and foreign entry decisions: A juxtaposition of real options and risk diversification theories. Strategic Management Journal, 41, 1191-1209.

Benito, G. R., \& Welch, L. S. (1993). Foreign Market Servicing: Beyond Choice of Entry Mode. Journal of International Marketing, 2 (2), 7-27. 
Benito, G. R., Pedersen, T., \& Petersen, B. (2005). Export Channel Dynamics: An empirical Investigation. Managerial and Decision Economics, 26 (3), 159-173.

Benito, G. R., Petersen, B., \& Welch, L. S. (2011). Mode Combinations and International Operations . Management International Review, 37 (2), 27-42.

Bernard, C. I. (1938). The Functions of the Executive. Cambridge: Harvard Business Press.

Bettany-Salitkov, J. (2012). How to do a Systematice Literature Review in Nursing. Brekshire: McGraw Hill.

Blackwell, R. D., Miniard, P. W., \& Engel, J. F. (2006). Consumer behaviour. Ohio: Thomson Higher Education.

Bloomberg (2013). Shell expands Brazil project after blocking Sinochem. Business Standard.

Bowen, G. A. (2009). Document Analysis is as a Qualitative Research Method. Qualitative Research Journal , 9 (2), 27-40.

Boyatzis, R. R. (1998). Transforming qualitative information: thematic analysis and code development. Thousands Oaks, Ca.: Sage.

Braun, V., \& Clarke, V. (2006). Using thematic analysis in psycholgy. Qualitative Research in Psychology, 3 (2), 77-101.

Breen, L. J. (2007). The researcher 'in the middle': Negotiating the insider / outsider dichotomy. The Australian Community Psychologist, 19 (1), 163-174.

Brouthers, K. (2002). Institutional, cultural and transaction cost influences on entry mode hoice and performance. International Business Studies, 33 (2), 203-221.

Brouthers, K., \& Hennart, J. (2007). Boundaries of the Firm: Insights from International Entry Mode Research. Journal of Management, 33 (3), 395-425.

Bryman, A. (2008). Social Research Methods (3rd Ed.). Oxford: Oxford University Press.

Bryman, A., \& Bell, E. (2011). Business Research Methods. Oxford: Oxford University Press.

Buckley, P., \& Casson, M. (1981). The optimal timing for a foreign direct investment. The economic Journal, 91 (361), 75-87.

Bureau, U. S. (2019). Language translation of data collection instruments and supporting materials. Retrieved from http://www.census.gov/cac/www/00755.html 
Calof, J. L. (1991). The Internationalization Process: an Examination of Mode Change. London: Unpublished doctoral dissertation, University of Western Ontario.

Calof, J. L. (1993). The Mode Choice and Change Decision Process and its Impact on international performance. International Business Review, 2 (1), 97-120.

Calof, J. L., \& Beamish, P. W. (1995). Adapting to Foreign Markets: Explaining Internationalization. International Business Review, 4 (2), 115-131.

Calveras, A. \& Orfila-Sintes, F. (2019). Intermediation in hospitality and transaction cost theory: Evidence from the Balearic Islands, 2001-2010. Journal of Destination Marketing \& Management, 11, 281-291.

Carlson, L. K., \& Kaiser, K. (1999). Intuitive Intelligence. Health Forum Journal, 42 (5), 50-54.

Cavusgil, S. T. (1984). Differences among exporting firms based on their degree of internationalisation. Journal of Business Research, 12 (2), 195-208.

Charmaz, K. C. (2003). Grounded theory: Objectivist and constructivist methods. In N. K. Denzin, Lincoln, \& Y. S. (Eds.), Strategies of qualitative inquiry (pp. 249-291). Thousand Oaks: SAGE.

Chetty, S., \& Blankenburg Holm, D. (2000). Internationalisation of small to medium-sized mnufacturing firms: a netw.ork approach. International Business Review, 9 (1), 77-93.

Chetty, S., \& Campbell-Hunt, C. (2001). Paths to internationalisation among small and medium sized firms. Europena Journal of Marketing, 28 (11), 18-21.

Ciravegna, L., Kundu, S.K., Kuivalainen, O., \& Lopez, L.E. (2019). The timing of Internationalization - Drivers and outcomes. Journal of Business Research, 105, 322332.

Clark, T., Pugh, D., \& Malloroy, G. (1997). The process of Internationalization in the operating firm. International Business Review, 6 (6), 605-623.

Coase, R. H. (1937). The nature of the firm. Economica, 4, 386-405.

Cohen, L., Manion, L., \& Morrison, K. (2011). Research Methods in Education. Oxon: Routledge.

Cohen, M. Z., Kahn, D. L., \& Steeves, D. L. (2000). Hermeneutic phenomenological research: A practical guide for nurse researchers. Thousand Oaks: SAGE. 
Copeland, T., \& Tufano, P. (2004). Komplexe Entscheidungen leicht gemacht. Harvard Business Manager, June, 74-87.

Crandall, W., \& Parnell, J. A. (2017). The contribution of behavioural economics to crisis management decision-making. Journal of Management \& Organization, 26 (4), 1-16.

Dane, E., \& Pratt, M. G. (2007). Exploring intuition and its role in managerial decision-making. Academy of Management Review, 32 (1), 33-54.

Datta, D., Herrmann, P., \& Rasheed, A. A. (2002). Choice of foreign market entry modes: critical review and future directions. Advances in International Comparative Management: Managing Transnational firms: Resources, Market Entry and Strategic Alliances, 14, 85 - 154.

David, C., LaPorte, J., \& Seawright, J. (2007). Putting typologies to work: Tools for comparative analysis. Berkeley: University of California at Berkeley.

David, P. A. (1985). Clio and the economics of QWERTY. American Economic Review, 75 (2), 332-336.

Delay, J. B. (2004). Using Concept Maps in Qualitative Research. Milwaukee: University of Wiscounsin.

Delios, A. (2011). Experience and a firm's performance in foreign markets : A commentary essay. Journal of Business Research, 64 (2), 227-229.

Denyer, D., \& Tranfield, D. (2009). Producing a systematic review. In D. Buchanan, \& A. Bryman, The Sage handbook of organizational research methods. Londog: Sage.

Denzin, N. K., \& Lincoln, Y. (1994). Part V: The art of interpretation, evaluation, and presentation. Handbook of qualitative research (pp. 479-483). Thousand Oaks: SAGE.

Dixon-Woods, M., Agarwal, S., Jones, D., Young, B., \& Sutton, A. (2005). Synthesising qualitative and quantitative evidence: a review of possible methods. Journal of Health Services, 10 (1), 45-53.

Drake, P., \& Heath, L. (2011). Practitioner research at doctoral level: Developing coherent research methodologies. London: Routledge. 
Duberley, J., Johnson, P., \& Cassell, C. (2012). Qualitative organizational research: core methods and current challenges. In G. Symon, \& C. Cassell (Eds.), Philosophies underpinning qualitative research (pp. 15-34). London: SAGE Publications Ltd.

Dudovskiy, J. (2018). Research Methodology. Retrieved from https://researchmethodology.net/research-methodology/research-approach/inductive-approach-2/

Dunning, J. H. (2000). The eclectic paradigm as an envelope for economic and business theories. International Business Review, 9 (2), 163-190.

Easterby-Smith, M., Golden-Biddle, K., \& Locke, K. (2008). Working with Pluralism: determining quality in qualitative research. Organizational Research Methods, 11 (3), 419-429.

Easterby-Smith, M., Thorpe, R., \& Lowe, A. (2002). Management Research: An Introduction. London: SAGE.

Egger, P., Fahn, M. M., \& Wamser, G. (2014). On the genesis of multinational foreign affiliate networks. European Economic Review, 65 (C), 136-163.

Engelen, A., Heinmann, F., \& Brettel, M. (2009). Cross-cultural entrepreneurship research: Current status and framework for future studies. Journal of International Entrepreneur, 7, 163-189.

Epstein, S. (1994). Integration of the cognitive and psychodynamic unconscious. American Psychologist, 49 (8), 709-724.

Eriksson, K., Majkgard, A., \& Sharma, D. D. (2000). Path dependence and knowledge development in the internationalisation process. Management International Review, 40 (4), 307-328.

Erramilli, M. K., \& Rao, C. P. (1990). Choice of foreign market entry modes by service firms: Role of market knowledge. Management International Review, 3 (2), 135-150.

Fink, A. (2014). Conducting Research Literature Reviews (4th. ed.). Lomdon: SAGE Publications Ltd.

Fisch, J. H. (2004). Establishing foreign subsidiaries as investments under uncertainty. 30 th annual EIBA Conference. Ljubljana.

Flick, U. (2017). The Sage Handbook of Qualitative Data Collection. Singapore: SAGE Publications Limited. 
Flyvberg, B. (2006). Five Misunderstandings about case-study research. Qualitative Inquiry,12 (2), 219-245.

Fonfara, K., Ratajczak-Mrozek, M., \& Leszczyński, G. (2016). Change and transformation of networks and relationships - Fundamental aspects of business reality. Industrial Marketing Management, 58, 187-189.

Francioni, B., Musso, F., \& Cioppi, M. (2015). Decision-maker characteristics and international decisions for SMEs. Management Decision, 53 (10), 2226-2249.

Freeman, S., Deligonul, S., \& Cavusgil, T. (2013). Strategic re-structuring by born-globals using outward and inward-oriented activity. International Marketing Review, 30 (2), 156-181.

Gabrielsson, M., \& Kirpalani, M. (2004). Born global: How to reach new business space rapidly. International Business Review, 13 (5), 555-571.

Gabrielsson, M., Kirpalani, M., Dimitratosd, P., \& Solberg, C. A. (2008). Born globals: Propositions to help advance the theory. International Business Review, 7, 385-401.

Gall, M., Gall, J., \& Bong, W. (2006). Educational Research : An Introduction. New York: Longman.

Gentles, S. J., Charles, C., Ploeg, J., \& McKibbon, K. A. (2015). Sampling in Qualitative Research: Insights from an Overview of the Methods Literature. The Qualitative Report, 20 (11), 1772-1789.

Georgiou, M. (2014). Foreign Market Entry and Exit Process: The Case of BP Lubricants in Europe and Africa. Gloucestershire: PhD Thesis at the University of Gloucestershire.

Gersick, C. (1991). Revolutionary Change Theories: A Multilevel Exploration of the Punctuated Equilibrium Paradigm. The Academy of Management Review, 16 (1), 10-36.

Glase, B. G. (1992). Emerging vs forcing: Basics of grounded theory analysis. Mill Valley: Sociology Press.

Glaser, B. G., \& Strauss, A. (1967). The discovery of grounded theory. Chicago: Aldine.

Glowik, M. (2020). Market Entry Strategies. Berlin: Walter de Gruyter GmbH.

Grand View Research, I. (2020). Grand view research. Retrieved from https://www.grandviewresearch.com/industry-analysis/lubricants-market. 
Grant, A.M., Berg, J. M., Cable, D. M. (2014). JOB TITLES AS IDENTITY BADGES: HOW SELF-REFLECTIVE TITLES CAN REDUCE EMOTIONAL EXHAUSTION. Academy of Management Journal, 57 (4), 1201-1225.

Gray, D. A. (2009). Doing Research in the Real World. London: SAGE Publications Ltd.

Guba, E., \& Lincoln, Y. S. (1985). Naturalistic inquiry. Berverly Hills: SAGE.

Guemueu, Sefer, \& Apak, S. (2011). Strategies of international growth in enterprises and strategic. Procedia Social.

Guest, G., \& MacQueen, N. (2012). Introduction to Thematic Analysis. Applied Thematic Analysis, 3-20.

Hakim, C. (2000). Research Design: Successful Desings for Social and Economic Research (2nd ed.). London: Routledge.

Han, J. (2020). Curent Situation and Improvement Strategies of Internationalization of Competitive Wushu Routines. Frontiers in Sport Research, 1(1), 14-20.

Hart, M., Andreosso-O'Callaghan, B., \& Lenihan, H. (2010). SMEs in a Globalised World: Survival and Growth Strategies on Europe's Geographical Periphery. Cheltenham: Edward Elgar Publishing.

Harzing, A.-W., \& Van Ruysseveldt, J. (2004). International Human Ressource Management. London: SAGE Publications Ltd.

Holding, C. (2020). Geschäftsbericht 2019. Retrieved from https://www. com/gruppe/investor-relations/finanzberichte-praesentationen/geschaeftsberichteund-zwischenberichte/

Hollensen, S. (2017). Global Marketing. Harlow: FT Prentice Hall.

Holtmann, J. P. (2008). Pfadabhangigkeit strategischer Entscheidungen. Köln: Kölner Wissenschaftsverlag.

Husserl, E. (1982). Ideas pertaining to a pure phenomenology and to phenomenological philosophie. 1st book: General introduction to a pure phenomenology. Nijhoff: The Hague. 
Hutzschenreuter, T., Pedersen, T., \& Volberda, H. (2007). The role of path dependency and managerial intentionality: a perspective on international business research. Journal of international business studies, 38 (7), 1055-1068.

Hymer, S. H. (1976). The international operations of national firms: a study of direct foreign. Cambridge: MIT Press.

Investopedia. (2019). Investopedia. Retrieved from

https://www.investopedia.com/terms/m/multinationalcorporation.asp

Isenberg, D. J. (1989). How senior managers think. In W. H. Agor (Eds.), Intuition in Organizations: Leading and Managing Productively (pp. 91-110). Newbury Park: Sage Publications.

Javadi, M., \& Zarea, M. (2016). Understanding Thematic Analysis and its Pitfalls. Journal of client care, 1 (1), 33-39.

Ji, J., Dimitratos, P., \& Huang, Q. (2016). Problem-solving dissension and international. International Marketing Review, 33 (2), 219-245.

Johanson, J., \& Vahlne, J. E. (1977). The internationalisation of the firm: A model of knowledge development and increasing foreign market commitments. Journal of International Business Studies, 8 (1), 23-32.

Johanson, J., \& Vahlne, J. E. (1990). The mechanism of internationalisation. International Marketing Review, 7 (4), 11-24.

Johanson, J., \& Wiedersheim-Paul, F. (1975). The internationalisation of the firm - four swedish cases . Journal of Management Studies, 12 (3), 305-322.

Jones, M. V., \& Coviello, N. (2005). Internationalisation: conceptualising an entrepreneurial process of behaviour in time . Journal of Business Studies, 36 (3), 284-303.

Jones, M. V., \& Young, S. (2009). Does entry mode matter? Reviewing current themes and perspectives. In M. Jones, P. Dimitratos, M. Fletcher, \& S. Young (Eds.), Internationalization, entrepreneurship and the smaller firm - evidence around the world (pp. 6-9). Cheltenham: Edward Elgar.

Kümmerle, W. (2005). The Entrepreneur's Path to Global Expansion. MIT Sloan Management Review, 46 (2), 42-49. 
Karnieli-Miller, S., Stier, R., \& Pessach, L. (2009). Power Relations in Qualitative Research. Qualitative Health Research, 19, 279-289.

Keller-Bacher, J. \& Zerfass, A. (2019). How Strategic Communication Facilitates the Internationalization of Firms: A Situational Framework. Advances in Public relations and Communication Management, 4, 1-24.

Khondokar, F. A. (2018). Exploring the Role of Private Commercial Banks (PCBs) in Increasing SMEs' Financial Accessibility in Developing Countries: A study in Bangladesh. Unpublished PhD thesis, University of Gloucestershire, Gloucestershire.

King, N. (2004a). Using Templates in the Thematic Analysis of Text. In C. Cassell, \& G. Symon (Eds.), Essential Guide to Qualitative Methods in Organizational Research (pp. 256270). London: SAGE Publications Ltd.

Koch, J. (2008). Strategic Paths and Media Management - A Path Dependency Analysis of the German Newspaper. Branch of High Quality Journalism, 60, 50-73.

Kopola, M., \& Suzuki, A. (1999). Using qualitative methods in psyhology. London: SAGE.

Kutschker, M. (1996). Evolution, Episoden und Epochen: Die Führung von Internationalisierungsprozessen. In J. Engelhard (Eds.), Strategische Führung internationaler Unternehmen. Paradoxien, Strategien, Erfahrungen (pp. 1-37). Wiesbaden.

Kutschker, M., \& Bäuerle, I. (1997). Three + One: Multidimensional Strategy of internationalisation. Management International Review, 37 (2), 103-125.

Kutschker, M., \& Schmid, S. (2006). Internationales Management. München: Wien.

Larsen, E. \& Piscitello, L. (2019). Entry mode deviation: A behavioural approach to internationalization theory. Journal of International Business Studies.

Leonidou, L. C., Katsikeas, C. S., \& Dafnis, N. (2010). Five decades of business research into exporting: A bibliographic analysis. Journal of International Management, 16, 78-91.

Levitt, T. (May-June 1983). The globalization of markets. Harvard Business Review, 92-102.

Li, L., Li, D., \& Dalgic, T. (2004). Internationalization Process of Small and Medium-sized Enterprises: Toward a Hybrid Model of Experiental Learning and Planning. Management International Review, 44 (1), 93-116. 
PhD Thesis Mario Gehrlein

Lincoln, Y. S., \& Guba, E. G. (1985). Naturalistic inquiry. Beverly Hills: SAGE.

Link, W. (1997). Erfolgspotenziale für die Internationalisation. Wiesbaden.

Liu, Y. (2017). Born global firms' growth and collaborative entry mode: the role of transnational entrepreneurs. International Marketing Review, 34 (1), 46-67.

Luoma, J. \& Martela, F. (2020). A Dual-Processing View of Three Cognititve Strategies in Strategic Decision Making: Intuition, Analytic Reasoning, and Reframing. Aalto University School of Science

Luostarinen, R. (1989). Internationalization of the Firm. Helsinki: WIDER.

Lynch, R. (2009). Strategic Management (6th ed.). Harlow: Pearson.

Lyons, E., \& Coyle, A. (2015). Analysing Qualitative Data in Psychology (2nd ed.). London: SAGE Publications Limited.

Macharzina, K., \& Engelhard, J. (1991). Paradigm Shift in International Business Research: From Partist and Eclectic Approaches to the GAINS Paradigm. Management International Review, 31, 23-43.

Macharzina, K., \& Wolf, J. (2005). Unternehmensführung - Das internationale Managementwissen. Wiesbaden: Gabler.

Machi, L. A., \& McEvoy, B. T. (2016). The Literature Review - Six Steps to success (3rd. ed.). London: Corwin.

Maguire, M., \& Delahunt, B. (2017). Doing a thematic analysis: A practical, step-by-step guide for learning and teaching scholars. All Ireland Journal of Teaching and learning in higher education, 3, 3351-3354.

Mallett, R., Hagen-Zanker, J., Slater, R., \& Duvendack, M. (2012) .The benefits and challenges of using systematic reviews in international development research. Journal of Development Effectiveness, 445-455.

Manen, M. (2014). Phenomenology of practice: Meaning-giving methods in phenomenological research and writing. Walnut Creek, Ca: Left Coast Press.

Mang, T., \& Dresel, W. (2007). Lubricants and lubrication (2nd Ed.) . Wiley-Vch.

Marcharzina, K., \& Wolf, J. (2005). Unternehmensführung - Das internationale Managementwissen. Wiesbaden: Gabler. 
Marshall, C., \& Rossmann, G. B. (1999). Designing Qualitative Research (3rd edn). Thousand Oaks: SAGE.

Matzler, K., Bailom, F., \& Mooradian, T. A. (2007). Intuitice Decision Making. Management Review, 49 (1), 13-16.

Maxwell, J. A. (2012). A Realist Approach for Qualitative Research. Sage.

Menzles, J., Orr, S. \& Paul, J. (2020). SME Internationalisation: The Relationship Between Social Capital and entry Mode. Management International Review, 60, 623-650.

Mercer, J. (2007). The challenge of insider research in educational institutions: wielding a double - edged sword and resolved delicate dilemmas. Oxford Review of Education, $33(1), 1-17$.

Merriam, S. B. (2009). Qualitative Research: A Guide to Design and Implementation. San Francisco: Jossey-Bass.

Metsola, J. Leppäaho, T., Paavilainen-Mäntymäki, E. \& Plakoyiannaki, E. (2020). Process in family business internationalisation: The state of the art and ways forward. International Business Review, 29(2).

Michaelson, C., Pratt, M. G. Grant, A., M, Dunn, C. P. (2014). Meaningful Work: Connecting Business Ethics and Organization Studies. Journal Bus Ethics, 121, 77-90.

Miles, M. B., \& Huberman, A. M. (1994). Qualitative Data Analysis: An Expanded Sourcebook. London: Sage.

Miller, G., Galanter, E., \& Pribram, K. H. (1960). Plans and the Structure of Behaviour. USA: Martino Publishing.

Moen, O., \& Servais, P. (2002). Born Global or Gradual Global? Examining the export behavior of small and medium sized enterprises. Journal of International Marketing, 10 (3), 4972.

Moran, D. (2000). Introduction to Phenomenology. London: SAGE.

Morse, J. (1995). The significance of saturation. Qualitative Health Research, 5 (2), 147-149.

Morse, J. M. (1994). Desgining funded qualitative research. . In N. K. Denzin, \& L. Y. S. (Eds.), Handbook of qualitative research (pp. 220-235). Thousand Oaks: SAGE. 
Morse, J. M. (2007). Strategies of intraproject sampling. In P. L. Munhall (Eds.), Nursing research: A qualitative perspective (pp. 529-539). Sudbury: Jones and Bartlett.

Mostafiz, M. I., Sambasivan, M. \& Goh S.K. (2020). The performance of export manufacturing firms: roles of international entrepreneurial capability and international opportunity recognition. International Journal of Emerging Markets, 18(1), 73-98.

Mulrow, C. D. (1994). Systematic Reviews-Rationale for Systematic Reviews. Bristish Medical, 309, 597-599.

Nan, Z. (2013). The Internationalization of Chinese Firms. York: University of York.

Newcomer, Kathryn E. (2015). Handbook of Practical Program Evaluation, John Wiley \& Sons Incorporate.

Oh, H.-M., Arnett, D. B., \& An, S. B. (2016). Export market expansion through indirect learning: evidence from Korean exporters. Journal of Korea Trade, 20 (4), 318-331.

Orlandi, B. \& Pierce, P. (2020). Analysis or Intuition? Refraiming the decision-making styles debate in the technological settings. Management Decision, 58 (1), 129-145.

Ormston, R., Spencer, L., Barnard, M., \& Snape, D. (2014). The foundations of qualitative research. In J. Richie, J. Lewis, C. M. Nicholls, \& R. Ormston (Eds.), Qualitative research practice: a guide for social science research students and researchers (pp. 1-23). London: SAGE Publications Ltd.

Osarenkhoe, A. (2009). An integrated framework for understanding the driving forces behind non-sequential process of internationalisation among firms. Business Process Management, 15 (2), 286-316.

Osmundsen, T. (2012). Going global - a trajectory of individual and organizational development. International Journal of Organisational Analysis, 21 (2), 124-136.

Oviatt, M. B., \& McDougall, P. P. (2005). Defining International Entrepreneurship and modelling the speed of internationalisation. Entrepreneurship Theory \& Practice, 29 (5), 537-553.

Palmer, R. (1969). Hermeneustics. Evanston: Northwestern University Press.

Pan, Y., \& Tse, D. K. (2000). The hierarchical model of market entry modes. Journal of International Business Studies, 31, 535 - 554. 
Patton, M. Q. (1990). Qualitative evaluation and research methods (2nd ed.). Newbury Park: CA: Sage.

Pedersen, T., Petersen, B., \& Benito, G. R. (2002). Change of Foreign Operation Method: Impetus and Switching Costs, International Business review, 11, 325-345.

Pehrsson, T. (2015). Market entry mode and performance: capability alignment and institutional moderation. International Journal of Business and Globalisation, 15 (4), $508-527$.

Penrose, E. T. (1959). Foreign investment and the growth of the firm. Economic Journal, 60, 220-235.

Perks, K., \& Hughes, M. (2008). Entrepreneurial decision- making in internationalization: propositions from mid-size firms. International Business Review, 17 (3), 310 - 330.

Picot-Coupey, K., \& Cliquet, G. (2014). Retaillers Expansion Mode Choice in Foreign Markets: Antecedents of Expansion Mode Choice in the light of Internationalization Theories. Journal of Retailing and Consumer Services, 21 (6), 976-991.

Pope, C., Mays, N., \& Popay, J. (2007). Synthesizing Qualitative and Quantitative Health Evidence. McGraw-Hill.

Prahalad, C. K., \& Doz, I. L. (1987). The Multinational Mission. New York: Free Press.

Rödenbeck, M. (2008). Individuelle Pfade im Management. Wiesbaden: Gabler.

Regima, K., Naidoo, J., \& Pilkington, P. (2010). Understanding the Processes of Translation and Transliteration in Qualitative Research . International Journal of Qualitative Methods, 9 (1), 16-26.

Reinhart, C., \& Rogoff, K. (2009). This time is different: Eight centuries of financial folly. Princeton: Princeton University Press.

Rezende, S., Galdino, K., Lamont, B. (2018) Internationalization process through an opportunity lens. RAUSP Management Journal, 53(3).

Reznde, S. F. (2006). Multinationals and Interdependence in Internationalisation Process. Brazilian Administration Review, 10, 1-16.

Riggs, D. W. (2015). Ensuring quality in qualitative research. Flinders University: ReserachGate. 
Rindfleisch, A. (2019). Transaction cost theory: past, present and future. Academy of Marketing Science.

Ripollés, M. \& Blesa, A. (2020). Widening International Entrepreneurship Research. Unknown: MDPI.

Robinson, O. C. (2014). Sampling in Interview-Based Qualitative Research: A Theoretical and Practical Guide. Qualitative Research in Psychology, 11, 25-41.

Robson, C. (2002). Real World Research. Oxford: Blackwell.

Root, F. R. (1987). Entry strategies for international markets. Lexington: Lexington Books.

Rosenthal, M. (8(4) 2016). Qualitative research methods: Why, when, and how to conduct interviews and focus groups in pharmacy research. Currents in pharmacy teaching and learning, 8, 509-516.

Roubin, N., \& Mihm, S. (2010). Crisis Economics: A crash course in the future of finance. Penguin Press.

Rugman, A. M. (1997). The theory of multinational enterprise: the selected papers of Alan M. Cheltenham: Brookfield.

Rundh, B. (2003). Rethinking the international marketing strategy: new dimensions in a competitive market. Marketing Intelligence \& Planning.

Ryan, A. B. (2006). Post-Positivist Approaches to Research. In Researching and Writing your thesis: a guide for postgraduate students. (pp. 12-26). MACE.

Saaty, T. L. (2008). Decision making with the analytic hierarchy process. Int. J. Services Sciences, 1 (1), 83-98.

Sachse, U. (2010). Internationalisation and Mode Switching - Performance, Strategy and Timing. Edinburgh: Edinburgh Napier University.

Sadler-Smith, E., \& Shefy, E. (2004). The intuitive executive: understanding and applying 'gutfeel' in decision-making". Academy of Management Executive, 18 (4), 76-91.

Saldana, J. (2009). The coding manual for qualitative researchers. London: SAGE.

Sandelowski, M. (1995). Sample size in qualitative research. Research in Nursing and Health, 18 (2), 179-183. 
Saunders, M., Lewis, P., \& Thornhill, A. (2012). Research Methods for Business Students. Harlow: Person Education Ltd.

Sefianie, Y. (2013). FACTORS FOR SUCCESS IN SMES: A PERSPECTIVE FROM TANGIER. Unpublished PhD thesis, University of Gloucestershire, Gloucestershire.

Schieritz, M., \& Thumann, M. (2019). Einmal Flagge zeigen. Zeit, 42.

Schmid, D. \& Morschett, D. (2020). Decades of research on foreign subsidiary divestment: What do we really know about ist antecedents? International Business Review, 29(4).

Schröter, A. (2014). Distribution of decision power in matrix organizations: A qualitative survey. Unpublished PhD thesis, University of Gloucestershire, Gloucestershire.

Schutz, A. (1967). The phenomenology of the social world. Evanston: Northwestern Press.

Schwarz, S. (2009). Muster erfolgreicher Internationalisierung von Handelsunternehmen. Dissertation, Gabler Edition Wissenschaft.

Scott, J. (1990). A Matter of Record. Cambridge: Polity Press.

SE, F. P. (2020). Retrieved from

https://wwwcom/gruppe/presse/pressemitteilungen/unternehmen-wirtschaftfinanzen/news-detail/view/244staerkt-praesenz-durch-joint-ventures-in-afrikasuedlich-der-sahara/

Seawright, J., \& Gerring, J. (2008). Case Selection Techniques in Case Study Research . Political Research Quarterly, 61 (2), 294-308.

Shakun, M. F. (2001). Unbounded rationality. Group Decision and Negotiation, 10 (2) 97-118.

Sharma, D. D., \& Blomstermo, A. (2003). The internationalizaion process of Born globals: a network view. International Business Review, 12 (6), 739-753.

Shoemaker, P. J., \& Russo, J. E. (1993). A pyramid of decision approaches. California Management Review, 36 (1), 9-31.

Silverman, D. (2014). Interpreting qualitative data (5th Ed.). Los Angeles: SAGE Publications Ltd.

Simon, H. A. (1987). Making management decisions: the role of intuition and emotion. Academy of Management Executive, 1 (1), 57-64. 
Simon, H. A. (1979). Rational Decision Making in Business Organizations. The American Economic Review, 69 (4), 493-513.

Simon, M. C. (2007). Der Internationalisierungsprozess von Unternehmen. Wiesbaden: Dissertation, Deutscher Universitätsverlag.

Simons, H. (2009). Case Study Research in Practice. London: Sage.

Sleuwaegen, L. (2013). Scanning for profitable (international) growth. Journal of Strategy and Management, 29, 106-120.

Smith, J. A., \& Osborn, M. (2015). Interpretative Phenomenological Analysis. In J. A. Smith (Eds.), Qualitative Psychology: A Practical Guide to Research Methods (pp. 25-52). London: SAGE.

Smith, J. A., Harre, R., \& Van Langenhove, L. (1995). Ideography and the case study. In J. A. Smith, R. Harre, \& L. Van Langenhove (Eds.), Rethinking Psychology (pp. 59-69). London: SAGE.

Smith, J. A., Jarman, M., \& Osborn, M. (1999). Doing interpretative phenomenological analysis. In M. Murray, \& K. Chamberlain, Qualitative Health Psychology. London: SAGE.

Sousa, F. J. (2010). Metatheories in research: positivism, postmodernism and critical realism. Organizational Culture, Business-to-Business Relationships, and Interfirm Networks Advances in Business Marketing and Purchasing, 16 (1), 455-503.

Stake, R. E. (1995). The art of case study research. London: Sage.

Steinkamp, A. M. (2020). Strategien und Ressourcen für die Internationalisierung. Springer.

Stiles, W. B. (1993). Quality control in qualitative research. Clinical psychology review, 13, 593-618.

Subramanian, R., \& Metin, S. (2009). The Influence of Macro Structure on the Foreign Market Performance of Transnational Firms: The Value of IGO Connections, Export Dependence and Immigration Links. Political Economy and Organizations, 52 (2), 229-267.

Sune, E. (2019) Internationalisation, global capitalism and the integration of Iran. Third World Quarterly. 41(2). 
Swoboda, B. (2002). Dynamische Prozesse der Internationalisierung: Managementtheorie. Wiesbaden: Gabler.

Swoboda, B., \& Jäger. (2008). Investments und Divestments - Gründe für den Wandel der Betätigungsformen aus Managementsicht. Auslandische Direktinvestitionen, 55-77.

Swoboda, B., Jager, M., Morschett, D., \& Schramm-Klein, H. (2008). A Behavioural-based Analysis of the Changes of Structure, Systems and Culture in the Internationalisation Processes Over Time. International Business Research, 4, 41-65.

Swoboda, B., Olejnik, E., \& Morschett, D. (2010). Changes in foreign operation modes: Stimuli for increases versus reduction. International Business review, 20 (5), 578-590.

Swoboda, B., Olejnik, E., \& Morschett, D. (2011). Changes in foreign operation modes: Stimuli . International Business Review, 20 (5), 578-590.

Sydow, J. (2009). Organisationale Pfade: Wie Geschichte zwischen Organisationen Bedeutung erlangt. In E. Martin, \& M. Thoma (Eds.), Die Okonomie der Organisation - die Organisation der Okonomie (pp. 15-31). Verlag für Sozialwissenschaften.

Sydow, J., Schreyögg, G., \& Koch, J. (2005). Organisational paths: Path dependency and beyond. Free University Press.

Sykes, W. (1991). Taking stock: issues from the literature in validity and reliability in qualitative research. Journal of Market Research Society, 33 (1), 3-12.

Symon, G., \& Cassell, C. (2012). Assessing qualitative research. In G. Symon, \& C. Cassell (Eds.), Qualitative organizational research: core methods and current challenges (pp. 204-223). London: SAGE Publications Ltd.

Symon, G, Cassell, C. (2012). Qualitative Organizational Research. London: SAGE Publications Ltd.

Teece, D. J., Pisano, G., \& Shuen, A. (1997). Dynamic Capabilities and Strategic Management. Strategic Management Journal, 18, 509-533.

Tihanyi, L., Griffith, D., \& Russell, C. (2005). The effect of cultural distance on entry mode choice, international diversification and MNE performance: a meta- analysis. Journal of International Business Studies, 36 (3), 270-283. 
Tranfield, D., Denyer, D., \& Smart, P. (2003). Towards a Methodology for Developing Evidence-Informed Management Knowledge by Means of Systematic Review. British Journal, 14, 207-222.

Tuohy, D., Cooney, A., Dowling, M., Murphy, K., \& Sixsmith, J. (2013). An overview of interpretive phenomenology as a research methodology. Nurse Researcher, 20 (3), 17-20.

University, O. (2019). Retrieved from https://www.ouh.nhs.uk/researchers/planning/documents/participant-informationsheet.pdf abgerufen

University of Gloucestershire (2020). Research Ethics: A Handbook of Principals and Procedures. Retrieved from https://www.glos.ac.uk/docs/download/Research/handbook-of-principles-andprocedures.pdf.

Unluer, S. (2012). Being an Insider Researcher while Conducting Case Study Research. The Qualitative Report, 17 (85), 1-14.

Vaismoradi, M., Turunen, H., \& Bondas, T. (2013). Content analysis and thematic analysis: Implications for conducting a qualitatitve descriptive study. Nursing and Health Sciences, 15 (3), 398-405.

Vasconcelos, A. F. (2009). Intuition, prayer, and managerial decision-making processes: a religion-based framework. Management Decision, 47 (6), 930-949.

Wadeson, N. (2020). Internationalisation theory and born globals. Multinational Business Review.

Walker, A. (2002). Living in Britain: Results from the 2000 General Household Survey . London: Stationary Office.

Wang, Y., \& Suh, C.-S. (2009). Towards a re-conceptualization of firm internationalization:. Journal of Internationa Management, 15, 447-459.

Weeks, A., Swerisson, H., \& Belfarge, J. (2007). Issues, challenges and solutions in translating study instruments. Evaluation Review, 31 (2), 153-165.

Welch, L., Benito, G. R., \& Petersen, B. (2007). Foreign Operation Methods - Theory, analysis, strategy. Northampton, Me: Edward Elgar. 
Welte, R., Feenstra, T., Jager, H., \& Leidl, R. (2004). A Decision Chart for Assessing and Improving the Transferability of Economic Evaluation Results Between Countries. Pharmaeconomics, 22 (13), 857-876.

Werle, R. (2007). Pfadabhangigkeit. In A. Benz, S. Lüzu, U. Schimank, \& G. Simoins (Eds.), Handbuch Governance (pp. 119-131). Verlag fur Sozialwissenschaften.

Werner, S. (2002). Recent developments in international management research: a review of 20 top management journals. Journal of Management, 28, 277 - 305.

Wilding, C., \& Whiteford, G. (2005). Phenomenological research: An exploration of conceptual, theoretical and practical issues. ccupational Therapy Journal of Research OTJR: Occupation, Participation and Health, 25 (3), 98-104.

Wilkinson, S. (1988). The role of reflexivity in feminist psychology. Women's studies international forum, 11 (5), 493-502.

Williamson, O. E. (1975). Markets and Hierarchies - Analysis and Antitrust Implications. New York: Free Press.

Williamson, O. E. (1985). The Economic Institutions of Capitalism. Firms, Markets, Relation. New York: Free Press.

Winter, S. (2003). Understanding Dynamic Capabilities. Strategic Management Journal, 24, 991-995.

Wójcik, P. \& Ciszewska-Milnaric, M. (2020). Intention to De-internationalise: Foreign-Based Competition at Home and the Effect of Decision-Makers' Role. Entrepreneurial Business and Economics Review, 8(2), 199-218.

Yakhlef, A., \& Maubourguet, F. (2004). The Lexus and the Olive Tree: a rising mode of internationalisation. International Journal of Entrepreneurial Behavior \& Research, 10 (3), 192-205.

Yan, J. (2020). Exploring the Unknown Requires Leveraging Uncertainty: Two Essays on a Real Options Perspective on the Pattern and Decision Making of Entrepreneurial Internationalization. Unpublished PhD thesis, University of Tennessee, Knoxville.

Yaw, W.K. \& Keong, C.C. (2019). THEORETICAL REVIEWS OF INTERNATIONAL TRADE: MALAYSIA AND CHINA EXPORTING GOODS IN ASIAETICAL REVIEWS OF INTERNATIONAL TRADE: MALAYSIA AND CHINA EXPORTING GOODS IN ASIA. Journal of Management, Economics, and Industrial Organization, 3(2),35-47. 
Yin, R. (2015). Case study research: Design and Methods (5th ed.). Sage.

Yip, G. S., Biscarri, J. G., \& Monti, J. A. (2000). The role of the internationalization process in the performance of newly internationalizing firms. Journal of International Marketing, 8 (3), 10-35.

Young, S., Dimitratos, P., \& Dana, L.-P. (2003). International Entrepreneurship Research: What scope for international business theories? Journal of International Entrepreneurship, 1 (1), 31-42.

Young, S., Hamill, J., Wheeler, C., \& Davies, J. (1989). International Market Entry and Development. Englewood Cliffs: Prentice Hill.

Zentes, J., Swoboda, B., \& Morschett, D. (2004). Internationales Wertschöpfungsmanagement. München: Vahlen.

Zhang, Y., Zhang, Z., \& Liu, Z. (2007). Choice of entry modes in sequential FDI in an emerging economy. Management Decision, 45 (4), 749-772.

Zhang, Q. (2009). Factors Influencing Foreign Retailers' Expansion Process in China. Unpublished PhD thesis, University of Brighton, Brighton.

Zollo, M., \& Winter, S. (2002). Deliberate Learning and the Evolution of Dynamic Capabilities. Organization Science, 13 (3), 339-351. 


\section{Appendix 1: Philosophical positions, Approaches and Alternative Positions}

\begin{tabular}{|c|c|c|c|c|}
\hline & Pragmatism & Positivism & Realism & Interpretivism \\
\hline Ontology & $\begin{array}{l}\text { External, multiple view chosen to } \\
\text { best enable answering of the } \\
\text { research question. }\end{array}$ & $\begin{array}{l}\text { External, objective and independent } \\
\text { of social actors. }\end{array}$ & $\begin{array}{l}\text { Is objective. Exists independently of } \\
\text { human thoughts and beliefs or } \\
\text { knowledge of their existence } \\
\text { (realist), but is interpreted through } \\
\text { social conditioning (critical realist). }\end{array}$ & $\begin{array}{l}\text { Socially constructed, subjective, may } \\
\text { change, multiple. }\end{array}$ \\
\hline Epistemology & $\begin{array}{l}\text { Either or both observable } \\
\text { phenomena and subjective } \\
\text { meanings can provide acceptable } \\
\text { knowledge dependent upon } \\
\text { the research question. Focus on } \\
\text { practical applied research, } \\
\text { integrating different perspectives to } \\
\text { help interpret the data. }\end{array}$ & $\begin{array}{l}\text { Only observable phenomena can } \\
\text { provide credible data, facts. Focus } \\
\text { on causality and law-like } \\
\text { generalisations, reducing } \\
\text { phenomena to simplest elements. }\end{array}$ & $\begin{array}{l}\text { Observable phenomena provide } \\
\text { credible } \\
\text { data, facts. Insufficient data means } \\
\text { inaccuracies in sensations (direct } \\
\text { realism). Alternatively, phenomena } \\
\text { create sensations which are open to } \\
\text { misinterpretation (critical realism). } \\
\text { Focus on explaining within a context } \\
\text { or } \\
\text { contexts. }\end{array}$ & $\begin{array}{l}\text { Subjective meanings and social } \\
\text { phenomena. Focus upon the details } \\
\text { of situation, a reality behind these } \\
\text { details, subjective meanings } \\
\text { motivating actions. }\end{array}$ \\
\hline Axiology & $\begin{array}{l}\text { Values play a large role in } \\
\text { interpreting results, the researcher } \\
\text { adopting both objective and } \\
\text { subjective points of view. }\end{array}$ & $\begin{array}{l}\text { Research is undertaken in a value- } \\
\text { free way, the researcher is } \\
\text { independent of the data and } \\
\text { maintains an objective stance. }\end{array}$ & $\begin{array}{l}\text { Research is value laden; the } \\
\text { researcher is biased by world views, } \\
\text { cultural experiences and upbringing. } \\
\text { These will impact on the research. }\end{array}$ & $\begin{array}{l}\text { Research is value bound, the } \\
\text { researcher is part of what is being } \\
\text { researched, cannot be separated } \\
\text { and so will be subjective. }\end{array}$ \\
\hline
\end{tabular}




Data
collection
techniques
most often
used

Mixed or multiple method designs,

quantitative or qualitative.

Highly structured, large samples,

measurement,

quantitative, but can use qualitative.
Methods chosen must fit the subject matter, quantitative or qualitative.
Small samples, indepth investigations,

qualitative. 


\section{Appendix 2: Overview of the main mode switch research from 1997 to 2016}

\begin{tabular}{|c|c|c|c|c|}
\hline & Authors & Main Research Question & Methodology / Data Content & Assumptions \\
\hline 1 & $\begin{array}{l}\text { Clark et al. } \\
(1997)\end{array}$ & $\begin{array}{l}\text { What additional information and } \\
\text { knowledge sources are available for } \\
\text { firms in the internationalisation } \\
\text { process? }\end{array}$ & $\begin{array}{l}\text { Quantitative survey of } 25 \text { UK- } \\
\text { based organizations. }\end{array}$ & $\begin{array}{l}\text { This article maintains that market-specific knowledge is not the only source of } \\
\text { information available to a firm. As firms operate in foreign markets they develop, in } \\
\text { addition to networks of institutional arrangements, a knowledge of the process of } \\
\text { internationalisation. }\end{array}$ \\
\hline \multirow[t]{3}{*}{2} & $\begin{array}{l}\text { Pedersen et al. } \\
(2000)\end{array}$ & $\begin{array}{l}\text { What factors motivate exporters to } \\
\text { change their foreign market servicing } \\
\text { mode from using independent } \\
\text { distributors and agents to setting up } \\
\text { their own local sales organization, and } \\
\text { what factors impede such changes } \\
\text { (switching costs)? }\end{array}$ & $\begin{array}{l}\text { Using data from a sample of } 214 \\
\text { Danish exporters, of which } 32 \text { had } \\
\text { changed their foreign operation } \\
\text { method between } 1992 \text { and } 1997 .\end{array}$ & $\begin{array}{l}\text { The analysis shows that switching cost factors are indeed of particular importance in } \\
\text { order to explain the incidence of such changes }\end{array}$ \\
\hline & $\begin{array}{l}\text { Petersen et al. } \\
(2002)\end{array}$ & $\begin{array}{l}\text { Main question: what and why the } \\
\text { companies change foreign mode? }\end{array}$ & $\begin{array}{l}276 \text { Danish exporters, later } \\
\text { reduced to } 214 \text {. Out of these: } 182 \\
\text { without a switch, } 36 \text { with a } \\
\text { complete switch of operation } \\
\text { mode, mainly from } \\
\text { agenUdistributor to companies' } \\
\text { own sales forces/subsidiary Data } \\
\text { collection at two points: } 1992 \text { and } \\
1997 .\end{array}$ & $\begin{array}{l}\text { Focus on the specific mode switch from a foreign intermediary to an own sales force and } \\
\text { the dilemma of the intermediary. Gathering data from different companies with focus of } \\
\text { one foreign market per company } \\
\text { Final Outcome: } \\
\text { - } \quad \text { Monitoring is the major driver of performance } \\
\text { - } \quad \text { Severance payments and contractual restrictions have no significant impact on } \\
\text { performance } \\
\text { - Safeguards helps to solve the dilemma of the intermediary }\end{array}$ \\
\hline & $\begin{array}{l}\text { Petersen et al. } \\
(2005)\end{array}$ & $\begin{array}{l}\text { What are the effects of switch } \\
\text { motivation/deterrents (e.g. } \\
\text { contractual restriction, loss of sales } \\
\text { revenue) on the choice of distribution } \\
\text { channel? }\end{array}$ & $\begin{array}{l}260 \text { Danish exporters in } 1992 \text { and } \\
\text { 1997: } 182 \text { did not change foreign } \\
\text { distribution, } 42 \text { replaced } \\
\text { intermediaries, } 36 \text { switched to in- } \\
\text { house operation. }\end{array}$ & $\begin{array}{l}\text { Focused on the mode switching process and especially on the within-mode switches, e.g. changing } \\
\text { from one intermediary to another } \\
\text { Final Outcome: } \\
\text { - Mode switch decision seems to be a cost-benefit analysis } \\
\text { - } \quad \text { Accumulation of market knowledge is associated positively to the switch to another sales } \\
\text { intermediary } \\
\text { - Export market growth as well as growth of the exporting company do not have a significant } \\
\text { effect on the switches } \\
\text { Anticipated loss of local sales revenue have an effect on in-house switches }\end{array}$ \\
\hline
\end{tabular}


3 Chetty \&

Campbell-Hunt

(2001)

The questions posed in this research concerns what path (or paths) are

followed by firms as they

internationalise?

\section{Rundh}

(2003)

5 Rezende

(2006)

6 Kaufmann \&

Jentsch

(2006)

relating to a company's product

technology will have an important

What interdependencies exist in

Internationalisation Processes?

Through which internationalisation
This paper is based on in-depth case studies of the

internationalisation path of ten

small- to medium-sized

manufacturing firms in

New Zealand.

\section{5 questionnaires were}

conducted in the Swedish export

industry with respect to companies

exports to Western Europe.

In the last step the questionnaires

were complemented with case

studies in three countries

influence on the marketing strategy?

Which internationalisation strategies?

modes do companies realise

strategies?

Which evolution paths can be

observed?

Which parameters influence supplier's choice of strategies and modes?

Literature Review

15 cases of automotive supply industry in China.

Mode time: Current mode and year when the new mode was established; intended mode in five years.
A conceptual model is developed from the findings of this study by integrating internationalisation theories.

The result in this study shows that there are several factors that will have an influence on the company's marketing strategy. The first factor consists of variables, which concerns the demand from the local export market in the form of local service. The second group of factors concerns the company's competitive advantage in the form of technology, pricing and distribution on the local export market.

The article concludes by claiming that the internationalisation of multinationals

(MULTINATIONAL COMPANYs) results from an intricate combination of independent, yet interdependent, internationalisation processes that evolve in various spatial and temporal contexts within the MULTINATIONAL COMPANY network.

Comparable research approach in respect to how to analyse decision-making

behaviour after market entry.

Identification of four main evolution pathways over a certain period of time in China (for automotive sector): 1. Risk-averse early entrant, 2. Equity Joint Venture with non-Chinese autnotive sector): 1. Risk averse ealy entront, 2. Equily Joint Vent Vith non-Chinese partners or Chinese original equipment manufacturer, 3. Equity Joint Venture with Chines suppliers, 4. Late-following wholly own foreign owned enterprise

Characterising and describing reasons of each pathway behaviour. 
6 Swoboda et al. (2008)

Asmussen et al. (2009)

7 Osarenkhoe (2009)
What are the perceived structural, systemic und cultural changes in relation to (1) past developments based on the country and/or mode dimensions, (2) incremental developments in these two dimensions, and ( 3 ) selected crucial decisions (e.g. establishment of the first foreign production subsidiary)?

Main focus: better understanding and explanation of foreign mode decisions

What are interdependencies between foreign operation mode decisions across countries and over time?

What might be managerial capacity to make these decisions?

Is non-sequential internationalisation process solely technology enabled or a product of mutually interdependent forces?

\section{German firms were}

interviewed with a questionnaire.

Conceptual paper

Descriptive model of foreign operation mode

Discussion of dynamic configuration of foreign mode

The data banks of the Swedish

Trade Council and the Chambers of Commerce are used to identify

firms with between 50 and 250 employees. Data are collected through the use of

questionnaires and in-depth

interviews from 60 Swedish firms operating in other countries and foreign firms operating in Sweden

that tends not to develop in

incremental stages with respect to their international.
The results show that internationalisation processes cause changes in systems in particular, followed by structural and cultural changes, even when reductions take place. The study provides insights for managers into structural, systemic and cultural changes when future internationalisation steps are planned.

\section{Proposing a framework on how to configurate foreign operation modes.}

ooking at firm's foreign operation diversity, i.e. country-by-country variations of mode portfolio and foreign operation fluctuation, i.e. tendency to change mode overtime.

Some of the findings are: that the sequential model is by no means reflective of, or appropriate for all firms' approaches to international business; the usefulness gained by using an international network approach to study the international activity of a firm; and the interplay between the identified driving forces behind a non-sequential internationalisation process. 
8 Wang \& Suh (2009)

9 Belova et al. (2010)

Sachse

(2010)
What are the links within the literature on subsidiary roles and

knowledge flows in MNEs?

What are the most important factors that influence the decisions made by

large Western MULTINATIONAL

COMPANYs concerning post entry

changes (PEC) in the BRIC markets?

Why these changes take place?

Which factors influence the selected

strategy after initial market entry has

been made?

Why do firms change or do not change

their modes of foreign operation?

How do firms decide to change the foreign operation mode?

What role do timing-aspects play in the switch of foreign operation mode?

How does the change of foreign

operation mode influence the firm's success?

Can success pattern of mode switching be identified?

What are the main reasons for mode

changes - increases as well as

reductions?

\section{Literature Review}

The paper uses a qualitative study

to explain and explore PEC

strategies in each of the four BRIC

markets, using case studies of

three Italian large MULTINATIONAL

COMPANYs: Artsana, De Longhi

and Luxottica.

Large-scale survey of 192

companies

265 German firms were

interviewed on 320 mode changes

with a questionnaire.
The authors re-conceptualized the internationalisation process as heterogenous process of strategic development of subsidiaries in overseas countries and regions. Additionally, they delineate peculiar roles played by subsidiaries in pursuit of multinational enterprise (MNE) headquarters' internationalisation strategies.

The study finds that firstly BRIC markets should not be seen as a whole, as academic literature has a tendency to suggest. Secondly, the study finds that country-specific

conditions directly affect PEC choices and decisions differently in each market.

This thesis focuses on the mode switching process of and which impact a mode switch can have on the performance in a foreign country.

Final Outcome:

- The timing of the mode switch is a crucial factor

Also non-switching companies can be successful

The results show that executives recognize a wide range of reasons for mode

change, but the importance and magnitude of those stimuli differ for mode increases and 


\begin{tabular}{|c|c|c|c|c|}
\hline & & & & $\begin{array}{l}\text { reductions. While performance and external environment increase the likelihood of } \\
\text { mode } \\
\text { reductions, internal environment and managerial attitudes induce mode increases. } \\
\text { Moreover, stimuli for incremental and radical mode changes differ as well. }\end{array}$ \\
\hline 11 & $\begin{array}{l}\text { Gümüú \& } \\
\text { Apak } \\
(2011)\end{array}$ & $\begin{array}{l}\text { What are the basic suggestions for the } \\
\text { enterprises to achieve business } \\
\text { success and to acquire growth, staying } \\
\text { power and competitive advantage? }\end{array}$ & Literature Review & $\begin{array}{l}\text { Merger has become attractive for companies on the basis of the facts that the } \\
\text { companies, which worry about their survival in the face of the rapidly changing } \\
\text { competitive conditions or which aim to grow stronger in the face of fierce competition, } \\
\text { plan to grow by merger and even to have a say in the markets by showing themselves off } \\
\text { on the international stage. }\end{array}$ \\
\hline 12 & $\begin{array}{l}\text { Benito et al. } \\
\text { (2011) }\end{array}$ & $\begin{array}{l}\text { Which, and how and why, companies } \\
\text { combine clearly different foreign } \\
\text { operation modes? }\end{array}$ & $\begin{array}{l}\text { In this paper, detailed information } \\
\text { about the operations of six } \\
\text { Norwegian companies in three key } \\
\text { markets (China, UK and USA) is } \\
\text { used as the basis for an exploration } \\
\text { and to answer the research } \\
\text { questions. }\end{array}$ & $\begin{array}{l}\text { The study reveals that companies tend to combine modes of operation; thereby } \\
\text { producing unique foreign operation mode "packages" for given activities and/or } \\
\text { countries, and that the packages are liable to be modified over time - providing a } \\
\text { potentially important optional path for international expansion. }\end{array}$ \\
\hline 13 & $\begin{array}{l}\text { Osmundsen } \\
\text { (2012) }\end{array}$ & $\begin{array}{l}\text { How is the internationalisation } \\
\text { process of a multinational company } \\
\text { (MULTINATIONAL COMPANY) is } \\
\text { shaped and formed by actors } \\
\text { engaging in collaborative inquiry? }\end{array}$ & $\begin{array}{l}\text { The paper is based on a qualitative } \\
\text { comparative study of } \\
\text { organizational units in Norway, } \\
\text { Sweden, Mexico, the USA, South } \\
\text { Korea and Poland. Over a four-year } \\
\text { period, } 165 \text { interviews were } \\
\text { conducted with both employees } \\
\text { and management. }\end{array}$ & $\begin{array}{l}\text { Through a perspective on learning, it is possible to show how organizational members } \\
\text { make use of their institutional environment as they mutually attempt to build shared } \\
\text { ideologies for conducting their business. To view organizational change as a learning } \\
\text { process allows for explaining how both actors and structures intertwined represent the } \\
\text { dynamic for change. Cultural-cognitive institutions are seen here as active living } \\
\text { phenomena which are created and enacted by individuals in their historical and } \\
\text { geographical contexts. }\end{array}$ \\
\hline 14 & $\begin{array}{l}\text { Freeman et al. } \\
\text { (2013) }\end{array}$ & $\begin{array}{l}\text { How do managers move through the } \\
\text { de-internationalisation (exit) to re- } \\
\text { internationalisation (re-entry) } \\
\text { process? } \\
\text { How do they choose their patterns of } \\
\text { internationalisation? }\end{array}$ & $\begin{array}{l}\text { To address these research gaps, } \\
\text { this study draws on } 26 \text { in-depth } \\
\text { interviews with senior managers } \\
\text { across nine Australian born- } \\
\text { globals. }\end{array}$ & $\begin{array}{l}\text { Moving between outward and inward-oriented activity as they de-internationalize and } \\
\text { reinternationalize is used as proactive strategic re-structuring by born-global managers } \\
\text { for survival during periods of global economic decline or changing competitive } \\
\text { conditions. }\end{array}$ \\
\hline
\end{tabular}




\begin{tabular}{|c|c|c|c|c|}
\hline & $\begin{array}{l}\text { Nan } \\
\text { (2013) }\end{array}$ & $\begin{array}{l}\text { What determines whether exporting } \\
\text { firms move to OFDI as part of their } \\
\text { outward internationalisation strategy? } \\
\text { What strategic assets do Chinese firms } \\
\text { intend to acquire through cross- } \\
\text { border merger and acquisitions } \\
\text { (CBMAs) and whether a partnering } \\
\text { approach is a viable strategy for post- } \\
\text { CBMAs? } \\
\text { Does the hybrid entry mode that } \\
\text { incorporates OFDI by exporting firms } \\
\text { lead to better performance than those } \\
\text { that focus on exporting only? }\end{array}$ & $\begin{array}{l}\text { Hypotheses are tested using a } \\
\text { recent survey of Chinese } \\
\text { privately-owned enterprises. }\end{array}$ & $\begin{array}{l}\text { Focus on the mode switching process and especially on the factors which are the determinants for a } \\
\text { mode switch } \\
\text { Final Outcome regarding the determinants: } \\
\text { - } \quad \text { Productivity } \\
\text { - } \quad \text { Technological Capabilities } \\
\text { - } \quad \text { Export Experiences } \\
\text { - Industry conditions } \\
\text { These factors are the main drivers for a mode switch. }\end{array}$ \\
\hline 15 & $\begin{array}{l}\text { Egger et al. } \\
\text { (2014) }\end{array}$ & $\begin{array}{l}\text { What are the key driver of gradualism } \\
\text { in the genesis of MNEs' foreign } \\
\text { affiliate networks? }\end{array}$ & Literature Review & $\begin{array}{l}\text { Provides the first systematic analysis of the genesis of MNEs' foreign affiliate networks. } \\
\text { Proposes a theory of correlated learning across markets to explain foreign affiliate setup. } \\
\text { Finds support of that theory through an analysis of simultaneous versus sequential } \\
\text { market entry. }\end{array}$ \\
\hline 16 & $\begin{array}{l}\text { Fonfara et al. } \\
(2016)\end{array}$ & $\begin{array}{l}\text { What changes and transformations of } \\
\text { networks and relationships are } \\
\text { currently happening in the business } \\
\text { realitiy? }\end{array}$ & $\begin{array}{l}\text { This article serves to announce the } \\
32 \text { nd Annual IMP Conference that } \\
\text { will be held in Poznań, Poland, this } \\
\text { year } \\
\text { where discussion will focus on } \\
\text { change and transformation of } \\
\text { networks and relationships. }\end{array}$ & $\begin{array}{l}\text { The research carried out in the beginning by the IMP Group was very phenomenon- } \\
\text { driven in character. Researchers associated with the IMP Group were linked because } \\
\text { they viewed companies as being a network of interdependent entities and this view was } \\
\text { commonly described in literature as the IMP network approach. Change is a } \\
\text { fundamental assumption embedded in the network approach. Changes occurring in } \\
\text { networks are caused by } \\
\text { interdependency, interactions and mutual adaptation. }\end{array}$ \\
\hline
\end{tabular}




\section{Appendix 3: Preparation Check-List for Semi- Structured Interviews (Saunders et al., 2012)}

\begin{tabular}{|c|c|}
\hline Key Preparation & Description \\
\hline Level of Knowledge & $\begin{array}{l}\text { How might your level of preparation and knowledge affect } \\
\text { the willingness of the interviewee to share data? } \\
\text { What are the themes that you wish to explore or seek } \\
\text { explanations for during a semi-structured interview? }\end{array}$ \\
\hline $\begin{array}{l}\text { Level of information } \\
\text { supplied to the interviewee }\end{array}$ & $\begin{array}{l}\text { What type of information, if any, will be useful to send to } \\
\text { the interviewee prior to the interview? }\end{array}$ \\
\hline $\begin{array}{l}\text { Appropriateness of } \\
\text { Location }\end{array}$ & $\begin{array}{l}\text { Have you considered the impact that your interview } \\
\text { location may have on the interviewee responses? }\end{array}$ \\
\hline $\begin{array}{l}\text { Appropriateness of the } \\
\text { researcher's appearance at } \\
\text { the interview }\end{array}$ & $\begin{array}{l}\text { How will your appearance during the interview affect the } \\
\text { willingness of the interviewee to share data? }\end{array}$ \\
\hline $\begin{array}{l}\text { Nature of the opening } \\
\text { comments to be made when } \\
\text { the interview commences }\end{array}$ & $\begin{array}{l}\text { How will you prepare yourself to be able to commence the } \\
\text { interview with confidence and purpose? }\end{array}$ \\
\hline Approach to questioning & $\begin{array}{l}\text { What will you tell your interviewee about yourself, the } \\
\text { purpose of your research, its funding and your purpose? }\end{array}$ \\
\hline $\begin{array}{l}\text { Nature and impact of the } \\
\text { interviewer's behaviour } \\
\text { during the course of the } \\
\text { interview }\end{array}$ & $\begin{array}{l}\text { How will you seek to overcome concerns of the } \\
\text { interviewee regarding the interviewer's behaviour? }\end{array}$ \\
\hline $\begin{array}{l}\text { Demonstration of attentive } \\
\text { listening skills }\end{array}$ & $\begin{array}{l}\text { What concerns, or need for clarification, may your } \\
\text { interviewee have? }\end{array}$ \\
\hline $\begin{array}{l}\text { Scope to test } \\
\text { understanding }\end{array}$ & $\begin{array}{l}\text { In particular, how do you intend to use the data to which } \\
\text { you ae given access, ensuring, where appropriate, its } \\
\text { confidentiality and your interviewee's anonymity? }\end{array}$ \\
\hline Approach to recording data & $\begin{array}{l}\text { How would you like to record the data that are revealed to } \\
\text { you during the interview? Where this involves using a tape }\end{array}$ \\
\hline
\end{tabular}


PhD Thesis Mario Gehrlein

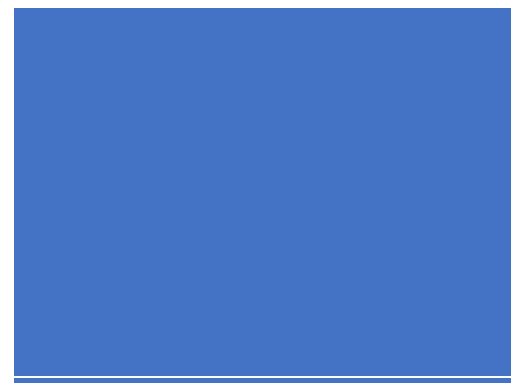

Cultural differences and

bias recorder, have you raised this as a request and provided a reason why it would help you to use these techniques?

What will you tell the interviewee about their right not to answer particular questions and to end the interview if they wish?

How will you seek to overcome potential issues related to the reliability of the data you collect, including forms of interviewer bias, interviewee bias and sampling bias? 


\section{Appendix 4: Design of the semi-structured Interviews}

\section{Introduction:}

- Welcoming words

- Thank the participant for considering the request of the interview

- Introducing the research theme to the participant

- Explaining the purpose and aim of the research briefly and its progress to date

- The previously explained and agreed right to confidentiality and anonymity is reiterated (without the clear permission of the participant no information will be outlined or released)

- The right of the participant to stop the interview whenever he / she wants and his / her right not to answer any question

- Explaining the participant about what will happen with the collected data

○ Where it will be stored?

- When it will be deleted?

-What will be released or used?

- Asking the participant to electronically record the interview

- Finally, asking the participant a last time for the permission to conduct the interview and to sign the informed consent form

First part of the main interview - experiences with the mode switching process: 
Main Themes:

- The respective steps of the decision-making process of mode switching

- Influencing factors of the decision-making process

- Key actors of the decision-making process

- The rational decision within the process

- The Influence of the key actors' behaviours and their experiences

Example-Questions:

- Does the biggest independent lubricant manufacturer have a general decision-making process of mode switching?

- How is this decision-making process structured? / What are the single steps of the decision-making process?

- Are there also intuitive decisions in the process?

- What rational aspects are involved in the decision-making process?

- What are the external and internal environmental factors of the decisionmaking process?

- Who are the key actors of the process?

- Does the human behaviour and the experiences of the key actors effect the decision-making process?

If yes, how?

- What are the switching motivators?

- What is the evaluation step within the decision-making process?

- Which process step is influenced by the external and internal environmental factors? 
- Are there specific external or internal environmental influencing factors at the separated process steps?

- Who is doing the final decision and on which basis?

- Who is generating the alternative mode options?

- What is the generation Phase of the decision-making process?

- What is your position in this process as one of the key actors?

- Is this decision-making process part of the global strategy?

- What are your experiences within the decision-making process?

- What are the main challenges within the process?

- What are the advantages of the current process in place?

- What is the implementation step?

- Who is doing the implementation?

- If you could change the process or parts of it, what would be your proposal (s)?

Second part of the main interview - interdependencies of simultaneous internationalisation process and mode switches:

Main Themes:

- Interdependencies between simultaneous international activities

- Transfer and influence of best practices

- Global internationalisation and export strategy

Example-Questions: 
- Do you think that there are interdependencies between simultaneous international activities?

- How do these interdependencies occur during the decision-making process of mode switching?

- Is it possible to group or cluster the interdependencies in specific sections?

- When do these interdependencies exist between simultaneous international activities?

- Why do these interdependencies exist between simultaneous international activities?

- How do these interdependencies influence the decision-making process of mode switching?

- How are the interdependencies of simultaneous internationalisation processes managed within the decision-making process?

- Does the biggest independent lubricant manufacturer have a global internationalisation strategy and decision-making process in place which considers the interdependencies between simultaneous international activities?

\section{Final comment and conclusion:}

- Do you have any further contribution?

- Do you have any useful secondary data which you can provide me for further investigation?

- Do you have any further question (s)?

- Giving the participant the researcher contact details in case he / she has further questions, ideas, information's or input afterwards 
PhD Thesis Mario Gehrlein

- The researcher expresses his THANK YOU to the participant! 


\section{Appendix 5: PARTICIPANT INFORMATION SHEET}

Title of the Study:

\section{Management decision-making in the transition of a multinational company's internationalisation strategy}

Researcher:

\section{Mario Gehrlein}

(PhD candidate/post graduate researcher at the Business School): University of Gloucestershire, The Park, Cheltenham GL50 2RH. Tel.: +49 151 42408139. Email: mariogehrlein@connect.glos.ac.uk.

This information sheet contains all relevant information related to the planned research. If you would like to participate in this study, please read the information sheet, the privacy notice and the informed consent form that is attached to it carefully. After you have read them and wish to participate, please sign the informed consent form and return it to the researcher.

It is important that you feel comfortable about your contribution. Please feel free to ask if any aspect is unclear or in case you need additional information.

\section{Purpose and aim of the expert interviews}

The expert interviews are part of my doctoral thesis, which I am writing at the University of Gloucestershire (United Kingdom). The aim of this research is to understand a global firm's management decision-making process during their transition between international entry strategies and the reason how these mode switching activities occur. The study will develop a new process model to illustrate 
and explain this business activity and expand the international management literature base.

\section{Your participation}

\subsection{Do I have to take part?}

You are being invited to take part in this research because we feel that your experience can contribute much to our understanding of the decision-making process of mode switching within multinational companies. This study is voluntary. You will only be included if you provide your permission.

\subsection{Can I withdraw from the study?}

You will be free to withdraw at any time and without giving a reason up to one month after the interview has taken place.

\subsection{What happens, if I take part?}

The expert interview will take place face-to-face in an appropriate setting and at times that are most convenient for you. It will last for approximately one to one and a half hour(s), depending on the information provided during the interview. The interview will be audio-recorded with your permission. The interview is semi-structured which means some questions and topics are prepared from me in advance, but I intend to add questions and topics depending on the content you are providing during the interview. At the beginning of the interview, I will introduce myself and the research to you and respond to any questions or issues you might have. After verbally reconfirming your consent to participate in the study (including the audio-recording of the interview), I will ask you questions related to the research project. As a reminder: you will have another month to withdraw from the study starting the day of the interview.

\subsection{Are there any risks in taking part?}

There are no known physical, social or psychological risks associated with taking part in this study. However, some questions asked during the interview, may be personal 
and may cause some distress. You do not have to answer any interview question that you do not want to.

\subsection{Are there any benefits to taking part?}

There are no monetary benefits to taking part in the study; as your participation is voluntary, you will not be paid. Potential costs and/or expenses will be incurred by you. However, your contribution may help to better understand the decision-making process of mode switches within multinational companies and provide new insights for follow-up studies. Please let me know, in case you are interested in obtaining a summary of the study.

\section{Anonymity and confidentiality}

Your personal information (i.e. any information from which you can be identified directly or in combination with other information indirectly) will be replaced by e.g. pseudonyms in the interview transcripts, the study and the thesis. Personal information (e.g. names) and data (e.g. transcripts, narratives and the thesis) will be kept separately and safely. All folders on the computer will be protected with passwords. Local legislation (e.g. the General Data Protection Regulation (GDPR) in the European Union) will be respected. Personal information will not be disclosed to anyone outside the University, to third parties or published in the thesis or other publications. Anonymised data may be used for further research or to support publication.

\section{Results}

Findings will be primarily published in my thesis which will be published in the library of the University of Gloucestershire. As the researcher is connected with the investigated company and the company does not want to disclose any actual information to the competition, the researcher will ask the University of Gloucestershire for a temporarily embargo of 2 years for his thesis at the end of the research process. This means that the thesis will not be published before the embargo is ended. This will ensure that no actual information from the investigated company will be published. Due to the nature of the study, interview transcripts will be published 
as part of the research. Anonymity and confidentiality are ensured at all times. In case you are interested in the results of the research, please let the researcher know in order to discuss how the findings can be made available to you.

\section{Licence}

By participating in the study, you grant the researcher an irrevocable, unlimited, nonexclusive, worldwide licence to download, copy, modify, distribute, perform, and use the transcripts of your interview for free, including for commercial purposes, without your permission.

\section{Funding of the study}

There is no funding for this study.

\section{Contact information}

Mario Gehrlein (PhD candidate/post graduate researcher at the Business School): University of Gloucestershire, The Park, Cheltenham GL50 2RH.

Tel.: [Tel No. redacted]

Email: [email redacted]

Thank you very much for your participation!

Best Wishes, Mario Gehrlein 


\section{INFORMED CONSENT FORM}

Title of the Study:

\section{Management decision-making in the transition of a multinational company's internationalisation strategy}

Researcher:

\section{Mario Gehrlein}

( $\mathrm{PhD}$ candidate/post graduate researcher at the Business School): University of Gloucestershire, The Park, Cheltenham GL50 2RH. Tel.: +49 151 42408139. Email: mariogehrlein@connect.glos.ac.uk.)

I understand that I have been asked to participate in a research study.

I understand that my participation involves

- an interview session

I have read and received a copy of the attached participant information letter. With my signature, I confirm the following:

- I have read and received a copy of the attached privacy notice, which is also available on the University's website (http://www.glos.ac.uk/docs/download/Privacy- notices/ResearchParticipants-Privacy-Notice.pdf).

- I understand the benefits and risks involved in taking part in this research study.

- I understand that I am free to contact the researcher (and supervisor) to take the opportunity to ask questions and discuss this study.

- I understand that I am free to refuse participation, or to withdraw from the study at any time before the interview and within one month after the interview, without consequences, and that my information will be withdrawn at my request?

- I understand that my data will be kept confidential. I understand who will have access to my information.

- I agree that the interview will be audio-recorded and subsequently transcribed. 
- I agree that this form contains my personal information that can be seen by designated faculty staff and auditors.

- I have understood how the data (e.g. interview transcripts, etc.) will be used.

- I have read and understood section Five of the attached information letter concerning the "licence".

- I consent voluntarily to take part in this study.

Printed name of the participant:

Signature:

Date:

Preferred contact number:

Email:

\section{Statement by the researcher}

With my signature, I confirm that the participant was given an opportunity to ask questions about the study, and all the asked questions by the participant have been answered correctly and to the best of my ability. I confirm that there has not been coerced into giving consent, and the consent has been given freely and voluntarily.

A copy of the Participant Information Sheet, the Informed Consent Form and the Privacy Notice have been provided to the participant. 
Printed name of the participant:

Signature:

Date:

Preferred contact number:

Email: 


\section{Appendix 6: Initial Code Overview}

\begin{tabular}{|c|c|c|}
\hline Short Cut Decisions & Rational Decision & Multiple Decision-Making \\
\hline Flexible Decision- & Process & Process \\
\hline Making & Data analysis & Interdependencies \\
\hline Low Risk & Starting Impulse & Role of Interdependencies \\
\hline Logical Conclusion & Incremental Process & Handling \\
\hline Decision-Making & Strategic Process & interdependencies \\
\hline Culture & Decision Making & Internal Interdependencies \\
\hline Global Strategy & Mode Options & $\begin{array}{l}\text { External } \\
\text { Interdependencies }\end{array}$ \\
\hline IMatrix-Organisation & Influencing Factors & Learning Process \\
\hline Export Strategy & Internal influencing & \\
\hline Company Culture & Factors & \\
\hline $\begin{array}{l}\text { Supply Chain } \\
\text { Synergies }\end{array}$ & $\begin{array}{l}\text { External Influencing } \\
\text { Factors }\end{array}$ & \\
\hline Decision Alignment & $\begin{array}{l}\text { Quantitative } \\
\text { Influencing Factors }\end{array}$ & \\
\hline $\begin{array}{l}\text { Local } \\
\text { Entrepreneurship }\end{array}$ & $\begin{array}{l}\text { Qualitative Influencing } \\
\text { Factors }\end{array}$ & \\
\hline
\end{tabular}


Appendix 7: First Concept Map

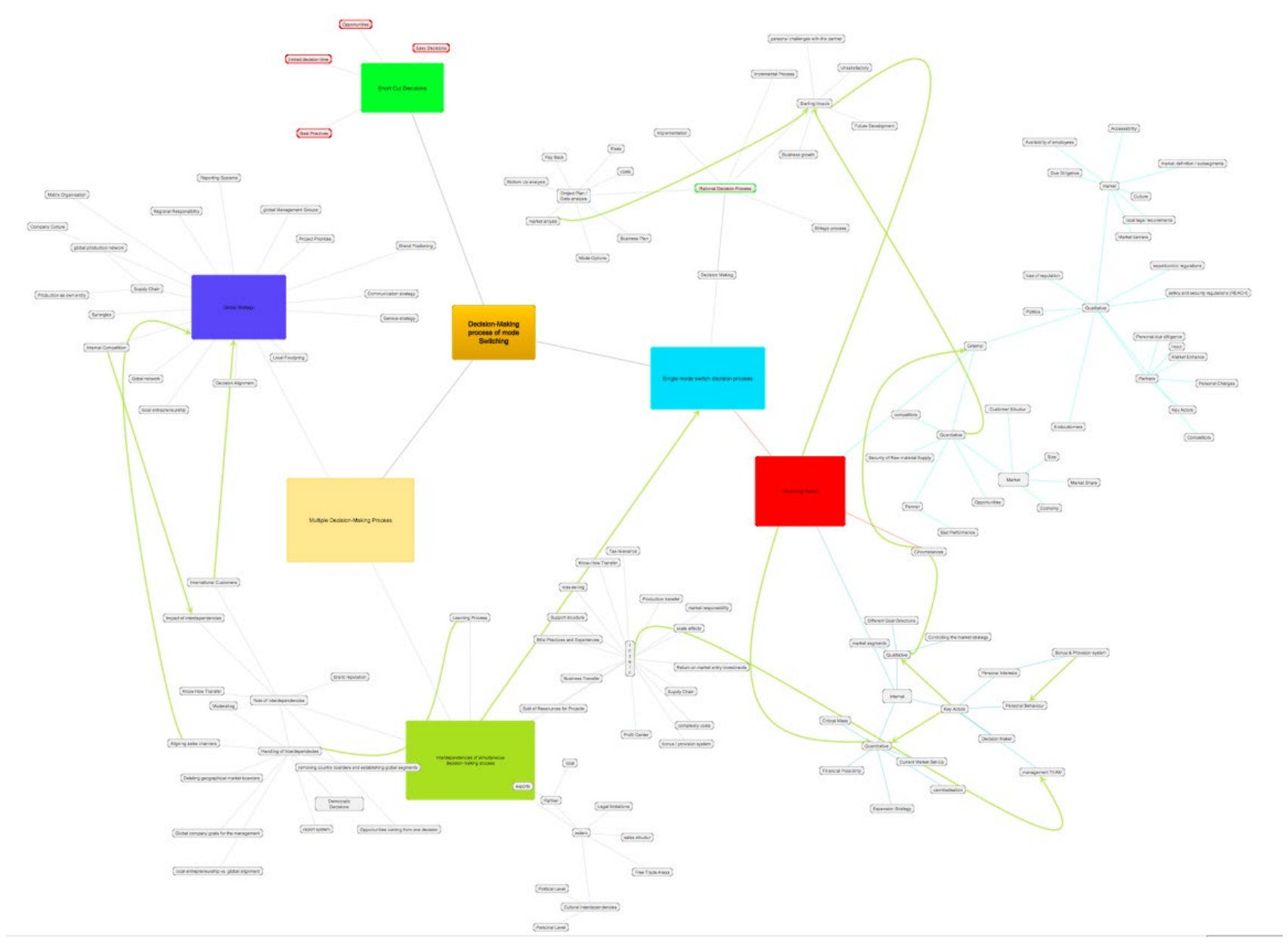




\section{Appendix 8: Final Concept Map}

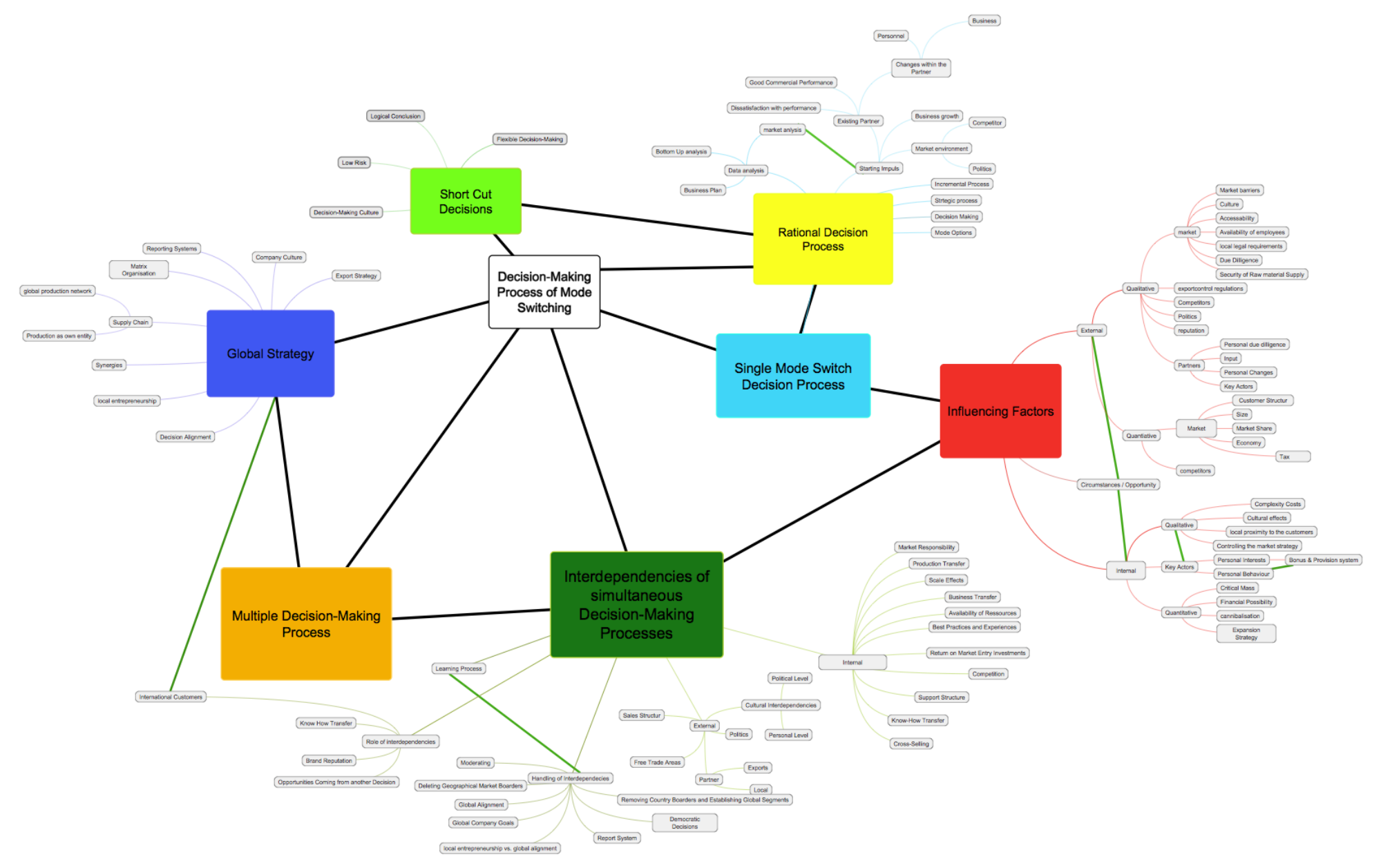




\section{Appendix 9: Extract of a Colour Coded Interview Transcript}

If you say it is not economically driven, can you also say it is not based on quantitative arguments and figures?

For example in the middle east, how did that change happen? The holding as a group participates in a global tender of a global key account. Some of these countries fell within responsibility of our joint venture and they were exchanged for other businesses for which our joint venture was not responsible. That was the counter transaction for the responsibility. That was one thing.

The other one in the past, where I have a positive picture, is e.g. The eastern european country. There we had a local partner and partly also supplied large end customers directly. A local holding company was then founded there and I think that this has a benefit for the holding because we simply have more staff on the local market.

All in all, however, I am not sure whether the establishment of a national company will always bring out the maximum possible profit. Of course, if you have a national company in The eastern European country, the focus of the managing director is on this country. In other words, local sales people are hired and decisions are made with local glasses. Finally, the managing director has to report to the division manager. Icould imagine that our local subsidiaries might need its own accounting, human resources, controlling, office services and purchasing departments. Many positions will probably be combined in one person. However, I believe that this results in a great deal of blindness, because a lot of the same work is carried out in the individual countries and a bloated organisational structure is created. And I could imagine, if you hire sales people physically locally in a country, with a good sales controlling, that it would be more efficient and better from the costs.

But does that mean that your suggestion still involves the sales staff being hired by the holding? 
Not necessarily, but this could be done. From my point of view, it is always good when employees are employed directly at the holding, because then you have direct access, both in the positive and negative sense.

If we come back to the decision-making process now, how does the decisionmaking process work at the holding? Who are the decision-makers?

I don't think there is a defined decision-making process. What I think is bad. I think a lot is driven by inner political or personal goals or opinions. I know that companies were founded without any real economic analysis. For example, how we are currently doing this in the project for $A$ small country in Europe was an extraordinarily in-depth analysis. Um, decision makers are usually regional managers who are responsible for the region and report to the board. 


\section{Appendix 10: Invitation E-Mail}

Dear....,

I am approaching you regarding my $\mathrm{PhD}$ thesis, which I started 2 years ago as a part-time student at a university of Gloucestershire.

After an intensive literature research and the development of my methodological approach, I am currently conducting my data collection in the form of expert interviews.

The title of my work is as follows:

\section{„Management decision-making in the transition of a multinational corporation's internationalisation strategy"}

In my opinion, you could give me interesting and helpful input for my $\mathrm{PhD}$ thesis with your expertise and I would therefore like to ask you if you would be willing to conduct an expert interview with me?

If you agree to be available as an expert, your data will of course be anonymized. In order to give you a better overview regarding the handling of your data and the consequences of your possible consent, I have prepared the attached "Participant Information sheet". For completeness I have attached the privacy policy of my university ("Privacy Notice").

I will be happy to explain the details to you personally shortly before our interview - you can cancel your participation at any time (before and during the interview) if you change your mind and still do not wish to participate.

I would be very pleased to receive positive feedback from you. If you have any questions, please feel free to contact me at any time. 


\section{Appendix 11: List of codes Extracts}

Short Cut Decisions

\begin{tabular}{|c|c|c|c|}
\hline Particpiant & Quote & Sub theme & Code \\
\hline & 1 So we at the holding are not documentary. When it's about shortcuts. So we don't deal with bad compromises, because they never pay off in the end until they have been cleared up again. & Flexible Decision-Making & \\
\hline & 2 I know that companies were founded without any real economic anahsis & Best Practices & \\
\hline & $\begin{array}{l}\text { The decision-making prooess for launching a subsidiary has oertainly been presented in a very simple way. The final conclusion that a local subsidiary will be established in Chile is actually a } \\
6 \text { very logical condusion if you look at the map and spend half a day looking at the countries and the lubricant market in South America. Then everyone would say that makes sense }\end{array}$ & Logical Conclusion & \\
\hline & $\begin{array}{l}\text { On the basis that there was a certain market potential in Chile and that the corresponding high-margin product segments have a high potential in which our brands could be well placed, } \\
\text { it was justified that a local subsidiary in chile would make sense. }\end{array}$ & Logical Conclusion & \\
\hline & $\begin{array}{l}\text { I think the establishment of a local subsidiary in Chile is also a country where there is little to explain. If you wanted to do this in a country with a much smaller market, wolume and potential, } \\
\text { more people would surely be interested and want a more detailed business plan or the decision would be based more on numbers, data and facts. But since Chile has a lot of inhabitants, is very } \\
6 \text { European, therefore the political risks are rather low e.g. regarding currency devaluation or political unrest, the risk was manageable. }\end{array}$ & Low Risk & \\
\hline & \begin{tabular}{|l|l}
7 & No, I don't think that this could happen. At least there are existing the figures and numbers of the existing business in a country.
\end{tabular} & Decision-Making Culture & \\
\hline & $\begin{array}{l}\text { I think that sometimes, there are ad hoc decisions that are made from the management board only and are not followed the before discussed process. I mean the management board is } \\
\text { really looking from the highest positive level on the different subsidiaries, markets and countries and consequently they might have knowledge or ideas which individual managers could not } \\
7 \text { recognize. }\end{array}$ & Flexible Decision-Making & \\
\hline & $\begin{array}{l}\text { I think that } 60 \% \text { of the decisions are made on the process and a business plan and } 40 \% \text { based on ad-hoc decisions. But I also think that this will change in future and that the percentage of } \\
\text { the decisions based on a business plan and the process will increase due to the new global functions which are currently established at the holding. And these new global functions will have an } \\
7 \text { impact on the decision-making process and will become main key actors in future. }\end{array}$ & & \\
\hline
\end{tabular}

*the complete code book is submitted with a one drive link and can be accessed. 
Rational Decision Process

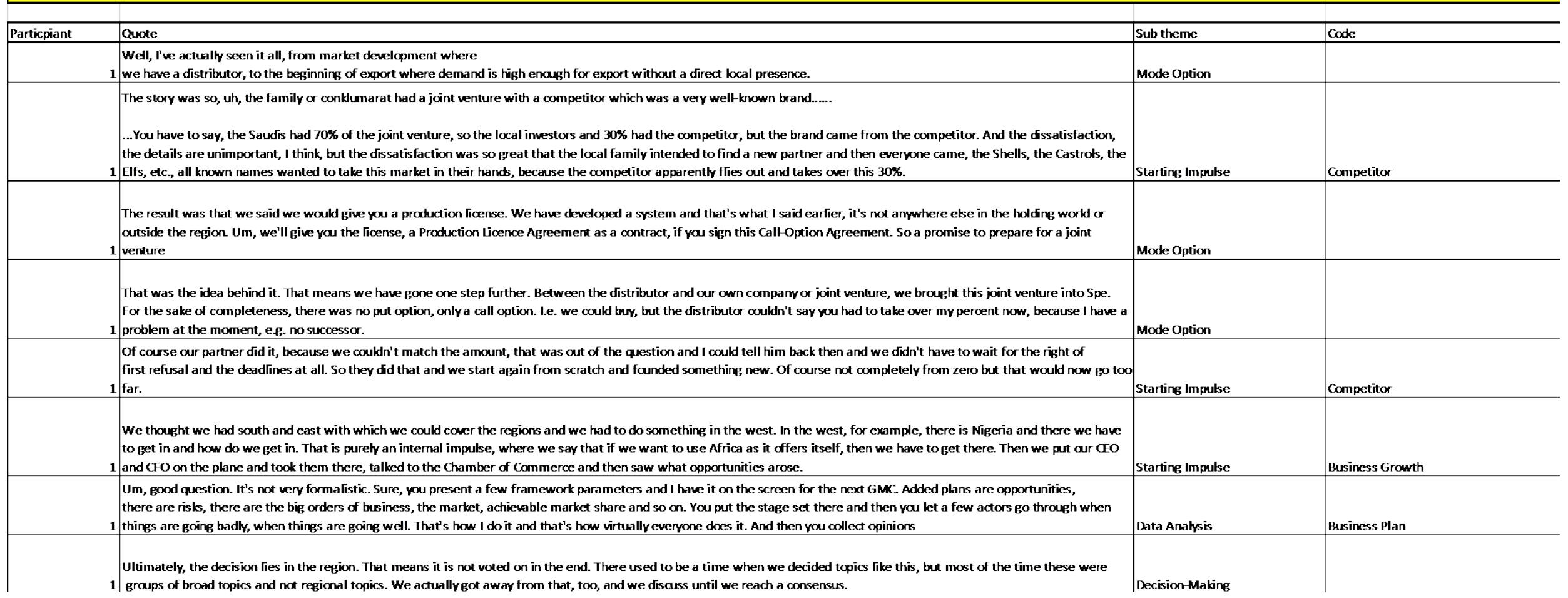

*the complete code book is submitted with a one drive link and can be accessed. 


\begin{tabular}{|c|c|c|c|}
\hline Particpiant & Quote & Sub theme & Code \\
\hline & 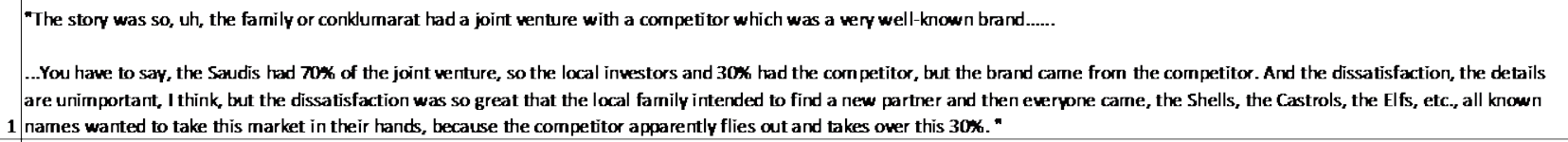 & Extemal & Qualitative, Competitor \\
\hline & $\begin{array}{l}\text { So, there are people who are very strongly extrinsically motivated, they want to win the prize and win the money for it or they want to maximize their salary and the share they have of all } \\
1 \text { that and take that as the measure of all things. You can be successful with that if you c can motivate with it }\end{array}$ & Internal & Key actors, Personal Behaviour \\
\hline & 1 I think this is the original cell of what can happen in market development and you can't sink ary deeper. Unless vou have a negative reputation. & External & Qualitative, reputation \\
\hline & $\begin{array}{l}\text { With this we created a pull, so that if we had to look for distributors again, we would now get completely different calibers, because now that the brand is known, we also have a } \\
\text { completely different attraction. }\end{array}$ & Extemal & Qualitative, reputation \\
\hline & $\begin{array}{l}\text { so we have high export barriers, sometimes } 25 \text { or even } 30 \% \text {, but if there are a lot of imports, the market pays the price and it is offen the case that when one is locally produced, } \\
1 \text { the custorns barriers are really raised in order to protect this local producer, so this interaction was there, even if we already had customs duties in many markets }\end{array}$ & Extemal & Quantitative, Market, Market Barriers \\
\hline & $\begin{array}{l}\text { The holding is the name of the compary, the founder, the brand, the technology, so we have practically rothing else. If a guy puts dirt on that rame, it's dirt for evervone. } \\
1 \text { I't' a high risk, we're going to control it tightly in terms of the content, the technology, what's used, the quality, the brand, the branding, evernthing. }\end{array}$ & Extemal & Qualitative, reputation \\
\hline & $\begin{array}{l}\text { We have very stric rules in place, we have also introduced control mechanisms, but then you can produce. It costs a small rovalty, which isn't much and it's more of a member fee and we } \\
\text { can't make a living from it, tut it shouldn't cost nothirg. But wou would have to give us his call option, i.e. if you really work well, proper accounting, proper systems and pou do your } \\
1 \text { production as we want, pou are profitable and pou grow. Then we want to have the option to purchase } 49 \% \text { of the shares. }\end{array}$ & Internal & Qualitative, Controlling the market strategy \\
\hline & $\begin{array}{l}\text { So and now we are quite much further in the system. Not as far as I would like it to be, because we had to wait } 5 \text { vears for a lawsuit, because our joint venture partners fought among } \\
1 \text { each other. So we had literally lost } 5 \text { vears in the development of this system and so it's a bit of a studder }\end{array}$ & Extemal & Qualitative, Partners, Personal Change \\
\hline & $\begin{array}{l}\text { But I think it is still in the foundations, the right system to get alorg in such markets, the difficult markets like Iraq, Syria, etc... In Morocco, for example, someone came, which may not be } \\
1 \text { a strategic market, tut is good but rather small, and therefore not strategic, tut we had a good partner and that is whty we did it. }\end{array}$ & Extermal & Qualitative, Market, Due Dilligence \\
\hline & $\begin{array}{l}\text { Yes exactly and that's where a compeitor has pushed in and wants to buy the } 50 \% \text { of our option so that they can have it or snap it away. This is dangerous because it happened in a country } \\
\text { with one of our licerse partners. Then another competitor came and offered an insanely high amount, even if the amount doesn't matter. They offered } 45 \text { times the usual value and } \\
1 \text { snatched away our license factory. They put down a strategic price that was fair enough and our partner told me and I had to honestly say take it. }\end{array}$ & External & Qualitative, Competitor \\
\hline & $\begin{array}{l}\text { Otherwise we wouldn't be so active in some markets today because we made the decision there because we found a very good local partner. In one country, for example, we have a } \\
\text { lubricant expert who has researched and looked into who might be an option, found an irmestor who had nothirg to do with lubricants, but had a pile of money to do with it. Both then came } \\
\text { to us and said we could do something together. This was also done and the whole } \\
1 \text { thirg was } 15 \text { vears ago now and is a huge cooperation. In this case, this is also an external factor, beccuse opportunity cornes to us and opportunity plays a thage role. }\end{array}$ & Gircu & \\
\hline
\end{tabular}

*the complete code book is submitted with a one drive link and can be accessed. 


\begin{tabular}{|c|c|c|c|}
\hline Particpiant & Ounte & Sub theme & Code \\
\hline & $\begin{array}{l}\text { We primarily deal with strattegic issues, hut also with communication within the overall network How can I sayrelieve, deslacken, deblock If two people get caught up somewhere and there } \\
1 \text { are legitimate interests that do not go in the same direction, we will try to show things to the last detail, what something has led to }\end{array}$ & Handling of Irterdependencies & Moderating \\
\hline & 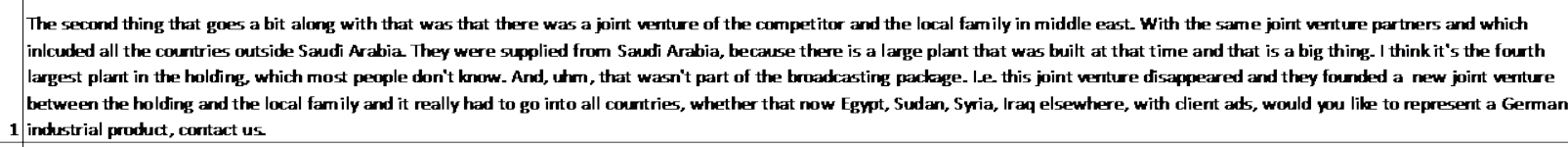 & External & Partner \\
\hline & 1 We had a German product, which of conrse connts a lot in the Middle East. & External & Cultural Interdependencies \\
\hline & 1 Then intermational customers come and say, now I can also buy locally directly from a holding compary. & Role of Interdependencies & Intermational Customers \\
\hline & 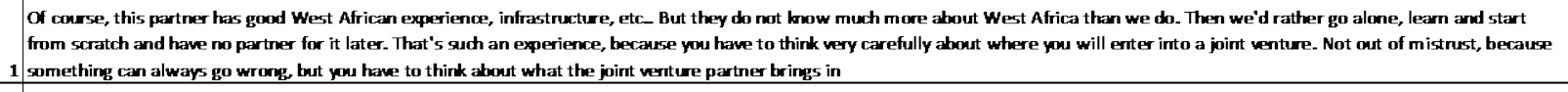 & Extemal & Partner \\
\hline & 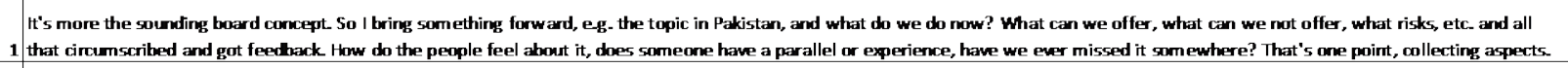 & Handling of Interdependencies & Global Aligrment \\
\hline & 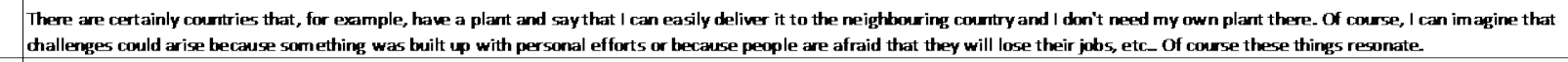 & Intemal & Market responsibility \\
\hline & 1 In the end the company wanted it that way and it was consciously built 4 by the company as a conflict. & Handling of Interdependencies & Global Company Goals \\
\hline & 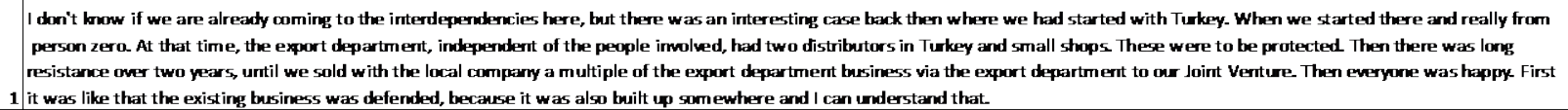 & Intemal & Business Transfer \\
\hline & 1 The brand is present, the intermational customers can be served and so on & Role of Interdependencies & Intemational Customers \\
\hline & 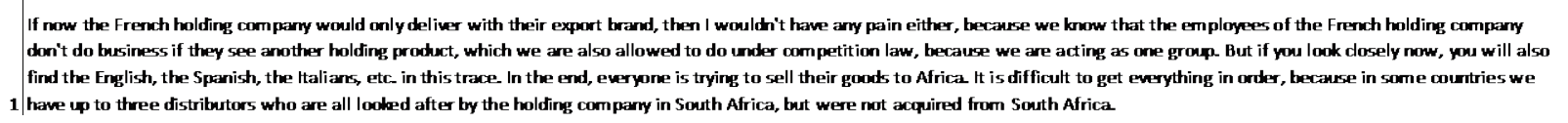 & |Intemal & Competition \\
\hline
\end{tabular}

*the complete code book is submitted with a one drive link and can be accessed. 


\section{Global Strategy}

\begin{tabular}{|c|c|c|c|}
\hline Particpiant & Quote & Sub theme & Code \\
\hline & 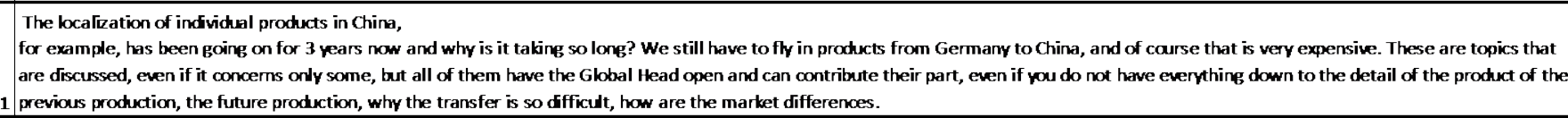 & Supply Chain & Global Production networt \\
\hline & $\begin{array}{l}\text { The best of these distributors, I would simply say, said at some point.... } \\
\text { I...and then one or the other came and said that without local prodhction we could not get any further or we could not get any further. I can't just Irve with the specialities, or I can do much } \\
\text { more if can prodkoe locally. }\end{array}$ & Supply Chain & Production as own entity \\
\hline & $\begin{array}{l}\text { would you say that the holding has a global eqqort strofegy? } \\
1 \text { No, I don't need to think about that, becanse we are in the prooess of buikfing one. }\end{array}$ & Export Stratgey & \\
\hline & 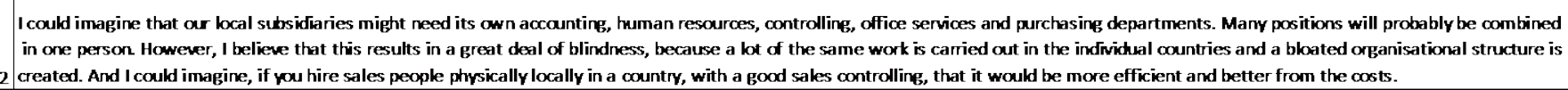 & Synergies & \\
\hline & 2 The global export strategy of the holding looks like there is no global export strategy, which is bad from my point of view. & Export Stratgey & \\
\hline & $\begin{array}{l}\text { That's why I think it's important that at some point a global export strategy is implemented, simply to minimize friction losses. I think that what has helped us to achieve this size is not the } \\
\text { right set-up in the export sector to grow further in the future. }\end{array}$ & Export Stratgey & \\
\hline & $\begin{array}{l}\text { My personal opinion is that I would probably separate the prochuction and distribution strategies. I think a global sales strategy would have to be established and I would assign the global sales } \\
2 \text { strategy to one person, inchuding regional managers and induding sales managers. So I would establish my own export sales company for the global export markets. }\end{array}$ & Supply Chain & Global Production Networ \\
\hline & $\begin{array}{l}\text { As an export department we do not have the possibifity to sell products from other national companies at all, but can only acoess the German portfolio. In other words, we are working as a silo } \\
2 \text { and cannot acoess the global prochuction network of the other marufacturing plants. }\end{array}$ & Supply Chain & Global Production Networ \\
\hline & 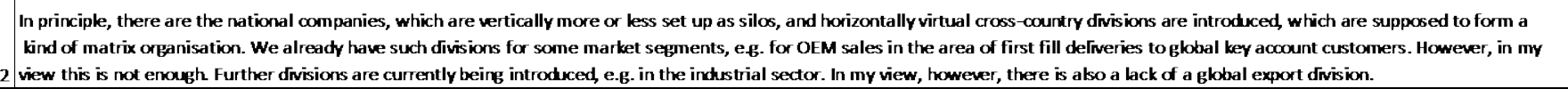 & Matrix Organisation & \\
\hline & $\begin{array}{l}\text { But there is a lack of understanding for export somewhere and the Vice President for Indsstrial Sales did not consider the export department in this respect. In other words, export does } \\
\text { not play a rode in many strategic considerations within the group. This mears that many decisions are made without the understanding that we as the export department have built up expert } \\
2 \text { knowledge. }\end{array}$ & Export Stratgey & \\
\hline & $\begin{array}{l}\text { If we were to go back } 10 \text { vears, when other responsible people were still in export roles, this would have been unthinkable in some stages, or would have triggered extreme resistance. } \\
\text { This is a sign that the company's culture is also changing and that it is chear that optimising one's own area of responsibiity is not the right thing to do. But it is definitely a critical element for } \\
\text { suocess and if you ask why, of course because people don't see the whole company, but sometimes their own area and also their own egoism, you have to say. }\end{array}$ & Comp & \\
\hline
\end{tabular}

*the complete code book is submitted with a one drive link and can be accessed. 


\section{Appendix 12: Approval process within the selected case company}

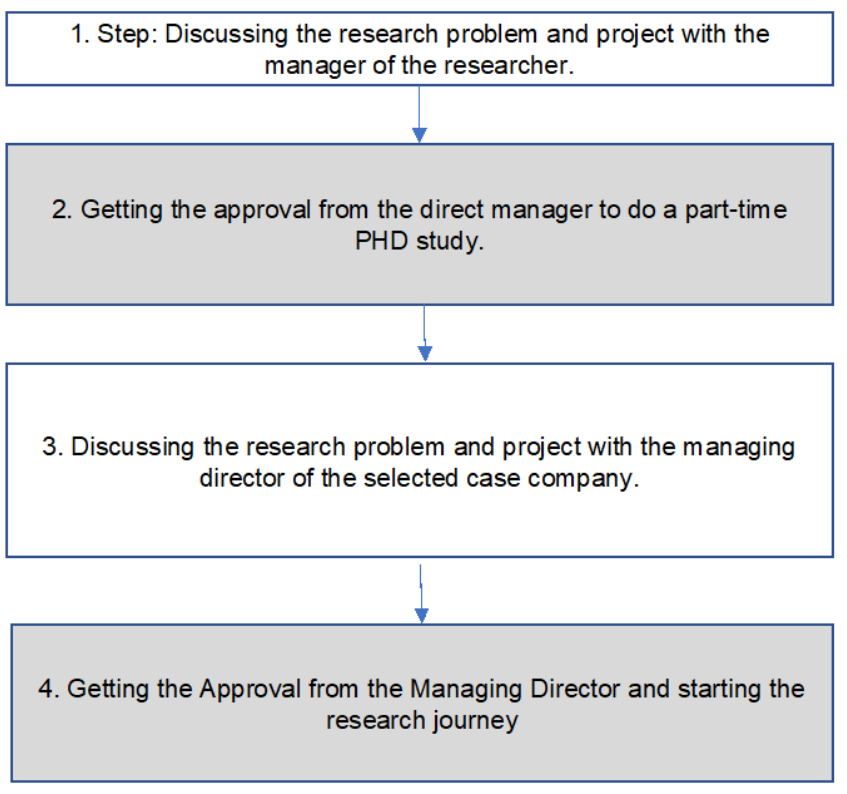

